\title{
FARM POULTRY
}

BY

GEORGE C. WATSON

\section{UC-NRLF}

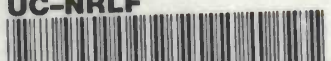

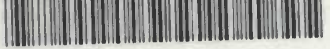

\$B $27 ?$ 36?

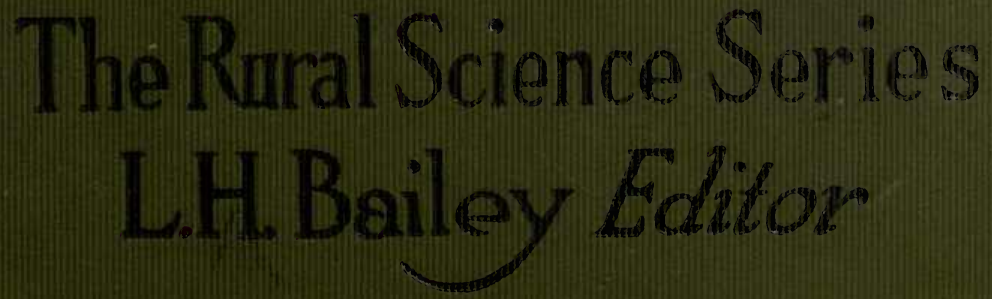




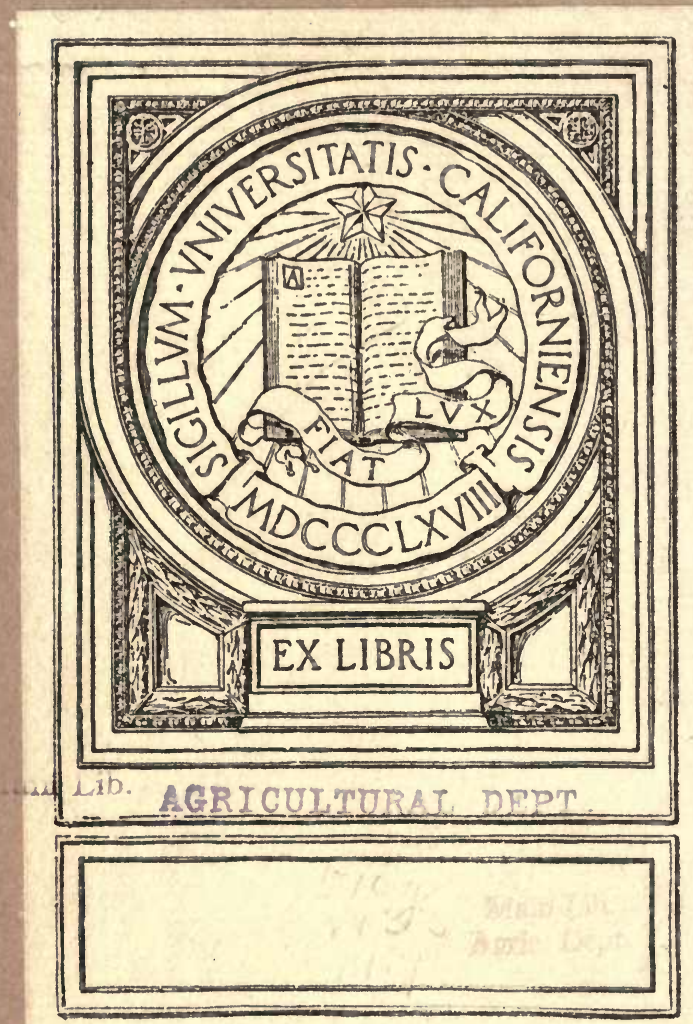







\section{The łatal Stience Setié}

Edited by L. H. Bailey

FARM POULTRY 


\title{
The laural Srience Series
}

\author{
Enited by L. H. Bailey
}

The Soll. King.

Tile Spraying of Plants. Lodeman.

Milk and its Products. Wing. Enlarged and Revised. The Fertility of the Land. Roberts.

The Principles of Fruit-growing. Bailey. 20th Edition, Revised.

Bush-Fruits. Card.

Fertilizers. Voorhees. Revised.

'The Principles of Agriculture. Bailey. Revised.

Irrigation and Drainage. King.

The Farmstead. Roberts.

Rural. Wealth ani) Welfare. Fairchild.

The Principles of Vegetalibe-garinening. Bailey.

Farm Poultry. Watson Enlarged and Revised.

The Feeding of Animals. Jordan.

The Farmer's Business Handbook. Roberts.

'The Diseases of Animals. Mayo.

The Horse. Roberts.

How to Choose a Farm. Hunt.

Forage Crops. Voorhees.

Bacteria in Relation to Country Life. Lipman.

'The Nursery-Book. Bailey.

Plant-breeding. Bailey and Gilbert. Revised.

The Forcing-Book. Bailey.

The Pruning-Book. Bailey.

Fruit-growing in Arin Regions. Paddock and Whipple.

Rural Hygiene. Ogden.

DRY-FARMING. Widtsoe.

LAw For the American Farmer. Green.

Farm Boys and Girls. Mckeever.

The Training and Breaking of Horses. Harper.

Sheep-farming in North America. Craig.

Coöperation in Agriculture. Powell.

The Farm Woondot. Cheyney and Wentling.

Household Insects. Herrick.

Citrus Fruits. Coit.

Principles of Rural Credits. Morman.

BeEkeEping. Phillips.

Subtropical Vegetable-Gardening. Rolfs. 


\section{FARM POULTRY}

A POPULAR SKETCH OF DOMESTIC FOWLS

FOR THE FARMER AND AMATEUR

BY

GEORGE C. WATSON, M.S.

FOURTEENTH EDITION

丹ew 聖ork

THE MACMILLAN COMPANY

LONDON: MACMILLAN \& CO., LND.

1917

All rights reserved 


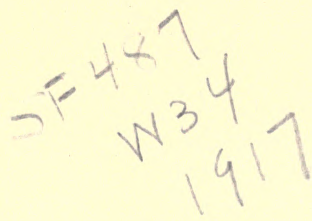

Copyright, 1901, 1912

\section{By THE MACMILLAN COMPANY}

Set up and electrotyped June, 1901

Reprinted February, 1903; February, 1904; July, 1905;

November, 1906; October, 1907; January, 1909;

July, 1909; October, 1910

New Edition, Revised and Enlarged, September, 1912

August, 1913; August, December, 1914; May, 1917
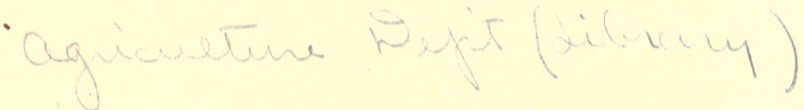

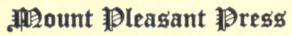

J. Horace MeFarland Company Harrisburg, Pa. 


\section{CONTENTS}

\section{CHAPTER I}

Poultry-Raising as a Business..................1-12

Extent of business........................ 2

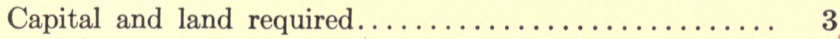

Business suitable for many persons.............. 9

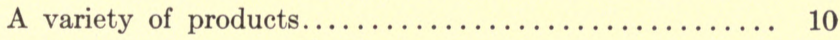

Products easy to market................... 11

\section{CHAPTER II}

Egg Breeds of the Domestic Hen...............13-40

Classification as to utility................. 13

General characteristics of egg breeds.............. 16

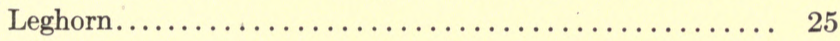

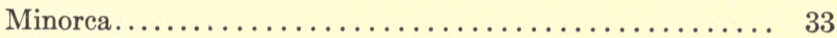

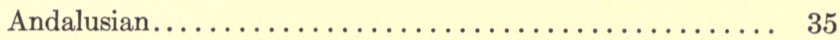

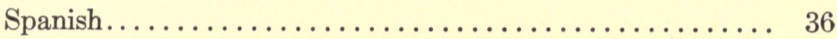

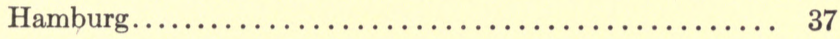

Red Cap........................... 40

\section{CHAPTER III}

Meat Breeds..........................41-56

General characteristics.................... 42

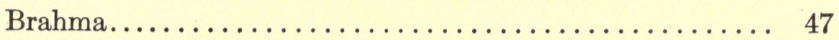

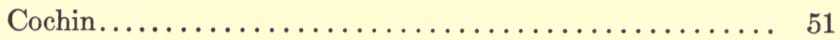

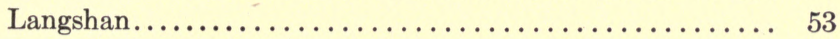

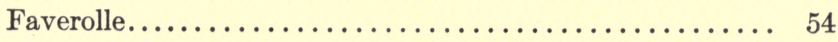




\section{CHAPTER IV}

General-Purpose Fowls.................. $57-80$

General characteristics..................... 59

Plymouth Rocks........................ 62

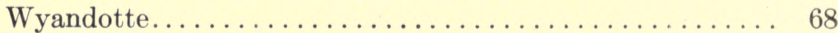

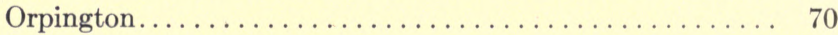

Java............................... 72

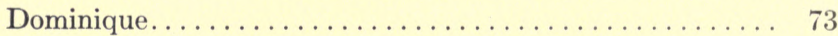

Dorking............................... 74

Houdan............................ 76

Cornish Game......................... 77

Rhode Island Red...................... 79

\section{CHAPTER V}

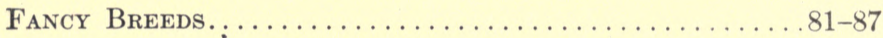

Polish................................ 82

Game.............................. 84

Silky............................ 84

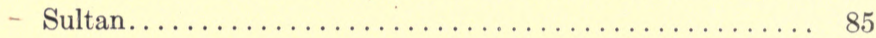

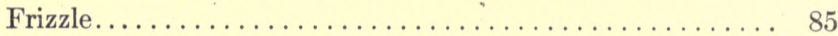

Bantam............................ 86

\section{CHAPTER VI}

Buildings for Fowls: Location, Plans and Construc-

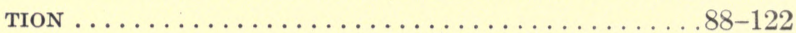

Selection of suitable location as to markets......... 88

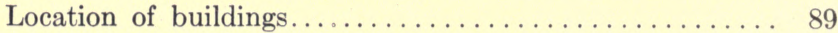

Convenience............................. 92

Construction of houses.................... 96

Size of buildings....................... 100 


\section{CHAPTER VII}

Buildings: Internal Arrangements and Yards.......123-142

Construction of perches................... 123

Nests............................ 126

Drinking-fountains ...................... 130

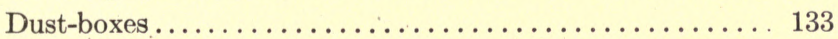

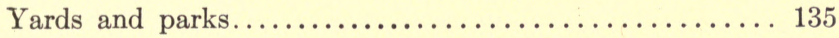

Orchards as ranges....................... 140

\section{CHAPTER VIII}

Improvement and Breeding of Fowls. ...........143-170

Selection............................. 143

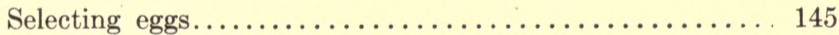

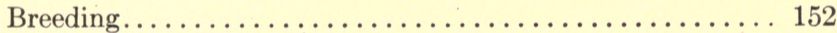

Heredity.............................. 152

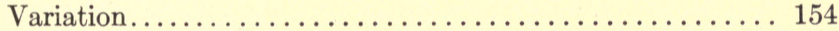

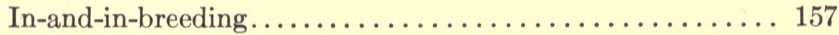

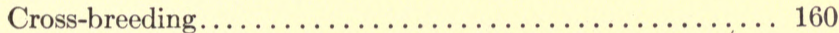

Pure-bred stock. . . . . . . . . . . . . . . . . . . 163

Improvement of common fowls............... 165

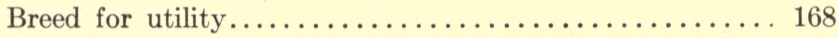

\section{CHAPTER IX}

Feeding for Eggis and for Meat..............171-201

Exercise.............................. 172

Quality of food.......................... 172

Forced feeding for eggs...................... 174

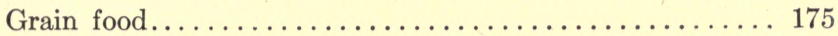

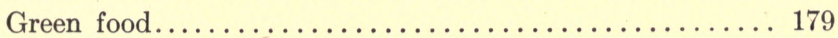

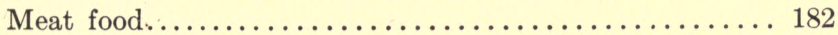

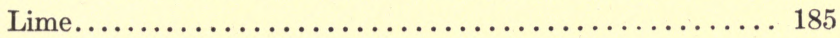


PAGE

Salt............................ 186

Grain rations........................ 193

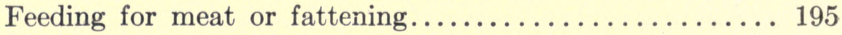

Care of fattening fowls.................. 197

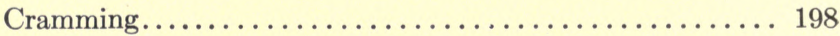

\section{CHAPTER X}

IncUBATORS AND BRoOders.....................202-223

Incubators in general. ................... 203

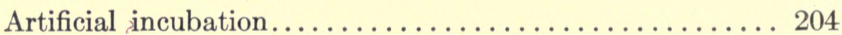

Selection of an incubator.................. 207

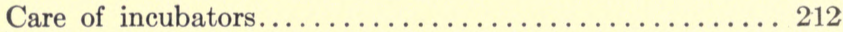

Brooders and brooder houses................... 215

Home-made brooders........................ 221

\section{CHAPTER XI}

Feeding and Care of Little Chickens............224-239

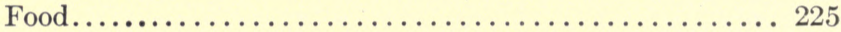

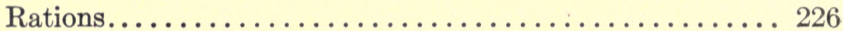

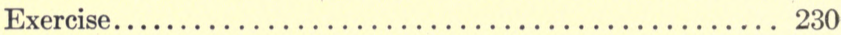

Feeding-troughs and -hoppers................. 232

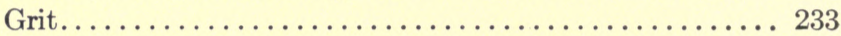

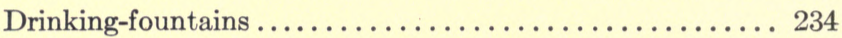

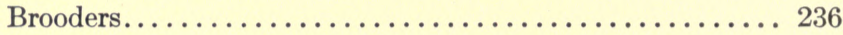

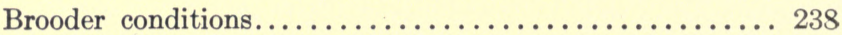

\section{CHAPTER XII}

Capons and Brollers.........................240-255

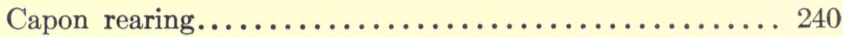

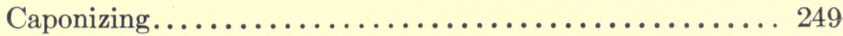

Preparing capons for market................... 250

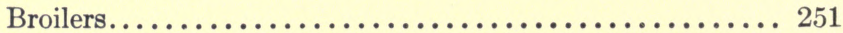




\section{CHAPTER XIII}

Ducks and Geese........................256-279

Ducks: General discussion................... 256

Pekin................................ 259

Aylesbury.............................. 260

Rouen.............................. 261

Black Cayuga.......................... 263

Ducks: Food and care.................... 264

Geese: General discussion.................... 269

Toulouse............................ 271

Embden............................... 272

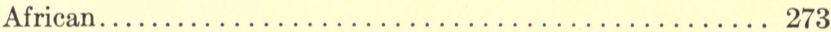

Chinese............................. 274

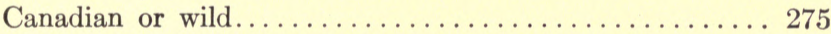

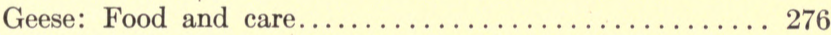

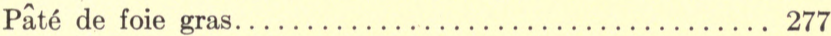

\section{CHAPTER XIV}

Turkeys, Guineas, Pea-fowls, Pigeons.............280-301 Turkeys: General discussion................. 280

Bronze............................ 286

Narragansett. . . . . . . . . . . . . . . . . . 287

White Holland........................... 287

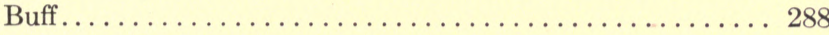

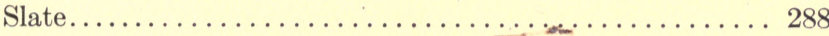

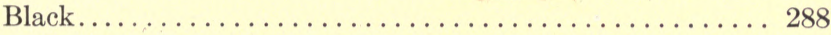

Bourbon Red.......................... 289

Turkeys: General care...................... 289

Breeding stock.......................... 290

Care and food for young................... 292

Guineas............................... 294 


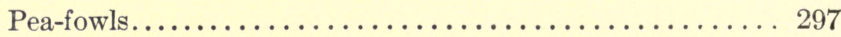

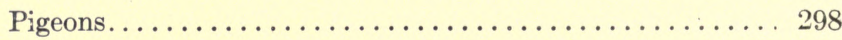

Squabs............................. 300

\section{CHAPTER XV}

Preparing and Marketing Poultry Products........302-329

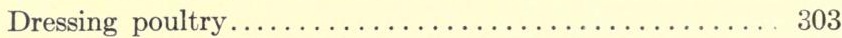

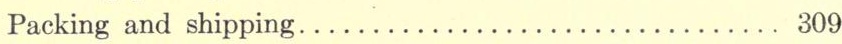

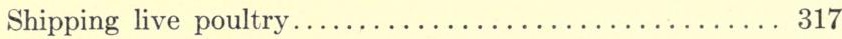

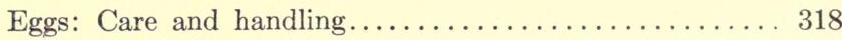

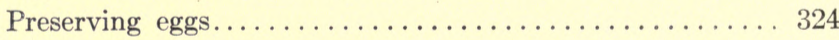

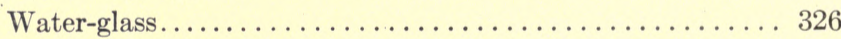

Lime-water............................ 329

\section{CHAPTER XVI}

Diseases and Enemies....................... 330-353

Lice. . . . . . . . . . . . . . . . . . . . . 330

Mites............................. 334

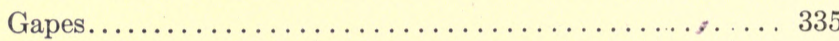

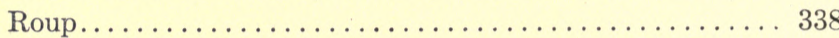

Cholera............................... 342

White Diarrhea........................ 345

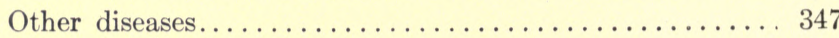

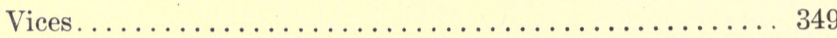

Enemies................................ 352

\section{APPENDIX}

Important Poultry Publications... . . . . . . . . . . . . 355-361 


\section{FARM POULTRY}

\section{CHAPTER I \\ POULTRY-RAISING AS A BUSINESS}

THE importance of the poultry industry, not only in this country but in all countries, is now generally recognized. Particularly is this apparent to those who have made the subject a study. It is not necessary, therefore, in this book, to enter into an extended discussion of the present or possible usefulness of domesticated fowls. It may be of interest, however, to note some of the difficulties that hinder, if they do not entirely prevent, the compilation of accurate statistics of the value of the poultry and poultry products of the United States.

When one attempts to compare poultry-raising with other agricultural industries, he is confronted with more or less inaccurate data. Many, at first thought, place the value of this industry far below its true worth, and it will require but a moment's reflection to understand why this is so. Both the rural and suburban population look to the domestic fowls for a little help each day in providing the table with wholesome and palatable food. So gen- 
eral is the consumption of fowls and of poultry products that some of these products are found among the constituents of almost every well-prepared meal. As a large proportion of the poultry products go directly to supply the daily wants of the producers' families, it is impossible to ascertain with any degree of accuracy the quantity thus consumed. Very few records are kept by producers of either the fowls or eggs thus consumed, and whenever statements are made for the censustaker or others, the aggregate is much more likely to be underestimated than exaggerated. Consequently, published data are likely to be more or less misleading, and to give far too low value to the industry.

The United States Census Reports for the last two census years give the following number of fowls on farms:

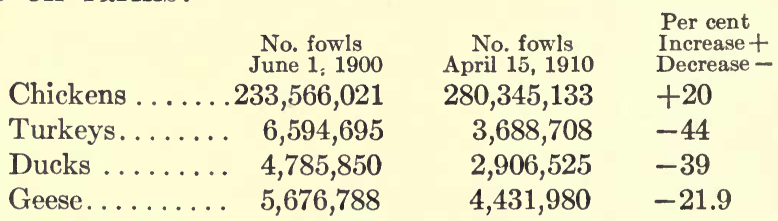

As these figures do not include the fowls kept on village lots, they probably fall far short of representing the actual number in the country. It should be noticed that the time of taking the last census was much earlier in the season than that of the previous census. So the difference in number 
does not necessarily mean that fewer turkeys, ducks, and geese are now kept than formerly, for without doubt the former figures include more young fowls than the latter. In like manner, the number of chickens determined April 15 by the 1910 census consists largely of fowls maintained for breeding purposes, while the numbers as determined by the enumerators of the previous census on June 1 necessarily included many young fowls. Consequently the increase in the development of this industry in this country is without doubt much more than that indicated by the statistics of the census reports.

\section{LITTLE CAPITAL REQUIRED}

To a person contemplating a new enterprise or the extension of a business already established, one of the first questions to be solved is, "What will it cost?" It often happens that the original or first cost of an enterprise prevents persons of moderate resources from making what in their judgment would be a safe investment. Probably there is no important branch of animal industry that requires so little outlay in labor and money as poultry-keeping. Unlike many enterprises, the poultry business may be begun in a small way and conducted successfully with the expenditure of a very meager sum of money. 
Pure-bred animals possessing individual merit, of families or of strains of blood that are recognized as being particularly valuable for the useful purposes for which these animals are maintained, have a high market value. Consequently one who begins with approved foundation stock must invest considerable capital in animals that are to be the beginning of his flock, herd or stud, as the case may be, before he really commences his breeding operations. With poultry, however, a small beginning, which is often desirable in order to give the preliminary training necessary to final success, may be made with the resources of an ordinary farm. This modest beginning would not in any way interfere with the development or extension of the business should circumstances and experience warrant such a course. In this respect the poultry business furnishes, a marked contrast to some other lines of work, particularly to those that require tools and machinery to place a finished product upon the market. If the business be largely increased, new and larger machines must be obtained in order to produce with the greatest economy, and consequently a sacrifice must be made in the equipment of the original small plant.

To those about to make their first attempt in poultry-keeping on an extensive scale, it may be said that one of the safest ways, if not the only sure way to success, is to start in a moderate way 
and to delay long enough to learn the business thoroughly before much is invested. Mistakes will certainly be made and difficult problems will present themselves for solution before success can be attained in any extended way. Many have made the experiment of investing considerable money and labor before the business was even fairly well understood, and failure, or discouragement-which often amounts to the same thing-has been the consequent result.

While failures due solely to inexperience are in evidence most of the time, yet new recruits are continually rushing forward to repeat the disaster. This is without doubt due largely to the desire on the part of many to accumulate money rapidly and before they have time to pass through the important apprenticeship of learning the business. Undoubtedly many are tempted to go into the poultry business on a somewhat extensive scale because a few fowls are kept on many farms seemingly with profit, and yet without much care. The small flocks that have the run of the farm may thrive with little care, but large colonies demand close attention from one who has passed the stage of a novice, if the greatest success is to be attained.

Many failures in the poultry business have resulted from a neglect of some or many of the little details so necessary to success.

Individuals have succeeded admirably even 
beyond expectation, when they were able personally to look after the business and to see that nothing was neglected, but failed entirely when they undertook to greatly enlarge the business and to trust the details to others who were giving their services for a moderate consideration.

\section{TIME OF YEAR TO BEGIN}

The question may arise as to the best time of the year to begin, for one who is wholly unacquainted with any of the phases of poultry work.

This perhaps is not so important, provided the manner of making the beginning has been fully decided upon, so that the time of year will not wholly determine the way in which this enterprise will be begun. If one should decide to make a start during the late summer or fall months, in all probability it will be found quite advantageous to make a beginning through the purchase of mature fowls. Whereas, if the beginning should be made in the late winter or early spring, eggs may be purchased so that the beginning may be effected in part or wholly in this manner.

If time and circumstances will permit, the fall of the year is an excellent time to begin, for then fowls may be purchased somewhat cheaper than in the spring, and the experience of caring for them during the winter will prove of great value during 
the coming season of incubation and rearing of young fowls with its many new experiences and perplexities. One should gain all knowledge possible as to care of fowls before this busy season approaches.

\section{COMPARATIVELY LITTLE LAND NECESSARY}

Unless it is desirable to raise all, or nearly all, of the grain which the fowls require, on the same farms on which they are kept, comparatively little land will be required. Especially is this true with ducks and chickens. Turkeys, on account of their roving nature, do best when given a wide range. Laying hens, however, will do well when confined in a comparatively small yard or "run" if the ground is kept clean by cultivation. Four or five acres will afford ample space for eight hundred hens if suitable arrangements are made to keep them in moderately small flocks. This amount of land will also provide ample space for the rearing of the young required for the maintenance of the flock. If the grain food be purchased, very little land will be necessary,- - only enough for the houses, yards and sufficient space whereon to grow the green or succulent food. A very small area will be sufficient on which to raise the green food if the land be kept in a high state of fertility. It is true that in some parts of the year it will be advantageous to have a wide range, if one can be provided. 
Fowls, like other classes of live stock, require more exercise while they are growing and developing, and do best in a large run or park, as so much depends on a strong body and constitution when the period of greatest usefulness is reached. It is of relatively more importance, therefore, to have a large run for the young and immature fowls than for the mature birds which are being maintained solely for the production of eggs. Fattening fowls require comparatively little exercise, their health is not materially impaired by a short confinement, and more rapid gain in weight is secured by confining them.

\section{QUICK RETURNS FROM MONEY INVESTED}

Of the various branches of animal industry there is probably none that brings such quick returns as poultry-keeping. It matters not whether the poultry-raiser desires to produce eggs, meat in the form of broilers, mature fowls, or capons, the product is ready for the market within a comparatively short time. Even though the slowest method be pursued,- that of selecting eggs for hatching, from which are to be reared the fowls to produce eggs,- - there should be no difficulty in producing for the market in from five to eight months.

With other classes of live stock, not only is 
a much longer time required in which to secure returns, but also a greater money outlay at the beginning, as above stated. The fact that so little time is required for the development of a paying business makes poultry-keeping an attractive field for those having little capital, and who must enter some business that will bring quick returns.

MAY BE CONDUCTED BY PERSONS OF EITHER SEX

The fact that the poultry business requires little land, few and inexpensive buildings and no heavy and complicated machinery, makes it well suited to persons of either sex who are unable physically, or who do not desire, to perform heavy manual labor or any work that requires the outlay of considerable effort and strength.

Those who desire to work more or less out-ofdoors, and who are willing to attend regularly to details, may find congenial employment, and may undertake to perform the necessary operations of poultry-keeping without the feeling that they are starting in a business for which they are not fitted. It will frequently be noticed that success in business is attained by those who for various reasons are more or less unfitted for the work which they have undertaken, and who consequently achieve success through great perseverance alone in the face of greater difficulties than their competitors experience. 
Many people of means and refined tastes have profitably taken up the study and occupation of poultry-keeping as a means of affording healthful out-of-door exercise, in order to regain failing health or to afford a change and rest from professional activity. Many women have become expert breeders, or producers of various poultry products, and are recognized as authorities in their respective lines of work. There is no branch of animal industry that offers so many inducements to women as some of the various branches of poultrykeeping, particularly if they desire to experiment in the production of new forms, or to improve for their particular purpose the breed or variety which they have selected as best adapted for their use.

\section{A GREAT VARIETY OF PRODUCTS}

Quite unlike other lines of live-stock work, in which only a few products are raised on the farm ready for the market, poultry-keeping fortunately offers to the poultryman and farmer an opportunity to choose from a number of marketable products those which he prefers to provide, or which in his judgment will most likely bring pleasure or financial success. It is noticed that circumstances are often such that certain lines of poultry work can be conducted with greater success than others, so that those who study closely 
their own adaptabilities are enabled to select at the outset the line of work that is likely to prove the most satisfactory.

To carry out this idea somewhat further by means of an illustration, it will readily be seen that if a poultryman had a somewhat limited space for fowls, including both buildings and yards, so that it would be quite impossible to keep to advantage more than a few hundred at most, he should either devote his energy to the production of fowls of high merit for breeding purposes or confine himself to egg production. The rearing of young fowls for market demands more space both in- and outof-doors than a business of the same magnitude in which egg production is the chief object. The various classes of domestic hen, with turkeys, ducks, geese, and pigeons, furnish a great variety of products that find ready sale in the markets. From these the farmer or poultryman may select those that offer to him the greatest special inducements.

\section{PRODUCTS EASY TO MARKET}

With modern facilities for rapid transportation, the various poultry products may be sent to market hundreds of miles distant and be placed before the consumer in excellent condition. Eggs only a few days old may be served as food after being shipped hundreds of miles by express. 
While the best products may be sent long distances by express with profit, the poorer ones seldom pay for the extra cost of rapid transit. Superior products create new demands. Since more attention is now paid to poultry-raising in this country than was given to the industry but a few years ago, many highly prized special articles have been produced which find a ready market at remunerative prices in nearly all of the large cities. As better products are placed on the market and as people of means become aware of this fact, the demand for a good article soon becomes as strong and constant as that for the cheaper and more staple articles. As soon as a worthy article is produced regularly, customers are ready to purchase. The best on the market is usually sold first, and at prices considerably in advance of that for common or ordinary grades. Better work with poultry will eventually insure better products, which find ready sales, and, in turn, create new demands. It should be the aim of each person who is about to enter the poultry business to produce the best which the market affords. The greatest skill is required to furnish the best, but articles which are produced with great skill and a thorough knowledge of the business usually yield the greatest profits. 


\section{CHAPTER II}

EGG BREEDS OF THE DOMESTIC HEN

Agriculturists may, for convenience, classify fowls as to their useful qualities as-
Egg Breeds
General-Purpose Breeds
Meat Breeds
Fancy Breeds

While this classification gives considerable information, in a general way, yet it should not be inferred that the distinctions between these classes are constant or very pronounced. In other words, a classification that is based on utility does not make use of positive characteristics. The distinctions are relative and therefore quite variable, as the usefulness of any breed will depend to a large extent upon various conditions, as food, care, climate, etc. Again, the so-called general-purpose fowls form a connecting link between those which are most highly esteemed as egg producers and the heavy, clumsy Asiatic fowls, whose most useful quality is the production of large bodies that are highly valued for table use. From the nature of the classification and the variation of the fowls from the standpoint of usefulness, it will readily 
be seen that different breeders may honestly differ as to the exact position of certain breeds.

To further illustrate, what would be recognized as a meat breed by one breeder might by another be placed among the general-purpose fowls on account of its good laying qualities. As we find all grades of domesticated cattle, from the heavy strictly beef type on the one hand, whose usefulness lies in meat production alone, to the dairy cow on the other hand, whose tendency toward milk production is so strong that she can with difficulty be induced to lay on enough flesh to look well, so do we find many intermediate grades of fowls, from the large, massive form noted for the production of flesh to the small, nervous fowl so famed for egg production. The inexperienced person will find more or less confusion on account of this faulty classification, and mistakes are to be expected, and these will be corrected only by study and observation.

As these terms are current and are likely to be used in the future, a brief discussion of them may aid in arriving at a better understanding of the points at issue.

The egg breeds include all the small or mediumsized fowls that have a strong tendency toward egg production. They are generally poor sitters, at least while young, of a nervous temperament, being easily frightened, and more readily take to flight 
than do the other breeds that are noted for utility. They are maintained for the production of eggs and for this purpose are unexcelled. Poultrymen who rear large flocks for egg production find it necessary, and often remunerative, to dispose as market fowls of large numbers of young male birds and also old hens that have passed the period of greatest usefulness as egg producers; yet this is incidental to the production of eggs and should not in any way mask the fact that egg production is the greatest useful quality of these fowls. The Leghorns, Spanish, Minorcas, and Hamburgs are good representatives of this class.

The meat breeds are larger than the egg or the general-purpose breeds. The largest breeds of fowls are represented in this class. They are generally considered to be poor layers except, possibly, in a few cases where the pullets are fairly good winter layers. They are heavy-bodied, slow-moving fowls, of gentle disposition, and are persistent sitters. The Brahmas, Cochins, and Langshans are representative breeds of this class.

The general-purpose breeds, as the term indicates, include those fowls that are of medium size and furnish a good quality of meat when properly fattened and prepared for table use. For certain methods of cooking, these fowls are preferred by many to the larger bodies and coarser-grained flesh of the distinctively meat breeds. As these fowls are good 
egg producers, when kept under favorable conditions for egg production, they have become most popular with a large class of poultry-keepers who maintain comparatively small flocks largely to supply the demands of the home table. Farmers and others, who keep a few fowls as a secondary consideration, find this class most useful. Aside from furnishing the home table they are sufficiently economical in the production of both eggs and meat to permit the surplus to be sold on the market to good advantage. The Plymouth Rocks, Wyandottes, and Rhode Island Reds, are familiar breeds of this class.

The fancy breeds include those fowls that are reared on account of their peculiar or pleasing appearance, and are not bred exclusively for utility. While many of the so-called fancy breeds may serve a useful purpose in furnishing eggs and meat, they cannot successfully compete with other classes when usefulness alone is considered. The Polish, Bantams, Frizzles, and Silkies may be taken as familiar representatives.

GENERAL CHARACTERISTICS AND SIZE OF EGG BREEDS

While those breeds and varieties of fowls that may be classed as distinctively egg producers vary somewhat in size and form, yet they differ so materially from the general-purpose and meat breeds that they may well be placed by themselves if for 
no other reason than the one distinguishing characteristic of size. Almost without exception the noted egg-producing breeds are small or medium in size and possessed of a neat, trim appearance, which gives them an air of activity. They are also somewhat longer-legged in proportion to their size than the meat breeds, yet those having the most robust constitution do not appear to be small or long-legged.

While mature fowls of some of the heaviest breeds of this class should weigh from six to nine pounds, yet the weight is seldom mentioned in descriptions of the most noted egg-producers of this class. This is undoubtedly due to the fact that egg production is the chief consideration, regardless of the weight of the fowl.

The specific purpose for which these fowls are reared being egg production, the breeder does not care to sacrifice this product for increased meat production, except as increased vigor in the individual is likely to bring an increase in size, a subject that is discussed somewhat fully in the chapter on breeding.

Disposition.-Almost without exception, a nervous, active disposition is characteristic of the various varieties of fowls which are noted for egg production. They are naturally quick, alert, easily frightened, and when once thoroughly aroused fly almost with the ease of wild birds. On account 
of this activity, they like a wide range and ordinarily do best when not closely confined. Many varieties, however, thrive well when kept within inclosures, if the confinement is not too rigorous, and good judgment is exercised in providing other conditions that are most sanitary and congenial to the fowls.

Whenever inclosures are provided to restrict their range, careful handling is necessary in order that the practice of using their wings as a means of locomotion may be avoided as far as possible. Habit, when once acquired, is not easily changed; consequently breeders find it difficult to correct the annoying tendency to fly on slight provocation when the habit is well formed. Many a fine fowl has suffered the death penalty for continually flying over inclosures. Whenever a few fowls of a flock or pen have acquired the habit of flying over the inclosures or fences, a reasonable modification of the inclosure to correct the evil rarely suffices. It has been said with much aptness that "Egg breeds of fowls, like honey bees, require slow movements and careful handling from the attendant, for success, while hasty movements bring annoyance and disaster."

All fowls may become gentle and tame by continued careful handling, so that the characteristic alertness of the egg breeds need not prevent the use of these types, even though tame fowls are required. Leghorn and Minorca hens 
have frequently been seen to perch on a basket carried on the arm of an attendant who was entering the pen or yard, in order that they might secure the first morsel of a coveted food. This degree of familiarity is attained only by continued thoughtfulness and gentleness on the part of the attendant.

The nervous fowls of the egg breeds, even though they have become gentle and tame by careful handling, are more suspicious of strangers than are the heavier and slower moving fowls of the generalpurpose and meat breeds. Consequently many poultrymen will not admit strangers to the yards and pens occupied by laying hens.

Early maturity.-The noted egg breeds are classed among the earliest maturing fowls. In fact, they almost form a class by themselves if judged from a standpoint of development. Early in life they assume the appearance of miniature adults, both in general outline or conformation and in the growth of plumage.

The early feathering greatly enhances the probability of the young chick living to reach maturity. Other things being equal, the more rapidly the young chick "feathers out" the more hardy it becomes. The time when a young fowl is growing feathers rapidly is always a delicate period in its existence. It is well known by those who keep song birds in cages that the molting period is a trying one for their pets. As these songsters in the molt- 
ing period are producing feathers, which make great demands on their systems, their condition is very similar to that of the young fowl that is producing feathers for protection at the expense of its physical organization. It is difficult, if not impossible, for a fowl having a weak constitution to produce feathers rapidly.

While all egg breeds are not of equal hardiness in this respect, yet as a class they pass rapidly through the most delicate periods of infancy, which goes a long way toward placing them as the most hardy of fowls. The individuals of egg breeds develop combs and wattles early in life, which still further give them the appearance of small adults. At no time do they appear so ill proportioned and awkward as do the good-sized though undeveloped young of the larger breeds.

Poor sitters.-All noted egg-producing fowls are poor and uncertain sitters. The term "non-sitters" has frequently been used to designate various breeds of fowls possessed of a marked tendency toward egg production at the expense of a disposition to incubate.

Breeders have long been trying to further develop the tendency of egg production that is inherent in all the Mediterranean fowls, which has resulted in producing an exclusively egg-producing machine. The marked development in egg production in this class of fowls has been accomplished 
at the expense of other desirable qualities. In other words, the whole energy of the fowl is devoted to the one particular purpose of producing eggs. That is so far as the breeders and improvers have been able to direct the energies of the fowl toward securing increased amount of useful products. So far has this been carried that breeders are now seeking to breed fowls having stronger constitutions, that this specialization may be carried to a still greater extreme.

The tendency toward egg production has become so great that the hen has comparatively little desire to rear young and otherwise exercise her maternal instincts. Almost without exception, those breeds of fowls that are noted especially for egg production cannot be depended upon for natural incubation if any considerable number of fowls are to be reared. Breeders are therefore compelled to resort to artificial incubation, or to keep largely if not wholly, for incubation, some fowls of another breed, whose maternal instincts make them good mothers. Occasionally individuals of the egg breeds become "broody" and under favorable conditions prove to be persistent sitters, but too frequently the desire to incubate is but a fickle one and indulged in at the expense of the owner who supplies the "sitting of eggs." As the hens become older the tendency to incubate becomes stronger. While these fowls are extremely poor sitters, yet so long 
as they continue to incubate, though it be somewhat rarely, the term "non-sitters" cannot strictly be applied to them.

Good foragers.-These egg breeds rank among the most active and industrious fowls, as many a good housewife can testify whose cherished flower garden has undergone a system of surface culture instituted by a Leghorn hen. All the noted egg producers are very alert, and are well suited to foraging, -and may obtain a considerable portion of their living if a wide range is provided. They are not only active, but seem to be constantly on the lookout for food. It is true that often, under otherwise favorable conditions, they seem to endure close confinement very well. This is undoubtedly due to the fact that they are hardy and will stand more or less abuse and still maintain a thrifty appearance. They thrive in spite of confinement, not because of it. The most skilful breeders, who are unable to give their fowls the desired run or yard, almost invariably provide means for giving the fowls exercise, which may be done by requiring them to scratch among litter for their food. This will in a degree modify the evil of close confinement.

There is not the least doubt that many fowls that are now kept in close confinement would be more healthy, give a larger percentage of fertile eggs, and in the end prove much more profitable if greater freedom could be afforded them. 
Sensitiveness to cold.-All of the noted egg breeds have large combs and wattles, which make them sensitive to low temperatures. Some of the breeds having extremely large combs and wattles are so liable to have them frosted in the colder latitudes that warm quarters must be provided, if the production of eggs in the winter time is a requisite. Theory and practice agree that a lower degree of temperature will be endured without serious results if the quarters occupied by the fowls are free from drafts. These fowls may become accustomed to a comparatively low temperature without any injury whatever provided actual freezing of any parts does not occur. Pure air, even though it be cold, seems quite essential to the highest degree of health and to greatest vigor.

Breeders have sought to remedy this somewhat serious objection by breeding "rose-combs," that are not so readily frozen. In practice this is found to be only a partial remedy, as the wattles, when extremely large, are almost as sensitive to cold as the large, thin, upright combs.

The egg breeds are much closer feathered than the fleshy Asiatics (Brahmas, Cochins, and Langshans), which endure low temperatures so well. The thicker coat of fluffy feathers of the Asiatics undoubtedly forms a thicker dead-air space than do the thinner and more compact coats of the egg breeds. The comparatively long and naked 
shanks, large combs and wattles, with a compact coat of feathers, ill prepare the latter to withstand the severity of the northern winter when more or less exposed by the neglect or indifference too toften accorded the fowls on many farms.

It should not be inferred, however, that these fowls are not suited to the northern, central and New England states, for they are the best winter layers when warm and comfortable quarters are provided. Even when more or less neglected they may still prove to be wholly satisfactory as winter layers on account of their hardiness and their great natural tendency to produce eggs. The very fact that they do so well under comparative neglect is one of the chief reasons for such unsatisfactory results in poultry-keeping: fowls that will live with little care are likely to receive little care. It often happens that the most delicate breeds receive the most care.

\section{BREEDS AND VARIETIES}

The most noted egg breeds now reared in the United States include the so-called Mediterranean fowls, which comprise the following breeds: Leghorn, Minorca, Ancona, Andalusian, and Spanish. To these should be added the Hamburg, Red Cap, and perhaps some others. Some of these breeds are further subdivided into numerous varie- 
ties which partake of the same general form and disposition but differ greatly in color of plumage.

In producing so great a variety in plumage as seen in the numerous varieties of some breeds, notably the Leghorn, foreign blood has been introduced which has modified, to some extent, the laying propensities. At first thought the practice of introducing the blood of an alien breed in the formation of a new variety of an egg breed would be condemned; but when it is once well understood that crossing within certain limits brings increased vigor to the progeny, it may be seen that for egg production alone the new variety, which is given a little more robustness, may be made to produce as many eggs by a process of moderately forced feeding as the somewhat more delicate pure breed whose inherent tendency to egg production may be a little stronger.

Leghorn.-This is one of the Mediterranean breeds whose name is supposed to have been derived from the city of Leghorn, in Italy, whence they are thought to have been brought to America. The early history of the breed is now more or less obscure, and this is due, no doubt, in a large degree, to the fact that they were unpopular for many years after they were introduced into this country. Although they are credited with being introduced in the early part of the nineteenth century, it was not until after the middle of the century that 
they attracted much attention. As the popular animals and crops are most written about, it is not strange that a more or less unpopular breed should pass for nearly half a century with comparatively slight notice. Since the introduction

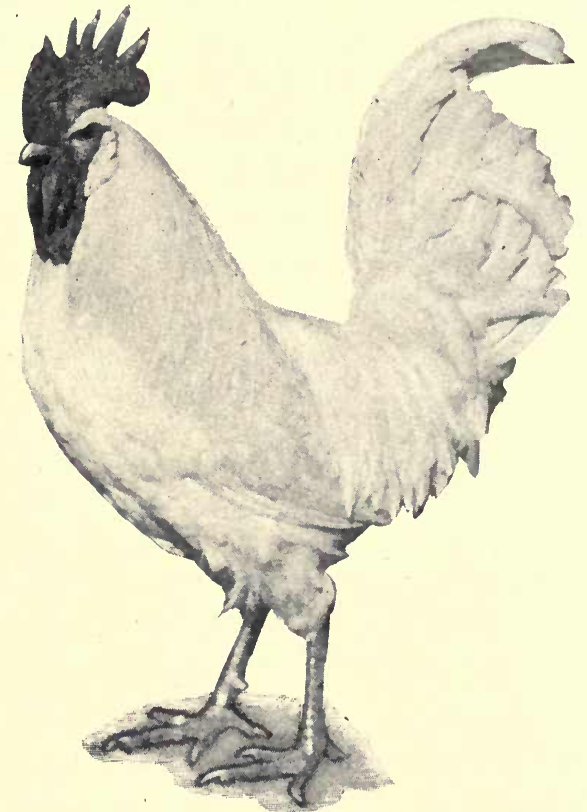

Fig. 1. A White Leghorn cockerel.

of the Leghorns, however, they have been considerably changed and bred to that degree of perfection that has designated them an Americanized, if not an American breed. In the early history of these fowls in this country they were spoken 
of as being of various colors yet all partaking of the same general nature, and were recognized as belonging to the same breed. The different va-

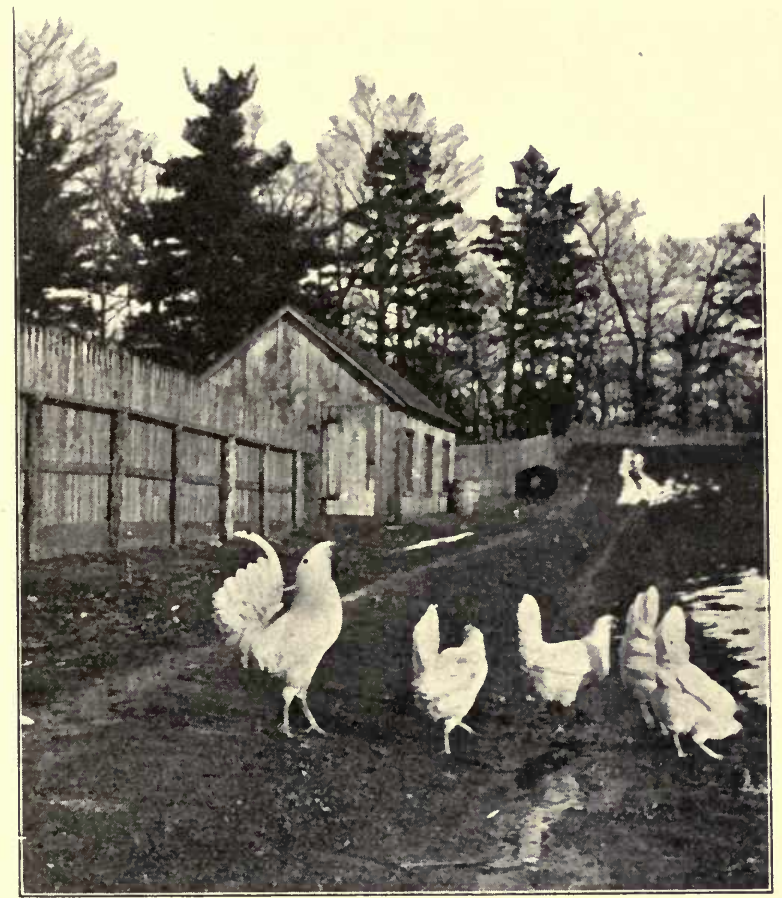

FIG. 2. White Leghorns.

rieties that are now recognized had not then been formed.

All varieties of Leghorns are comparatively small in size, and consequently are not well suited to those who depend largely upon their fowls for 
the supply of fresh meat for the table. They are active and do not fatten so readily under ordinary conditions as larger and less active breeds. These fowls are hardy, and all varieties are good layers, most of them being extremely prolific.

The fact of their being hardy in all stages of development, as well as extremely good layers, fits them for the farm, where a considerable revenue is expected from the sale of eggs and where comparatively little importance is placed on the production of meat. They are noted for laying early in life; frequently early-hatched pullets lay at five months of age and under favorable conditions will lay well throughout the winter and summer months. Many records of more than two hundred eggs per year from single birds are known, and even large flocks have produced two hundred eggs per hen in a single year.

The Leghorns are comparatively light eaters and are somewhat less expensive to raise to maturity than larger and heavier-bodied fowls. All varieties of Leghorns are active and do best if given wide liberty and if permitted to take much exercise in search of food.

The varieties of the Leghorn breed are:

Single-comb Brown

Rose-comb Brown

Single-comb White

Rose-comb White
Single-comb Buff

Rose-comb Buff

Single-comb Black

Silver 
All varieties except the Rose-combs have large single combs, which, in the males, should, be thin, firm and erect. In the females they should fall

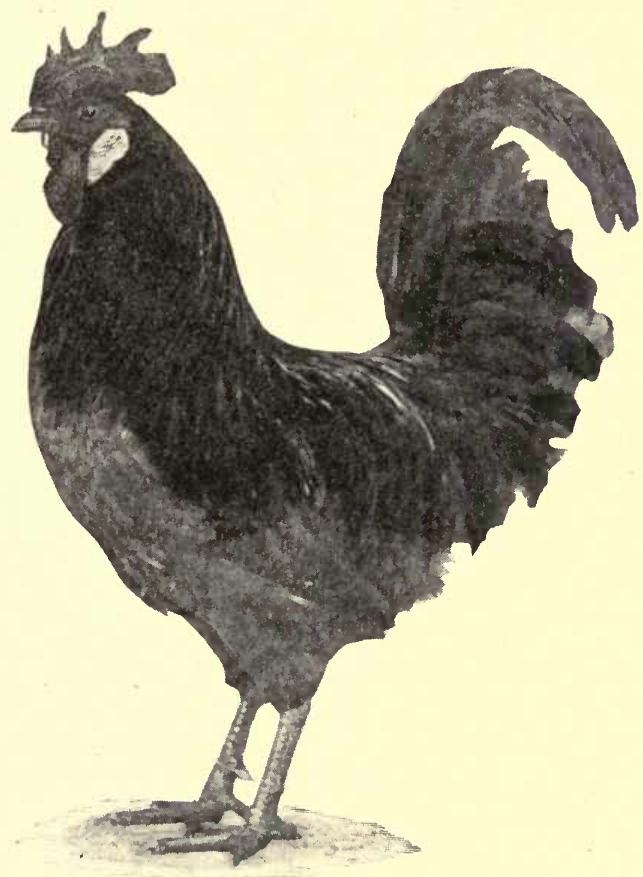

Fig. 3. Buff Leghorn cockerel (one-fifth size).

gracefully to one side, particularly during the laying period.

The White and the Brown varieties are older than the others and are usually selected when egg production is the sole object. Some of the new 
varieties have not been bred pure long enough to become thoroughly fixed in their distinctive characteristics.

There is practically no difference between the White and the Brown varieties in the number of eggs produced. The White, however, lays somewhat larger eggs than the Brown, and the shells are of a purer white; that is, the shells of the Brown Leghorn are a little tinted, although they readily pass for white eggs. The color of the shells is of minor importance, although it is recognized as one of the fancy points when highest-priced eggs are produced. In some markets white eggs sell for the highest prices; in other markets brown eggs are preferred. Under ordinary conditions the difference in the color will be of little or no value. If, however, the poultryman desires to produce the highestpriced eggs, some attention should be given to the color and other characteristics which go to make up uniformity of product.

It needs no argument to sustain the assertion that, other things being equal, those fowls that lay the largest eggs are to be preferred. At first thought it may appear to be of more importance to those who aim to produce eggs for their own table than to those who produce eggs for the market to be sold by the dozen. It should not be forgotten, however, that continued success in any business requires the business man to satisfy his customers. 
He should aim, therefore, to produce good-sized eggs, which will be acceptable not only as to quality but also as to weight. It will be evident to all that those fowls which lay the greatest weight of eggs during the year will be the most economical for the farmer to keep to supply the wants of his

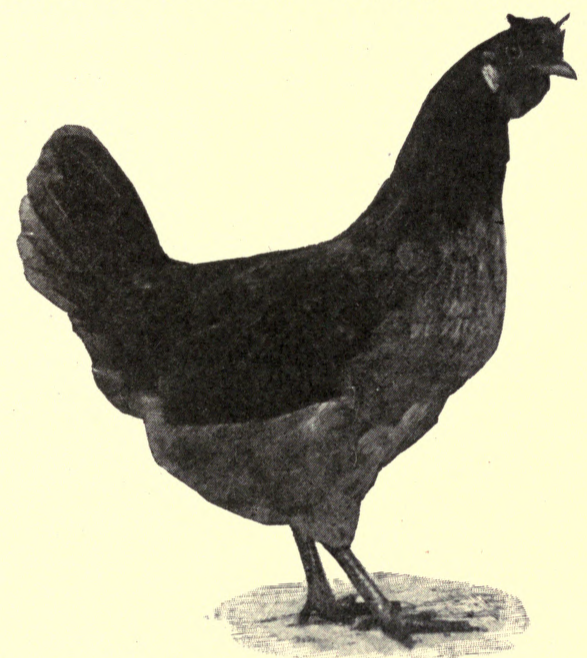

Fig. 4. Buff Leghorn pullet (one-sixth size).

own table. The difference in expense of keeping fowls which lay different-sized eggs is not commensurate with the difference in the value of the product. This subject will be given a fuller discussion in another chapter.

It is asserted that some of the other and newer varieties of Leghorns are equally as good egg pro- 
ducers as the White and the Brown varieties. However, the majority of practical poultrymen who have selected a variety of the Leghorns and have entered into the business of egg production for profit select either the White or the Brown variety.

Fowls of a solid color, like the White or the Black variety of the Leghorn breed, often prove most

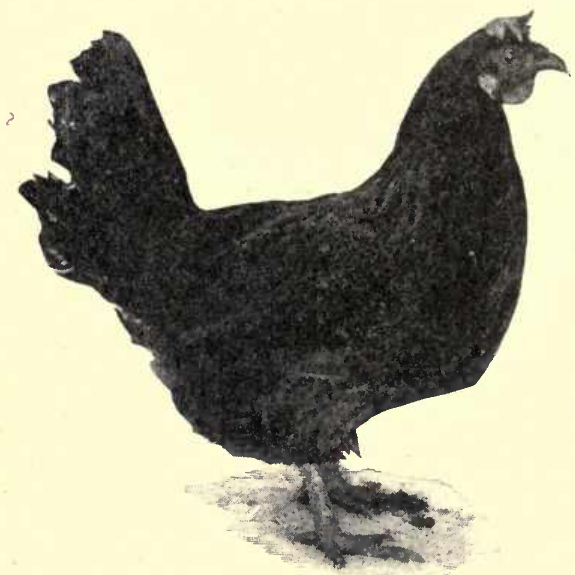

Frg. 5. Single-comb Brown Leghorn hen (two-thirteenths size).

satisfactory in the hands of a poultryman whose primary object is to produce eggs, and whose secondary object is to sell his surplus stock for breeding purposes at something more than the price of which dressed poultry brings in the market. The reason for this is readily seen when we consider that old fowls must be disposed of and be replaced by younger and more vigorous stock. Such stock 
may frequently be sold and used for breeders after having served a period of forced egg production, provided it represents fairly well the type of fowls to which it belongs. Fowls are more likely to represent a type in color if they are solid-colored than if the plumage is distinguished by various markings, as seen in many of the useful breeds. In other words, the poultryman finds it much easier to develop the one point of egg production than to breed for plumage and develop for egg production at the same time. One important principle in stock breeding should not be forgotten,- that it is much easier to develop one useful quality to its greatest perfection than to develop two qualities which are not closely correlated. Consequently, it is found much easier to produce strong, robust fowls of a solid color for egg production than to produce equally good birds of a colored variety, for both exhibition and useful qualities.

Minorca.-This breed is thought to have been introduced into England from the island of Minorca in the Mediterranean Sea, and it is said by some poultry authorities to be the progenitor of the Whitefaced Black Spanish breed. The varieties of this breed are:

Single-comb Black

Rose-comb Black

Single-comb White

These are the heaviest of the Mediterranean fowls. 
Of the Single-comb Black variety the cock should weigh 9 and the hen $71 / 2$ pounds. Of the other varieties the cock should weigh 8 and the hen $6 \frac{1}{2}$ pounds.

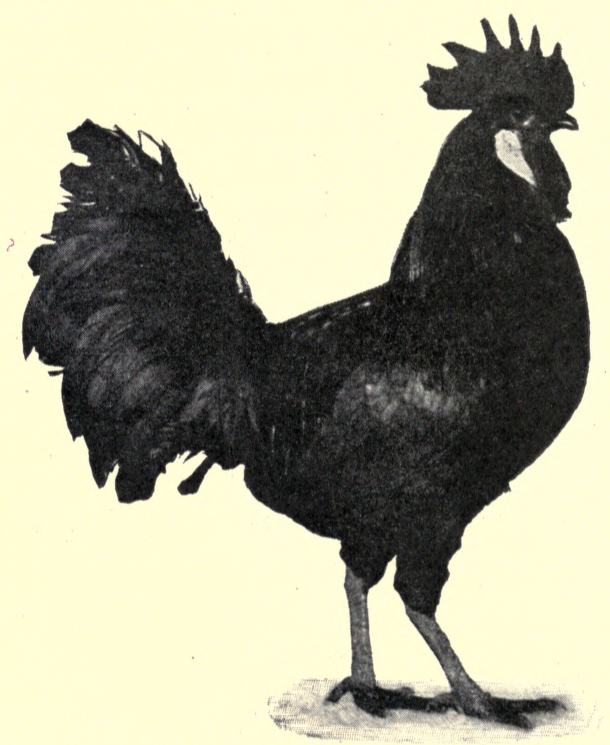

FIG. 6. Black Minorca cockerel (one-seventh size).

They have the great laying tendencies of the fowls of this class. Lewis Wright, writing of English fowls, places them second on the list of egg producers. In appearance they resemble the Leghorns, although they have larger combs and wattles. The solid color is in their favor, although there is a tendency toward white in the primaries of the 
Black variety. They have not been so popular for egg production as the Leghorns, although they are coming more into popular favor. The eggs of this breed are large and white. They average about eight to the pound. As Americans prefer fowls having yellow skin and shanks, the Minorcas are

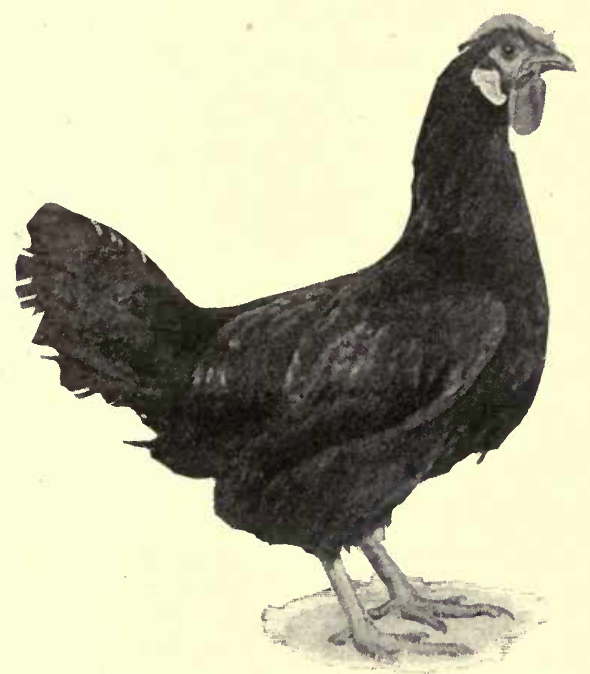

FIg. 7. Black Minorca hen (one-seventh size).

therefore placed at a disadvantage, as their skin is white and the shanks and feet of a dark leaden color approaching black.

Andalusian.-This breed is thought to be native to Andalusia, a province in the southern part of Spain. It is a large, hardy breed of the Med- 
iterranean class. These fowls have not been popular in the United States, partly owing, no doubt, to the color of their skin and shanks. The skin is white and the shanks and toes are slaty blue. For farm purposes they are considered about the same as the Minorcas. There is only one variety of this breed-the Blue. The plumage is of a bluish gray or dove color, approaching black on the back. They do not breed so true to color as some of the other breeds of this class. They are excellent layers but are not supplanting the Leghorns for this purpose. They are classed with the non-sitters, but have a somewhat greater tendency to incubate than Leghorns do. The cock should weigh 6 and the hen 5 pounds.

Spanish.-Now known as the White-faced Black Spanish. This breed has been bred pure for a great many years in England. It is called the oldest of the non-sitting varieties. There seems to be no doubt in the minds of many authorities that this Spanish breed came from some of the Mediterranean countries, and probably from Spain. The fowls are somewhat longer-legged in proportion to the size of the body than the other breeds of this class. They are glossy black throughout, without any white or gray feathers. The shanks and toes are dark in color, leaden blue approaching black. The Spanish is not so hardy as the other breeds mentioned, particularly when imma- 
ture and subjected to more or less dampness. The chickens do not feather so rapidly as the Leghorns and are considered more delicate. On account, no doubt, of the somewhat more delicate constitution, the eggs are more or less infertile, and breeders consequently are forced to keep a somewhat smaller number of females with one male than with other breeds of fowls noted for egg production. Breeders have attempted, and succeeded in a large measure, in developing more fancy points with the White-faced Black Spanish than with other noted egg breeds of a solid color. This breeding for fancy points is thought to have weakened the constitution considerably. On account of the development of these fancy points, some practical poultrykeepers are inclined to consider the Spanish as a fancy breed rather than to class it among the most useful ones. While they will undoubtedly produce a good supply of eggs under favorable conditions, yet the fact remains that few if any practical poultrymen select them solely for egg production. The white face is a distinguishing feature of this fowl, as the white of the face and the ear lobe form a continuous smooth, white surface extending down below the wattles and uniting in front. They have large, single combs. For farm purposes they should be placed after the Leghorns, Minorcas, Andalusians, and Anconas.

Hamburg.-The Hamburgs have long been known 
as prolific egg producers. This breed consists of six varieties:

Goldell-spangled

Silver-spangled

White
Golden-penciled

Silver-penciled

Black

The Hamburg breed was introduced into England from Holland or North Germany, and eventually took the name of the noted seaport, Hamburg, although they were known at that time, and for many years after their introduction into Great Britain, as the "Dutch every-day layers," or "everlasting layers." They are small, active fowls, and are recognized as being extremely good layers if kept under favorable conditions. It is said that when properly kept they will equal the Leghorns in egg production, although as a matter of fact comparatively few poultrymen select Hamburgs in preference to the Mediterranean fowls when egg production is the sole, or even the chief, object. They are quite as difficult to keep in confinement as any of the Mediterraneans, being small, light, and easily frightened. Their tendency to fly makes it difficult to keep them in the yards or runs. Of all breeds, probably there is none that likes a wide range better than the Hamburgs. Their eggs are small and white, being somewhat smaller than those of the Leghorns. All varieties have blue, or leaden blue, shanks and toes, except, possibly, the Black, which may have dark, leaden blue or black shanks 
and toes. All have rose combs, which terminate in a spike or point at the rear. This point is usually somewhat elevated, and is one of the characteristic features of the Hamburg comb. When these fowls are entered for competition at shows or exhibitions there is no weight qualification. Their small size

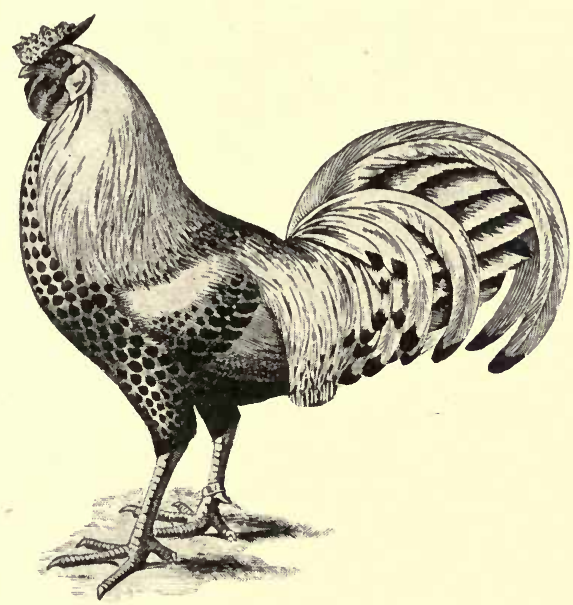

FIG. 8. Silver-spangled Hamburg cock.

makes them unprofitable as table fowls; then, too, the color of their shanks and skin is against them for table use. The chickens are not noted for their vigor, and it is said that both old and young are likely to suffer from want of cleanliness more than any other egg breed, with the possible exception of the White-faced Black Spanish. Wright says they do not stand crowding well, and that "where 
six Brahmas could be kept, four Hamburgs are quite enough."

Red Cap.-This is recognized as a distinct breed, yet the fowls resemble the Hamburgs in many respects. They are somewhat larger than the Hamburgs, and compare with them in size much as the Minorcas compare with the Leghorns. They are quite hardy, and are extremely good layers. They have large rose combs, which have 'a tendency to grow somewhat irregular. This makes them difficult to breed for exhibition purposes. They have slate-colored shanks. The plumage is red and black. Cocks should weigh $71 / 2$, hen $61 / 2$, cockerel 6 , and pullet 5 pounds. 


\section{CHAPTER III}

\section{MEAT BREEDS}

Those breeds that are reared especially for the production of meat, either for home consumption or for the market, are good-sized, compactly built fowls, probably of Asiatic origin. They are much heavier than those that are reared especially for egg production and differ from them almost as much in general outline as they do in size and weight. It should be borne in mind that the term "meat breeds," as used in this volume, refers chiefly to those breeds whose greatest usefulness is in the production of meat. While the quality of the flesh of these fowls may not exceed, or even equal, the flesh of some other breeds, yet on account of their large size they are especially prized for table use under certain conditions. As a good-sized roast of meat is preferred to a small one, so large fowls are preferred for certain methods of cooking. Certain it is that large fowls are usually served to better advantage than small ones.

As a rule, the noted meat breeds are larger, more compact and "blocky" than the Mediterraneans. They are broader and deeper in body, 
fuller in breast and have shorter necks and legs. While some of the intermediate, or general-purpose fowls, as they are sometimes called, are reared wholly for their flesh, they should not be classified with the distinctively meat breeds. The latter fowls produce, under favorable conditions, a good number of eggs, which, together with their size, warrants placing them in the intermediate class, which may be called general-purpose breeds, for convenience of discussion. Whatever may be said of those fowls noted for meat production will apply only in part to the smaller general-purpose fowls, so far as they enter into competition for meat production. As a matter of fact, many of the so-called general-purpose fowls are reared extensively for meat production, but they are nevertheless of a different type from the large, heavy, phlegmatic breeds, whose greatest usefulness is in the production of large, plump bodies, most highly prized for table use. These meat breeds form a class by themselves even when the fowls are considered from the standpoint of weight only.

Disposition.-Without exception, all the noted meat breeds are slow and more or less sluggish in movement and are not easily frightened. They become very tame and gentle with careful treatment and do not show a dislike to handling, as do some of the smaller and more nervous breeds. They are not well calculated to seek their own 
living, even though a wide range be provided. They have little desire to roam far from home unless compelled to do so in search of food. Even then their slow and, in many cases, awkward movements totally unfit them for foraging for insects and other foods which nature provides, in competition with more active breeds. Preëminently, they are fowls which should be fed, rather than allowed to shift for themselves. As the more active, nervous Mediterraneans illustrate an ideal fowl for foraging, so the heavy, clumsy, phlegmatic meat breeds represent the opposite extreme, or that of gentleness and docility.

Easily confined.-If only the heavy-bodied fowls are to be reared on farms where all fowls are to be kept within enclosures, comparatively low fences will suffice. When mature, fowls of the heaviest breeds rarely fly from the ground, and are satisfied with comparatively low perches. On account of their gentle dispositions they make most excellent "lawn fowls," and may be given liberty without fear of trespassing on the holdings of a near-by neighbor. In the minds of many, a few fowls on the back lawn during certain portions of the year add to the attractiveness of the surroundings and bring pleasure to the owner, who delights in the freedom of his birds. This is particularly true if he is assured that these birds, which, in a sense, have become pets, are quite certain not to annoy 
either the members of his own household or his neighbors. There are probably no breeds of fowls so well suited to have the liberties of a small farm or lot as these slow-moving Asiatics.

Laying qualities.-The laying qualities of these fowls are considerably below the average, and, as a rule, are not to be compared with those of the more active fowls which originated in the countries bordering on the Mediterranean.

The useful qualities of animals reach the highest state of development when one quality is developed at the expense of others. Experience has shown that it has not been possible to develop in the same individual or breed two or more useful qualities to the highest stage of perfection. The two most highly prized useful qualities in our domesticated fowls are meat and egg production. When one is unusually well developed the other is lessened in value or importance, so that both are never developed to the greatest extent in one individual. Admirable illustrations are seen in the development of animals that are highly prized for the production of meat or of milk. In no instance has the best milker been most highly prized for meat production. A similar condition exists in the poultry world. While the breeding of fowls solely for egg production, or for meat production, has reached a high state of perfection, yet these two qualities are not brought to the highest stage of perfection in one individual. 
The development of either is largely held to be a matter of food and constitutional vigor, although some investigations tend to show some differences between egg production, a reproductive function, and other useful qualities that previously had not been given so careful consideration. This is discussed more fully in the chapter on breeding.

The re'ative importance of meat production and egg production in this country is continually becoming more widely separated as the price of food and labor advances. The importance of egg production is steadily advancing faster than that of meat production, just as the dairy interests of the country are becoming of far greater importance than the beef interests.

This condition has a tendency to cause undue claims to be made for the meat breeds as to egg production. Those about to purchase fowls to be used as foundation stock for a flock should not be misled by any claims that breeders of meat breeds may make as to the profitable egg production of their fowls.

While some breeds or varieties of large fowls, notably the Light Brahmas, are good winter layers while young, yet it is not to be inferred from any records these fowls may have made that they are equal to some of the Mediterranean breeds as economical egg-producing machines, when the entire life of the fowl 'is taken into consideration. The 
modern poultryman regards his fowls much as a manufacturer regards his machine, and, in either case, the machine that will run at its fullest capacity for the longest period, other things being equal, will bring to the owner the most profit. While poultry-keepers may rightly consider their fowls as machines for the production of meat and eggs, yet it should be understood that it is not only desirable, but necessary, that the successful poultryman regard his flock from a standpoint other than a purely business one. It is necessary to the most successful poultry business that the poultryman love his fowls. Unless the live-stock owner has a love for the animals under his charge, and which is entirely distinct from the purpose for which he is breeding them, he is not likely to study their necessities and comforts.

The distinctive meat breeds include all of the Asiatics, namely, the Brahmas, Cochins, and Langshans. Of the Brahmas, there are two varieties, the Light and the Dark. The Cochins are represented by four varieties,-Buff, Partridge, White, and Black; while the Langshans have but two varieties,-Black and White.

Late maturity.-It is well understood that in the development of animal life large size' is not conducive to early maturity. Thus, heavy meat breeds require a much longer time in which to reach maturity than do the smaller, more active fowls. 
On this account the chicks are considered somewhat more delicate. This is because they require a much longer time while passing the early and critical periods of their existence. Little chickens are more delicate than mature fowls; consequently, the longer the time required to pass through the juvenile period the more difficult they are to rear. On the other hand, the little chicks are well suited to withstand the hardships of early life if they are kept dry and clean. The young of some varieties are much better protected with down and feathers than others.

\section{BRAHMAS}

These are frequently called the leading breed of the Asiatics. Light Brahmas, particularly, have long been popular with many poultry-keepers throughout the country. The origin of these fowls

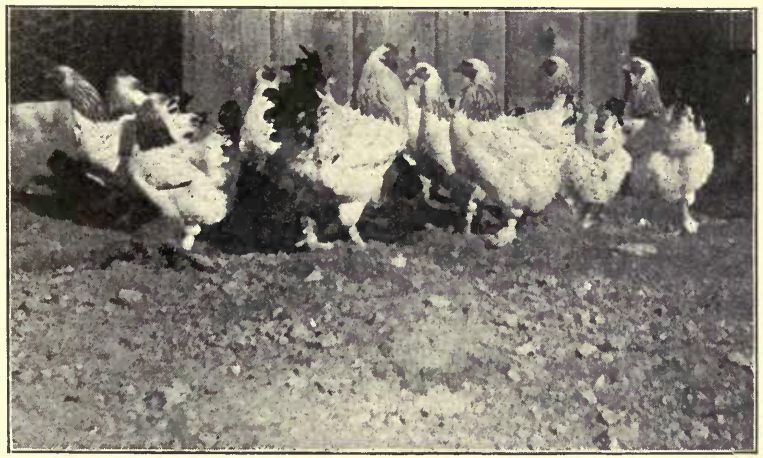

Fig. 9. A flock of Light Brahmas. 
is somewhat obscure. Wright and others think that they probably have descended from the fowls of India, while Tegetmeier asserts that this breed was probably formed in America.

A distinctive feature of the Brahmas is the comb, which is known as the pea-comb. It is unlike

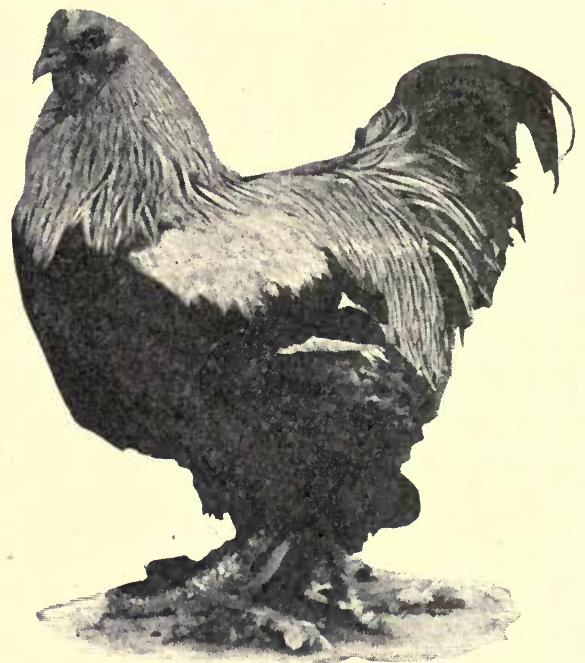

Frg. 10. Dark Brahma cock (one-eighth size).

either the rose or the single comb. The pea-comb has been described as the union of three single combs, joined at the front, rear and base, the middle comb being somewhat larger than the other two. Each comb should have distinct serrations.

The Brahmas are large fowls, -in fact, the largest variety known is the Light Brahma. The 
Light Brahma cock should weigh 12 and the hen $91 / 2$ pounds. The Dark Brahmas are a pound lighter. The Brahmas have yellow skin and shanks, and the outersides of the shanks are feathered. Leg-feathering is undoubtedly a protection during the severe winter weather, but it is somewhat objec-

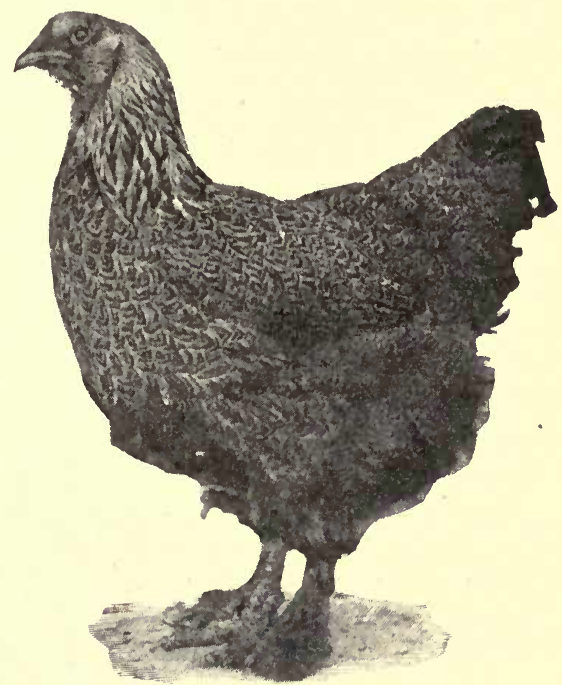

Fig. 11. Dark Brahma hen (one-seventh size).

tionable, as the majority of consumers prefer a clean-legged fowl.

The young birds do not "feather out" so rapidly as the young of the Mediterraneans, and consequently are ill-looking while young on account of their partially naked appearance. Sometimes 
this partial nakedness continues throughout a considerable period of their growth. Some farmers object to Brahmas on account of this slow feathering, but this characteristic cannot detract materially from their usefulness.

When not injured by breeding for fancy points, as sometimes is done in the production of fowls for exhibition, the pullets make good winter layers. For egg production, however, they should not be kept longer than two years. If the pullets are early hatched and mature reasonably early, for Brahmas, they should not be kept longer than one complete season of usefulness if egg production is an important essential.

The Dark Brahmas are not considered to be as good layers as the Light variety, and are quite as difficult to breed true to color. The Dark Brahmas have somewhat delicate feather markings which are difficult to produce with that degree of excellence necessary for exhibition purposes.

The Brahmas are good sitters, in fact sit too much for general-purpose fowls, and are considered too heavy to sit on eggs of light-weight fowls. All Asiatics lay buff-colored eggs. Some of them are much darker than others. The Brahmas are "good growers" and make excellent table fowls. They are fairly hardy and gain rapidly in weight. 'The meat is of fair quality, but does not equal that of the Dorking or Game. The Dark Brahmas 
are not quite so popular as the Light, which is no doubt due to the superior egg production of the latter. Brahmas do well in small runs or yards. When liberally fed, the Brahmas have a tendency to become too fat for laying and for breeding purposes. Excessive fatness not only causes fewer eggs, but a larger proportion of infertile ones.

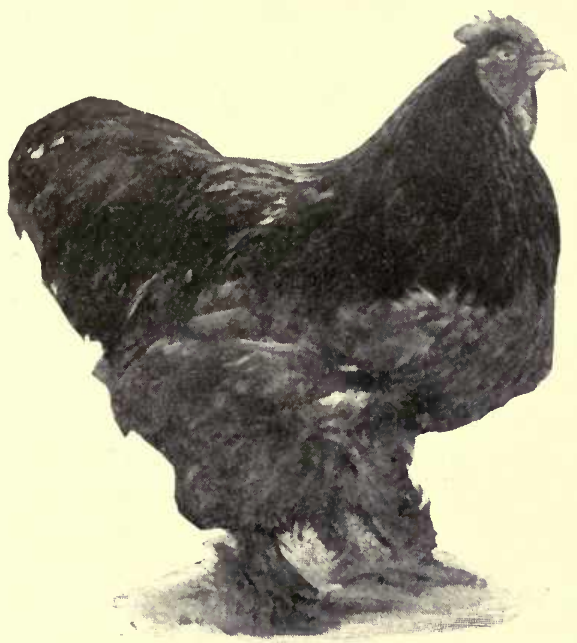

FIG. 12. Buff Cochin cock (one-eighth size).

\section{COCHINS}

The Cochins were introduced into England from China about 1843, when the ports of China were opened to European traders. The cock is a pound 
lighter than the Light Brahma; the hens have the same weight. They are distinctively table fowls. The hens are good sitters, easily handled, and are slow and awkward in movement. The young are

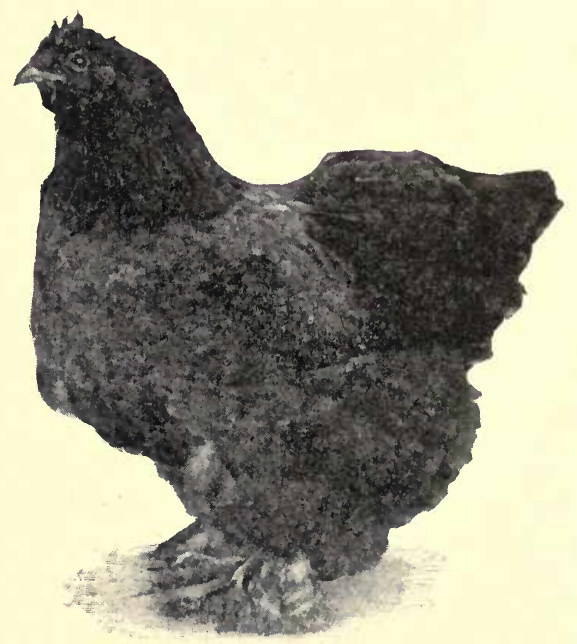

Fra. 13. Buff Cochin hen (one-seventh size).

fairly hardy after the chickens once get a good start. They grow fast and furnish a good quantity of meat, but not of the best quality. They are considered indifferent layers. These fowls are gentle and tame, very peaceable, seldom quarrel and stand confinement well. They do well where others would not thrive for lack of exercise.

The Buff Cochins are as pure buff as any of the buff breeds. This variety is the most popular 
of the Cochins. The fowls have an abundance of fluffy feathers which enable them to withstand severe cold weather. Their shanks are well feathered on the outer side. The middle and outer toes are also feathered, while the inner toes are entirely naked. They have small, single, upright combs. They are much admired by those who delight in large, gentle, slow-moving fowls.

\section{LANGSHANS}

Langshans are natives of Northern China and were introduced into England more than a quarter of a century ago. They have not been bred to a great extent in America until the last few years. They endure severe weather well, and are said to be good winter layers. It is also said that the tendency to incubate is not so great as in the Cochins. The cock should weigh $91 / 2$ and the hen $71 / 2$ pounds. The Langshans are the smallest and most active of the Asiatics, and more nearly approach the general-purpose fowl than do the other Orientals. They have white skin and dark shanks, while the others have yellow skin and yellow shanks. The quality of the flesh is considered excellent, being fine-grained for such large fowls. They are better foragers than the Cochins and Brahmas. They are somewhat longer-legged than the Brahmas and Cochins, and consequently appear taller in propor- 
tion to their size. Their leg feathering is less than that of the other Asiatics.

Langshans are steadily gaining in popularity, although they will probably never become so popular as the general-purpose breeds unless they undergo a marked modification. They are preferred by some because they are more active than either the Brahmas or Cochins.

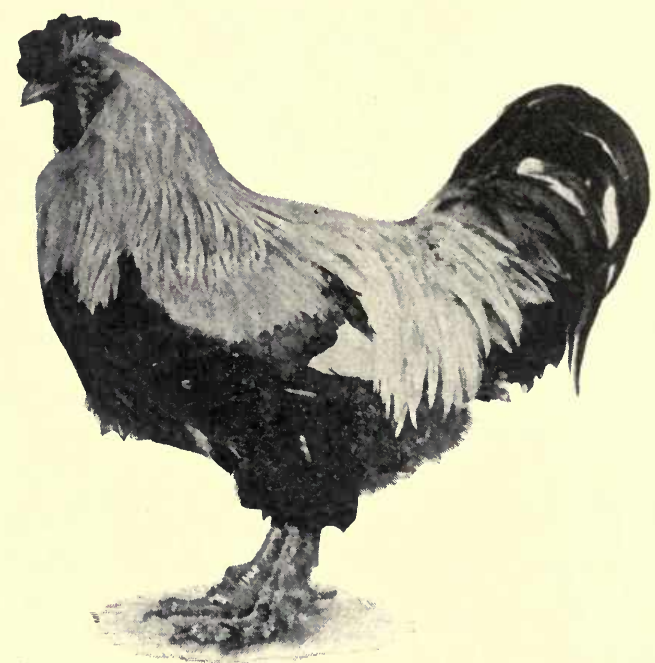

Fig. 14. Faverolle cock (one-eighth size).

FAVEROLLE

This is a class of cross-bred fowls, not being a distinct breed, but serving a useful purpose as 
meat producers. It has supplanted the Houdan and other French breeds in some parts of France, where the production of good-sized young birds for the Paris market is the chief aim.

The Faverolles were produced by crossing the following breeds: Cochin, Brahma, Dorking, and

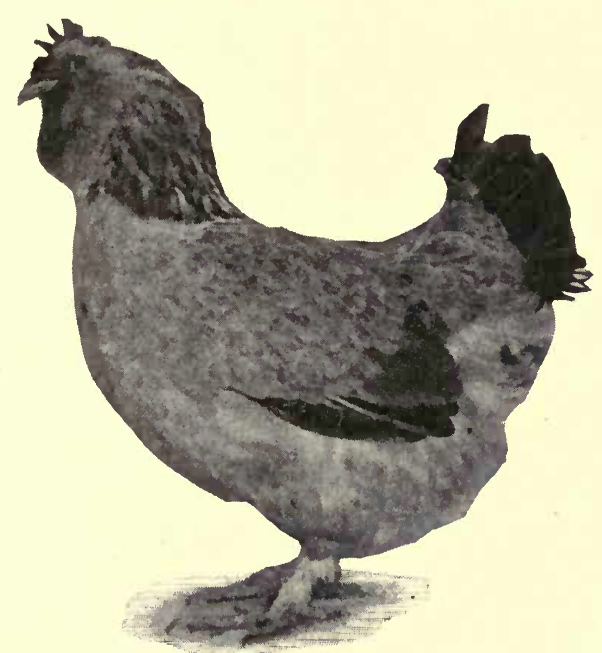

Fig. 15. Faverolle hen (one-sixth size).

Houdan. They are bearded and sometimes have a crest, frequently have five toes, and show white skin and light-colored shanks. The shanks are usually feathered unless the Dorking blood predominates, in which case they are frequently bare. For early rearing and quick-growing chickens that produce tender and juicy flesh, the Faverolles 
are highly prized where they are best known. It is undoubtedly true that the flesh of the mature birds is somewhat coarse and undesirable. While these fowls may become a well-established breed and may be highly prized for the fine quality of their meat, it is doubtful if they ever will become popular in America as farm fowls. 


\section{CHAPTER IV}

GENERAL-PURPOSE FOWLS

As the name indicates, the general-purpose breeds include such fowls as may profitably be kept on the farm for the production of both meat and eggs, particularly under the conditions that require natural incubation. They are adapted to common and general conditions. It should not be forgotten that the term "general-purpose" is relative and is not intended to express exact conditions. It is impossible to make definite classifications of the various breeds of fowls, as some breeds in the hands of skilled poultrymen may prove profitable, while in the hands of an unskilled person they would not compare favorably with many other breeds that really are less productive when under the care of those who supply the necessary - conditions for profitable production. Fowls of all breeds and varieties lay eggs, and the flesh of all fowls furnishes good and wholesome food, yet not all breeds are equally desirable for these purposes.

Farmers, from the fact that they are somewhat isolated, require fowls that are noted for utility 
along more than one line of production. They look not only for a fairly good egg production, but also for a body of considerable size that will furnish a good quantity of meat of first-class quality for table use. Both eggs and meat are of the highest importance for the practical farmer, for upon his poultry he depends to a greater extent than he himself is aware. The quality of the meat, as well as its quantity, is to be considered. Not only does the farmer demand meat when the fowls are mature, but the meat of fowls of all ages after the young reach the broiler stage must be of good quality. It is vitally important, also, that the fowls produce the greatest quantity and best quality of meat from the food consumed; for some fowls eat much and produce relatively little. Good layers also are required, especially during the winter months. Steady winter layers are demanded by the farmer quite as much as by the poultryman whose business it is to produce eggs for the market. Most farmers do not expect to consume all the product of the poultry-yard at home. If eggs are produced in good numbers during the cold weather, a high price is usually realized for them. A greater price is realized from winter eggs than from those produced during the spring and summer months when fowls lay most abundantly. It is also desired that the farm hen should become "broody," incubate and prove a good mother for her young. Many 
farmers do not feel that they can afford to be burdened with the extra care and study which the successful operation of the modern incubator would incur. They therefore depend upon the natural instincts of the fowls to provide incubators and brooders. Some of the more noted characteristics of the general-purpose fowls are discussed in the following paragraphs.

Size.-These fowls are usually of medium size; that is, they rarely represent either extreme, although the largest breed-the Light Brahmas-may, under exceptionally favorable conditions, prove to be fairly good farm fowls. The general-purpose fowls, as a rule, have blocky, compact bodies, which is one of the requisites for meat production. They are rarely long-legged. They are most economical feeders; that is, they make a good growth for the food consumed.

Disposition.-Gentleness is one of the characteristics of these breeds. The fowls are not easily frightened, and are more easily confined than the breeds which are noted for egg production alone. They rarely attempt to use their wings in order to escape from inclosures of medium height. While they may become wild and easily frightened by improper management, yet with proper care they become quite as docile and tame as is consistent with ease of management and profit. They occupy a medium position between the Mediterraneans 
and the Asiatics as regards size, egg production, and docility.

Early maturity.-These fowls are hardy, grow quickly and pass through the delicate stages of early life rapidly. They closely resemble the most hardy of the noted egg breeds in this respect. They are considered to be hardy at all stages, which is an important point for farm poultry. The many cares of busy farm life during the growing seasons of the year sometimes prevent giving the fowls the close attention which the more delicate breeds require in order that they may be brought safely to a stronger stage of development. Hardiness at all stages of development is, therefore, an important characteristic of farm poultry. Early maturity produces early-laying pullets. The so-called general-purpose breeds mature early and frequently produce pullets that will lay at five months of age. Early-hatched pullets, as a rule, will lay at an earlier age than those hatched later in the season. The early-hatched fowls generally grow most rapidly and reach maturity in the shortest time. Early-hatched fowls are usually preferred for breeding as well as for utility.

Good sitters and good brooders.-While these fowls are not so persistent sitters as the Asiatics, yet they may be depended upon for natural incubation, particularly if the hens are kept until they are two or three years old. They make excellent mothers, as they care for their young excel- 
lently and have a great abundance of fluffy feathers, which enable them to do their brooding well. They are probably somewhat better sitters and brooders than the extremely heavy fowls. Fewer eggs are likely to be broken by these careful birds than by the larger and more clumsy kind.

Good foragers.-These fowls are good foragers, considering their size. While they are not inclined to roam so far as some of the lighter and more active breeds, yet they are well calculated to seek their own living when an opportunity is afforded them. The young fowls will roam a considerable distance for insects and green food, and in this respect they occupy a medium position between the active, nervous breeds and the heavy Asiatics, approaching more nearly the former than the latter.

Endure cold weather well.-The compact body and medium-sized combs and wattles enable the general-pupose fowls to withstand the severe weather of the winters. While a frosted comb may occasionally result, yet they are not nearly so liable to injury by freezing as are the more noted egg breeds. They have a somewhat thicker coat of feathers and more fluff than the Mediterraneans. The thick coat of feathers gives them a much better protection than a thin one, for the reason that the air space inclosed by a thick coat is considerably greater than that inclosed by a thin one. While they do not equal the Asiatics in this respect, yet they are suffi- 
ciently protected to withstand the rigors of the northern winters.

\section{PLYMOUTH ROCKS}

For half a century these fowls have been steadily gaining in favor until they now occupy the highest position as to popularity. Probably no other breed has ever been so widely distributed and so numerously bred under such varying conditions as the Plymouth Rocks. They seem to have remarkable powers of adapting themselves to the conditions under which they are placed.

It has been said of them by an eminent poultry authority that "Where any fowl will thrive this breed will do well." The fact that these fowls are so numerously bred on the farms of this country, where usefulness is the important consideration, is perhaps the highest testimonial that any breed of fowls can have.

There has been, and still continues, an effort on the part of poultry fanciers to create a large number of varieties. This breed, like many others, shows the result of this work. While the older varieties are not necessarily injured through the formation of new ones, yet one must lament the fact that so much effort has been bestowed on a useful breed to simply please the eye, without any marked improvement along the lines for which these fowls 
are maintained. The fact that comparatively easy tasks are more likely to be accomplished than are very difficult ones may possibly explain why the easier task of creating a new variety has become more popular than the more difficult one of improving the useful qualities of a well-established breed. The recognized varieties of this breed are the following:

$\begin{array}{ll}\text { Barred } & \text { Silver-penciled } \\ \text { White } & \text { Partridge } \\ \text { Buff } & \text { Columbian }\end{array}$

All varieties have the same weight-cock $91 / 2$, hen $71 / 2$, cockerel 8 , and pullet 6 pounds.

\section{BARRED PLYMOUTH ROCKS}

This variety probably originated in Massachusetts about the middle of the last century. It is said to have sprung from the cross of a Dominique cock and a Black Java hen. The Barred Plymouth Rocks combine largely the qualities of both these breeds. They more nearly approach the Java in size, but retain many of the good qualities of the Dominique. While they do not have the color of either parent, yet they more nearly approach that of the Dominique. These fowls approach the Asiatics in size, the Leghorns in egg production, and constitute one of the most useful varieties. They also produce flesh of an excellent 
quality. It is maintained by some breeders of Plymouth Rocks that the quality of the flesh approaches that of the Dorking. They are blocky fowls, havelarge, full; plump, well-proportioned bodies, yellow shanks and skin. The flesh is of good texture and flavor. They are early maturing, considering their size,

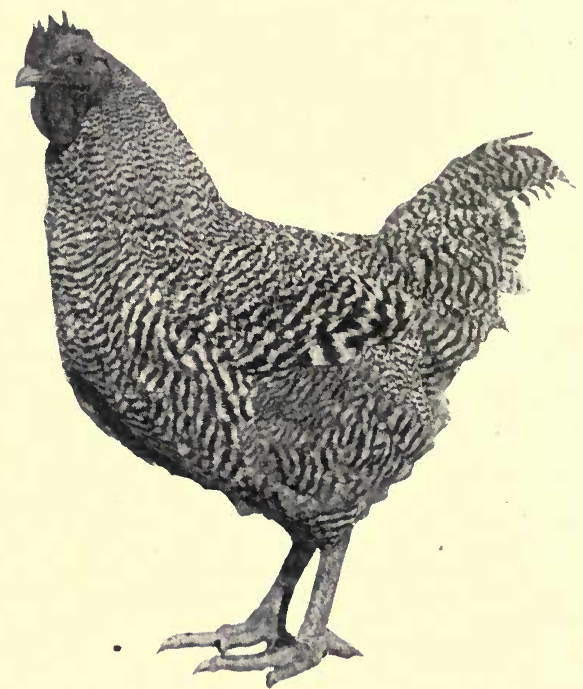

Fig. 16. Barred Plymouth Rock cockerel.

are good layers, hardy both as little chicks and mature fowls. They are excellent mothers, kind and persistent sitters. The laying capacity is considerably above the average of fowls. Authentic records are reported of more than two hundred and thirty eggs per year from single birds. The pullets 
make excellent winter layers, but for greatest egg production in the wintertıme fowls should not be kept longer than two years. They are easily kept in confinement and are adapted to nearly all climates. Probably no breed better combines these two qualities - egg production and the yielding of a large amount of good meat for the table. This

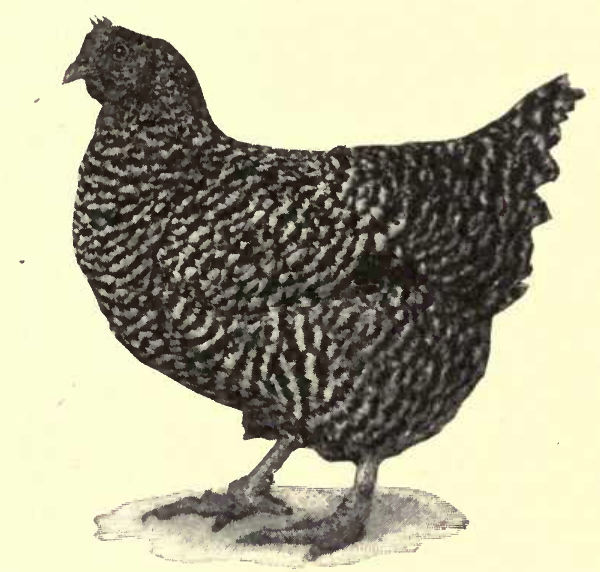

Fig. 17. Barred Plymouth Rock hen (one-seventh size).

variety, more than any other, has won for this breed its remarkable popularity.

\section{WHITE PLYMOUTH ROCKS}

In a general way, what has been said of the Barred Plymouth Rocks will apply to all varieties of this breed, although the newer varieties are not 
quite so well fixed in their distinguishing characters as the Barred. It is asserted that the White Plymouth Rocks originated as an off-shoot from the Barred Plymouth Rocks early in the history of the latter.* The Plymouth Rock form predominates in all varieties, and the solid colors have the advantage of the Barred in mating, as often, with the Barred, the best formed fowl will be objectionable on account of some imperfection in color, so that it must be discarded from the breeding-pen if characteristic colors are desired.

The White variety is preferred by poultrymen who rear young fowls for market. White fowls present a better appearance when dressed than colored ones do, particularly if the fowls are not in the most perfect condition. Immature fowls of all breeds and varieties have more or less undeveloped feathers, the removal of which, in colored varieties, leaves a discoloration beneath the skin. On this account, young birds of a white variety that are dressed for the market present a better appearance than equally good birds of a colored variety. As long as attractive appearance is a desired quality in dressed fowls, white varieties will be preferred.

\section{BUFF PLYMOUTH ROCKS}

The Buff variety of this breed is of more recent origin than those already described. It, however, came *"Barred and White Plymouth Rocks," by Wallace. 
at once into favor with a large number of poultrymen who may be regarded, to some extent at least, as poultry fanciers, and also with others who have a decided liking for fowls of this color. The advocates

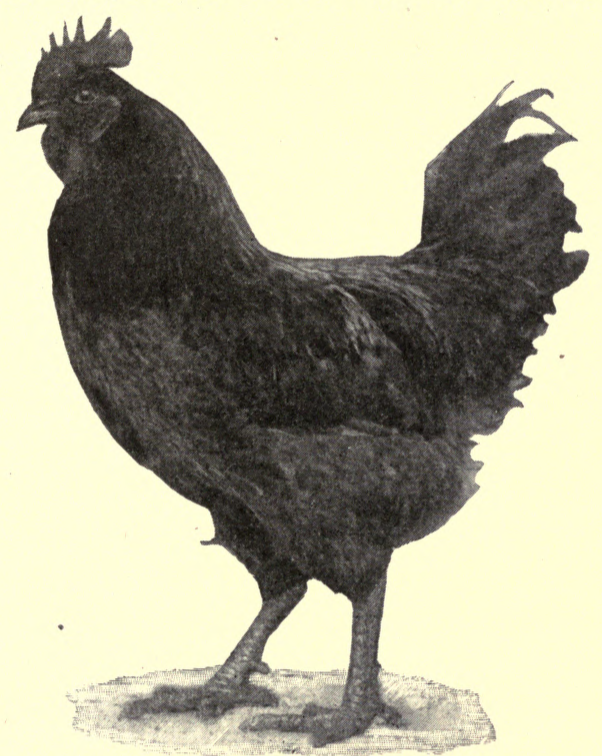

Fig. 18. Buff Plymouth Rock cockerel (one-seventh size).

of this variety maintain that the useful qualities measure favorably with the older and better known varieties.

\section{OTHER VARIETIES}

These are of still more recent origin, and as yet have not been given an opportunity to prove their 
value under the great variety of conditions as have those of the Barred variety that won for the Plymouth Rocks their remarkable reputation.

Each of the varieties has medium-sized single combs. In size, the combs and wattles occupy a medium position between the Cochins and the Mediterraneans. The eggs of each variety are buff in color, but vary considerably in shade.

\section{WYANDOTTES}

The Wyandottes are not so old as the Plymouth Rocks. When first introduced, they came at once into popular favor, and are now crowding the Plymouth Rocks for supremacy as the most popular general-purpose fowl. They are purely of American Origin. They were recognized as a distinct breed by the American Poultry Association in 1883, and at that time were given a new name, which they now bear.

Previous to that time they were known and sold as American Sebrights, Excelsiors, Ambrights, etc. They are a little smaller than the Plymouth Rocks, the cock weighing $81 / 2$, hen $61 / 2$, cockerel $71 / 2$, pullet $51 / 2$ pounds. They have yellow skin and shanks, with the exception of the black variety, which has black shanks shading into yellow, and the bottom of the feet are yellow. As producers of broilers to weigh two pounds apiece they are highly esteemed. 
The hens are excellent sitters and make good mothers. In this respect they closely resemble the Plymouth Rocks. The Wyandottes have a neat and trim appearance, are good sized, produce excellent flesh, and have a gentle disposition. They are generally called handsome fowls. In appearance, they are

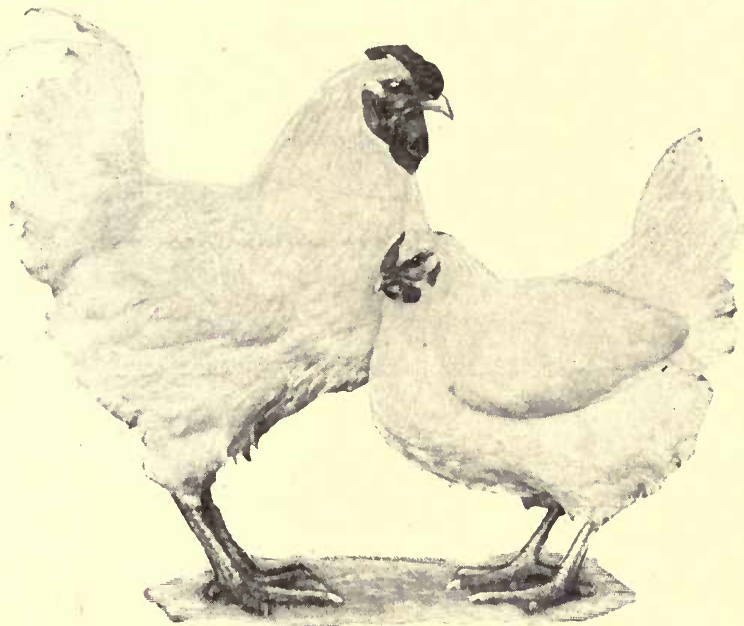

Fra. 19. A pair of White Wyandottes, young (one-eighth size).

somewhat neater than the Plymouth Rocks. In fulfilling the demands of the farmer for the economical production of both eggs and meat the Wyandottes are not wanting. Joseph Wallace says, "It should not be claimed that the Wyandottes, in quality and quantity of breast meat, equal the Dorking, Houdan or Game." Neither do they equal the Leghorns or the Minorcas in egg produc- 
tion, yet they are excellent general-purpose fowls. They are called good layers and bear confinement well. They are hardy, both as mature fowls and when young. They have a low rose comb, which makes them well suited to a cold country. They are well feathered and attractive in appearance.

The object of the originators of this breed was to obtain a compact, blocky, clean-legged fowl of good size, one particularly deep in the breast, that should produce a good number of eggs. The results fully meet these various requirements. The flesh is of a superior quality, being tender and juicy. The proportion of bone to the total weight of dressed fowl is comparatively small. In general outline as compared to the Plymouth Rocks they are smoother and more compact, they have shorter backs and have deep round bodies. They are often spoken of as the fowl of curves. Their low and close-fitting comb that conforms pretty well to the outline of the skull adds even more to their smooth and rounded appearance.

There are eight recognized varieties of this breed:

Silver

Golden

White
Buff

Black
Partridge

Silver-penciled

Columbian

\section{ORPINGTONS}

This breed is said to have originated in the hands of William Cook, of Orpington, England; 
hence the name. They have come into popular favor both in England and America. They are said to be the most popular fowls in England. Since their introduction here many breeders have become very enthusiastic over them. It is significant that those who are loudest in their praise are those who have bred them longest and understand them best. The Orpingtons are particularly prized by

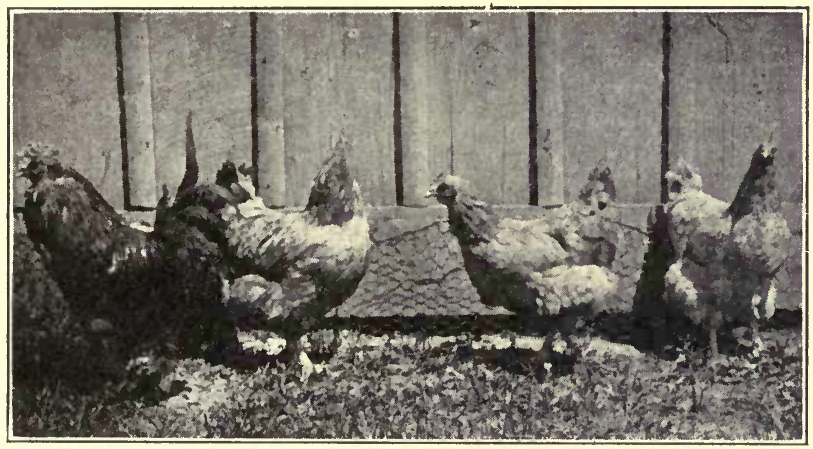

FIG. 20. Buff Orpingtons.

those who desire a white-skinned fowl for table use. This feature has, without doubt, aided materially in making them popular in England, where the white skin is prized, as the yellow skin is prized in this country. There is, however, an increasing appreciation of white-skinned fowls in America. The idea that yellow color indicates greater richness is becoming less general, particularly with those who are most fastidious in their tastes. 
There are ten or more varieties of this breed recognized in England but only three have been recognized by the American Poultry Association,the White, Buff, and Black, all solid colors. It is claimed that no one variety is superior to the others as to usefulness. Breeders claim that Orpingtons are profitable egg producers. The cock should weigh 10, and the hen 8 pounds. They are particularly prized for quantity and quality of their flesh. The White is perhaps the most popular of any of the varieties. They are easier to breed to feather, being pure white throughout. However, each variety has many ardent admirers. All varieties are, without doubt, most useful farm fowls.

\section{JAVA}

Javas are one of the valuable, useful breeds of this country. They are said to have originated in Missouri near the middle of the last century, about the time the Plymouth Rocks originated, perhaps a little earlier. It is asserted that they have been bred pure longer than any of the recently formed breeds. Javas are noted for their good size, being the same size as the Plymouth Rocks, and are quick maturing. They are of two varieties, the Black and the Mottled. It is said that, when cooked, the meat of the Black variety does not present the objectionable dark color of some other black 
breeds. They are good layers, perfectly hardy, and are easily reared, endure confinement well, and are easily kept in inclosures. It is said that the fowls breed quite as true as any of the breeds of this class. They are good winter layers, and the chicks make good broilers at an early age. They are not raised so extensively as some other breeds of this class. They are becoming more popular, yet in this respect are still far behind the Plymouth Rocks and the Wyandottes. The Black variety has been the most popular. This variety is rich black throughout, with a metallic luster. They have single combs, their shanks and toes are free from feathers but are nearly black in color. The Javas may be recommended as useful farm fowls. The cock should weigh $91 / 2$ and the hen $71 / 2$ pounds.

\section{DOMINIQUE}

Dominiques are smaller than the Wyandottes, and are compact and hardy. This is one of the oldest American breeds. The origin is obscure. The general color is a grayish white, with yellow shanks, somewhat like the Plymouth Rocks, yet the fowls are lighter in color. For a time they were unpopular, but are now receiving attention and are apparently coming into favor. They endure confinement well. It is said of them that they change little by in-and-in-breeding. It is also asserted 
that they suffer comparatively little from uncleanliness. They have rose-combs, and endure cold weather well. They are excellent table fowls, good mothers, good foragers, mature early, and are a most useful farm breed. There is but one recognized variety, the Rose-comb. The cock should weigh 7 , and the hen 5 pounds

\section{DORKING}

The Dorking is preëminently an English breed. The fowls approach the ideal for general purposes.

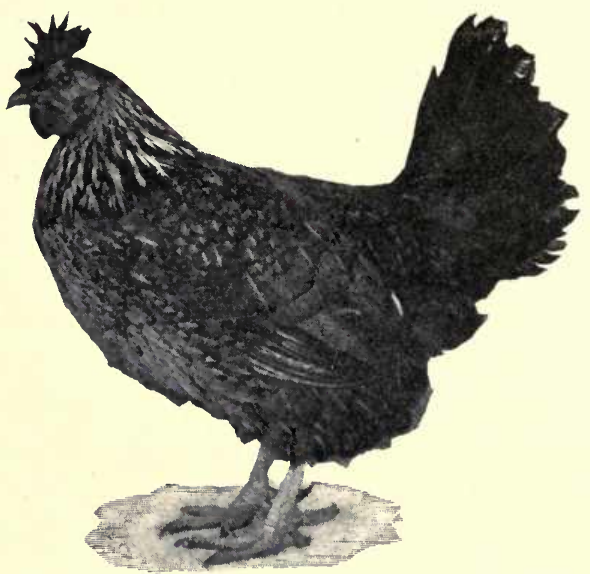

Frg. 21. Colored Dorking hen, English (one-eighth size).

They are fairly hardy if kept dry, although somewhat delicate if subjected to dampness, particularly in cold weather. This is, without doubt, one 
of the oldest of domesticated breeds. It is said by some authorities that the fowls were taken to England by the Romans. They are low, heavybodied fowls, with single combs. A distinguishing

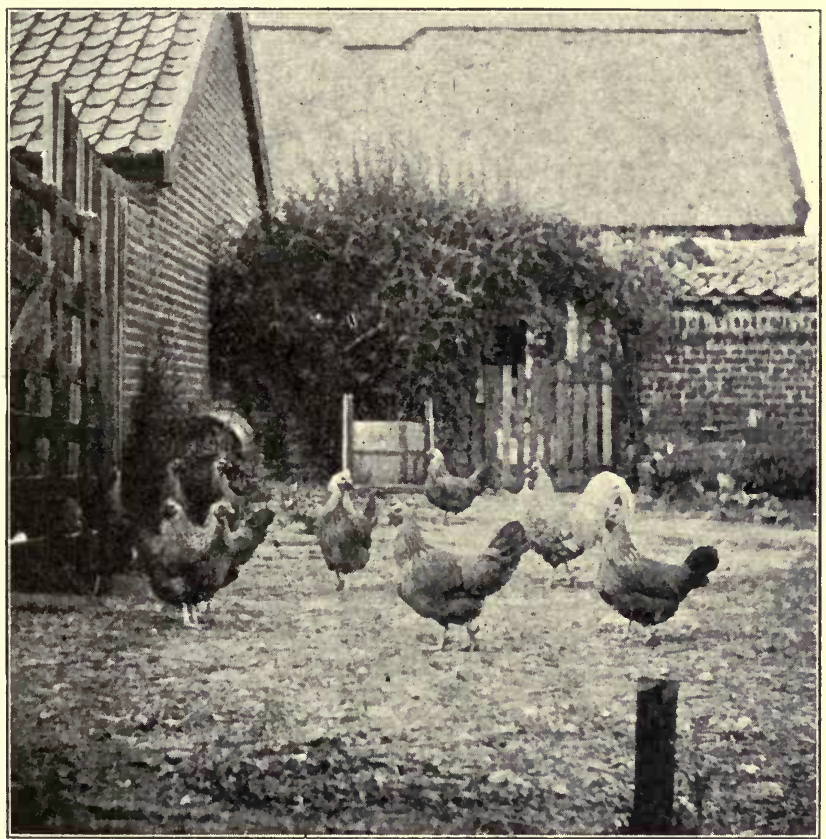

Fig. 22. Flock of Dorkings, Acle, England.

mark of the Dorking is the fifth toe. They are good layers, persistent and careful sitters and good mothers. They are excellent farm fowls, especiallyprized for the table. Their flesh is light-colored 
and of fine texture. Some even hold that the flesh of the Dorking is superior to that of the Game. American breeders prize the Dorkings highly for quality of flesh, and also for the small proportion of bone. They are especially noted for a broad, deep breast, and the breast meat is distinctly fine in quality. They fatten easily, and stand confinement fairly well, although a wide range in dry weather suits them best. It is said that the hens remain longer with the chickens than do the hens of most breeds.

The fifth toe is objected to by some breeders. It is at least a superfluous organ so far as usefulness is concerned. It is, however, one of the prominent characteristics of the Dorking. Some English writers, notably Wright, assert that those varieties of fowls which have five toes are more afflicted with bruised feet-"Bumblefoot"-than are other varieties.

\section{HOUDAN}

The Houdan is without doubt the most popular of French varieties that are bred in the United States. The other French breeds are the Crevecœur, and the La Fleche. The Houdans rank among the useful fowls and are noted for the production of a goodly number of eggs, and, at the same time, furnish a moderate quantity of fine flesh. The cock should weigh $71 / 2$ and the hen $61 / 2$ pounds. Wright says of them: "Better table fowls 
are none, the laying powers are great, the chickens fledge and grow faster than almost any breed, and the eggs are invariably prolific."

The Houdans are crested, bearded, and have the characteristic fifth toe. Notwithstanding these objectionable characteristics, they are reared to some extent for their useful qualities, but are not nearly so popular as the Plymouth Rocks and Wyandottes.

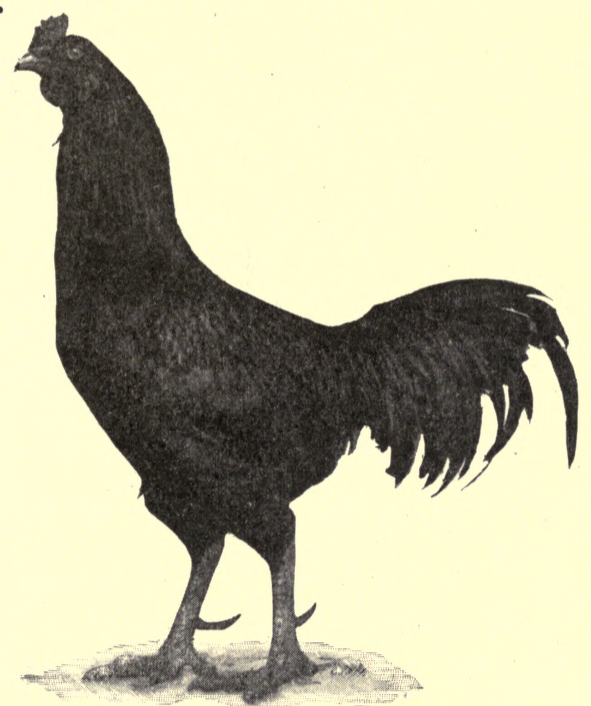

Fig. 23. Dark Cornish Game cock (one-ninth size).

CORNISH GAME

'These are hardy and most excellent table fowls. They are considered profitable general-purpose fowls; 
are fairly good layers, mature rapidly and are unexcelled for quality of flesh. The hens are good sitters and excellent mothers. All Games are closefeathered and muscular, which gives them a firm and compact feeling to the touch. They weigh

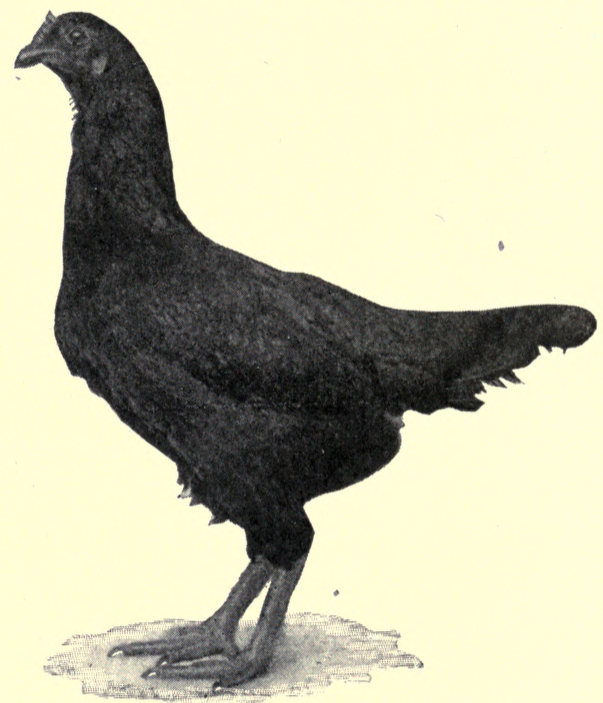

Fig. 24. Dark Cornish Game hen (one--ixth size).

very heavily for their apparent size. The thighs of games are well developed and appear prominent. The Cornish Games are represented by three varieties, the Dark, White, and White-laced Red. The Dark and the White are best known and are most highly prized as useful fowls. They should weigh, cock 9 and the hen 7 pounds. The White. 
laced Red is a pound lighter. For general farm use they are not so desirable as most of the other breeds discussed in this class.

They are considerably more pugnacious than the other breeds mentioned in this chapter and in certain localities are highly prized on this account. It is said that they suffer less from attacks of hawks than most other breeds.

The Games of this class are sometimes used to cross on other fowls for the purpose of infusing vigor and of improving the quality of the flesh.

\section{RHODE ISLAND REDS}

These fowls are of American origin and are generally recognized as a new breed, although they have been bred in Rhode Island for many years. They are there bred numerously and are recognized as practical, useful fowls that are well adapted to the conditions under which farm fowls are usually kept. The American Poultry Association recognizes two varieties, the Single- and the Rose-comb. The cock weighs $81 / 2$ and the hen $61 / 2$ pounds, the same weight as the Wyandottes.

This breed has undoubtedly been developed by men who thoroughly appreciate utility, and they claim for these fowls all the essentials of a generalpurpose fowl. Some remarkable egg records have been made, yet it has not been shown that they 
have the remarkable powers of adaptability accredited the Plymouth Rocks.

Breeders assert that they mature earlier than the Plymouth Rocks and in a general way occupy a position between these fowls and the Leghorns. It is claimed that they yield from the live weight a large proportion of dressed meat. The color of these fowls is designated as red and should be rich and brilliant; a little black is desired in some places, notably the tail. A lustrous red, which is quite distinct from the buff of other breeds, is characteristic of these fowls. Where they are well known they are highly prized as farm fowls.

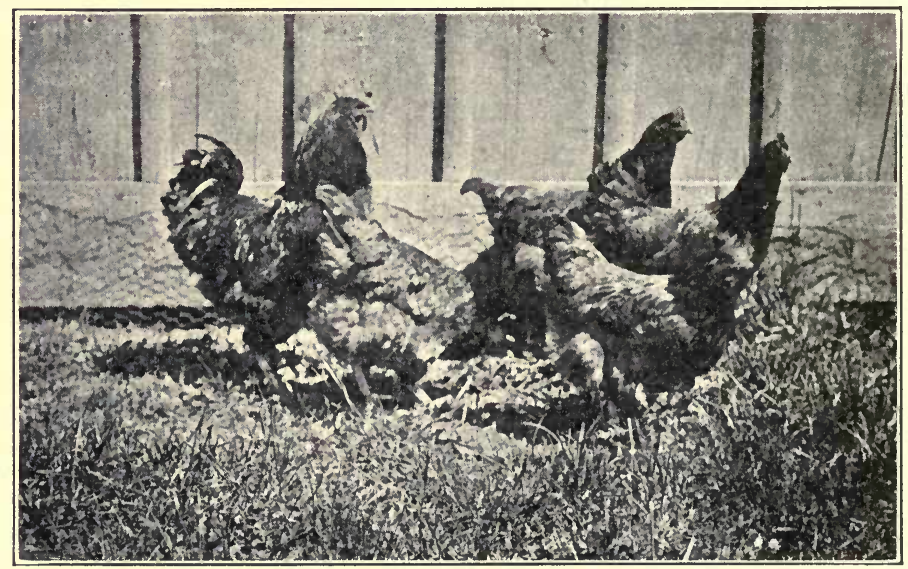

FIG. 25. Rhode Island Reds. 


\section{CHAPTER V}

\section{FANCY BREEDS}

WHILE the breeds discussed in this arbitrary class are more or less useful, yet they are less adaptable as farm fowls than those mentioned as egg or general-purpose breeds. Fowls of these breeds will undoubtedly lay a good number of eggs under favorable circumstances, and will produce flesh that is excellent for food, yet they are all less important for the furnishing of the useful products than are the varieties mentioned in previous chapters. This class of fancy breeds includes great variety as to size, form and color. Some of the breeds, in the hands of skilful poultrymen, would prove quite satisfactory as general-purpose fowls, yet, in the hands of the farmer, under ordinary farm conditions, they are of minor value.

Nearly all kinds of fowls may be greatly improved by skilful breeding and management, and undoubtedly these so-called fancy breeds could be improved as to useful qualities if given food and management conducive to that end. If one desires to attempt improvement for useful purposes it will be best to select fowls of one of the more useful breeds, as the 
stock on which to work. There are so many useful breeds, that, beyond doubt, are susceptible of still further improvement that it would seem injudicious to start with some of the least useful. The same skill and care transferred to other breeds will give much greater returns in useful products than can be secured from these breeds whose energies have been expended in developing a variety of characteristics that are highly prized for exhibition purposes but have little value toward the production of eggs and meat.

\section{POLISH}

It is generally conceded that the name Polish, or Poland, has no connection with the country of that name. Charles Darwin says that probably the name was given on account of their elevated crest or poll just back of the nostrils on the top of the head, where there is an elevation in the bony structure. These fowls have been bred for many years. It is said that they have a known history extending as far back as the sixteenth century. They were introduced into England about 1835. They are generally considered handsome fowls, but are not noted for hardiness. They certainly cannot hold their own in a promiscuous flock. When bred in small flocks and given extra care they are said to pay very well. They are only fair layers of small white eggs. They 
cannot withstand wet weather well, and require extra care in time of snow or rain.

The very large crests, which obstruct their sight to some extent, make them a somewhat easy prey to hawks in localities where these enemies are numerous. In stormy weather the crests are liable to become wet and to cause inconvenience to the fowls, as well as to make them more liable to take cold. On account of their delicacy, small size, and moderate egg production, they are designated a fancy breed.

They endure confinement quite well if kept in dry and clean houses and yards. Their flesh is esteemed for its fine quality. If one desires a few handsome fowls, and is willing to give them extra care, they will probably prove satisfactory, but they are not practical for the poultry-keeper who desires to realize the largest profit from the production of eggs or meat.

Both sexes have large and handsome crests. The comb of Polish fowls is peculiar in form and differs materially from the combs of the breeds previously described. It is $\mathrm{V}$-shaped or branched in form, and is often nearly, or quite, hidden by the crest.

The American Poultry Association recognizes eight varieties of Polish fowls, namely:

Bearded Golden

Bearded Silver

Bearded White

Buff-laced
Non-bearded Golden

Non-bearded Silver

Non-bearded White

White-crested Black 
The shanks of all varieties are of a slate or bluish color and the skin is white. Probably the Silver, Golden, and White-crested Black are the most popular varieties.

\section{GAME}

The varieties of Games are especially noted for the production of flesh of fine quality. Some varieties are sometimes recommended as farm fowls, but on account of their pugnacious disposition and their deficiency in egg production it is extremely doubtful whether they will prove as useful as the breeds discussed under the head of general-purpose fowls (Chapter IV).

They are among the most popular of exhibition or fancy fowls. The classes of these fowls are usually well filled at the large poultry shows and fairs. They are called good sitters and good mothers, traits which, in general, are common to all Games. There are eight recognized varieties of the Exhibition Games, and of these the Black-breasted Red and the BrownRed are probably the most popular.

\section{SILKY}

The Silkies are not bred to any extent in this country, although in England they are in considerable favor. Their great peculiarity is that their feathers are not webbed, and when in good condition 
present a fluffy, loose appearance. Standing well out from the body in all directions, the plumage causes them to appear much heavier than they really are. They are compactly built birds, and are reared chiefly for their odd appearance, and for hatching the eggs of other breeds. They are said to make good mothers for tender little chickens on account of their light weight and soft, downy feathers. They have irregular rose combs of a dark color. The comb and face present a dark, purplish appearance, in marked contrast to other varieties of fowls.

\section{SULTAN}

Sultans were taken into England from Turkey about 1850. They were not brought to America until many years later. On account of their crest they somewhat resemble the Polish, particularly the Bearded Polish. Their shanks and toes are heavily feathered. They are reared chiefly for their peculiar appearance. No particular claim is made as to usefulness. They thrive well in small inclosures, and are gentle and readily become pets.

\section{FRIZZLE}

Frizzles are peculiar fowls, and are reared wholly for their unique appearance, their feathers curving upward and backward at the ends. The curve is 
most pronounced in the hackle feathers and feathers of the back. Any color is recognized. Single combs are preferred. The chief requisite of Frizzles is that the feathers turn upward and toward the head. On account of this peculiarity of the feathers, they do not well withstand unfavorable weather. They should not be classed among the most useful breeds. They are not bred extensively. Without doubt they might be made more useful than they now are should skilful breeders give them some attention. However, the fact that they are not prepared to withstand the hardships that more useful breeds endure will tend to prevent them from becoming other than fancy fowls.

\section{BANTAM}

The Bantams are purely fancy or ornamental breeds. There are many varieties. While some breeders maintain that they can be profitably kept for eggs and for the table, yet on account of their diminutive size they cannot compete with the larger breeds. As ponies represent the children's horse and are in a way ornamental, so do the Bantams occupy a similar position among fowls. They are often reared as children's pets and undoubtedly afford a great deal of pleasure for both young and old. Among the most common and popular varieties of Bantams may be mentioned the Black, White, 
Buff, and Partridge Cochin; Dark and Light Brahma; Golden and Silver Sebright; Bearded White and Buff-faced Polish; Black-tailed, White and Black Japanese, and many varieties of Games. Probably the Golden and the Silver Sebright and the Buff Cochin are quite as popular as any.

For exhibition purposes the plumage and form of these miniature representatives correspond closely to the varieties of larger fowls. Small size is preferred. There seems to be a marked tendency on the part of some varieties of Bantams to revert to the larger fowls from which they were derived. 


\section{CHAPTER VI}

BUILDINGS FOR FOWLS: LOCATION PLANS AND
CONSTRUCTION

THE convenience of location both as to the situation and arrangement of buildings is a most potent factor bearing on the financial success of the business. Poultrymen who aim to make a commercial enterprise of poultry-keeping consider proximity to market and shipping facilities before taking up the many minor details.

The larger questions that affect the whole enterprise should receive attention first, as a serious mistake in locating may turn into failure what otherwise would have been a success.

The location of poultry houses is often thought to be of minor importance when compared with the location of other farm buildings. This may be true when but few fowls are to be kept for the sole purpose of supplying the home table, but the profit derived from keeping these few fowls is frequently very much less than it would be if the same care and thought were given them that is devoted to other farm stock. The greatest success requires thought and judgment in all operations. 


\section{LOCATION OF BUILDINGS}

In selecting a site for poultry houses and yards, three important points should be constantly borne in mind: (1) health of the fowls, (2) convenience of the attendant, and (3) liability to vermin and other poultry enemies.

Health of the fowls.-As cleanliness and freedom from moisture are two highly essential conditions of successful poultry-keeping, the natural surroundings which strongly influence them should receive first consideration. A dry, porous soil not only insures a suitable yard or run, whenever the weather is favorable for the fowls to take out-ofdoor exercise, but also controls to some extent the amount of moisture in the buildings. If the highest degree of success is to be attained, cleanliness and freedom from moisture must be secured. Partial success or entire failure is undoubtedly more frequently due to filthy houses and yards, together with dampness, than to any other causes. Particularly is this true with those whose chief interests lie in other directions, and who, consequently, more or less neglect their smaller poultry interests during certain portions of the year. If it is desired to keep poultry on heavy or wet soils, the land should be thoroughly underdrained. The removal of the surplus water from the yards or runs very much lessens the labor of keeping them clean, par- 
ticularly during the growing season. During the summer months a yard or run of loose sand or gravelly soil will require comparatively little labor to keep it clean, while a similar one on a heavy and impervious clay will demand continual attention, and even this will not always suffice to keep the yards in a satisfactory condition. A heavy soil not only retains nearly all of the droppings on the surface, but by retarding the percolation in times of frequent rains soon gives a coating of filth. This is particularly true of those parts of the yard most frequented by the fowls.

A slightly raised elevation is to be preferred, particularly if the ground slopes gently on all sides from the building. This will insure good surface drainage in times of heavy showers and whenever the ground is frozen. While a somewhat light or porous soil that is naturally well underdrained is to be preferred, it should not be inferred that success may not be attained on somewhat heavier soils if they are thoroughly underdrained. Any good potato soil that is naturally well drained will not be objectionable on account of excessive moisture.

Another important consideration is the admission to the houses and yards of abundant sunshine. Fowls, like other classes of live stock, do not thrive so well when deprived of sunshine. This is particularly true of laying fowls during the cold winter months. The houses, yards or runs should be so 
planned, if possible, as to give them a southern or southeastern exposure (Figs. 26, 27). Many buildings for domesticated animals are so constructed that they do not admit sufficient light and air for the best health of the occupants. It has been found by experience that animals have a somewhat whiter

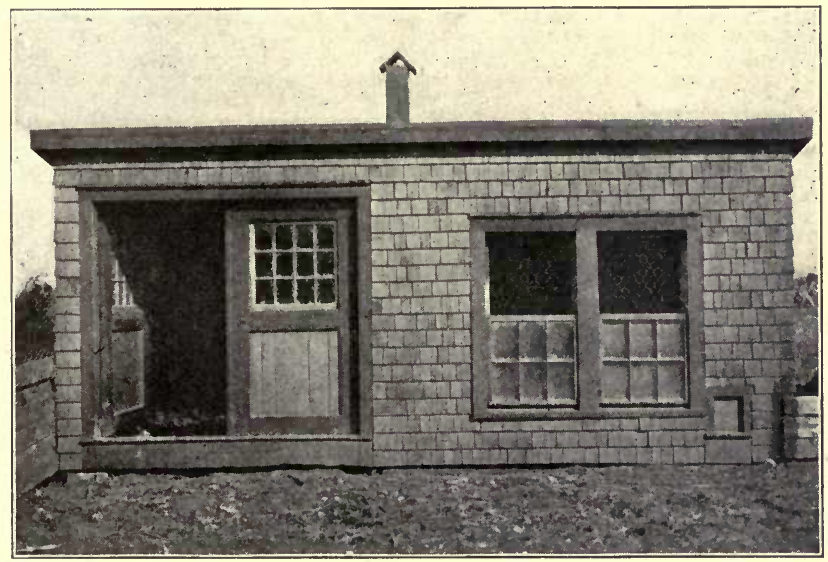

Fig. 26. A poultry house-Massachusetts Agricultural College.

skin and present a somewhat more delicate appearance when deprived of direct sunlight than when they are permitted to bask in the sunshine at will. This is frequently noticed in dairy cows, in which a yellow skin is so highly prized.

Poultrymen turn to good advantage all the sunshine they can secure in the winter time in order to maintain a high standard of vigor and to 
stimulate egg production. It is an advantage to have the yard on the south side of the house, in order that the fowls may have the benefit of the first dry ground in the early spring. It frequently occurs in localities where snow is more or less abundant that the ground on the south side of the building will be dry many days before that on the north

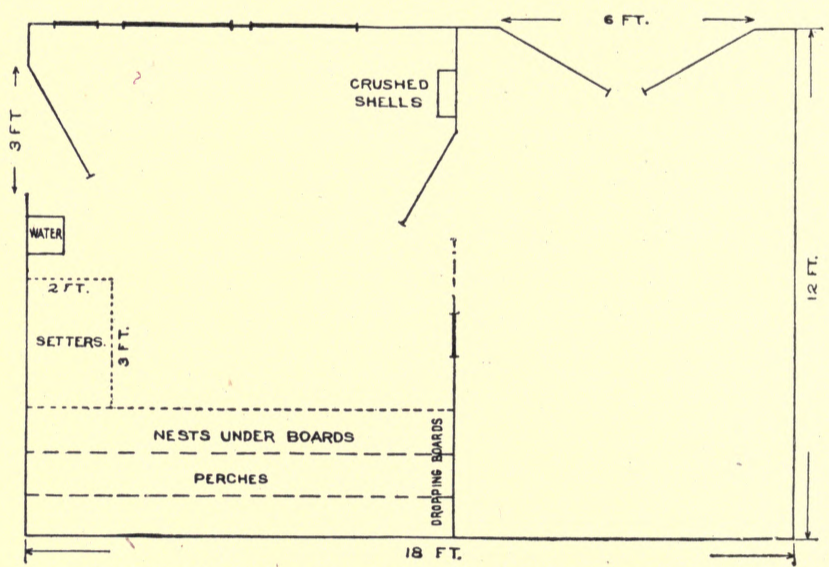

Fig. 27. Ground plan of poultry house-Massachusetts Agricultural College.

side is entirely free from frost and dampness. The relative location of the house and yard is, therefore, of sufficient importance to demand one's best thought and care in planning.

Convenience.-The poultry business, if properly conducted, necessitates close attention to many details, each one, perhaps, somewhat insignificant in itself, yet of so much importance 
when considered in the aggregate that success or failure may depend on its performance or neglect. In a general way, the labor is not considered heavy or burdensome, but constant vigilance and attention are necessary. The mere fact that there are many small details requiring attention demands that convenient houses and yards be built, since a little inconvenience each day, or perhaps several times a day, will, in time, create an unnecessary expense of considerable magnitude. Economy of labor requires convenience of appliances, and nowhere is this better illustrated than in the poultry business. It should also be borne in mind that whenever labor may be performed conveniently it is less likely to be neglected than when it is performed with difficulty. While one should not enter into the poultry business with the thought of neglecting any of its details, or to plan for any but thorough work, yet, knowing the shortcomings of human operations and tendencies, one will fail to make the most of his opportunities if he does not consider the inclinations of those who are expected to perform the work. To do the work thoroughly will require a little attention several times a day. The fowls must be fed and watered, houses must be kept clean and other attentions given. In nearly all kinds of agricultural work the labor account is one of the greatest items of expense in conducting the business. 


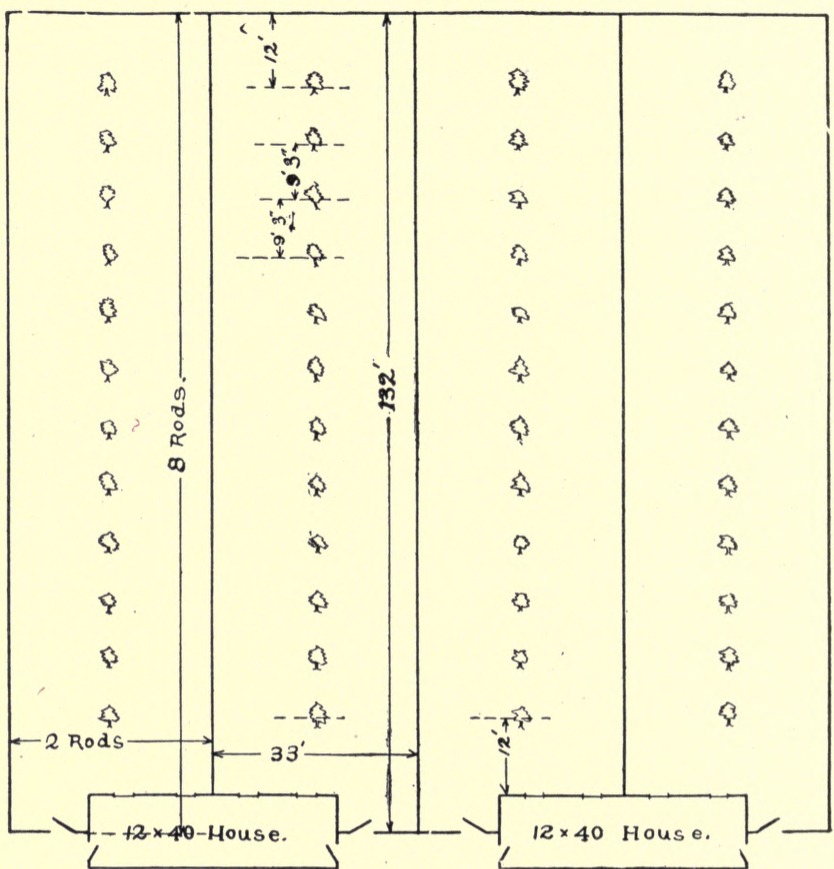

FIg. 28. A good plan for poultry houses and yards. Each house will accommodate from 80 to 100 fowls. The yards are planted with fruit trees.

A convenient arrangement of houses is illustrated in Fig. 28. The attendant may go from one house to another, passing through each pen without going through yards, which would necessitate opening and closing gates. It should be observed that each house is provided with two doors, in order that the poultryman may enter one and pass out at the other in less time than would be required if but 
one door were provided. This arrangement, however, may not be found to be applicable on many farms, particularly where but one small house is needed.

Vermin, etc.-Rats and mice often become serious pests in poultry houses, particularly if grain is kept in these buildings. For the same reason, it is generally best to locate the poultry houses some distance from other farm buildings, particularly from those in which grain is stored. Every farmer well knows how difficult it is to store grain for any considerable length of time and keep it entirely free from these pests. While convenience of access is of prime importance, yet often it is best to make a slight sacrifice of labor in order to secure the greatest freedom from rats and mice. Isolated buildings will probably give the greatest satisfaction in the end. Mice will probably not be troublesome in poultry houses unless grain is stored in these buildings, but rats are likely to give more or less trouble, particularly in brooder houses and in pens or yards frequented by young chickens.

In some localities, crows, hawks, skunks and other poultry enemies give some trouble, and one must plan to meet these annoyances according to his best judgment. It may be necessary in some cases to cover entirely small yards in which young chickens are kept, with netting, in order to protect them properly from hawks and crows. A covered run for 
little chickens is described in the chapter on feeding. Skunks may be excluded by proper fencing. Wherever vermin are numerous enough to give serious annoyance, all possible ingenuity should be exercised to exclude them before resorting to destruction by poison. While poison may sometimes be safely used, the danger of poisoning the fowls and other domestic animals is so great that one is not warranted in using it except as a last resort.

\section{CONSTRUCTION OF HOUSES}

In designing poultry houses, the form is necessarily one of the first points to be determined. While the design is under consideration, the essentials of a farm poultry house should be continually kept in mind. The chief essentials may be enumerated as warmth, dryness, light and cheapness. In order to assure proper lighting, it is often found necessary to deviate somewhat from the form that would give the greatest warmth for the least cost. In all poultry houses in which fowls are confined during the cold winter months, some provision should be made to admit sunlight on the floor, where the fowls may congregate. In order to accomplish this to the best advantage, it is necessary to have a considerable frontage toward the south or southeast. During December, January and February it is most difficult, yet most essential, to have the direct 
sunlight. Square or octagon houses inclose the most space for the money expended, and also give opportunity for warm houses which may be con-

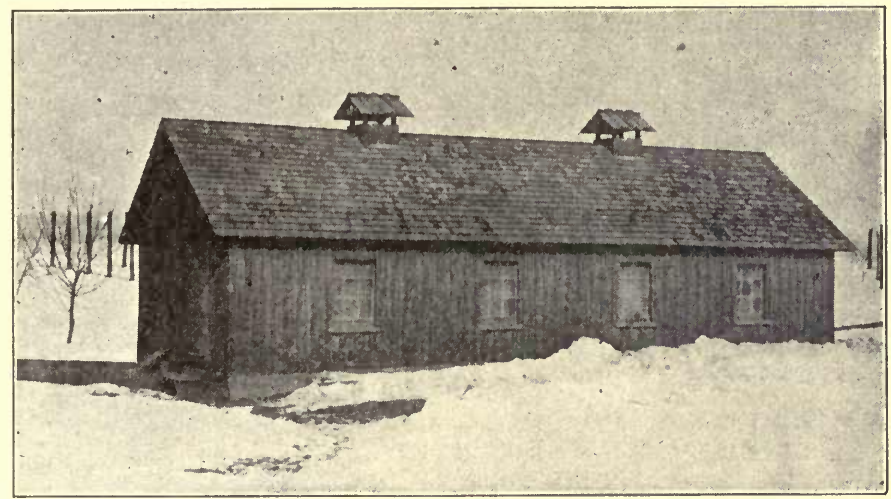

Frg. 29. A double house-Pennsylvania State College

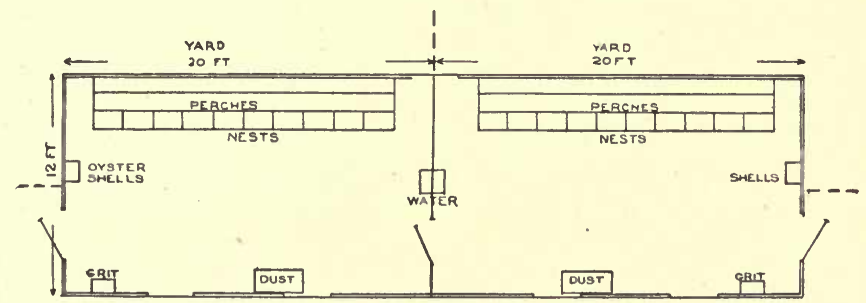

Fig. 30. Ground plan of double house-Pennsylvania State College.

structed cheaply, but in order to secure sunlight it is necessary to build the house considerably longer than wide. For economy, it is also desirable to build a house longer than is necessary for one pen or flock of fowls. A long and comparatively narrow 
house, with light partitions constructed largely of netting, may be erected for considerably less expense than two or more separate houses having the same capacity. That is, it is much cheaper to construct a partition across a narrow poultry house than to construct two end walls. Then, too, adjoining poultry pens, connected by an easy swinging door,

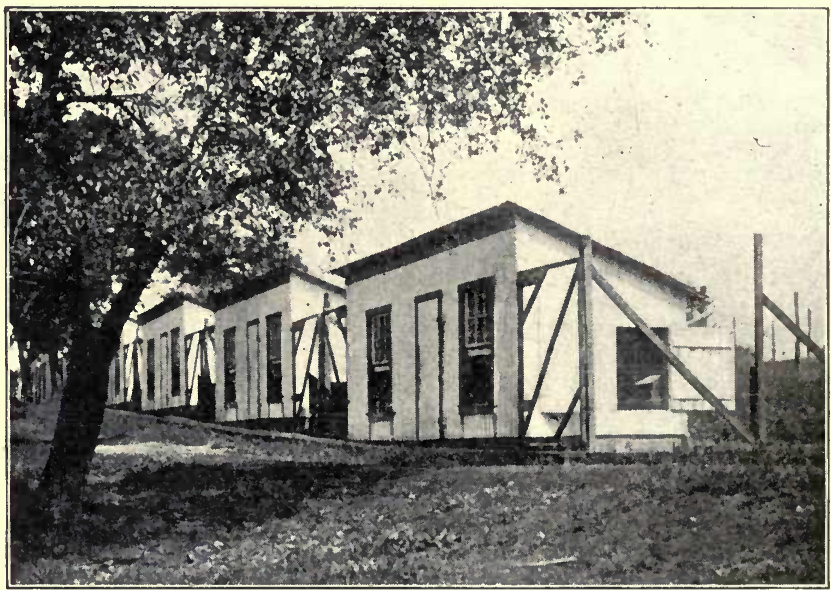

Fig. 31. Poultry houses-West Virginia Agricultural Experiment Station.

are more convenient for the attendant than two separate houses. The arrangement of having two or more pens in one building is of the utmost importance where warm houses must be provided to guard against frosted combs and wattles. (See Figs. 29 and 30.)

In constructing poultry houses, the material 
to be used and the manner of building will depend largely upon the material at hand. In one locality certain materials may be comparatively cheap, while in other localities the same articles may be relatively more expensive than other material equally suitable for the purpose. In selecting material, it should be borne in mind that the building is to provide a

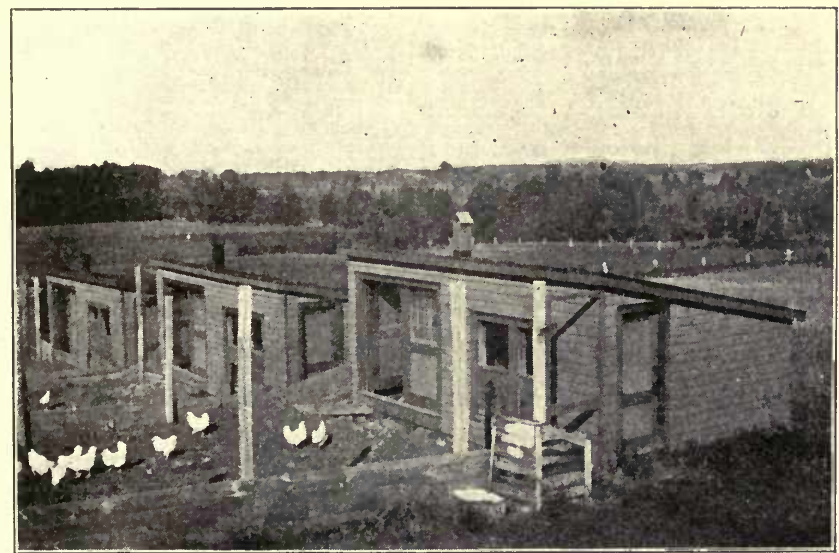

FIG. 32. Poultry houses and yards-Massachusetts Agricultural College.

warm, dry, well-ventilated, well-lighted home for the fowls. If these requirements are satisfactorily complied with, it will be necessary to provide roof and side walls that are impervious to moisture and relatively poor conductors of heat. Suitable arrangements for ventilating and lighting the building must be provided, and some provision should be made 
to exclude the moisture from beneath, particularly if the soil is damp.

Size of building.-The size of the building required will depend largely upon the number of fowls to be kept. While fowls of some breeds require more room than the same number of individuals of other breeds, yet the number is of more importance than the breed in determining the size of the building. The noted egg breeds are much more active than the heavier, slow-moving breeds, and therefore require quite as much room, although in weight they are far inferior.

The climate will determine to a considerable extent the size of the buildings. If the climate is so mild that it is not necessary to keep the fowls confined within doors much of the time, smaller houses will suffice than in colder latitudes where the fowls are kept in the house for weeks at a time. In the latitude of New York City and farther north, where fowls are expected to be kept within doors a considerable portion of the year, five square feet of floor space per fowl will suffice for most breeds, and it will be none too much for best results. This may be taken as a general rule when the house is to be kept in good condition as regards cleanliness and ventilation. If the houses are to be more or less neglected, considerably more space should be provided.

It is somewhat more difficult to give a good 


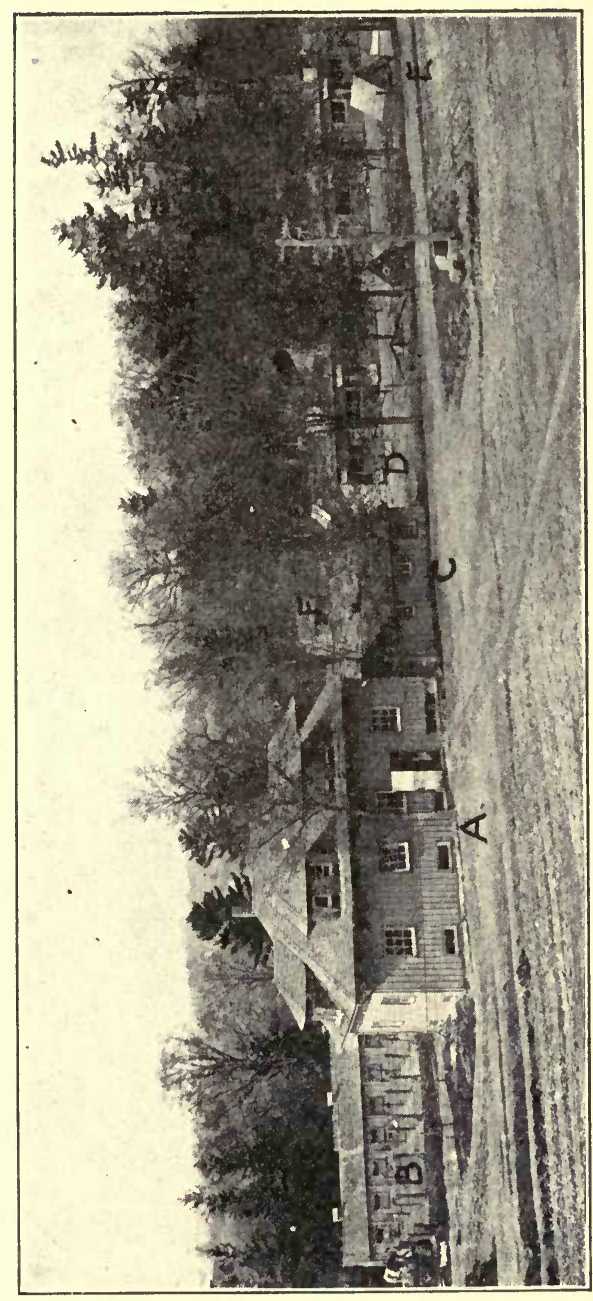

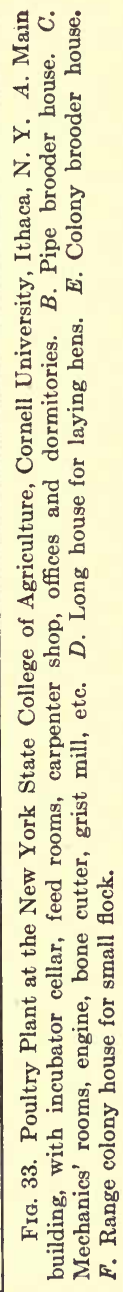


working rule as regards air-space or cubical contents of the building. Under good average conditions, six or eight cubic feet per pound of live weight will perhaps be quite satisfactory. The amount of air-space, of course, will depend upon the ventilation, and also upon the sources of contamination, aside from the fowls themselves. If manure is allowed to accumulate and the litter becomes damp, the air will become impure. Other things being equal, it will become impure sooner in small houses than in large ones. The above rule as regards air-space has given good satisfaction under favorable conditions, and may be used in the absence of more definite ${ }^{-}$information derived from actual experience.

Foundation.-When permanent houses are to be built, it is undoubtedly most economical, in the long run, to erect them on foundations made of brick, stone or concrete. Such foundations should extend into the ground below the frost line, should be vermin-proof, and so constructed as to exclude drafts of air. Some provision should be made to give thorough ventilation during the warm seasons of the year, if the floor and its supports are to be constructed of wood.

It is not safe to inclose wooden floor supports with solid walls of masonry on account of the liability of "dry rot" to destroy the supports and even to ruin the floor. A free ventilation should be pro- 
vided by means of openings in the foundation walls of all buildings when the floors are placed within a few feet of the ground.

When wooden floors are constructed near the ground, it is essential to arrange the foundation walls so that rats cannot gain access underneath the floor. This may be readily accomplished by covering windows or openings in the walls with fine-meshed wire screens. Close-fitting blinds may be used to close the windows and prevent draft underneath the house during the colder part of the year. If suitable stones are at hand for the construction of foundation walls, they undoubtedly may be used to good advantage. When neither brick nor stone is readily available, the foundation walls may be made of grout or concrete, provided small stone or gravel can be readily obtained. On many farms small field-stones, which prove a hindrance to cultivation, may be used to good advantage.

Walls of this description may be constructed without the aid of skilled labor and at a very moderate expense. In order to construct such walls satisfactorily, it is necessary to dig narrow trenches below the frost line. A simple and effective manner of proceeding is as follows: Drive rows of stakes into the ground, one row on each side of the trench, and nail boards on the inside of the stakes. The boards are used to hold the concrete in place until 
the cement hardens. Old, rough or uneven boards may be used, except for the top ones, which should have the upper edges straight. The upper boards should be placed level, as they will determine the top of the wall. The stakes which hold the boards should be firm enough to withstand the pressure

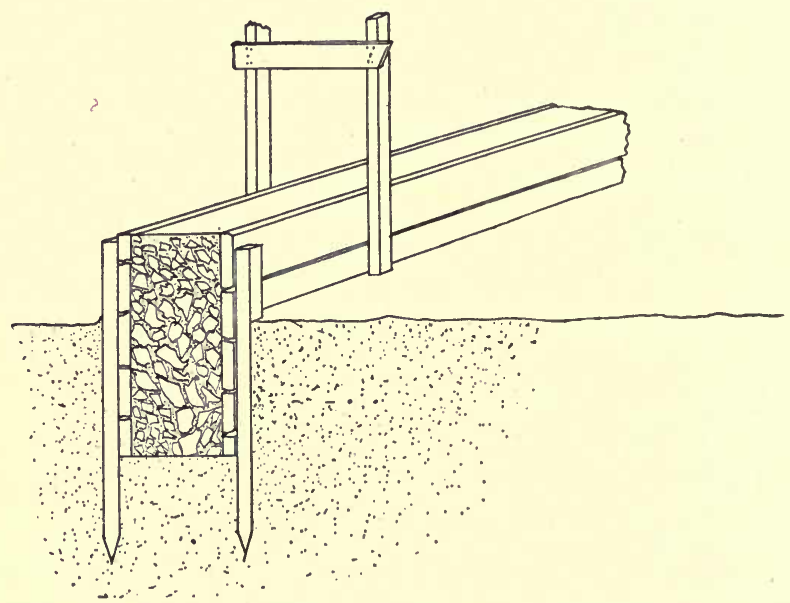

Frg. 34. Method of constructing a concrete wall.

of the stones and cement without yielding very much. If the ground is so hard that stakes cannot be driven readily, tall stakes may be used and supported by fastening the tops together as shown in Fig. 34. Place a few layers of stone in the bottom of the trench, then put on some thin cement, and pound down by means of a light pounder. This operation should be repeated until the desired 
height is reached. The top may be smoothed off with a ditching spade or trowel, using the top board as a guide.

The wall should be left until the cement is hard, when the building may be placed upon it. The boards at the side may be removed at any time after the cement becomes hard. If old boards have been used at the bottom, it will not pay to remove them. A concrete wall of this kind may be constructed of cheap material and with ordinary farm labor.

Side walls.-The side walls of poultry houses are usually built of wood, which is a comparatively cheap material and is a poor conductor of heat. The side walls are constructed in various ways. For convenience of discussion the various kinds of walls may be placed under two heads: solid walls and hollow walls. In cold countries the hollow walls, or those with a dead air-space, are to be preferred, because of their greater warmth and freedom from moisture. In moderate or warm climates solid walls will undoubtedly answer every purpose.

For latitudes south of New York, solid walls, constructed of one or two thicknesses of inch boards, will prove quite satisfactory, particularly in the hands of the skilled poultryman. The amateur will undoubtedly prefer the hollow walls, as imperfect appliances and buildings are greater hind- 
rances to him than they would be to the skilled and experienced man. Buildings with hollow side walls are cooler in summer, warmer in winter, and are not so likely to be covered with frost in severe weather as solid walls, particularly if the solid wall consists of but one or two thicknesses of boards. If the side walls and roof become more or less frosted in severe weather, dampness results whenever the temperature moderates sufficiently to melt the frost. A cheap and efficient wall for the sides and ends of the building may be constructed of two thicknesses of rough inch lumber. Both thicknesses of this siding should be put on ver- Broken Stone tically, with a good quality of tarred building-paper between. When walls of this nature are constructed, it is best to nail on the inner siding first. On the outside of these boards put a coat of the tarred paper in 
such a manner that the whole surface is thoroughly covered, providing for a liberal lap wherever the edges meet. The object of this tarred buildingpaper is to prevent drafts of air from penetrating the side walls. (See Fig. 35.) The boards of the outside covering should be put over the buildingpaper in such a way that they will break joints with the inner boarding. If boards of a uniform width can be selected for this purpose, the ease of breaking joints will be greatly increased. A wall of this thickness of inch boards, with building paper, constructed as previously described, will prove satisfactory under ordinary conditions. It should be remembered, however, that these walls will be covered somewhat with frost in severe weather, particularly if the houses are well filled with fowls.

A hollow wall may be constructed at about the same expense as the solid wall just described. One method of constructing a cheap and efficient poultry house having hollow side walls is shown in Fig. 36. The sill may be of $2 \times 8$ or $2 \times 6$ scantling, laid flat on the foundation wall. A $2 \times 2$ scantling or strip is nailed on top of the sill, at its outer edge. This gives the width of the space or hollow in the side walls. The plate may be constructed of a $2 \times 3$ or $2 \times 4$ scantling, placed edgewise. The boards which constitute the side walls are nailed to the sides of the plate and to the sides of the strip which 
was nailed to the top of the sill. Rough lumber may be used for the side walls, if strict economy is desired. The inner boarding should be nailed on first and covered on the outside with tarred building-paper. This paper will be within the wall when it is com-

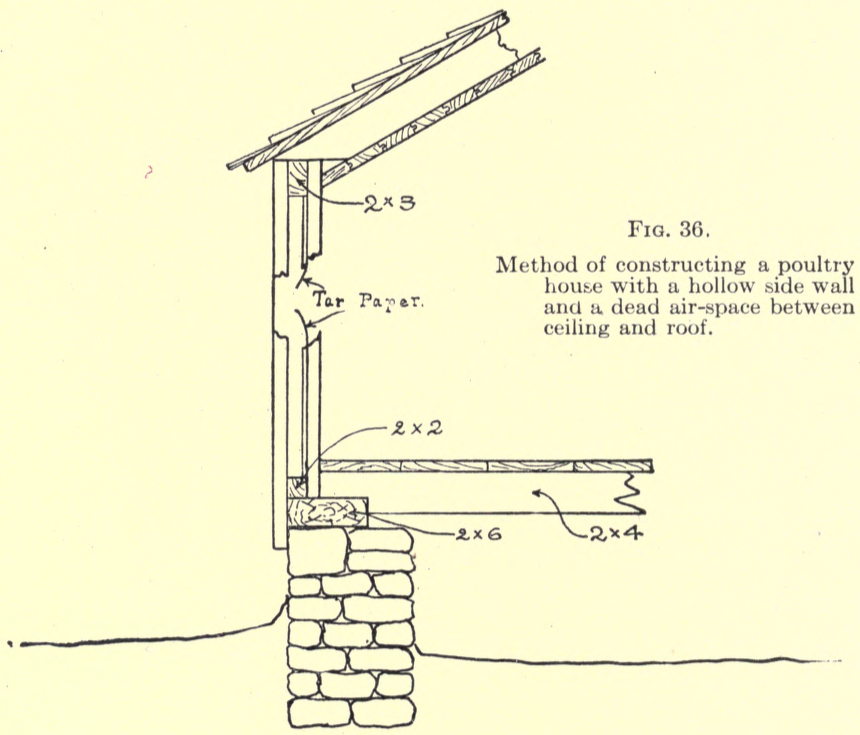

pleted. It is preferable to fasten the paper in place by means of thin strips, laths, pieces of thin boards, etc., rather than to depend wholly on the heads of tacks or nails. The outside boarding may now be put on, and the cracks between the boards covered with inexpensive battens, if they are secured with small nails at frequent intervals. If cheapness is of 
considerable importance, the ordinary building laths may be used, and will answer the purpose admirably, although somewhat heavier battens will be more durable. A mistake is sometimes made in selecting heavy battens which will not draw down by nailing as well as lighter ones. The battens on the outside boarding and the tarred building paper on the inside boarding make two coverings, each of which is impervious to wind, with an air-space between them.

Roofs.-Various kinds of material are used in the construction of roofs for poultry houses, although shingles are more generally employed than anything else. Tin, steel, and various kinds of roofing-paper are used, although they are more or less objectionable on account of the great heat radiated in the building during the hot summer months.

Roofs of various forms are constructed. The gable and lean-to or shed roofs are used most. A shed roof may be constructed with a trifle less labor than a gable roof, yet it is not nearly so economical in the matter of space as the latter. At first thought, a shed roof may seem to include the most space, but upon closer analysis it will be found that the gable roof, other things being equal, includes considerably more space. To further illustrate, we will suppose that boards twelve feet long are to be used for the side walls in constructing a house twelve feet wide, the roof to be one-third pitch. If the gable form be used, the building would then 
have side walls six feet high, and the area included in cross section would be 96 square feet. (See Fig. 37.)

If the shed form of roof be used and the same material as described above for side walls, but 72 feet in cross section would be included. (See Fig. 38.) It is undoubtedly true that the shed roof may

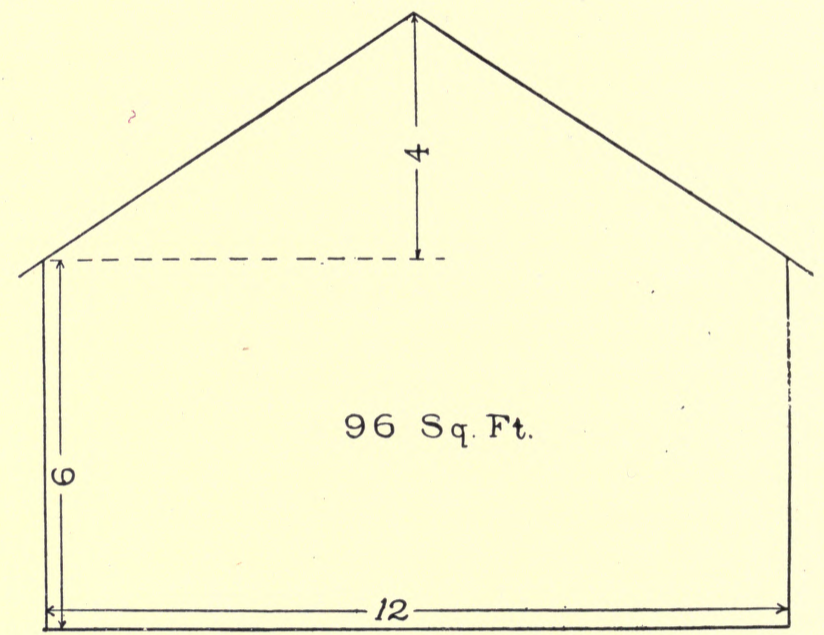

FIG. 37. Cross section of a poultry house with a gable roof, 96 square feet.

be constructed at a trifle less expense for labor than the gable roof although it will be found necessary to use somewhat heavier rafters than would suffice v for the gable roof. As long as the pitch of the roof remains the same, practically the same roofing material will be required for all forms of roof. The advantage that one form of roof may have over 
another as to material of construction will occur in side walls, ends and partitions. It often happens that one style of roof may be preferred for reasons other than those mentioned. It may be desirable to have all the water from the roof on one side of the building, that the other side may be kept as dry as possible; then the shed roof would be preferred.

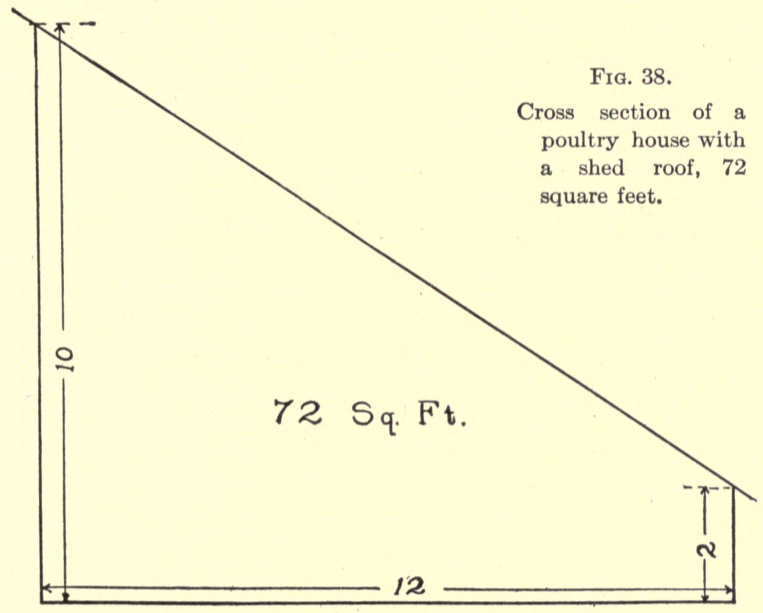

Then, too, the shed roof, if the building faces the south, will absorb less heat from the direct rays of the sun than would a roof of the gable form: this of course will be most noticeable during the hot summer months and if a dark roofing material be used.

It often happens that the location or peculiar conditions as to soil, exposure, etc., on the farm 
in question will require a particular form of building that might not be advisable to construct on another farm under very different conditions. It is for each one to determine for himself that which may answer his purpose best. There is no hard and fast rule as to the construction of buildings

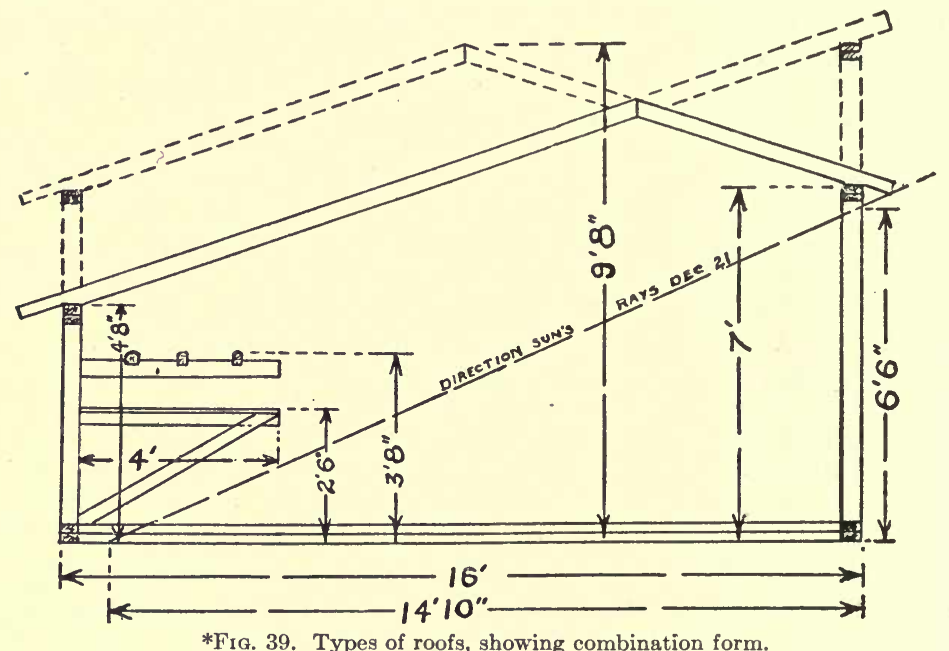

that will apply equally well to all of the vast multitude of conditions under which fowls may be profitably maintained on American farms. Each individual poultryman should ever bear in mind the ideal conditions for profitable work, and so construct his buildings that the ideal may be approached as nearly as possible.

*Michigan Agricultural Experiment Station Bulletin No. 266. 
A form of roof known as the "Combination" has become quite popular and under some circumstances has many advantages.

Whatever form of roof be used, it should be so constructed that it will effectually exclude all drafts of air. Shingled roofs, as ordinarily constructed, do not sufficiently exclude drafts. In order to make such roofs satisfactory it is necessary to cover the roof boards with building-paper before the shingles are laid, or to provide an inner ceiling for the poultry house. Either of these will exclude the drafts, but both are more or less objectionable. Each one must choose what seems to him to be the lesser of the two evils. The building-paper underneath the shingles prevents the shingles from drying as readily as they otherwise would, and, consequently, materially shortens the life of the roof. Experience has taught that the shingled roofs that dry quickest last longest. The ceiling on the inside of the ordinary shingled roofs is objectionable on account of the additional expense. With the steady advance in the price of shingles, other roofing materials are gaining in popular favor. Felt and paper that are protected by various kinds of paints and other protective material are largely used. These roofing materials seem to be particularly well adapted to the small, low and easily accessible roofs of poultry houses.

Floors.-Some successful poultry-keepers pre- 
fer earth floors to artificial ones, but as these are somewhat more difficult to keep clean many prefer an artificial floor constructed of wood or cement. Wooden floors are used, although they are somewhat more expensive to construct, and it is often necessary to replace them every few years. The "submerged cement floor" is preferred by some. In constructing this floor the ground should be slightly excavated so that the top of the cement floor when finished will be a trifle lower than that desired for the fowls. The cement may be placed directly on the ground if the earth is firm. If the earth is not firm it should be further excavated and filled with stone, which should be thoroughly pounded before applying the cement. (See Fig. 35.) After the cement hardens, sand or gravel may be used to cover it to a depth of from one to three inches. Some poultrymen prefer to place the cement floor somewhat higher than the surface of the ground in order to secure good drainage, depending on litter to protect the fowls from coming in contact with the cement when the weather is cold. A cement floor properly constructed is a most excellent protection against rats and mice and has become very popular, particularly where an abundance of suitable litter may be obtained cheaply. These floors if properly constructed are most durable and are easily cleaned, -a most important feature.

Windows.-For the colder latitudes, windows 
should not be large, not more than one to every ten feet in length for a house twelve feet wide. These should be placed on the south side and at such distance from the floor as to allow the greatest possible amount of sunshine to fall upon the floor during the cold winter months. It is desirable to have the windows of such size that one may be placed in each division or pen. One square foot of window opening for each fifteen to seventeen square feet of floor-space will be quite sufficient under ordinary conditions. In order to secure most sunshine on the floor the windows should be so placed that their greatest length is vertical. At noon, during the shortest days of the year, in the latitude of New York City, the sun's rays make about the same angle with the horizon as that of a quarter pitch roof; that is, an object one foot high would cast a shadow two feet long. Then, if the bottom of the window be placed eighteen inches from the floor, the sunshine on the floor will be three feet from the side of the building in which the window is placed. In cold latitudes it is a common and somewhat serious mistake to use more windows than are absolutely needed for the health and convenience of the fowls. While sunlight is desirable, many windows make the building cold, unless they are covered with shutters or heavy curtains, during the severest weather. It has been found that windows radiate about four times as much heat as the same area of side walls 


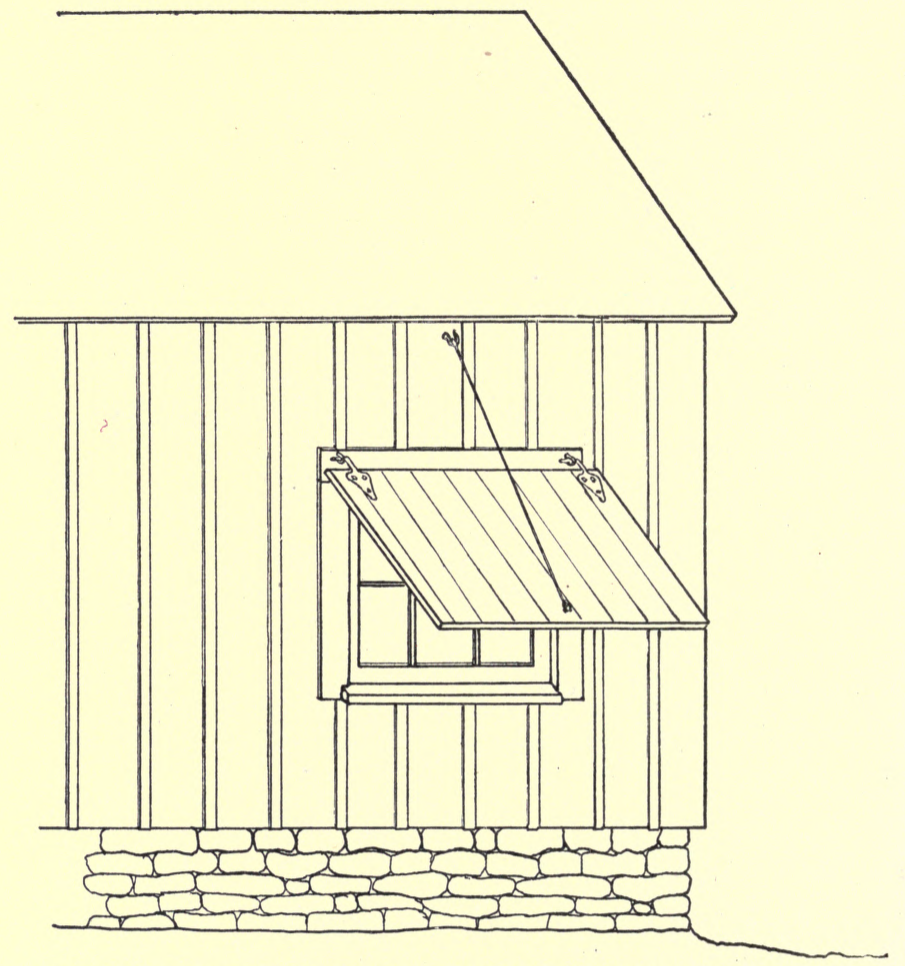

FIG. 40. Window of poultry house protected by a wooden shutter for summer use.

in average well-constructed dwelling houses. If warm houses are desired large window surface should be avoided. A coat of whitewash on the interior will aid materially in making the building light. Sliding windows are preferred on many accounts to those that open by means of hinges. They can 
be partially opened for ventilation in warm weather, and during the extreme heat of summer they may be left entirely open. The opening should be covered with poultry netting to confine the fowls, and if the mesh is fine enough to exclude the English sparrow, annoyance is sometimes avoided.

Whether the windows are made to slide either vertically or horizontally, or are hinged either at the top or at the sides, is a matter for each poultryman to determine for himself. After considering the various methods of construction it is for the owner or manager to select that which appears to be best for him. He should be able to give a reason for the particular construction of every poultry appliance with which he has to deal.

Comparatively cheap window shades may be made of thin matched lumber nailed together so as to make a solid shutter. This shade, or shutter, may be hinged to the side of the poultry house just above the window with loose hinges, the lower edge supported by a wire, as shown in Fig. 40. Such shades exclude the sun and serve as a protection from the heat during the warmest part of the year when the windows are left open. The loose hinges permit of easy removal for winter storage.

Ventilation.-During the warm weather the open windows will afford sufficient ventilation, but during the colder months some means of ventilating the building should be provided, aside from that 
afforded by the doors and windows. Many ventilators have been planned for poultry houses, but all ventilators that are in continuous operation either give too much ventilation during the coldest weather or not enough during the warm, still days. As a rule, they furnish too much ventilation during the cold nights, and not enough during the sunny part of the day. Any system of ventilation that will

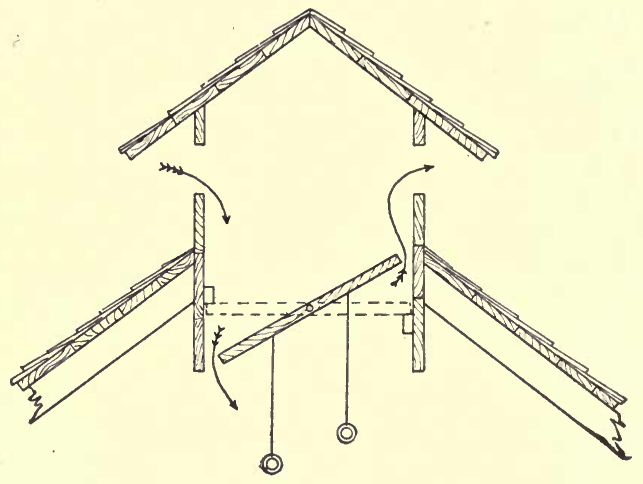

FIG. 41. A good ventilator.

fully meet the requirements of the busy farmer or poultryman must be simple and readily controlled by the attendant. Ventilators are not needed in the severest weather, but during the warm days of spring and whenever the temperature is above freezing point during the winter and early spring, some ventilation should be given. Farmers and poultrymen should aim to ventilate their poultry houses as they ventilate their own sleeping apartments. 
Little or no ventilation is needed at night during the severest weather in the colder latitudes, but during the day, when the fowls are more or less actively engaged in scratching in the litter, the house should be ventilated just as regularly as a sleeping apartment should be aired when not occupied or when the occupant is actively engaged in light manual labor. Houses with single walls will become quite frosty on the inside during the severest weather, and this will cause more or less dampness whenever the temperature is sufficiently high to thaw the frost from the walls and roof. At this time ventilation is most needed and may be supplied by placing a ventilator in the highest part of the roof, which will permit the heated air to escape. It is rarely necessary to provide special means for cold air to enter, as there is usually a sufficient number of cracks about doors and windows to admit cold air if means be provided for the lighter air to escape. Fig. 41 illustrates the construction of a cheap and effective ventilator. This may be readily closed and opened by means of cords or chains as the attendant passes through the house.

Muslin windows have had and still have many earnest advocates. As a means of ventilation with minimum drafts they serve a most useful purpose. They transmit light also, but, like many other appliances; have some serious faults. Under some conditions they soon become soiled and then are 
not so effective either as transmitters of light or as ventilators. Their use, however, is to be com. mended even though they may require somewhat frequent renewals. Houses have been constructed with a straw ceiling as an aid to ventilation. They are constructed as follows: A gable-roofed house is floored over with narrow boards placed a few inches

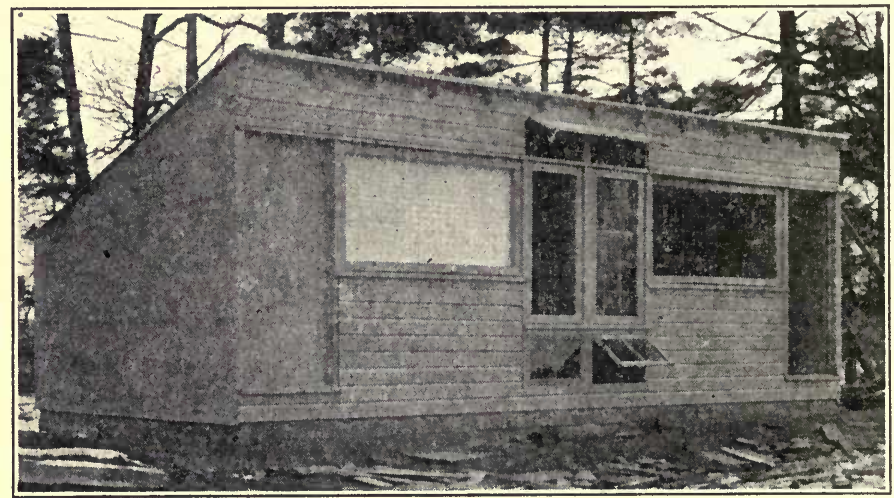

FIG. 42. A combined muslin and open front house-Cornell University.

apart at the height of the plate or a little higher. These boards are then covered with clean straw to the depth of eight inches or a foot. The space between the straw and the roof is ventilated by means of open windows in the ends of the building. The heated air of the building will pass up through the straw and out at the windows. This may work nicely under certain conditions but unless other means are used for ventilating it will be found to 
be insufficient at times and more than is needed in extreme cold weather. Then too, the straw soon becomes dusty and requires changing. This manner of ventilating has not become very popular.

Open-front houses. - These have been recommended largely on account of the extreme venti-

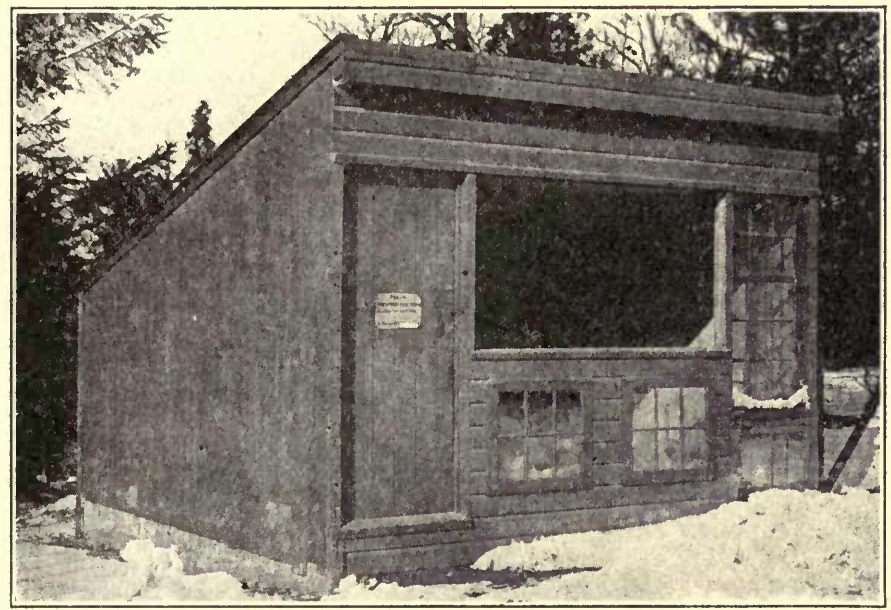

FIG. 43. An open front colony house.

lation which they afford, but for cold climates they cannot take the place of the warmer and more comfortable quarters provided by careful poultrymen. While reasonably cold pure air is to be preferred to warmer impure air, yet it should not be forgotten that it is the purity of the air and not the low temperature that is desirable. A moderately 
warm pure air is desired. The greatest vigor cannot be secured if the fowls are required to breathe impure air. Neither can greatest production be obtained if the fowls are uncomfortable on account of the low temperature. For prolificacy the springtime conditions in central northern United States are without doubt the nearest ideal,-a moderately warm temperature, pure fresh air, plenty of exercise with fresh vegetable, grain and animal food. 


\section{CHAPTER VII}

BUILDINGS: INTERNAL ARRANGEMENTS AND YARDS

Perches.-While the construction of the perches is perhaps of less importance than many other details of a well-equiped poultry house, yet one should be able to give a reason for constructing each part of the house in a particular way, and it will be necessary to give considerable thought to the planning and arrangement of minor features. In the construction of perches two objects should be kept in mind: (1) The perches should be convenient for the fowls and (2) so arranged that the droppings may be readily caught without falling to the floor or soiling the litter. For heavy-bodied fowls the perches should not be more than two and one-half or three feet from the floor, and all should be of the same height. Many fowls prefer to perch far above the ground in order, without doubt, to be more secure from their enemies. It may be accepted as natural for fowls to perch at a considerable distance from the ground in order that they may be better protected from skunks, minks, foxes, etc. In the poultry house, from which these enemies are excluded, however, low perches 
are considered just as safe and much better for heavy-bodied fowls. More or less clumsy, heavybodied fowls ascend to high perches with difficulty, and are likely to be injured in alighting from any considerable elevation. Convenient ladders or walks may be constructed, which will enable the fowls to approach the perches without great effort, but there are always times when clumsy fowls will attempt to fly to the floor, although injury to themselves may result. Leghorns and other egg breeds may safely perch somewhat higher than the Asiatics, and if the buildings are well constructed this may be an advantage in cold weather, as the fowls will undoubtedly find it somewhat warmer on high perches than on low ones. For houses in cold latitudes that have large cubic contents for the number of fowls they contain high perches may be quite desirable, particularly if the roof or ceiling immediately above the perches be partitioned so as to exclude drafts quite effectually.

Only movable perches should be constructed. A $2 \times 3$ scantling, set edgewise, with the upper corners rounded, answers every purpose and makes a satisfactory perch. Poles or narrow boards may be used, but whatever material is selected the perches should be so constructed that they will be firm and will not tip or rock when fowls alight on them. A small scantling is easy to secure firmly and also to clean and to disinfect. Underneath 
the perches a smooth platform should always be placed to catch the droppings. This is recommended for two reasons: first, it is much easier to keep the house clean and free from objectionable odors if the droppings are easily removed; and, second, the droppings are valuable as a fertilizer and should

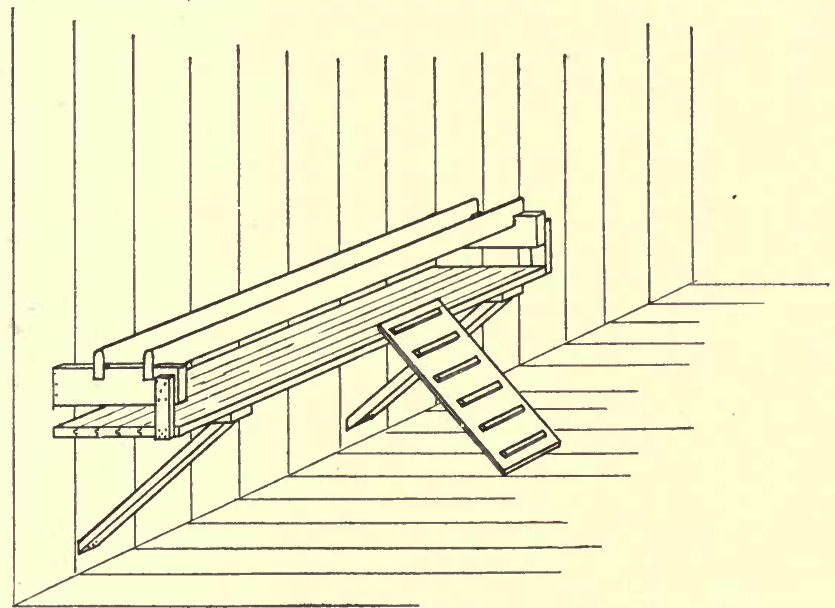

Fig. 44. Movable perches with board platform underneath to catch droppings. not be mixed with the litter on the floor. The distance from the perch to the platform will depend somewhat on the size of the fowls and on the implement used in removing the droppings. It will also depend on the form of platform constructed.

The distance between the perches and a level platform should not be great enough to permit the fowls to walk on the platform underneath the 
perches. If a broad iron shovel with a tolerably straight handle is used, the perches need not be more than from five to eight inches from a level platform. It is desirable to have the platform some distance from the floor, in order that the fowls may occupy the floor-space underneath the platform. This will permit the construction of perches, and, at the same time, will allow the fowls to use all of the floor-space. The perches may be supported by brackets secured to the side wall, as shown in Fig. 44.

Nests.-In the construction of nests in poultry houses, at least three points should constantly be kept in mind. First, the nest should be situated in a place which is more or less dark; second, it should be readily accessible to the fowls from more than one side; and, third, it should be constructed in such a way that it can be readily seen, easily cleaned, and thoroughly disinfected. Since it is important to give the fowls as much floor-space as possible, it is usually best to have the nest attached in some manner to the side or end walls of the building. In a general way it may be said that the number of fowls which a poultry house will accommodate depends on the floor-space and air-space which the house contains. Anything, therefore, that unnecessarily occupies floor-space will diminish the capacity of the house. Various plans of arranging nests have been adopted, and it is difficult and 
probably impossible to say which is the best. Each has advantages and disadvantages. A somewhat simple and easy plan of arranging nests when the perches are placed not more than two and onehalf or three feet from the floor, is as follows: Underneath the platform, which should always be underneath the perches, as described above, the nests are placed in a row on the floor. From the front edge of the platform to the floor, in front of the nests, a tight board partition is constructed. This board partition is opened by means of a long door, hinged either at the top or bottom. In either case the lower edge of the door should be about level with the top of the nests. A small opening at one end of the door will admit fowls to the nests. This arrangement secures darkness for the nests, plenty of room for the fowls to approach the nests from two or three sides, and the nests are readily accessible for cleaning, gathering eggs, etc. Some of the disadvantages of this plan are that the nests occupy considerable floor-space and the fowls are sometimes inclined to deposit their eggs on the floor back of the nests. It is desirable to arrange the nests so that they may be approached from more than one side for the following reason: In flocks of fowls of any considerable size there are usually individuals more or less aggressive in character, that seem to delight in exercising their mastery over others; such birds, when seeking a nest, will 
almost invariably drive others off the nests rather than take equally as convenient a nest which is unoccupied. If the nests can be approached from only one side, one hen in trying to drive the other off, which she will eventually accomplish, will force the occupant to spring from the nest

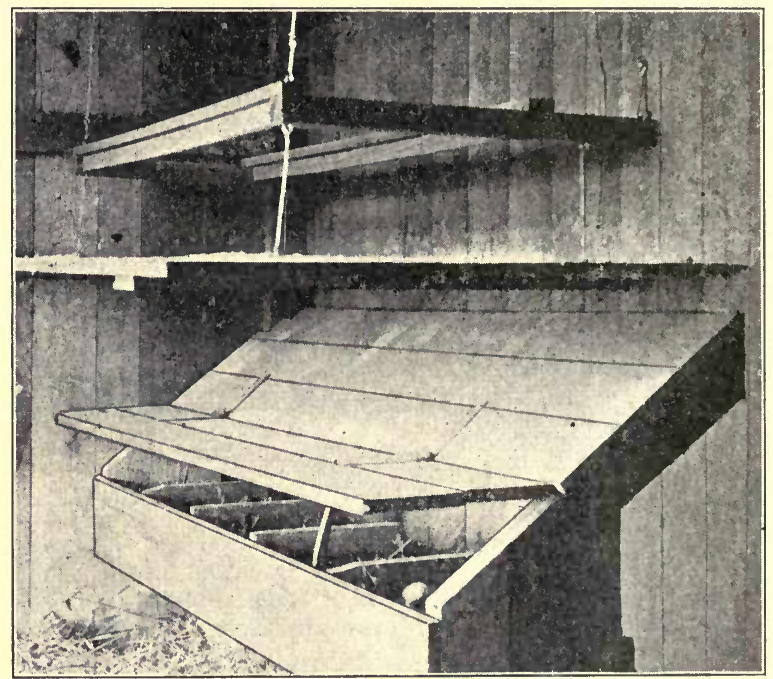

Fig. 45. Perches and nests-West Virginia Agricultural Experiment Station.

suddenly. This may cause the eggs to be thrown violently to one side, and often a broken egg is the result.

The vice of egg-eating is undoubtedly largely caused by eggs being broken accidentally, or by frozen eggs. If the nests can be placed in partial 
darkness, the habit of egg-eating should be reduced to a minimum. While it may not suffice to cure the habit when once well formed, yet it should prevent, in a large measure, the development of this vice. It is the duty of those constructing poultry houses to arrange them so that this vice, together with other undesirable features of poultry-keeping, may be avoided so far as possible. Another arrangement of nests, in which they are attached to the side or end walls, and therefore do not occupy floor-space, is recommended by many practical poultry-keepers.

It is important to arrange the nests so that they may be readily cleaned and disinfected, for it is well known that if the perches and nests of the fowls can be kept free from mites, or so-called summer lice, the fowls themselves will be entirely free from them. If the nest boxes, therefore, are movable and can be readily taken out-of-doors for thorough cleaning, it will be found somewhat easier to keep them entirely free from these pests than if stationary nests are used, and it will certainly be easier to exterminate them should they once gain a foothold.

Nests of Leghorns, Hamburgs, and Minorcas may be constructed of boards, 6 inches wide, making boxes $8 \times 10$ inches in the clear. The American breeds and Asiatics should have somewhat larger nests. 
Fine hay is satisfactory for nest material and excelsior answers the purpose admirably. Seagrass, so extensively used in packing china and crockery, is an excellent material. Whatever material is used, it should be such as will not easily stain the eggs. An egg when first laid is moist, and if the nest material stains or gives up its coloring matter readily, the egg is likely to be more or less stained, particularly if it has a white shell. If the nests are placed side by side, the partitions should extend two inches or more above the nest material to prevent the fowls from attempting to draw the eggs from one nest to another, and, in so doing, cause the eggs to roll back and be broken.

Drinking-fountains.- It is of the utmost importance that fowls be supplied with pure water. This is one of the somewhat difficult problems that every poultryman has to meet. It is difficult to keep the water-dishes clean, particularly when the fowls are confined in the houses, as they are during the severe winter months. Scratching in the litter will cause more or less dirt to enter the drinking-dishes, and usually such fowls are fed soft food once a day at least,

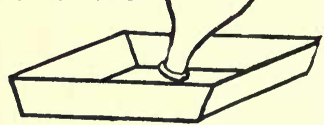

FIG. 46. A simple drinkingfountain; a bottle or jug used as a reservoir. and this food will also enter the drinking-dishes to some extent when the fowls drink after eating. There are a number of patented drinking-fountains 
on the market, many of which are automatic and keep a small supply of water constantly before the fowls. Under favorable conditions these fountains will, undoubtedly, prove very satisfactory. Under adverse conditions, however, some of them have not given satisfaction, for the reason that they are difficult to clean. If the fountain becomes tainted, as it is very likely to do in warm weather, it is not so readily cleaned as a simple tin or earthen dish. Drinking-fountains that are not readily cleaned are objectionable. Many automatic fountains are constructed on the

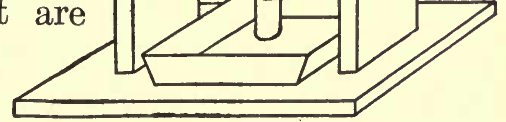

FIG. 47. An improved drinking-fountain with a revolving reservoir. principle of the student lamp, which permits a small quantity of liquid to pass from the reservoir whenever a bubble of air is permitted to enter it. The inverted jug or bottle, with its opening placed in a shallow dish, illustrates the principle. (See Fig. 46.) An improved arrangement is seen in Fig. 47. The reservoir is supported between two uprights and so arranged that it may revolve for convenience in filling.

Another arrangement, which has given satisfaction in the hands of successful poultrymen, may 
be constructed as follows (Fig. 48): An ordinary shallow milk-pan is placed on a block or shallow box, the top of which is four or five inches from the floor. The water or milk to be drunk by the fowls is placed in this pan. Over the pan is placed a board cover supported on pieces of lath about eight inches long nailed to the cover so that they are about two inches apart, the lower ends resting on the box which forms the support of the pan. In order to drink from the pan, it is necessary for

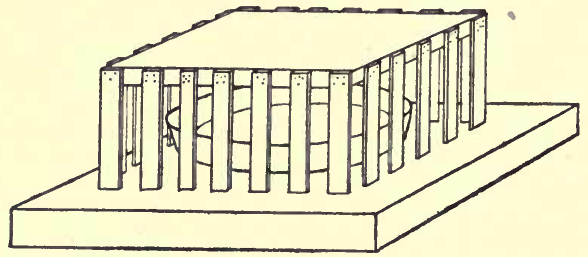

Fig. 48. A shallow milk-pan used as a water basin, and protected with a board cover having supports of laths. the fowls to insert their heads between these pieces of lath. The cover over the pan and the strips of lath at the sides prevent the poultry from fouling the water in any manner except in the act of drinking. When drinking-pans of this kind are used, it is very easy to cleanse and scald them with hot water as occasion demands. This arrangement can be carried a little further by placing a pan or, what would be still better, a long, narrow dish, something like a tin bread-tray, on a low shelf a few inches from the floor and hinging the cover to one side of the poultry house so that it can be tipped up in front for the removal of the dish or for filling it with water. (See Fig. 49.) 
If desired, the cover may be so constructed that it will be on an incline to prevent fowls from perching on it.

There are various forms of drinking-fountains on the market that are kept in stock by poultrysupply houses. Selection may be made from these, or fountains may be made from special designs,

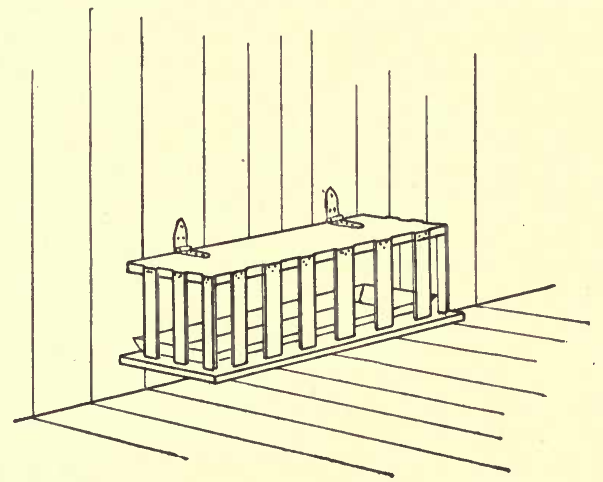

Frg. 49. A protected water basin.

but whatever arrangement is made for furnishing water for the fowls, it should comply with these conditions: (1) The drinking-pan must be so constructed that it may be easily and thoroughly cleansed; (2) fowls should have access to pure water at all times.

Dust-boxes.-It is not only desirable, but necessary, to provide dust-boxes for the fowls if they are to be kept reasonably free from body-lice. This is particularly true during the winter months. 
During the summer, if the fowls have a more or less wide range, dusty places will be found out-ofdoors wherein they may take dust-baths. During the late fall, winter and early spring, conveniences should be supplied the fowls within doors, wherein they may wallow in the dust. A comparatively small box will answer for a flock of a dozen or

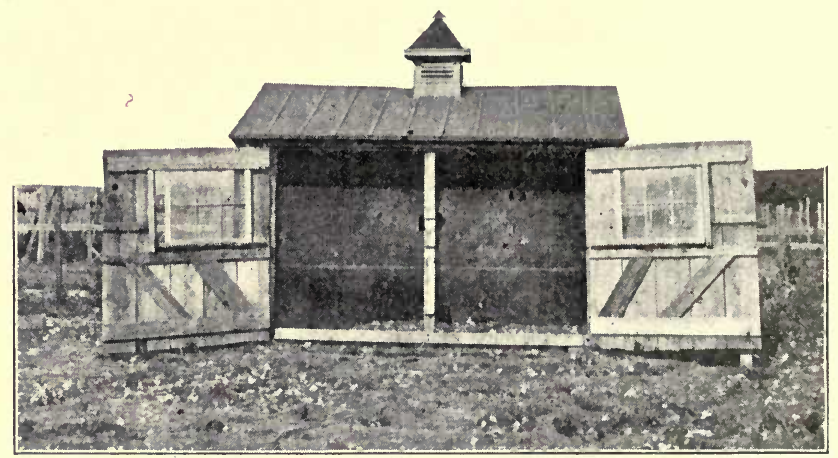

Frg. 50. Combined house and scratching-shed, an excellent plan. Rhode Island Agricultural College.

twenty hens if the attendant will see that the box is kept well filled with dry dust and free from litter and other coarse material. If these boxes can be so placed that they receive some sunshine on bright days it will be found easier to keep the dust dry, and fowls prefer them so located rather than in some dark corner. Fine road dust procured during the hot, dry weather of July and August from a much traveled highway has no superior for this purpose. Probably there is no 
way in which the poultryman can better combat the body-lice than by providing dust-boxes for his fowls.

Dust-boxes are objectionable because their use makes the houses so dusty and dirty. If space will permit, a special room or closed dust-bath with window facing the south can easily be constructed, and will keep the house comparatively free from dust, and the bath will be kept free from the litter used in the poultry house.

It is true that the fowls may be kept comparatively free from these pests by the occasional use of insecticides dusted thoroughly among the feathers of the various parts of the body, but as this method necessitates the handling of each bird several times during the season, most farmers will prefer to have the fowls use the dust-bath. If an insecticide, as powdered sulfur or insect powder, is used, it should be dusted through the feathers next to the skin, preferably in the evening when the fowls are quiet and on the perches, in order that the material may remain in the feathers for several hours.

Yards and parks.-The question of confining fowls is perhaps somewhat undecided in the minds of many farmers. Because the fowls of a comparatively small flock, when given their liberty or the run of the farm, thrive well and produce many eggs with very little attention on the part of the owner, it should not be inferred that large flocks will prove 
equally satisfactory under similar conditions. While a few fowls may be given the run of the farm without causing very much annoyance, large flocks would be objectionable for many reasons.

Each individual must decide for himself whether he will permit his fowls to have the run of the farm, or whether he will confine them in pens or yards. Generally speaking, it is far better to confine the

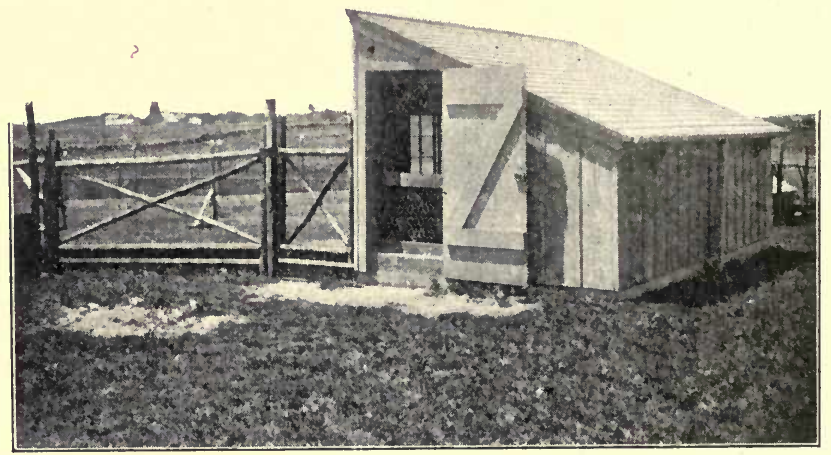

Fra. 51. Poultry house and yard.

Rhode Island Agricultural Experiment Station.

fowls within suitable inclosures. The owner then has control of the conditions and is more nearly master of the situation than it is possible for him to be when his fowls are given full liberty. Those who provide yards or runs for the fowls do not all agree as to the best method. There are two systems in use, each possessing its own advantages, and each having warm adherents. One system or plan provides comparatively small areas for small- or 
medium-sized flocks; the other fences more extended areas for large flocks or masses. It is undoubtedly best for each beginner to learn what he can of the experience of others and then to select the plan that best meets his own. requirements.

Undoubtedly there is no best method of constructing yards or runs for fowls. What may answer the purpose admirably for one would be quite unsuited to the conditions of another. The yards should be so constructed that they best meet the natural as well as the artificial conditions under which the fowls are to be kept. Figs. 52 and 53 illustrate a way of constructing poultry houses and adjoining yards for moderate-sized flocks. This system has been used satisfactorily by successful poultrymen on comparatively level land. It is particularly advantageous when small yards are to be used that will require thorough cultivation. Whatever may be the form or size of the yard, it should be borne in mind that the first requisite is cleanliness, that part of the yard nearest the poultry house undoubtedly requiring frequent cultivation. The ideal condition is to have one part of the yard in permanent grass and another part well cultivated. If a rocky or rough piece of land, more or less woody, is near at hand, there is no reason why this may not profitably form a part of the poultry run or yard. Poultry yards accommodating fifty hens should inclose about sixteen 
square rods. If fifty fowls are kept confined in the house and yard throughout the year, as described above, it will be necessary to have a considerable part of the yard thoroughly cultivated in order to keep it clean.

The expense of constructing and maintaining poultry fences is considerable, and the plan to be preferred is the one that will give the greatest satisfaction with the least amount of fence.

If the yards are to be cultivated, it will be found advantageous to have them long and comparatively narrow. A yard two rods wide and eight rods long is convenient to cultivate, and is very satisfactory for other reasons. As it is found most convenient to have several pens in one house, it is therefore convenient to have several poultry yards side by side, one fence forming the boundary of two yards. (See Fig. 28.) Provision should be made for two-horse cultivation, for sometimes yards will need to be plowed. Whether the fences be entirely wood or of wire netting, they should not be less than seven feet high, if egg breeds are to be confined. In either case, it is well to have a wide board placed at the bottom. Sometimes it is desirable to confine comparatively small chickens in these yards. Boards at least a foot wide at the bottom will be very satisfactory, if the remainder of the fence is constructed of the ordinary two-inch mesh poultry netting. Should the boards be omitted, 
the lower part of the fence should be formed of netting having a mesh smaller than two inches. It is undoubtedly best to provide some shade for the fowls. "For this purpose fruit trees have given

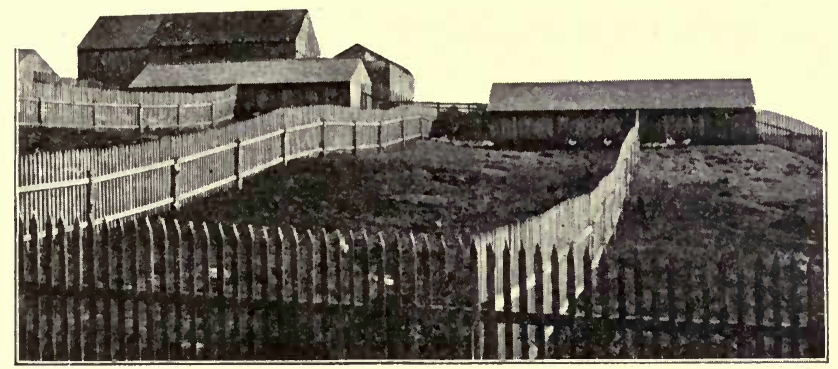

FIG. 52.

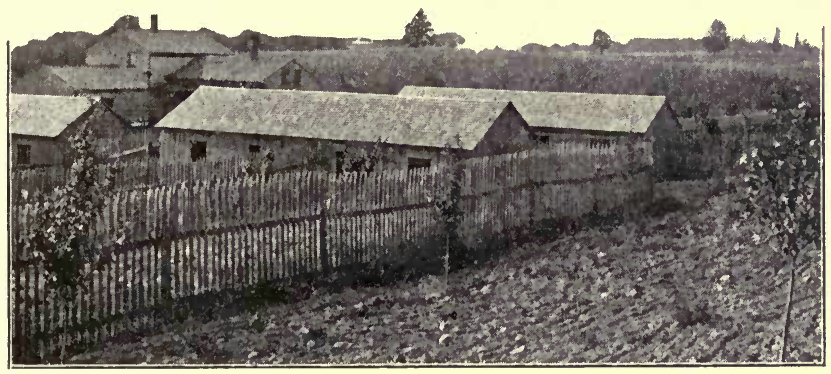

Fig. 53.

Poultry houses and yards of C. H. Wyckoff, Groton, N. Y.

entire satisfaction. Pium trees are éspecially recommended for poultry yards. One of the greatest difficulties experienced in raising plums is caused by the attacks of the curculio. It has been found by trial that plums grown within the poultry yard 
are much less liable to injury by this insect than those grown under similiar conditions outside of the yards. If several poultry yards are arranged side by side, the owner may provide for a plum orchard by planting a row of plum trees through the middle of each yard. The following varieties of plums have been especially recommended for this purpose:

\section{Lombard}

Bradshaw

Peter Yellow Gage
Burbank

Coe Golden Drop

There is no reason why an apple orchard may not form a poultry yard to good advantage. Particularly would this be true if the orchard were kept under thorough cultivation, a practice which is now so strongly recommended by the most advanced orchardists. The whole orchard may be inclosed with the poultry fence and the fowls given the run of it. If thought advisable, simple, temporary yards may be provided for the various flocks during a part of the year, when it is desired to keep them separate. At other times all of the flocks may be given the run of the entire orchard.

When the fowls have once become accustomed to their house or home, they will give the owner very little trouble by perching elsewhere, even though they be given the opportunity to do so. Whenever small yards are used, it will be found desirable to place the young birds or pullets in 
their permanent yards, if possible to do so. Mature fowls, when moved from one pen to another, are more likely to fly over the enclosure than if kept throughout the season in the yard they have learned to recognize as home. It has frequently been noticed that Leghorn and Minorca hens will remain peaceably in the yard in which they have been reared, but if moved to other yards will give the owner

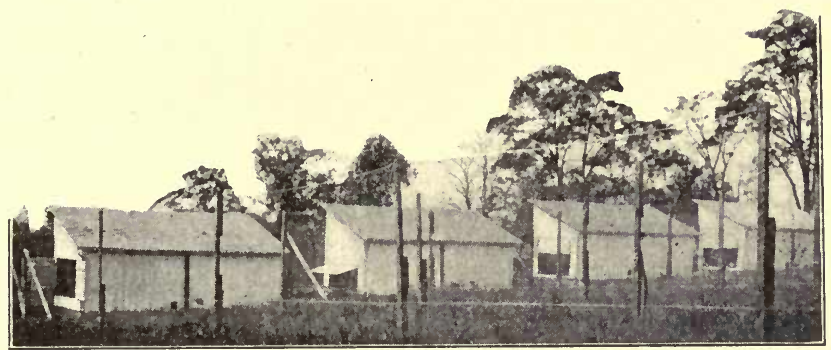

FIG. 54. Poultry houses and yards.

West Virginia Agricultural Experiment Station.

more or less trouble by flying over the fences, although the latter may be as high as seven feet.

In latitudes where it is not necessary to provide warm houses for protection against freezing, many small portable houses in a field of considerable size are preferred to more pretentious stationary houses with permanent yards. It is true that the labor of the attendant in feeding is somewhat increased, but considerable labor is saved in cleaning and cultivating the land by merely moving the 
buildings a short distance. The houses are usually constructed on rude and inexpensive runners, and are moved from place to place by means of horses. Small, light houses, that are used chiefly for shelters and roosting places, can be moved readily short distances by one or two horses if suitable provision be made for such moving when the houses are constructed. Many poultrymen prefer this method, that they may avoid cultivating the yards and yet secure fresh, clean runs for their fowls. 


\section{CHAPTER VIII}

THE IMPROVEMENT AND BREEDING OF FOWLS

As a dairyman would make a serious mistake in selecting cattle for his dairy if he should draw from any but the noted dairy breeds, so the poultryman or farmer would make an equally serious mistake if fowls were chosen that were not specially adapted to his purposes. The ultimate success of a business depends largely on the skill of the manager in selecting the proper agents or machines to do the work. If inferior agents are used to produce a merchantable article, either the article produced is not first-class or the cost of production is not reduced to a minimum. In either case the producer is not able to compete successfully with those who have a better equipment.

\section{SELECTION}

The importance of choosing a suitable breed or variety for a special purpose is likely to be underestimated. Apparently the same importance is not given to differences between the useful breeds of fowls that is recognized between the different 
breeds of cattle and horses. In reality, as great differences exist. The importance of a proper selection is still further emphasized when the conditions under which the fowls are to be kept are taken into consideration. Some fowls will thrive fairly well under conditions that would not prove adequate for the profitable maintenance of others. Too often a particular variety is selected for farm use because some fine-looking or profitable flock has been seen which has created a desire in the mind of the visitor to possess a similar flock. This is sometimes done without considering the special purposes for which these fowls are to be kept, and perhaps without taking into account the conditions under which the flock is to be maintained, even though these conditions differ materially from those under which the admired flock existed.

The great variety of fowls now bred in this country offers to the poultryman and farmer a wide field for selection. It must be borne in mind that of this great variety all are not equally well adapted to various purposes of utility. While a certain breed may give entire satisfaction in the hands of one poultry-keeper, another may find these fowls quite unsatisfactory because he is unable to give them the necessary care and to provide the conditions under which they thrive best. It may happen, therefore, that under a somewhat careless management the most noted egg-breeds may not 
prove the most satisfactory for egg production. The capabilities of the fowls and the conditions under which they are to be kept should both be taken into consideration before fowls are selected for a special purpose.

The wide-awake, progressive poultryman will ever be watchful to improve his fowls for the purpose in view, after procuring those that seem best adapted to his wants. He must not be content with merely choosing a proper flock. Selection should go on year after year, and the fowls be continually improved for the purpose for which they are kept, and under the existing conditions.

Selecting eggs.- In the attempt to still further increase the productiveness of his flock it will be well for the poultryman to study carefully, or at least as best he can, the accomplishments that have already been achieved along the lines of increased egg production and the manner in which these improvements have been brought about.

It will not be questioned that the most prolific fowls of today are, as egg producers, greatly superior to the wild fowls from which they have descended. And also that marked improvement has been made well within the memory and even practice of poultrymen who are now maintaining flocks of fowls for market products. Lessons drawn from these achievements cannot fail to be of value to one who aims to still further improve the medium by 
means of which ordinary commercial feed is transformed into desirable poultry products. Whatever may be learned from these improvements will surely have the important quality of being practical. Imitators of the successful are following a safe guide, even though they may seem to be "making haste slowly."

Some of the noted, if not the most noted breeders and improvers of fowls for egg production, have laid great stress on egg selection. They were careful to select the best layers of the pullet year for breeders, and from these hens eggs were selected for hatching. That is, year-old hens, that were used for the maintenance and improvement of the flocks, were the best layers during their pullet year. This practice carefully pursued year after year, by these poultrymen, resulted in the steady improvement of the fowls for egg production.

Without doubt all of the improvers who have achieved success have been skilful feeders and also have provided congenial homes for their fowls. It will be impossible to say just how much of the improvement has been due to egg selection, to feed, to environment, and how much to the influence of the males; but surely the noted breeders who have secured marked improvement in egg production have laid much stress on egg selection.

Whenever it is convenient to do so, a few of the best-laying hens should be placed by them- 
selves in order that their eggs alone may be used for hatching. If it is impossible to select fowls for breeding purposes from the records of egg.production, which is the true test of the laying hen, the owner must resort to other methods. One of the best substitutes for actual performance undoubtedly is to select for strength and vigor of constitution. It is well understood that if the animal machine is not strong it will be unable to perform the greatest service. The best layers are strong, large-bodied, vigorous fowls. They are known to have strong constitutions.

If breeders are to select for vigor, they can do no better, perhaps, than to make the choice at the molting period. Strong, vigorous fowls pass through the molting period very much more rapidly than do those having a weak constitution. The robust hen that lays a large number of eggs during the year will pass through the molting period quickly, and will hardly stop laying, while the one having a weak constitution will be a long time in producing a new coat of feathers, and will not lay for many weeks. The experienced poultryman, therefore, finds this period in the life of the fowl a most excellent one in which to make his selection. The fact that the bird with a strong constitution is the most profitable for egg production may explain why the fowls of poultrymen who make a specialty of egg production average larger than the fowls of those who breed 
for exhibition. Almost without exception, the average size of fowls of flocks specially noted for egg laying is considerably larger than the average size of fowls of the pure-bred stock of that breed. As a good-sized body and a deep and broad breast are indicative of a strong constitution, so are they the requisites of a good laying hen.

If one is compelled to make a selection for egg production solely from the general conformation or appearance of the fowl, he should select deep, long-bodied birds. Those having a short underline, circular in outline, should be discarded. The feeding capacity of the hen is important, for those that are able to digest and assimilate large quantities of food are vigorous fowls and consequently can produce eggs in abundance.

At present there is a wide divergence of opinion as to the manner in which improvement has been brought about. Some of the experimenters hold that egg production in the female ancestry is not a potent factor in improvement.

*'"That the egg record of an individual hen gives no definite indication whatever as to what the probable laying of her daughter will be. Examination of hundreds of pedigree records leaves no doubt as to the truth of this fact. Individual birds with high egg records are as likely as not to produce daughters that make poor egg records, and vice

*Maine Agricultural Experiment Station, Bulletin No. 192. 
versa. From the laying record of an individual hen it is quite impossible for any one to tell whether its progeny will be good layers or poor layers."

However, the more conservative breeders are still pursuing the methods that have been productive of greatest good in the past.

Americans look very much closer to the color and feather markings than do the English. So far as meat and egg production are concerned, the English, without doubt, have the advantage. As shown in a previous chapter, it is undoubtedly much more difficult to develop two unrelated characteristics to the highest state of perfection than to develop a single characteristic. The Englishman, therefore, who seeks egg production without special regard to the color of the plumage finds it easier to reach the highest state of perfection than does the American who desires to breed fowls for egg production and, at the same time, have them true to feather.

If one must select fowls for exhibition purposes and breed them for fancy points, it will undoubtedly be best to choose some solid-colored breed or variety whose tendency to depart from the standard color is not strong. It should not be inferred that all solid-colored fowls are easy to breed true to color; in fact, some of the so-called solid colors, notably the buffs, are the most difficult to breed to perfection.

The question of securing fertile eggs for incu- 
bation is one that always gives breeders more or less concern. Some breeders are more successful than others in securing fertile eggs, and, apparently, all breeders are more successful during some seasons than others. Some breeds of fowls are noted for producing fertile eggs, while others are generally recognized as inferior in this respect. The freedom given the fowls of a flock, the vigor of the individuals, and the number of males, very largely determine the fertility. Pullets' eggs are generally not selected for hatching. It is thought that they are not so likely to be fertile, and will not produce so strong and vigorous chickens as hens' eggs.

Those who have had experience in operating incubators know that not all fertile eggs will hatch. There seem to be all grades of fertility, from the egg having a vigorous germ that will produce a strong, healthy chicken, to that having a weak germ and is practically an infertile egg. As the two extremes are united by various intermediate grades, it is impossible to draw a definite line of separation which shall divide the fertile from the infertile ones.

Fresh eggs are to be preferred for hatching, although good hatches from eggs that were kept several weeks are reported. Eggs are sometimes sent long distances and still retain their vitality sufficiently to produce a good number of strong chicks. The following is quoted from an experi- 
ment station publication:* "Where the incubator is placed in a room whose temperature is reasonably even and is properly managed, a high percentage of hatch may be expected only $(a)$ when the hens have plenty of exercise, (b) when the eggs are freshly laid."

After the male is removed, the eggs are thought to be fertile for a few days,- "from four to fourteen days" is given by some authors. The following gives the results of definite observations: "On the farm of the Ohio State University, 40 Leghorn hens which had previously been kept without males were placed in pens with the male birds February 18, and the percentage of fertile eggs observed for nine days after mating. This increased regularly from 0 , on the day of mating, to 95 per cent on the eighth day after mating. July 1 the males were removed from the pens. The fertility of the eggs was apparently not materially affected until the twelfth day after removing the roosters. . . Unfortunately the eggs were saved only fifteen days, and hence it is not shown how long hens must be removed from the male before all the eggs become infertile."

For the greatest production of eggs, males are not required except for the breeding-pen. Many poultrymen who have made a speciality of egg

*Bulletin No. 158, Michigan Agricultural Experiment Station.

†Agricultural Student I (1894), in Experiment Station Record. 
production and have won for themselves a reputation in this direction, have found by experience that males are of no use in the laying-pen, and are often a positive injury when eggs for food only are desired. Tests that have been made at experiment stations to determine the influence of males on egg production tend to show that the practice of poultrymen in excluding males is most advantageous. The following paragraph is taken from an experiment station bulletin:*

"A pen of pullets kept without a male produced eggs at about 30 per cent less cost than an exactly similar pen with which a cockerel was kept. . . In each of the two pens without male birds some pullets had begun to lay from one to two months earlier than any in the corresponding pens in which male birds were kept."

\section{BREEDING}

Heredity.-Since the earliest times of which any authentic records have been preserved, owners of live stock have made attempts to improve the animals under their charge by the art of breeding. Accounts state that the ancients recognized the principle in breeding that "like begets like," and depended on it quite as much as on any other principle. It is on this principle that the poul-

*Bulletin No. 57, New York Agricultural Experiment Station. 
tryman and stock owner depend for the perpetuation of species, breeds and varieties. In this principle is recognized the law which, within certain limits, makes offspring like their parents. The development of this theory no doubt came from a close observation of domesticated animals. Had only wild animals been observed, it is likely that the similarity of offspring to parents would have

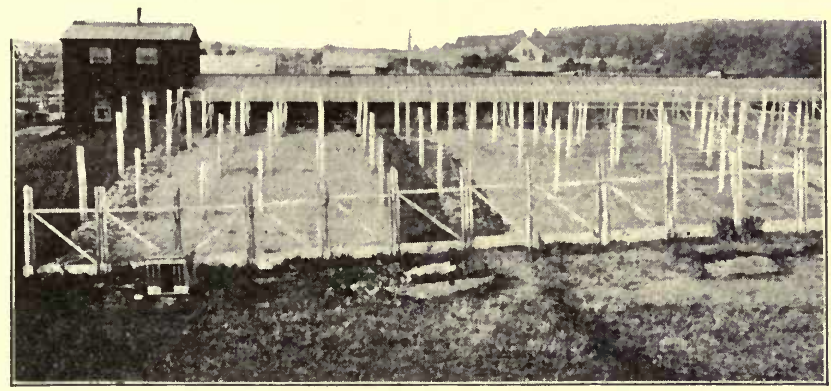

FIG. 55. Breeding and exhibition house and runs-Rhode Island Agricultural College.

been taken as a matter of course, and what is now known as the law of heredity would have been studied comparatively little.

Poultry-breeders recognize the law that offspring resemble their parents within certain limits, and depend upon this law more than upon any other as the foundation upon which the improvement by breeding depends. If it were not for the law of heredity, selection would be practically of no value. If strong, hearty, vigorous parents, which 
are noted for their useful qualities, were unable to transmit their desirable traits, it might be quite as profitable to breed from the most useless of animals. In other words, the value of selection depends upon the ability of the parent to impress its own characteristics upon its offspring. That characteristics are transmitted to a certainty, within certain limits, is evident to all. Were this not true there would be no continuity of species, and plants and animals would not "bring forth after their kind." A description of one typical Clydesdale horse will apply to all Clydesdales.

Variation.-It has long been recognized that there is a tendency to vary within certain limits, and that this tendency is always present in all classes of animals, whether wild or domesticated. The fact that wild birds and animals possess sufficient individuality to make them readily recognizable by each other is adequate proof that these animals are not precisely alike in all respects. We readily distinguish the differences between individual members of our herds and flocks, although all members of a flock or herd may have sprung from the mating of two individuals, and therefore have the same lineage. It is more difficult to observe the differences in wild birds and animals, yet such differences exist sufficiently to show that the law of variation is universal and constant in its action. It has been said that "no two animals are exactly alike in all respects." 
The tendency to vary is transmitted from parents to progeny in the same way that other peculiarities are transmitted. This has often been of the greatest importance in the improvement of fowls, mammals and plants. Breeders who are trying to improve their stock are continually endeavoring to bring the law of heredity into force so far as desirable characteristics are concerned, and as continually striving to prevent the operation of the law so far as undesirable characteristics are concerned.

The fact that animals vary permits of an individual being an improvement on its parents. If this individual is allowed to transmit its good characteristics, improvement may be attained. Without progressive variation breeders could not secure improvement. Probably all they could do would be to prevent deterioration.

If a breeder is trying to improve his flock, he looks closely for those individuals that show the greatest tendency to vary. These individuals he selects for breeding stock. He finds that their young vary considerably. They do not closely resemble each other, nor do they closely resemble their parents. If an abundance of good food and congenial surroundings be provided, he may expect, in the course of a few generations, that some individuals will show a marked tendency to vary in the direction of improvement. By judicious mating, 
some or all of the desired improvements may be transmitted and rendered permanent. The improvement of breeds consists essentially in fixing the desired variations.

Poultrymen usually. look to the male for the greatest tendency to vary.* Consequently in many improvements and in the development of many new breeds the male leads. As a rule, the males

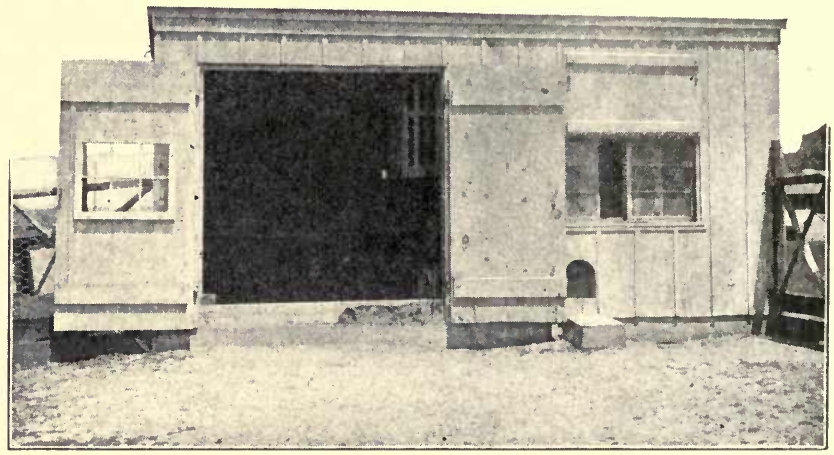

Frg. 56. An inclosed scratching-shed, an excellent plan-Rhode Island Agricultural Experiment Station.

of a breed or variety differ more from one another than the females differ from each other. The young more nearly resemble the female than they do the male. It is also observed that the organs most highly developed in the male differ more than do the organs which are most highly developed in the female,- that is, the comb, wattles, and tail, which are most highly developed in the male, differ more 
than those parts which are most highly developed in the female. The improvement of domesticated fowls depends upon the transmission of desired characteristics which have been produced through the action of this law or fact of variation.

In-and-in-breeding.-This term is often used in a rather loose sense to indicate the breeding together of animals which are more or less closely related. It is generally used, however, to indicate the breeding together of animals that are closely related for several successive generations; and in this sense it is used in this discussion. As breeders have not agreed on an exact definition of in-and-inbreeding, there is a considerable difference of opinion as to just what the term implies. Some breeders hold that the term implies only the mating of animals of the closest relationship, while others strenuously maintain that more distant relationship should be included. It is held by some that breeding together animals which have a more distant degree of relationship than that known in the human family as aunt and nephew or uncle and niece, should not be recognized as coming within the meaning of this term. On the other hand, others are emphatic in including more remote relationship.

In-and-in-breeding has played a most important part in the formation of breeds and also in the improvement of breeds that were well established. As variation and selection enable the breeder to 
produce individuals of superior merit, he will naturally try to perpetuate this superiority and to reap the advantages of it through successive generations in his herd or flock. This has been made possible through in-and-in-breeding. Almost without exception marked improvement is first noted in one or two animals. If the progeny of these animals are bred to each other or to one of their parents, the young resulting from this mating will contain a much larger percentage of the "blood" of the animal in which the improvement was noted than could be obtained in any other way. Consequently the chances that the improvement will be transmitted are considerably enhanced.

In other words, in-and-in-breeding enables the breeder to accumulate or "pile up" the blood of a superior animal in the descendants of this valuable individual. To make use of an illustration, it may be supposed that $A$ and $B$ represent two animals of the same breed and that $\mathrm{A}$ is of superior merit. If these animals are mated, the blood of the progeny will be represented by one-half $\mathrm{A}$ and one-half B. If A be bred to one of the progeny; the blood of the offspring of the last union will be represented by three-fourths A and one-fourth B. This practice may be repeated in succeeding generations and would be accepted by all as in-and-in-breeding. As the percentage of blood is increased the improvement is more likely to be perpetuated. 
While in-and-in-breeding serves a most useful purpose, under certain conditions, it should not be forgotten that it may also cause deterioration in various ways. A commonly accepted belief is, that the practice of in-and-in-breeding may result in a reduced constitution, may weaken the mental vigor, reduce the size of the individuals and make them less prolific. Many instances might be cited to show that any one or all of these evils may accrue from in-and-in-breeding, and it is also true that any one or all of these evils will not be produced to a certainty by this practice.

It is recognized that both good and evil results may follow the practice of in-breeding, but it is not generally accepted that the good or evil results are in proportion to the degree of relationship between the animals mated. If in-breeding is to be practised, the degree of relationship should not be the determining factor. A more rational selection is based on the individual merits of the animals to be mated. When related individuals are to be bred together, the selection should be made on the suitability of the animals to each other and not wholly on the degree of relationship.

The safety with which in-and-in-breeding may be practised will depend largely on the skill that is used in selecting the related animals that are to be mated, and on the extent to which the practice is carried. The skilful breeder will be able to derive 
many benefits, and will cease the practice before positive injuries accrue. It may safely be asserted, that promiscuous or indiscriminate in-and-in-breeding should not be practised.

Farmers sometimes select from their young fowls the best cockerel to head the flock the next year, and hold that as long as they are breeding from their best stock, improvement should follow. In so doing, they perhaps forget that the weaknesses are more likely to be multiplied in the progeny than the desired characteristics.

Anything like general or flock in-and-in-breeding should not be attempted; neither should in-and-inbreeding be practised by any except careful and keen observers who have a good knowledge of the animals with which they are dealing and are able to detect tendencies for good or evil at an early stage of development.

Cross-breeding. - This may be defined as breeding together animals of two distinct breeds. For many years cross-breeding was a favorite method, and probably became popular because of the frequently observed fact that increased vigor was imparted by it. During the eighteenth century, animals were frequently cross-bred, which, undoubtedly, produced in the progeny a plasticity of constitution and well prepared them for the hands of skilful breeders who later attempted to improve them. Crossing does not always bring improvement, 
although there seems to be a somewhat prevalent idea that such improvement necessarily results. While certain breeds may be crossed and will thus produce increased vigor in the progeny, yet there is frequently a tendency to reversion. That is, the progeny will resemble a remote ancestor, perhaps one of the original breeds from which the improved animals were descended. Charles Darwin bred a Black Spanish and a White Silky together and in the second generation secured a fowl that very much resembled the wild Jungle Fowl of India, from which domesticated fowls are supposed to have descended.

Whenever a cross is made between individuals of distinct and well-established breeds, reversion is most likely to occur. That is, the blood of certain distinct breeds does not blend well. It is said that a well-established white breed crossed upon a black one that is equally well established, is quite as likely to produce copper-colored chicks as black or white, or a mixture of the two. There seems to be a greater tendency to reversion whenever violent crosses are made.

There is a somewhat prevalent idea that if a fowl that has certain good qualities be crossed on one having other good qualities, the offspring will have the good qualities of both. This is a most serious mistake. In fact, the poor qualities of both parents are even more likely to be seen in the off- 
spring than are the good qualities of both. Some authorities state that the poor qualities of both parents are more likely to be seen in the offspring than the good qualities of either.

When we consider that the characters of the parents that are most likely to be transmitted to the offspring are those that are common to both parents, we can understand that when the improved characters of the parents differ widely the unimproved characters that are common to both are most likely to be transmitted.

There is much controversy over the influence of a preceding sire on the offspring. Some breeders hold that in mammals if a pure-bred female becomes pregnant by a mongrel she is forever after incapable of bearing pure-bred offspring. Poultrymen, however, do not hold such extreme views. It is doubtful whether it has been clearly shown that the breeding qualities of a pure-bred hen have been injured by a previous mating.

Cross-breeding has rendered a great service in the formation of new breeds. The Plymouth Rocks and Wyandottes are familiar examples of breeds formed by crossing well-established breeds. It is of doubtful economy to cross pure-bred fowls of well-established races, except for special purposes which will rarely be of service to the general farmer. It may happen that skilled poultrymen will find it to their advantage to cross distinct breeds for 
the production of a speciality which has become quite famous. Successful practices of this kind are comparatively few, and are of foremost interest to the specialist. Whenever pure breeds are crossed it is for the production of a merchantable product, and the use of these fowls for the production of purebred stock is therefore lost.

Breed pure-bred stock.-The question is frequently asked whether it will pay to breed pure-bred stock. If the answer is made candidly and honestly it must be given as both affirmative and negative. It certainly will pay to breed pure-bred stock if proper food, care and management be given. It probably will not pay the average farmer to invest in expensive pure-bred stock and to keep this stock in the way in which the fowls of mixed breeding are generally kept throughout the country. As the purebred stock had received superior advantages in order to bring it to its greatest usefulness, so must it receive advantages which the common stock of the country does not receive if it is to remain superior. In other words, the common stock of mixed breeding throughout the country is practically equal to the thoroughbred stock that is kept under the same conditions for any considerable length of time. If neglect and improper feeding are not to enter into the problem, the pure-bred stock will, undoubtedly, give by far the best satisfaction. The grainraiser finds that a certain variety of grain is hardy 
and is recognized as "sure," that is, it rarely fails to bring a reasonable crop, yet under the most favorable conditions would not produce a maximum crop. Under the most favorable conditions other varieties may outyield this hardy one, but under adverse conditions would not be able to withstand the severe test endured by it. So we find pure-bred stock, in some respects, resembles the improved and more productive but less hardy varieties of grain. Under the most favorable conditions the pure breeds will, undoubtedly, prove most remunerative. Under adverse conditions, where hardiness is the all-important consideration, the useful qualities cannot remain so highly developed.

It is frequently said that if pure-bred stock is good for anything it should prove superior in the same conditions under which common stock is usually kept; but the owner of common stock says that he does not believe in pampering his fowls. This is a serious mistake, and one that frequently prevents the true appreciation of improved breeds. It should not be forgotten that the best of improved breeds have reached their superiority through years of skilful feeding and breeding. Food has always played an important part in the formation and improvement of all noted useful breeds. Abundant feeding and good care have produced an organization that is capable of digesting and assimilating large quantities of food and turning it to good 
account. That is, the machine is an economical one and strong enough to do much work. The farmer who invests in pure-bred stock and gives it the same treatment that has maintained for years an indifferent lot of fowls finds the improved stock satisfactory at first, but succeeding generations become more and more unsatisfactory until they reach the level of the common stock, which was the highest standard that his care and feeding could maintain. Such breeders stoutly maintain that it does not pay to breed pure-bred stock.

Improved breeds are the best, and should be selected whenever it is possible to give them proper food and care. While they may not prove greatly superior under adverse conditions, yet they respond so much more quickly to improved conditions that those who are able to care properly for their fowls will derive much greater profit from the best than from the ordinary. Improved breeds are most remunerative when an abundance of suitable food is provided, and the fowls are given care conducive to the particular purpose for which they are kept.

\section{IMPROVEMENT OF COMMON FOWLS}

If it is desired to improve the fowls of the farm without the outlay of any considerable time or money except that which is to be given in providing better food and environment, perhaps the most 
satisfactory way is to use a pure-bred male. This method enables the farmer or poultryman to change at once one-half of his breeding flock to pure-bred stock so far as influence on the progeny is concerned. From the breeders' standpoint the male constitutes one-half of the flock, and under the average existing conditions this will probably be a fair statement of the male's influence. Undoubtedly there are many instances in which the male's influence is very much greater than the combined influence of all the females of the flock. Instances of this kind are more likely to be seen when the male is a wellformed, strong, vigorous bird, from equally wellformed, strong, pure-bred ancestors. If these conditions have existed for several generations, the importance of the male is all the more marked.

If the females are of mixed or no particular breeding, their influence is likely to be far less than that of the male. So it may be safely said that the influence of a strong, vigorous, pure-bred male, introduced into a flock of females of mixed breeding, will be at least equal to that of all the females in a transmission of parental characteristics. The progeny from a well-bred male and females of mixed breeding are generally quite uniform in form and color. Many a farmer's boy has been delighted with the sudden improvement of a flock of fowls by the introduction of a pure-bred male. In fact, many of them have found that the progeny of this breed- 
ing have proved to be the most desirable fowls for the farm. Some of them, to their sorrow, have tried to maintain the fine appearance and highly useful qualities of these fowls by selecting breeding stock from the general flock. Consequently, the next generation was less satisfactory and the third and fourth were disappointing. This condition has been most noticeable when the pure-bred male and the more or less indifferent females have represented quite marked differences in type. Instead of selecting a male from the general flock, another pure-bred male of the same breed as the first should have been secured. This process is known in stock-breeding as "grading up." The larger the proportion of pure-bred blood the higher the grade.

In breeding for egg production it is held to be of great importance to select males whose female ancestors possessed the desired characteristics to a marked degree. The fact that the characteristics of our fowls are transmitted through the male makes it comparatively easy for the poultryman to improve his flock through the introduction of superior pure-bred males. It is held by some that egg production, which is a reproductive function, is transmitted almost wholly through the male. However, the conservative breeder will be slow to entirely give up certain practices as to selection that in the past have apparently been potent factors for 
good, and place his whole dependence on the influence of the male.

A rational method of improving a flock of fowls is first to choose with great care the breed for the purpose; from this breed pick a strong, vigorous, pure-bred male, and mate him with the best hen; from the progeny of this mating select the best females, to place with another vigorous, pure-bred male of the same breed as the first. This operation should be repeated each year, and eventually the fowls will have all the characteristics of pure-bred fowls. The yearly choice of a pure-bred male should be continued.

It is undoubtedly best to breed from unrelated stock so far as possible. It may also be safely said that if the greatest improvement is to be made, only-mature fowls should be used for breeding purposes. Particularly is this true with the females of egg breeds. Pullets are not so desirable as hens for breeding purposes. Continued breeding from immature stock has a tendency to weaken the constitution and to reduce the size. If it is necessary to use pullets they should, as a rule, be mated with mature males. On the other hand, it is frequently desirable to mate hens with cockerels.

Breed useful fowls. - It is the object of the farmer to breed useful fowls. While the individuals may not possess the requisite fancy points to win prizes at exhibitions, yet these same individuals should 
be noted for usefulness. The most noted flocks for egg production, those that have gained a national reputation, have been selected and improved for this one particular quality to the exclusion of fancy points, on which so much importance is placed at the great poultry exhibitions. In the early history of these flocks, the surplus birds were not largely sold for breeding purposes. The reputation of these flocks had not been established, and because the birds did not possess the prize-winning fancy points, the demand for them was not equal to the supply. In later years, when the reputation of these flocks became well known, the surplus stock found ready sale at remunerative prices, solely because of their usefulness. While farm stock should receive recognition at agricultural fairs, yet it will be shown at a disadvantage when placed in competition with the fanciers' fowls, which are bred largely for exhibition. The farmer's stock should be selected and maintained for the profit of eggs and meat, rather than for the profit which the fowls may bring when sold for breeding stock.

It is quite possible that many farmers may sell breeding stock at remunerative prices, although the main object should not be to produce birds for this purpose. Whenever one depends on the sale of fowls for breeding purposes for profit, it becomes necessary to enter into competition with other breeders at the great poultry shows. This necessi- 
tates a departure from the purpose for which farm fowls are kept.

Farmers and others who maintain flocks for usefulness should not forget the importance of selection. Remember that all improvement is largely due to selection, and that after the flock is well established it can be further improved for the purposes for which the breeds are kept by rigorous selection, skilful breeding, and improved feeding. It is possible for every farmer to improve any breed of fowls for his purpose. This of course implies productiveness under certain conditions. A breed of fowls, or a flock of fowls of a distinct breed, may be brought to a high state of perfection by a poultryman, considering the conditions under which he keeps them, and under more favorable conditions they may be still further improved. 


\section{CHAPTER IX}

FEEDING FOR EGGS AND FOR MEAT

The successful poultry-keeper recognizes that not all kinds of wholesome poultry food which the market affords are equally well suited to his fowls which he keeps for the production of either eggs or meat. He lays great stress on the careful selection of food for the making of special products.

\section{FEEDING FOR EGGS}

If one desires to feed economically for egg production, and has learned little or nothing from experience, a most valuable lesson may be learned from nature. It will be observed that those fowls which are more or less neglected, and, consequently, not so far removed from the natural state, lay most abundantly in the spring. In this respect, then, the poultry-keeper may profitably aim, so far as it lies within his power, to prolong the spring throughout the year. In the spring these fowls are at liberty to roam at will and to find abundant green food in the tender shoots of grass and other plants. They find meat food in 
the form of insects, worms and other low forms of animal life. These, with grain in some form, make a most perfect food for laying hens. If the grain food is not supplied to them by the poultry-keeper, they may still find it in the form of seeds of various plants. In other words, it should be the aim of the poultry-keeper to supply the food and conditions which tend to produce eggs most abundantly. While it is true that the physical organization of fowls is such that they will be unable to maintain throughout the year the abundant supply of eggs of the springtime, yet this will be most nearly approached if the conditions are springlike the year round.

Exercise.-In the spring season the fowls that are given free range obtain abundant exercise. It is important to provide exercise for all noted egg breeds, as these fowls are active in disposition. Close confinement without exercise is not conducive to the best results, although the quality and quantity of food provided may be most excellent. While exercise is required for egg production, it is not desirable when the finest quality of meat is sought, particularly during the last of the fattening period, so that what may be said of exercise for egg production should not be applied to fattening fowls.

Quality of food.-It has been clearly shown by experiments that the food consumed by laying hens affects the flavor of the eggs. In extreme 
cases, not only is the flavor of the food imparted; but the odor as well. Onions* have been fed to fowls in sufficient quantity to impart a decided flavor and odor to the eggs. So marked was the result that persons wholly unacquainted with the experiment had no difficulty in distinguishing these eggs from those which were laid by hens fed a normal ration.

The mere fact that food influences the flavor of eggs in extreme cases, is a sufficient reason for the poultryman to reject all food that is not strictly wholesome. It has not been determined to what extent the ordinary poultry foods influence the flavor; but tainted food should not be permitted to enter into the composition of the ration. If food of high and objectionable flavor imparts its peculiar taste and odor to the egg, it is not safe for those who desire to produce a prime article to run unnecessary risks in feeding doubtful food. Pure, wholesome food is so abundant and cheap that there is no excuse for a questionable practice.

Oftentimes food of an inferior quality as to market requirements may serve a most useful purpose as poultry food, and its use would not in any way be condemned. Shrunken and cracked grain, and mixed grains that cannot be readily separated may make most excellent food, while

*From unpublished results of experiments conducted by the author, at Cornell University. 
those foods that are moldy or have objectionable odors or flavors should be avoided.

Forced feeding for eggs.-It is maintained by some authorities that, when hens are given a course of forced feeding for egg production, their period of usefulness is materially shortened. This, no doubt, may be true in some instances, when the fowls have been injudiciously fed. Experience has shown that it is possible with ordinarily vigorous animals to carry the forcing process so far that many individuals will be permanently injured. These cases, however, should be considered as extreme and do not come within the province of judicious feeding. The injury done to dairy animals by forced feeding is undoubtedly chiefly due to the injudicious feeding of unnatural foods. The injury is associated mostly with the digestive functions. While it may be possible to injure the digestion of laying hens by forced feeding, yet the danger from this practice is very much less with poultry than with other classes of farm stock. Given a suitable ration and an opportunity to take necessary exercise in pure air, the hens' judgment as to quantity will not often lead the poultryman astray.

Egg production is a reproductive function, and in this respect differs from milk production in the dairy cow. To what extent this reproductive function may be injured by feeding has not been fully determined. It has been observed many times 
that after a year of forced egg production the number of eggs laid has been somewhat decreased; that is, it is possible, by means of extra food and care, to induce fowls to lay more eggs than would be produced under good average conditions; but it is not possible to keep up the highest degree of egg production through two or three. successive years. It is, therefore, the practice of many poultrymen to keep only young birds for egg production and to force them for this product. When the hens have served a period of forced egg-laying, they are replaced by younger fowls. This method will necessitate keeping older fowls as breeding stock, which is in accord with the most approved practice.

The question will naturally arise: Will the forced feeding of young fowls for egg production lessen their vitality or in any way injure their value as breeding stock? At the present time there is not sufficient accurate experimental data at hand to warrant a positive answer, yet it is well known that many of the most successful egg-producing flocks have been built up by persistently pursuing this practice for many years.

Corn.-Of the grain foods that are usually supplied to farm poultry, corn has been, and still is, the most popular. This, no doubt, is largely due to the abundance of this grain and to its relative cheapness. If the fowls are somewhat closely confined, a corn ration is found to be somewhat too 
fattening for most satisfactory results, particularly when fed to general-purpose fowls. If this grain is supplied to the noted egg breeds that have a wide range, much more satisfactory results are likely to be obtained. It should be the aim of the poultryman to feed considerable grain in such manner as will not cause the fowls to become excessively fat. Fat fowls, as a rule, do not lay so abundantly as do those in moderate flesh. When corn is fed to laying hens that have opportunity to take plenty of exercise and to secure for themselves insects and green food, much better results will be obtained than when it is fed to the same kind of fowls closely confined. Experiments have shown that a clear corn ration, given to closely confined Leghorn hens, has resulted in a marked decrease in egg production and is sometimes accompanied by feather pulling. Feather pulling usually indicates a faulty ration. The fowls have a craving for something not supplied to them, and resort to feather eating to obtain it.

Experiments have clearly shown that food has a great influence on the color of the yolk of the egg. Corn will give deep yellow or highly colored yolks. Clear corn and water, the feeding of which would be considered an extreme case, will produce yolks which are objectionable to many consumers on account of the extremely high color. Fairly highcolored yolks are generally preferred, and a moderate 
amount of corn in the ration can be depended upon to produce the desired color.

The greatest economy in feeding fowls will depend largely upon the ability of the feeder to make the best use of corn. In supplying food for domesticated fowls, it should be remembered that three kinds of constituents should be present, in tolerably well-fixed proportions, if the desired results are to be obtained most economically. These constituents are mineral, nitrogenous and carbonaceous. Corn is deficient in both mineral and nitrogenous matter. So, whenever corn forms a considerable proportion of the daily ration, these deficiencies should be supplied in some acceptable form. Animal meal, cut bone, animal charcoal and bone ash are all used for this purpose.

Wheat.-Wheat is preferred to corn by many because it is not quite so fattening, and is, therefore, a somewhat safer food in the hands of the unskilled feeder. On account of the low price of wheat in recent years, it is becoming a very common poultry food. Wheat, when fed alone, produces eggs having much lighter-colored yolks than are produced by a corn ration. Wheat alone has somewhat too wide a nutritive ratio for best results. This grain should be supplemented by some meat food or skimmed milk in order that the proportion of protein may be materially increased. Wheat should not form all of the grain ration of laying 
hens, but when mixed with other grains it is most highly prized.

Buckwheat.-Buckwheat, like wheat, when fed alone, has too wide a nutritive ratio and produces white flesh and light-colored yolks. These are objectionable features to most Americans, but in some large cities the foreign population prefers white skin and light-colored flesh. This grain has never been so popular as a poultry food in the United States as corn or wheat.

Oats.-Oats are considered a most excellent food, and perhaps come nearer the ideal than any other single grain, particularly if the hull or outer covering is removed. This hull, being tough and woody and quite indigestible, is not relished by the fowls, although some fowls will learn to eat whole oats. Oats also tend to give the fowl lightcolored flesh and light-colored skin. On this account oats are not recommended for a finishing food, unless skin and shanks of a light color are desired.

Linseed meal.-A little linseed meal in the ground food serves a most valuable purpose, particularly at the molting period. "Hens having linseed meal molted nearly all at the same time, earlier in the season, and more rapidly."*

Green food in general.-When fowls are somewhat closely confined in yards or pens, it will be necessary to supply some kind of green food in

*Bulletin No. 39, New York Agricultural Experiment Station. 
order to obtain the greatest production of eggs. This should be given them throughout the year. The question of how to supply the best food at the least cost is one that each poultry-keeper must decide largely for himself. It will probably make very little difference what kind of green food is supplied, provided that it is relished by the fowls. If the runs or yards are large, so that fresh grass may be supplied to them during the summer months, little or no other green food will be required.

Clover, etc.-Clover cut during the early spring is perhaps one of the cheapest and best of foods. It is nitrogenous and is readily eaten when cut fine in a fodder-cutter. If clover is frequently mowed, a good quality of green food may be obtained nearly all summer, particularly in seasons of abundant rainfall. Should the supply of clover be limited, or the season prove an unusually dry one, other legumes may provide a satisfactory substitute. Alfalfa will answer the purpose well if fed to the fowls in a fresh condition. A small plot, if well established, will afford a great quantity of green food if it is frequently mowed. Young alfalfa is tender and is relished by the fowls, but when it approaches the blossoming stage it becomes more woody and is not so valuable. Canada field peas are sometimes grown for this purpose, and the peas, if fed whole while in a tender and crisp condition, are eaten readily by the fowls. 
Beets (Mangel-wurzels).-These beets make an excellent green food for the winter months. As they are easily raised and will maintain their fresh condition in an ordinary root cellar during the winter months, they fulfil many of the requirements of a practical poultry food. They may be fed by simply splitting the root length-

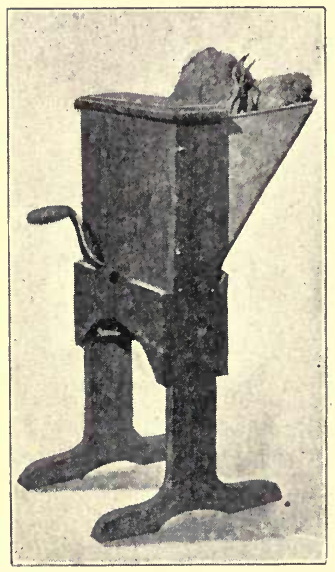

Fig. 57. A vegetable-cutter. wise with a large knife. If given to the fowls in this form, they will pick out the crisp, fresh pulp from the cut surface. Root-cutters are on the market which cut beets in fine shreds somewhat resembling earthworms in form. (See Fig. 57.) These shreds are eaten readily. Under ordinary conditions, fowls should have, once a day, about all the green food they will eat. The form in which the beets are offered is not important, provided they are consumed while in a clean, fresh condition. Unless the pieces of roots be small enough for the fowls to swallow them, large pieces like half a beet are preferable. When beets are fed from an open trough, in pieces of the size usually made by ordinary root-cutters, many pieces are likely to be scattered in the litter and more or less soiled before eaten, if eaten at all. Either very small, 
or large and practically immovable pieces, are preferred.

Cabbage.-Cabbage is relished by fowls, and is highly prized as a poultry food by many experienced poultrymen. Cabbage, like beets, should be fed in a fresh condition. It is the practice of some poultry-keepers to suspend heads of cabbage within reach of the fowls and permit them to partake ad libitum.

Rape, etc.-Rape, sea kale, and other plants of the cabbage family, which are noted for their crisp stems and leaves, furnish excellent green poultry food. Dwarf Essex rape may be sown in narrow rows and given horse cultivation. When the leaves are large enough to furnish considerable food, they may be picked and fed to the fowls. If hand-picking is objectionable, the leaves may be cut with a sickle or scythe. If cut a few inches from the ground, a second or third crop will often be produced from one seeding.

Clover hay.-If green food is not at hand for winter feeding, a good substitute may be found in steamed clover hay, particularly if it is mixed with the soft or ground grain food. It is important to have this hay finely cut. If the steamer is not at hand, the hay may be satisfactorily treated by putting it in a tight vessel and pouring on boiling water sufficient to moisten all the cut hay, permitting it to remain tightly covered over night. 
Meat foods.-Poultrymen find it to their advantage to imitate the natural food of the fowls and to furnish some meat food. Fowls that are given a wide range in the summer time feed largely on insects and earthworms; but during the winter

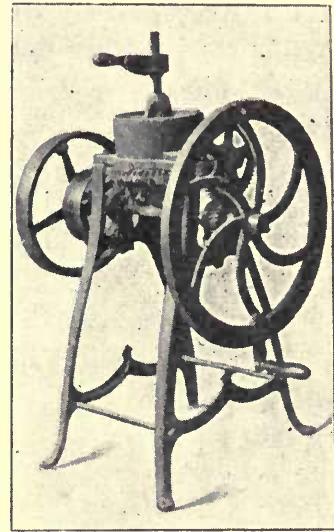

Fig. 58. A bone-cutter. months, and when fowls are confined in comparatively small houses and yards, it will be best to feed meat in some form. "Vegetable foods, even though furnishing equal amounts of all nutrients and in the proportions considered suitable, are shown to be much inferior to animal foods furnishing the same amounts of nutrients and in the same proportions." $*$

Fresh bones, which may be obtained from meatmarkets, if finely cut with bone-cutters (Figs. 58, 59 ), make one of the best, if not the best, of meat foods for laying hens. This is also excellent for little chickens. Many poultrymen, however, cannot depend upon the local meat-markets for their supply, particularly during the warm weather. After the bones have become tainted they should be rejected as unfit for poultry food. When fresh

*Eighth Annual Report, Mass. Hatch Experiment Station. 
bones cannot be obtained, animal meal may be relied on for satisfactory results. Only meal that is guaranteed wholesome should be procured. A good quality will generally contain about 10 per cent of nitrogen. This meal should be dry enough to keep well for several seasons if necessity requires.

Canned meat foods, specially prepared for poultry, are on the market. These give satisfactory results under ordinary conditions, but are usually found to be somewhat more expensive than the animal meals. Some of the so-called poultry meat foods that are preserved in tin cans consist largely of liver.

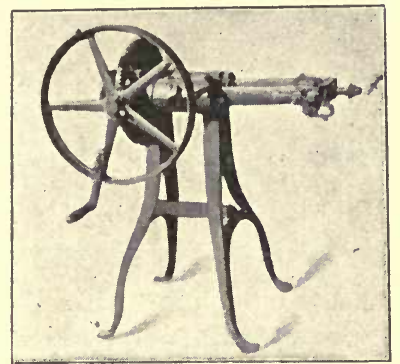

FIG. 59. Another style of bone-cutter.

Skim milk.-Skim milk may be substituted, wholly or in part, for meat food without a marked decrease in egg production, provided the proper grain ration is given. In order to substitute milk entirely for meat, it will probably be necessary to give the fowls milk to drink instead of water and to mix soft food with the milk. If milk be depended upon entirely to take the place of meat, somewhat greater skill will probably be required in feeding than if a good quality of animal meal is fed. 
Evaporated milk by-products, known as granulated milk, milk albumen and various other trade names, have been fed to fowls, both young and mature, with quite satisfactory results. These products are rich in protein and may often be used to good advantage in compounding rations.

Grit.-It is necessary that fowls be supplied with some kind of grit, which is used in the gizzard for grinding the food. Fowls at all ages, from the little chicken just hatched to the mature fowl, require grit if hard food is given them. When soft food alone is supplied, little or no grit will be required. During the summer months, when fowls have a large range, they are usually able to find sufficient grit for themselves. Small pieces of stone, cinders, etc., are eaten. Crushed limestone and crushed granite also answer the purpose admirably when it is necessary to supply grit artificially. Crushed granite, on account of its excessive hardness, is more durable than pieces of softer material. There are many poultry-supply houses that keep crushed granite in various sizes, suitable for all kinds of poultry. Crushed oyster shells will also furnish material for grinding the food, although they are not recommended solely for this purpose.

"Long or sharp splinters of glass or dry bone should be avoided. The size of particles of grit, for hens, had better be larger than a kernel of wheat and should be smaller than a kernel of corn. An 
unlimited supply of pounded glass has been attended with no bad result when the food and other grit available to the fowls contained an abundance of lime, but, when the food was deficient in lime and no other grit was attainable, hens ate an injuriously large amount of glass."*

Lime.-Many experiments and also chemical analyses of foods and of eggs show that there is not sufficient lime consumed by the fowls, in ordinary poultry foods, to form the shells of eggs produced by laying hens, particularly when they are producing eggs most abundantly. It is therefore necessary to supply lime, in some form, to laying hens. Crushed oyster shells are recommended for this purpose. It is found to be satisfactory to place the crushed shells before the fowls in such a manner that they may eat the amount needed, and it is usually safe to rely on the judgment of the fowls in this respect. Some poultrymen, however, mix crushed oyster shells with the soft food in addition to the supply which should be kept before them all the time. "The feeding of oyster shells during the laying season, when they can be cheaply obtained, is recommended. One pound will contain lime enough for the shells of about seven dozen of eggs. Fine gravel containing limestone will probably as well supply the deficiency of lime existing in most foods,

*Bulletin No. 38, New York Agricultural Experiment Station. 
but the use of some sharper grit with it may be of advantage."**

Salt.-A little salt is undoubtedly beneficial and necessary, but it is poisonous if taken in large quantities. Instances are frequently reported of fowls being injured by eating salt. They are undoubtedly frequently misled in eating it, supposing that they are eating grit. Rock-salt is particularly dangerous on this account. Some instances have been known of fowls being poisoned by eating salt fish which had been carelessly thrown where they could gain access to it. When fowls have a wide range they eat grass, insects, and many other things that furnish salt in some quantity. This may explain why it is not necessary to feed salt under these conditions.

Experiments made at the New York Agricultural Experiment Station showed that salt was not injurious in quantities below .063 ounce per day for each hen (that is, nearly one-half pint per day for 100 hens). The following, taken from Bulletin No. 39, gives results of the experiment: "The number of eggs laid during this trial is of no great significance, as it was about the end of the laying season and the hens were old; but, inasmuch as the yield of eggs was twice as great from the hens having salt, while it was mixed with the food, it would appear that not enough was fed to very

*Bulletin No. 38, New York Agricultural Experiment Station. 
injuriously affect egg production. The salt used was ordinary barrel salt, although not coarse. Should rock-salt be exposed, or salt that contained large crystals or fragments as large as the particles of gravel and grit eaten by hens, it would of course not take long for a fatal amount to be swallowed. For mature fowls it is probable that salt at the rate of one ounce per day for 100 fowls could, under ordinary conditions, be fed without injury."

Sulfur.-Sulfur is generally recognized as a blood purifier, but should not be fed in any considerable quantity unless its action is well understood and precautions are taken to guard against any undesirable results. It is generally recognized that fowls take cold easily when fed sulfur.

Pepper.-Pepper is sometimes given to fowls suffering from cold or in the first stages of roup. This is a stimulant and is sometimes given to improve digestion. It is the general opinion, however, that it is not necessary to feed it if the proper conditions are maintained.

How to feed.-If those who have the responsibility of providing food for fowls and other stock will bear in mind that food is given for a twofold purpose, it will help them to appreciate the importance of a bountiful supply of the proper kind. Food sustains the physical organization of the fowl and furnishes material for a useful prod- 
uct in the form of eggs or meat, or both. It may also be considered largely as the basis of improvement in breeds and varieties, and is often spoken of as the cause, and breed as the effect. While this may not be strictly true in all cases, yet all authorities believe that food has been a most potent factor in the improvement of breeds-if not the chief cause.

The profit in feeding comes from the food consumed in excess of that required for the maintenance of the body. If the individual makes good use of the food consumed, that which is not required for maintenance should be directed chiefly toward the production of merchantable articles. It should not be held, however, that all of the food consumed in excess of that required to maintain the body may be devoted to the production of eggs or meat. As the ration is increased, the work required of the fowls to digest and assimilate this food is also increased. So no matter whether the animal be a hen or a cow, the physical organization is required to do more work on a full ration than on a light one, and food is required to supply energy for this increased work.

There is little danger of overfeeding laying hens if the proper kind of food is given. The difficulty lies in not being able to secure fowls that are. sufficiently strong to digest and assimilate enough food to give the greatest profit. A strong 
tendency toward egg laying, a vigorous constitution, and an abundance of suitable food, are three prime essentials for profitable egg production. Other things being equal, those fowls that are able to digest and assimilate the largest quantities of food will prove the most profitable.

It is the practice of some successful poultrymen to feed a part of the daily grain ration ground, and moistened with either milk or water. It is held to be more economical to do a part of the grinding by steam or water power than to require it all to bedone within the body of the fowl. In other words, water or some other power is thought to be cheaper than the muscular power of the laying hen. It is true that the hen is required to take considerable exercise, but this exercise does not materially aid in grinding the food.

Some experiments have been made which tend to show that there is considerable to be gained in feeding ground or soft food. The following is taken from an experiment station publication:* "Two pens of laying hens, one of a large and the other of a small breed, having a ration the grain of which was whole, ate during their second year somewhat more food at a little greater cost than two similar pens having a ration in which half the grain was ground and moistened.

"Cochin hens having the whole grain ration

*Bulletin No. 106, New York Agricultural Experiment Station. 
laid much better than those having the ground grain, although neither lot laid at a profitable rate during the second year. Leghorn hens having a ration in which the grain was whole, consumed on the average for two years over 20 per cent more food for the same egg production than did similar hens having half the grain in their ration ground and moistened. The hens having whole grain had on the average for two years 6.4 pounds of water-free food for every pound of eggs produced. Those having ground grain had on the average for two years 5.3 pounds of water-free food for every pound of eggs produced."

Poultrymen do not agree as to the time of day when the soft food should be fed. Some hold that such food should be given in the morning, for the reason that the fowls have been on the perches during the night and have largely digested the food which was consumed the day before, and consequently have comparatively empty crops and digestive organs. In order that the morning meal may be rapidly and easily digested they feed only ground and moistened grain. They also hold that, if the fowls are to be fed three times a day, whole grain should be fed at noon and at night. Other careful observers maintain that whole grain should be given in the morning and that the ground food should be given at noon. It is probably more important to feed a part of the grain food in a ground 
or soft condition than it is to feed this food at any particular time of day.

All poultrymen believe that it is important to give the laying hens considerable exercise, particularly during the winter months, and when they are more or less closely confined. This may be accomplished, in part, by requiring them to scratch in the litter for their grain food.

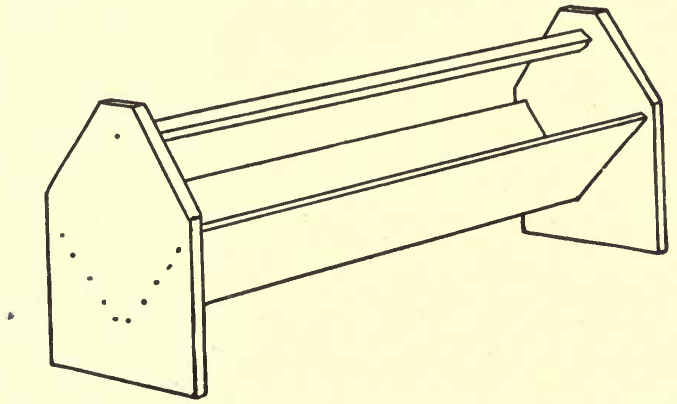

FIG. 60. Feed trough protected by a revolving rod.

Equal parts of corn and oats ground, mixed with an equal weight of wheat bran and fine middlings, make an excellent soft food when moistened with milk or water. That is, the bran and fine middlings together constitute one-half the weight of the ration. The proportion of bran and fine middlings may be varied somewhat. If the mixture appears too sticky, less middlings and more bran should be used. It is usually preferred thoroughly wet; that is, enough milk or water 
should be added to the ground grain to. wet all of the grain after it is thoroughly stirred. It will be necessary to feed this food in troughs. Considerable ingenuity has been exercised in devising convenient troughs that will keep the food clean. A swinging trough, or one protected by an easy-turning rod, as shown in the illustrations, will answer the purpose very well. (See Figs. 60 and 61.) Any safe and convenient arrangement that will prevent the

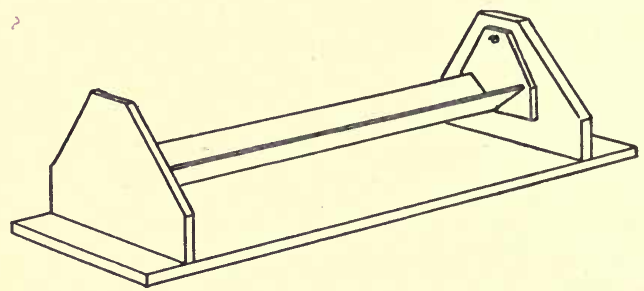

FIg. 61. A swinging feed trough.

fowls from perching on the sides of the troughs will meet the requirements of a satisfactory device.

Many poultrymen prefer to feed animal meal in this soft food. From one to two pounds of animal meal per day should suffice for twenty-five hens, particularly if milk is used to moisten the ground grain. A little linseed meal, which is particularly valuable during the moulting period, may also be added. Horsemen have long known that when animals are shedding their coats a little linseed meal added to their ration hastens the shedding of the old coat and gives more luster to the 
new, and so poultrymen find that a little of this meal during the molting period aids in the production of a new coat of feathers.

The practice of feeding the mixed ground grain in a dry condition has become popular with many poultrymen. After extended trials it has been found to be particularly well adapted to laying hens. This feed is often spoken of as "dry mash" and should constitute about one-third by weight of the total grain food consumed. This "dry mash" is fed from a hopper that is kept open before the fowls for a part of the day only. The following rations are recommended by the Poultry Department of Cornell University:

\section{Grain}

Winter Ration

Lbs.

Wheat................................60

Corn...............................60

Oats.....................................

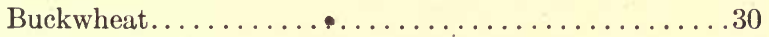

Summer Ration

Wheat .............................60

Corn ..............................60

Oats....................................

Ground Feed "Dry Mash"

Corn meal ...........................60

Wheat middlings .....................60

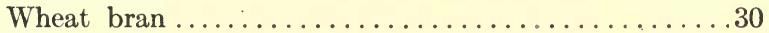

Alfalfa meal............................. 10

Oil meal ...............................10

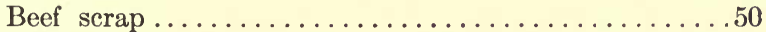

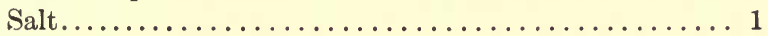


The whole grain should be fed once or twice a day and scattered in the litter during the cold months or whenever the fowls do not have ample opportunity to take exercise out-of-doors. This grain may be scattered in the litter and given in such quantity that the fowls will eat it up clean. In fact, they should not be given quite all they want to eat. They should be made to scratch over the litter and pick out the last kernels. At night, about an hour before they go on the perches, the last meal of the day may be given them. This should be given in such quantities that it will all be consumed and still afford the fowls about all they care to eat. In other words, they should go on the perches at night with full crops. During the night they have nothing to do except to digest and assimilate the evening meal.

Litter.-Straw, either cut or whole, makes a good litter for poultry houses for both winter and summer. Hay may also be used for this purpose if it is more convenient or cheaper than straw. Buckwheat hulls are preferred by many on account of cheapness. In the vicinity of mills, where large quantities of buckwheat are floured, buckwheat hulls may be obtained cheaply. Shredded corn fodder makes satisfactory litter, although it is somewhat more expensive and answers the purpose no better than straw. During the winter months, the floor of the poultry house should be covered 
to a depth of a few inches with some kind of litter. This litter should be changed whenever it becomes soiled or damp.

FEEDING FOR MEAT OR FATTENING

Feeding fowls for meat production may properly be discussed under two rather distinct heads so far as exercise is concerned: Fattening mature fowls, and feeding young growing fowls that are to be sent to the market when a few months old. Mature fowls will require little or no exercise during the process of fattening, while young fowls that are growing rapidly will require considerable exercise in order to keep them in a healthy and vigorous condition, except perhaps for a short time during the last of the fattening period, which is sometimes called "the finishing."

Whenever a choice quality of meat is to be produced, little or no exercise should be given for a few weeks immediately preceding the killing. When the fowl is shut up or closely confined, the muscles soften and the flesh becomes more tender. It is conceded by those who most highly prize tender flesh that close confinement; without exercise, greatly improves the quality. It is also true that fowls under these conditions take on fat rapidly if the close confinement is not continued too long. Little exercise, with plenty of pure air and an abun- 
dance of soft food, are among the chief essentials for economical fattening. If it is desired to fatten fowls as quickly as possible, the ration should consist largely of corn. Ground oats, wheat, buckwheat, and barley may also be used to some extent. A variety of foods undoubtedly will serve a good purpose in maintaining a good appetite somewhat longer than could be maintained with but one or two kinds of grain. After fowls have been kept for some time on soft food, whole grain cannot form a considerable portion of their ration without a loss. The organs for grinding and digesting hard food have been so long in disuse that they are quite unfitted to perform the office required of them when hard or whole grain is provided.

The kind of food and the form in which it is to be given will depend somewhat on the kind of fowls. Some successful poultrymen, who make a specialty of young fowls of fine quality, are accustomed to feed animal meal in such proportion that it will form 10 to 20 per cent of the total ration. No one would think of using so large a proportion of animal meal in compounding a ration for fattening matured fowls. In one case, the object is to produce large quantities of tender flesh; in the other, to improve the quality of the flesh by confinement, and to induce the fowls to fatten readily.

Separate the sexes.-The sexes should be sep- 
arated before the fattening period begins. It is always advisable to have the individuals as nearly uniform as possible as regards age and size. Uneven flocks are not nearly so satisfactory to feed as uniform ones and are quite as unsatisfactory to sell, particularly if they are sent to market alive.

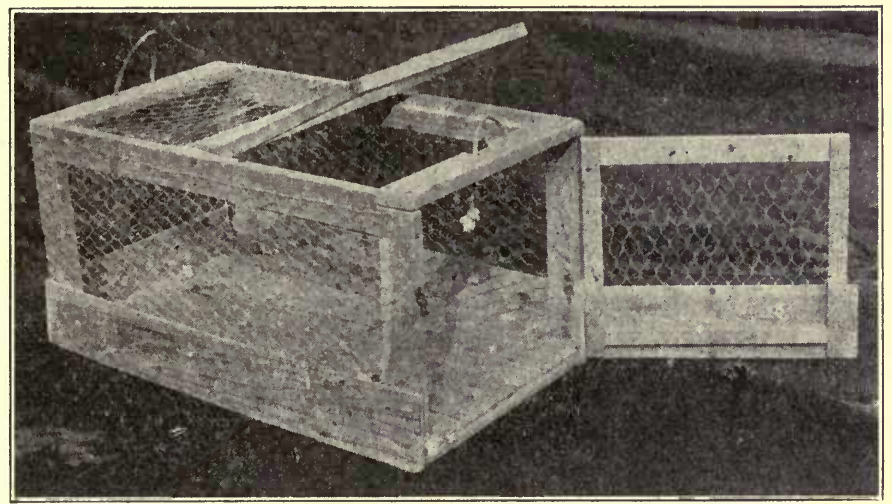

Fig. 62. A handy crate for carrying live fowls.

If it is desired to fatten cocks or cockerels that show a disposition to fight, they should be confined in coops which are provided with slat bottoms or bottoms made of poles near enough together so that the fowls cannot drop between them. These coops should be placed at some distance from the ground, so that the droppings will not foul them. While attempts may be made to fight, yet as one or both of the combatants will almost surely step between the slats the combat will not be carried far. 
Cramming.-The English and French resort to the system of forced feeding, known as cramming, for the production of the choicest poultry for the London and Paris markets. The English learned this process from the French, and now carry it on to a large extent in some parts of southern England. The Heathfield district in Sussex County,

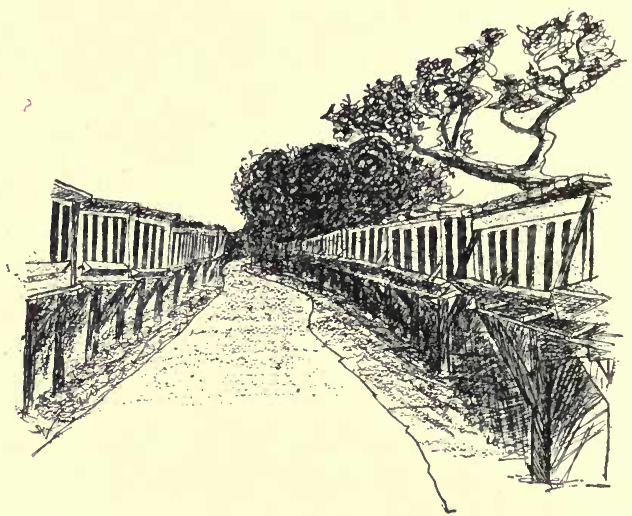

FIG. 63. An English method of arranging coops, where cramming is practised.

England, is noted for the large quantities of poultry that are fattened for the London markets by this process. Young birds four or five months old are placed in coops, which are raised about three feet from the ground. These coops have slat sides and bottoms and are protected from the weather by a roof. Each coop is large enough to hold comfortably four or five birds. (See Fig. 63.) For the first ten days after placing the fowls 
in the coops, they are fed twice a day soft food from little troughs suspended within easy reach. After they have eaten all they will, the troughs are removed and no food is offered until the next meal. The food consists largely of ground oats, with the hulls removed, and ground barley. To this is added a little tallow so that each fowl may receive about a teaspoonful a day. The fowls are fed in this manner for about ten days, at the end of which time they will not eat so much on account of loss of appetite. They are then fattened by the cramming process,

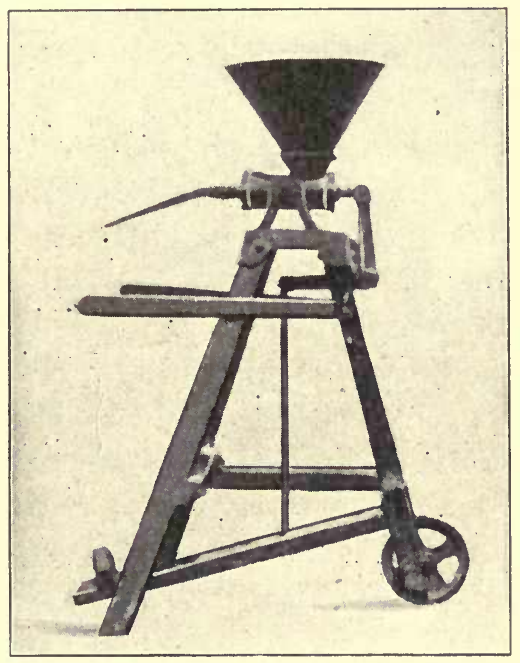

FIg. 64. An English cramming machine. the food being forced into the crop by means of a machine. Fig. 64 illustrates a cramming machine similar to those used in the great poultry districts of England. The food is mixed with milk or water to the consistency of thick porridge; that is, just about as thick as it will pour well. This is placed in a receptacle or hopper in the machine and is 
forced through a rubber tube into the crop of the chicken. This tube is forced down the chicken's neck and a light pressure on a lever with the foot forces the food, while the hand on the outside of the crop will detect the proper quantity. Men operating this machine become very skilful. A good operator can feed thirty dozen fowls per hour. This cramming process is continued for about ten days, when the fowls are dressed and sent to market. During the major part of the fattening season the coops are placed out-of-doors. (See Fig. 63.) When the weather becomes too cool, indoor coops are used.

Before fowls are placed in fattening-pens they should be given a thorough dressing of sulfur or some other insecticide to kill the vermin. This is particularly essential, as the fowls kept in coops have no opportunity to combat these pests. Laying hens and other fowls should be provided with dust-baths, but when fowls are placed in close confinement for fattening, it is not feasible to provide baths. Cleanliness is of the utmost importance for these confined fowls. The coops or cages of fattening fowls should not be allowed to become filthy, neither should they be too hot in summer or too cool in winter.

The French and English use oats and buckwheat largely as fattening foods. They prefer fowls having light-colored flesh with white skin. 
Americans prefer yellow skin and flesh. Corn is, therefore, to be preferred in this country as a fattening food to wheat, barley, or buckwheat. It not only produces the desired product but is the cheapest food that the market affords.

Fattening by means of cramming has been tried in several places in this country, but without pronounced satisfactory results. The American market does not demand so excessively fat fowls to bring the highest prices as do some of the great markets of Europe. Some experiments tend to show that almost equal gains in weight may be obtained by ordinary methods of feeding to those gained by cramming. The gains in weight by the cramming process are due mostly to the addition of fat, while the ordinary methods produce more flesh. 


\section{CHAPTER X \\ INCUBATORS AND BROODERS}

Whether it is best to use incubators on farms where only small flocks of fowls are kept, is often a difficult question to decide, particularly for those who are familiar with only the natural method of incubation. As the adoption of modern methods includes not only the purchase of an incubator and a brooder to care for the young fowls, but also carries with it a marked change in their management, it is a question of considerable importance.

One frequently hears it said that if success is to be attained, new and "up-to-date" appliances must be used, and that old methods are too slow for the present age. In one sense this is undoubtedly true, but when seen from another viewpoint it becomes very misleading. It is true, and probably always will be true, that in order to achieve success in any line of work one should employ the best means at his command. This does not prove, however, that because the modern incubator is a new invention and has proved to be a great advantage to many, it is best for every person who desires to keep fowls to purchase one. Many 
incubators have been purchased that have been little used.

\section{INCUBATORS}

Before an incubator is purchased for the farm, it should be understood that it will be necessary to devote more time and labor to its management than is usually given to natural incubation. Even the most successful and experienced poultrymen feel that there is yet much for them to learn, in order to accomplish the best results with modern appliances for hatching and rearing the various kinds of farm poultry. The successful management of incubators requires close attention and the best thought of the operator. In other words, it is a business that should be thoroughly learned. It should not be entered into with the idea that it is a simpler or easier method of hatching eggs than the older and rather slow method of natural incubation.

If only small flocks, consisting of from fifty to one hundred fowls, are to be kept, probably it will not pay the farmer who expects but a small cash revenue from his fowls to attempt artificial incubation. Particularly is this true if his fowls belong to one of the so-called general-purpose breeds. On the other hand, if it is desired to keep a larger flock which consists principally or entirely of one of the distinctively egg breeds, it undoubt- 
edly will be best in the end if the art of artificial incubation is thoroughly learned. The natural processes of incubation are too slow to meet the demands of the modern poultry-keeper who is extensively engaged in the business. When one undertakes to produce eggs exclusively and desires as many as possible in the winter, pullets will, of course, be largely kept for this purpose, and these cannot be depended on for natural incubation. Under these conditions, it will be advisable to resort to the use of incubators and brooders, by means of which the flock can be maintained. It would be quite impossible for the poultrymen of modern times to maintain large flocks of young birds for egg production and rear chickens by the natural method.

ARTIFICIAL INCUBATION

The art of hatching eggs by means of artificial heat has been known for a long time. Early travelers in Egypt gave accounts of ovens that were used for hatching the eggs of ducks, geese, and chickens. Heat was supplied by fermenting manure. Remains of these ovens are said to have been seen in comparatively recent times. It is said that the French became interested in artificial incubation as early as the fifteenth century, but not until the latter part of the eighteenth century was use made of hot water as a means of conveying heat for artificial incubation. 
From this time until the middle of the nineteenth century, comparatively little advancement was made in the construction of incubators. Since 1870 many improvements have been made and a large number of incubators have been placed on the market.

In the manufacture of the modern incubator, the idea has been largely to imitate nature. As the hen applies heat above the egg, so nearly all incubators apply heat to the egg-chamber from above. In natural incubation the hen provides a nest or shallow receptacle for the eggs, usually on the ground. After laying a number of eggs, the hen becomes "broody" and commences to sit, or incubate. At this time the underpart of the hen's body is more abundantly supplied with blood than during the laying or molting periods. In other words, what is known as the organ of incubation, or plexus, most fully develops at this time. This consists of a network of arterial blood-vessels, near the surface of the body, which bring greater heat to the eggs than would otherwise be supplied. In order to perfect systems of artificial incubation, many persons have made a close study of the natural method and have been led to adopt some devices or practices which were accidental or necessary to the hen, but not essential to perfect incubation. The fact that hens sometimes leave the nest in the early morning to search for food, when the grass is still wet with dew, and upon returning moisten 
their eggs with their wet feathers, has led some to sprinkle the eggs at various periods during the process of incubation. This, however, has been shown to be unnecessary, except possibly in localities where the air is very dry. Poultrymen have also learned by close observation that, in the nest, particularly as the period of incubation advances, the eggs are arranged mostly with the large end uppermost or toward the outer side of the nest. This is probably due to the form of the nest and the fact that the small end of the egg is heavier in proportion to its size than the large end; that is, the center of gravity approaches the small end, which is, as incubation progresses, due to the development of the air-chamber in the large end. The fact that the eggs are arranged with the large end uppermost, has led some persons to place the eggs in the incubator trays in a similar position. Without doubt, the position of the eggs does not have any particular influence on the hatching.

Many tests have been made to determine the actual temperature of eggs when natural incubation is taking place. These tests show a considerable variation until the ninth or tenth day. Until this time the eggs seldom reach $100^{\circ}{ }^{*}$ Although the temperature of the fowl is usually above $106^{\circ}$, yet the temperature of the eggs is seldom raised above $103^{\circ}$, owing to the fact that heat is applied only on one side.

* "Incubation and Its Natural Laws," Cyphers. 
Selection of an incubator.-An inexperienced person should exercise the same care and judgment in selecting an incubator that would be exercised when purchasing a mowing machine or other expensive implement. It is no longer thought that one

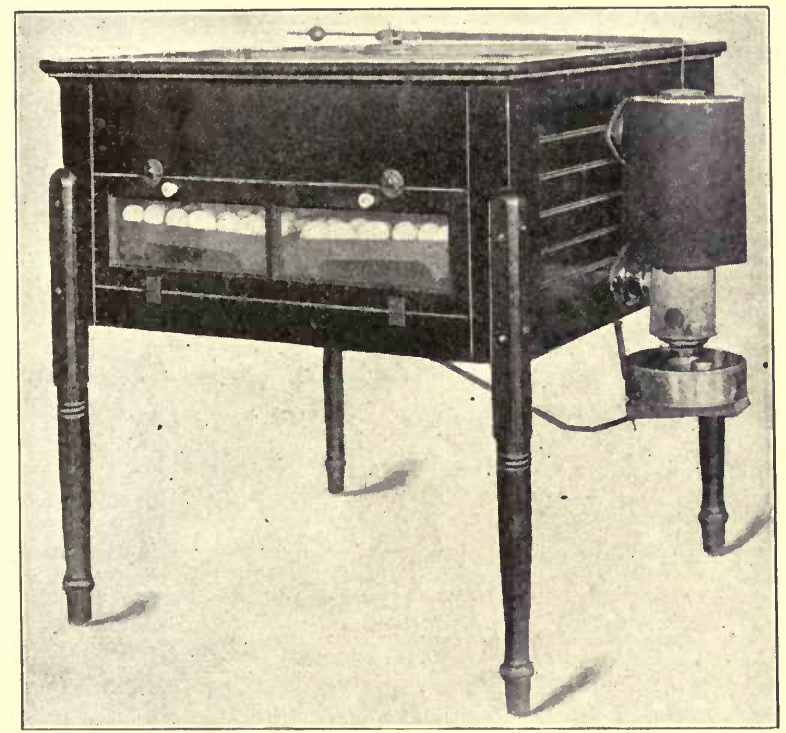

Fra. 65. One hundred-and-eighty-egg incubator.

particular kind of mowing machine is far superior to all others. Similarly, it may be said that there are many good incubators on the market. A wellmade machine, similar to those in use by successful poultrymen, will probably give satisfaction after the business is once thoroughly learned. It should 
be remembered that machines do not think, and that the good judgment of the operator is one of the most important essentials in artificial incubation. While incubators are often placed before the public with somewhat flaring announcements,

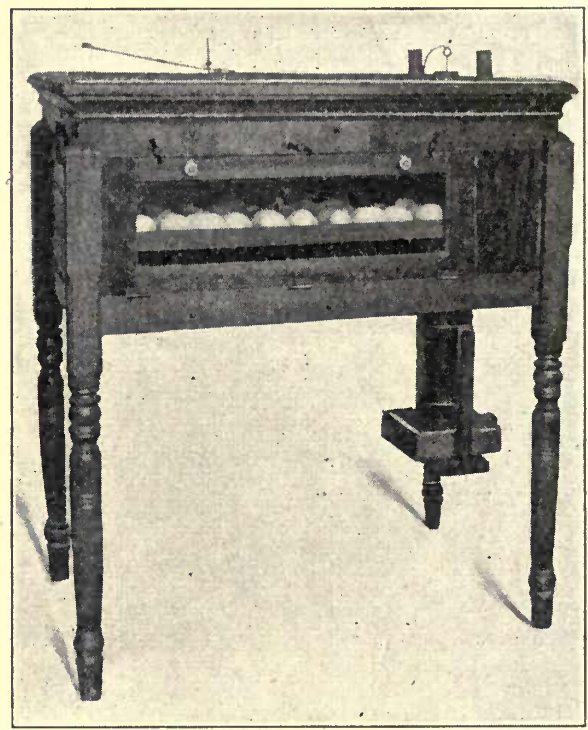

Fig. 66. One-hundred-egg incubator.

stating that the operation of the machine is most simple, it should not be forgotten that the most successful operators are those who have given the business their best thought and attention throughout a long experience.

While there is much to be learned about arti- 
ficial incubation by experience, yet the beginner cannot afford to ignore the knowledge which has been gained by the experience of others. Manufacturers of incubators have studied their own machines more or less carefully, and are therefore able to give some valuable information. Those who are about to invest in an incubator should make the most of the information given by manufacturers and others, and expect to learn many valuable lessons by their own experience.

Placing the incubator.- On many farms it is not easy to prepare a suitable place for an incubator. In selecting a location four essentials should be kept in mind, namely, ventilation, even temperature of room, convenience, and freedom from danger of fire. Most incubators are heated by lamps, and if they are placed in a small room, considerable ventilation will be required in order to keep the air pure.

An even temperature is of considerable importance, although some tests with modern incubators tend to show that the best hatches do not necessarily result from the most uniform temperature of the egg chamber. Uniform temperature is desired, however, and is easiest to maintain when the temperature of the room in which the incubator is placed varies least.

It is important that the incubator be placed in a room in which the air is in a normal condition,that is, neither too dry nor saturated with moisture. 
The ideal condition as to purity will approximate the air out-of-doors where there is a free circulation. The air should also contain at least a moderate amount of moisture. The amount of moisture in the

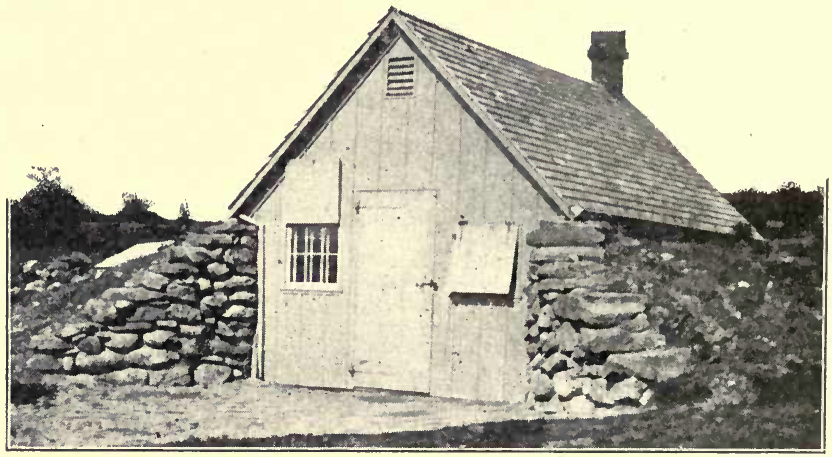

Fra. 67. An incubator house-Rhode Island Agricultural Experiment Station.

atmosphere should control, to some extent, the ventilation of the incubator. It is desirable that a considerable proportion of the moisture of the egg be evaporated during the process of incubation. If the air is very dry, a little ventilation will be sufficient to secure the desired evaporation, while a moist atmosphere would require much more ventilation to secure the same result. The moist air of a wet cellar which contains decaying fruit and vegetables is not suited to incubation.

Whenever kerosene oil lamps are kept continually burning for weeks at a time, as they are in incubators, there is some danger from fire. It is true 
that the modern incubator lamps are well adapted to the purpose, but the element of danger from fire cannot be said to be wholly eliminated so long as these lamps are permitted to burn in wooden buildings without the watchfulness of an attendant.

The convenience of an incubator room is probably one of the least of the essentials, yet it is of so much importance that it should not be wholly overlooked. Everything considered, probably a dry, airy cellar or half-basement will make the most desirable location for an incubator on the farm. Many incubator rooms have been con-

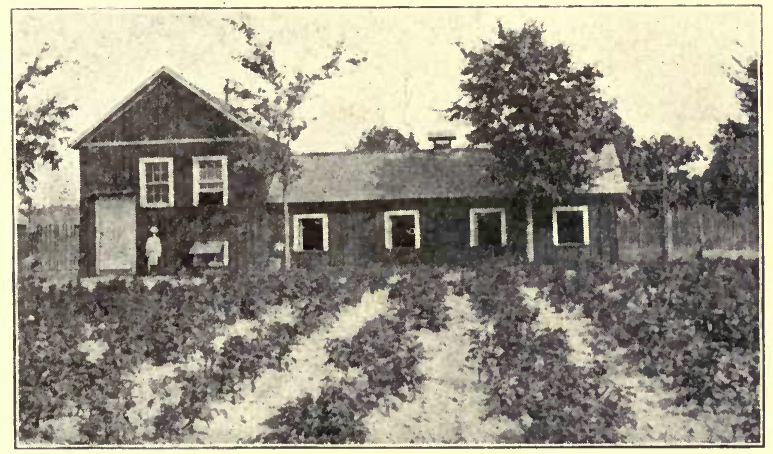

FIG. 68. A small incubator building with poultry house attached. Cornell University.

structed in excavations which were sufficiently deep to permit of most of the room being below the surface of the ground. (See Figs. 67 and 68.) This method will indoubtedly secure an even tem- 
perature, but the room is likely to be ventilated with difficulty unless special provisions are made. During the warm days of spring and early summer it is somewhat difficult to ventilate a cellar or even a basement without causing drafts, which would interfere with the lamps and prevent them from burning steadily. During cold weather, when the air in the cellar is warmer than that outside, it will readily escape through ventilating flues if given an opportunity to do so; but whenever the outside air is warmer and consequently lighter than the cool impure air of the cellar, ventilation without drafts becomes a serious problem.

Care of incubators.-Incubators should receive the same care and careful adjustment that are given to other delicate machines. The accurate working of the incubator will depend very largely on the treatment it receives from the operator or attendant. Whoever has charge of an incubator should plan to give it a careful inspection at regular intervals. It should not be necessary, however, to visit an incubator oftener than twice a day. It is always well for the beginner to run the incubator for a few days before filling it with eggs, in order that it may be properly adjusted, and also to give the operator a little experience before risking loss.

After the machine is adjusted and the attendant has gained some knowledge of operating it, 
the eggs may be put in, although it is well to place them in a warm room for a few hours previous, to prevent so great a change in the temperature of the incubator as would result from the use of cold eggs. It will be of some advantage to the beginner to keep temperature records of the machine by means of both an incubator thermometer and a registering thermometer. These records will sometimes be of value in regulating the machine for subsequent hatches.

Within a comparatively few years some large or mammoth incubators have been constructed that have the capacity of holding thousands of eggs each, at one time. These incubators have been operated successfully for several seasons and may be considered beyond the experimental stage. In these machines heat is furnished by means of hotwater pipes somewhat after the plan of hot-waterpipe brooding systems.

They are too large for farm use except perhaps that they may be used for what is known as the "community system of hatching," that is, one machine doing the hatching for many near-by poultry raisers. Close proximity is not, however, wholly essential, as newly hatched chicks may be transported many miles with safety. "The community system of hatching" is becoming quite popular in some places. Many farmers prefer to purchase newly hatched chicks rather than care for an incubator. 


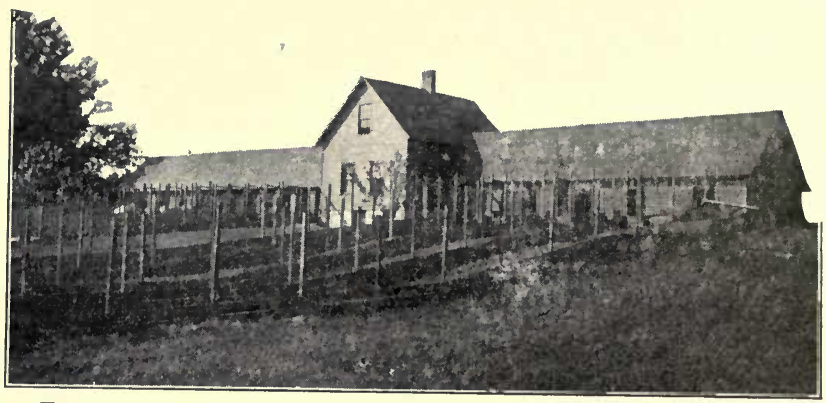

FIG. 69. House for brooders and incubators; also breeding pen3-New York Agricultural Experiment Station.

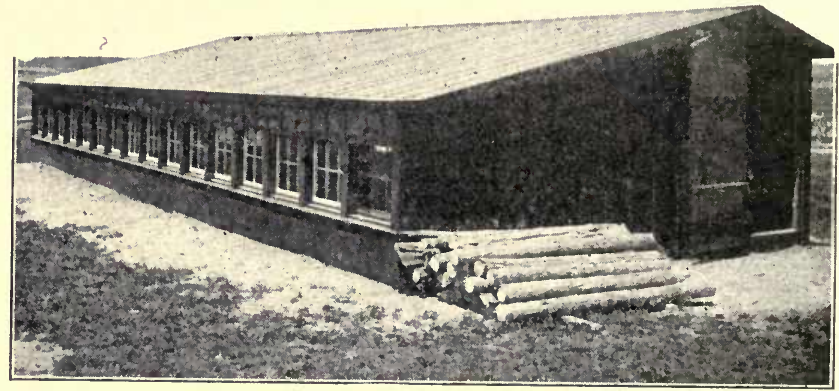

FIG. 70. Brooder house-Rhode Island Agricultural Experiment Station.

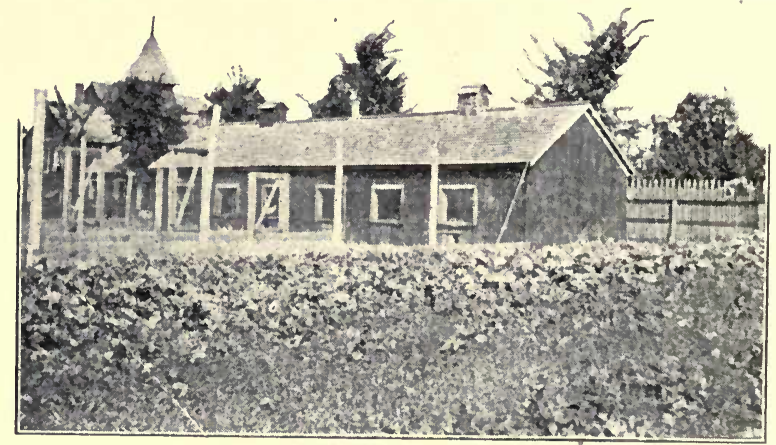

Fig. 71. A small brooder house-Cornell University. 


\section{BROODERS}

If artificial incubation is employed, some provision must be made for the care of the little chickens as soon as they leave the incubator. Various kinds of machines have been devised for this purpose, which vary considerably in regard to efficiency, but some kind of an artificial brooder must be provided. From the great variety of brooders on the market the farmer or poultryman has an opportunity to make a selection according to his wants and best judgment. Brooders vary greatly in size, as some of the smaller ones accommodate no more than fifty chickens, while the larger ones are devised to furnish accommodations for many hundreds of young fowls. For convenience, we may separate the various kinds of brooders into two classes. These classes represent two entirely different systems of furnishing heat and providing for the comforts of the little chickens. One class supplies heat by means of hot-water pipes. (See Fig. 72.) Brooders of this kind are capable of extension and of providing heat for many hundreds of young chickens. The other system is represented fairly well by small portable brooders, which supply heat by radiation from hot air or from hot-water tanks. These are usually. heated by small oil lamps or by gas jets. The pipe system is most extensively used by poultrymen who rear fowls on a somewhat extensive scale. One 
fire, producing the heat for many hundred chickens, gives to this system an advantage over the smaller brooders which require a separate lamp for each small flock. Oil lamps require close attention, and even then they are likely to give more or less trouble

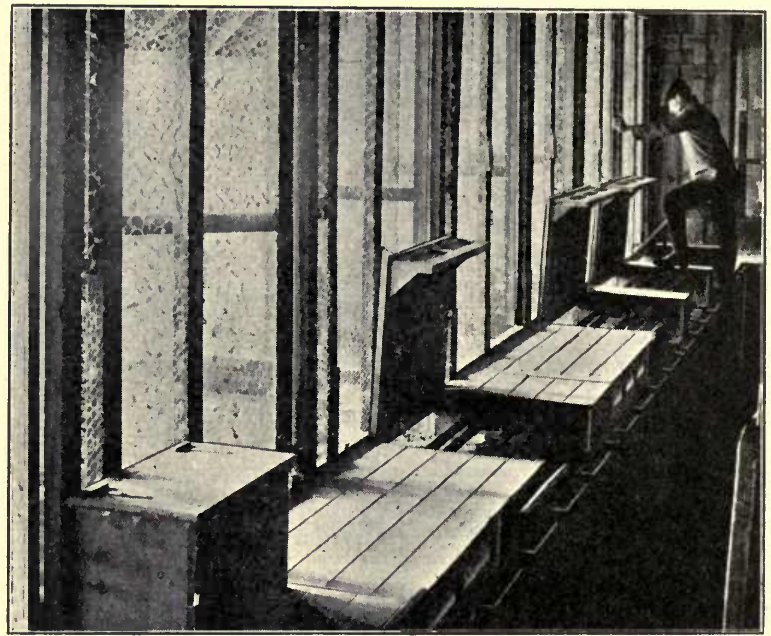

FIG. 72. Hot-water-pipe brooders, covers of three lifted, man raising the fourth-New York Agricultural Experiment Station.

by some imperfection in the burner or deposit of soot or carbon in some parts of the flue, which may lead to overheating and, in some cases, may produce disastrous results. Brooders, and even poultry houses, have been set on fire by careless or improper handling of brooder lamps.

Some of the most important requisites of a good brooder may be enumerated as follows: 
1. Capable of maintaining a proper temperature.

2. Be easily cleaned.

3. Provide good ventilation.

4. Of such form that all the chickens may readily be seen.

5. Must be dry.

6. Economical of heat.

7. Easy of construction.

(1) A satisfactory brooder must maintain a proper temperature for delicate little chickens. It will be necessary to maintain an even temperature, from $90^{\circ}$ to $100^{\circ}$, for the first week. After that a somewhat lower temperature will be required. Breeds of fowls that feather early in life do not require so high a temperature in the brooder after two or three weeks. The temperature should always be so high that the chickens are not inclined to huddle together to keep warm. Huddling indicates that the temperature is too low for best results. The amateur poultryman finds it difficult to overcome the tendency toward bowel disorders in little chickens. One of the potent causes of these disorders is a cold brooder or frequent chills.

(2) A brooder should be easily cleaned. There are several reasons for this. The labor of cleaning is an important item. The time occupied is frequently of considerable importance, and then, if the brooder is not readily cleaned, it is much more 
likely to be neglected, particularly during the busiest seasons of the year. A brooder should be so constructed that it may be swept clean, preferably with an ordinary broom. The floor should be kepi

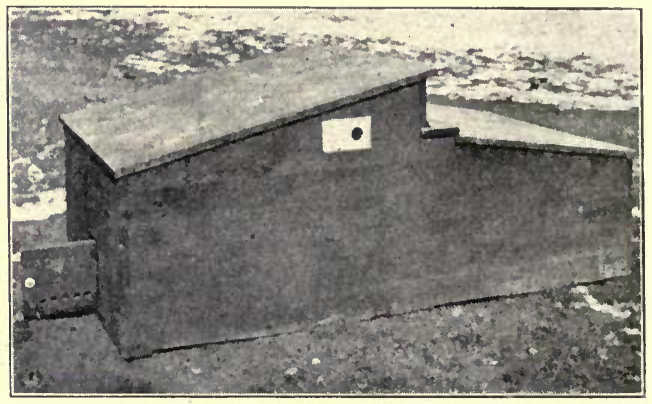

FIG. 73. An out-of-door brooder

littered, so that all the manure may be readily swept out. As filth and dampness are two great causes of failure with the amateur poultryman, it is of the greatest importance that poultry houses and brooders be kept as clean as possible.

(3) The air in a brooder will become foul if not changed frequently. Usually, when sufficient heat is supplied to give proper temperature, ventilation is also secured; but occasionally the source of heat is barely sufficient to maintain the required temperature with the least possible ventilation. Then, in order to keep the chickens warm, ventilation must be cut off. Pure air should be supplied at all times. It should be remembered that little chick- 
ens have a high temperature, that they breathe rapidly, and that the supply of pure air is of the greatest importance to them.

(4) It is important to have the brooder so arranged that all the chickens may readily be seen by the attendant. If dark and inconvenient corners are permitted to exist, weak chickens find these nooks a place of refuge, and may escape the attention of the attendant. As it is important that all of the chickens be seen at each feeding, the ease of thorough inspection is of considerable importance in the care of brooders.

(5) A brooder must be dry. At no time in the life of a hen is she so sensitive to moisture as in

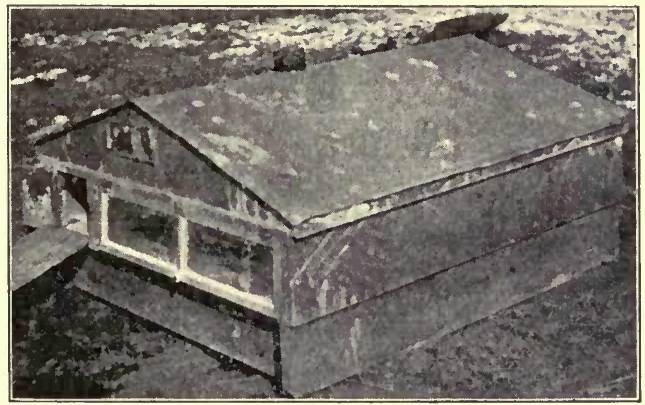

Fig. 74. An out-of-door brooder.

the early stages of her existence. All parts of the brooder should be kept dry and clean. Whenever the floor of the brooder becomes moist, some means should be taken at once to correct the evil. There 
should be sufficient bottom heat or enough heat near the floor to keep it dry. Too much bottom heat is objected to by many poultrymen. A somewhat popular belief is held that bottom heat, if considerable, is likely to produce what is known as "leg weakness."

(6) It is of some importance to have a brooder that is economical of heat, or, in other words, one that makes good use of the fuel consumed. The . provision of fuel is an item of expense.

(7) It is of considerable importance that the brooder be simply constructed. Machines that are more or less difficult to build are necessarily more expensive than those that are easy of construction. Then, too, some parts of the appliance may require renewal, and if the brooder is easy of construction the farmer or poultryman may readily perform the labor which otherwise would require an additional expense in sending the machine to the factory for repairs.

The amateur should bear in mind that it is necessary for each person to learn the business for himself by study and experience, that there are no hard and fast rules for the selection and operation of the various kinds of brooders. One person may succeed well with a brooder that would prove unsatisfactory in the hands of another. One person may learn how best to operate a particular machine, and, from his study of the condition of 
the brooder and chickens, soon learn how to remedy the most serious difficulties, whereas another, through a lack of sufficient knowledge of that particular brooder, would fail to secure the essentials in rearing young fowls. There are many brooders that are capable of producing good results if the

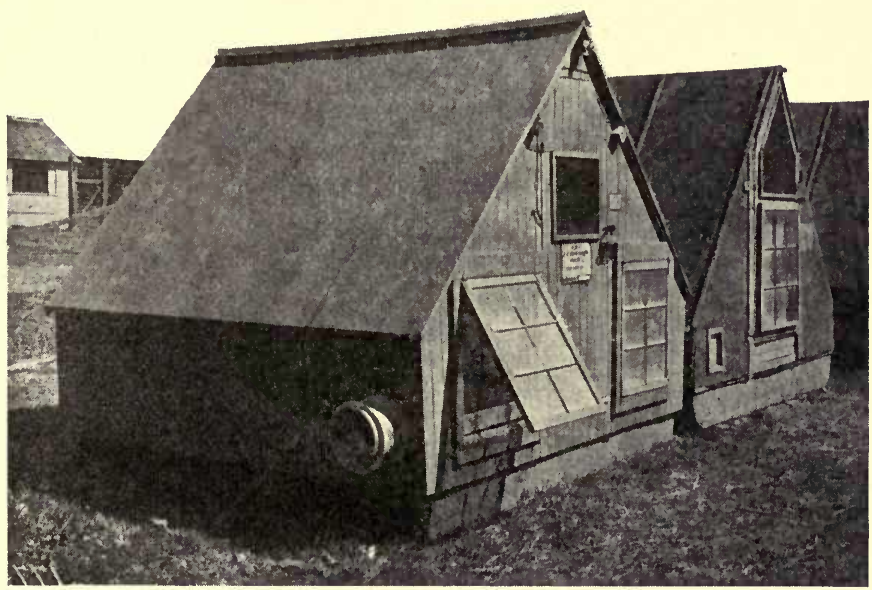

FIG. 75. Gasoline-heated, colony brooder houses-Cornell University.

proper attention be given them; but the manner of caring for the young, which find in them a home, is of greater relative importance than the particular construction of the machine.

Home-made brooders. - It is often desirable and sometimes necessary to construct at home a considerable portion of the appliances used in the modern poultry yard. Sometimes material is at 
hand that may be turned to good advantage in the construction of machines. It sometimes happens that more chickens are hatched than were provided for, and an extra brooder is needed for the emergency.

Satisfactory brooders may be made at home, at a small expense for materials, by any one who is able to work well with the most common of carpenters' tools. Drygoods boxes may be utilized to

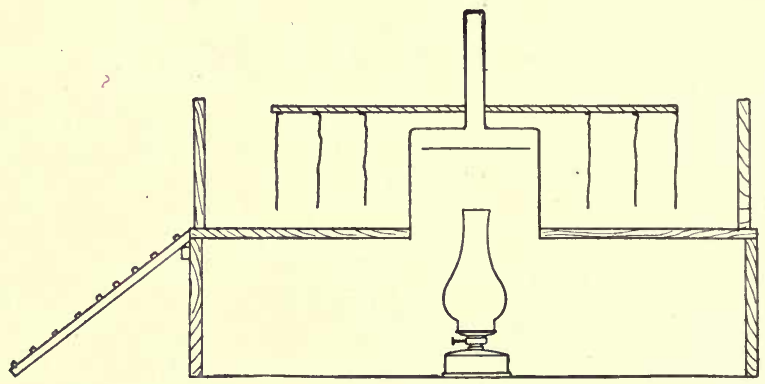

FIG. 76. A home-made brooder in cross-section.

good advantage. If a part of a large drygoods box is placed bottom upwards so that the bottom will form a level floor about a foot from the ground, a good foundation for a cheap brooder is established. In the center of this a square or circular opening is cut, into which is fitted a box of tin which is also placed bottom up. A straight-sided tin bucket or pail may be used instead of the tin box. If the former is used, a circular opening should be made to fit the pail. In the bottom of this pail (which is bottom upwards) should be fitted a small tube 
of iron or tin to carry off the smoke and gases from the lamp which is placed underneath. On the top of the tin box or pail is placed a cover of light boards which supports woolen or felt curtains. The illustration (Fig. 76), which shows an indoor brooder in cross section, may aid in the proper understanding of this device.

The chickens should be confined by a board railing for several days, after which they may be given an opportunity to take more exercise than would be permitted within the brooder. Little chickens should have a chance to return to the brooder whenever they desire to do so. The illustration shows a board railing, in section, which will effectually confine the chickens until they require more exercise than the brooder will permit. There is also shown an approach which will provide a means by which the chicks may easily enter and leave the brooder, provided a suitable opening be made in the board railing. The curtains mentioned above prevent the heat from escaping, and provide warm, comfortable compartments for the chicks.

One objection to indoor lamp brooders is the difficulty in carrying off the fumes from the lamp. If possible, some provision should be made to carry the vitiated air and fumes from the lamp outside the brooder and brooder house. A little ingenuity on the part of the poultryman is sometimes required to accomplish this object. 


\section{CHAPTER XI}

FEEDING AND CARE OF LITTLE CHICKENS

In rearing fowls it will be found that the attention given to little chickens and the manner of feeding them are of the greatest importance. While it is difficult and probably impossible to discuss satisfactorily care and feeding separately, yet it may safely be said that care and attention are quite as important as the selection of food.

One successful poultry-feeder may find it to his advantage to make use of certain foods, while these same foods in the hands of others may be so misused that disappointment will surely result. To further illustrate, one successful poultryman may insist that comparatively little of certain kinds of grains should be fed. Other successful feeders may make a most satisfactory use of these objectionable grains. It is for each one to learn for himself how to feed to the best advantage those foods which are at hand, and to learn how to supplement them with others if they do not form the desired combination of themselves. In preparing food for little chickens, it will be well to remember that they are delicate organisms and require careful 
handling and suitable food, particularly during the first few days of their existence, or until they become strong enough to seek food for themselves.

\section{FOOD}

The little chickens will require no food for the first twenty-four or forty-eight hours after hatching. A mistake is often made in feeding them frequently before the system requires food. The close observer will readily determine by the action of the chickens when food is required. The first food should be of such a character that it may be readily digested without the aid of grit; consequently, soft food is preferred. Stale bread thoroughly moistened with milk makes a most excellent food for newly hatched chickens. An experienced poultryman will recognize that there is no best food for little chickens. There are many good kinds, if fed judiciously. Again, it may be said that the manner of feeding is of the utmost importance, and that the attendant who fails to study closely the condition and wants of the little chickens will fail to reach the best results. While stale bread dipped in milk makes an excellent food, yet it may be so treated as to be quite unfit for use. It should be allowed to drain, after dipping, so that the bread is only thoroughly moistened. In this condition, if finely crumbled, it makes a most satisfactory food. On the other hand, bread that, 
is fresh and not perfectly baked will be quite too sloppy, if saturated with milk. Ground grain may be mixed with milk and fed to good advantage. If this grain is mixed some time before it is to be given, it will become more thoroughly soaked and will be in a much softer condition than if fed immediately after preparing. This is thought to be of considerable importance by persons who have had years of experience in the preparation of food for little chickens. Sour milk is thought by many of the most successful poultry-raisers to be equally as desirable as sweet milk. Some, however, prefer to use chiefly the curd of sour milk in mixing the soft food.

The following rations are recommended for young chickens:

MixtURE No. $1^{*}$

Lbs.

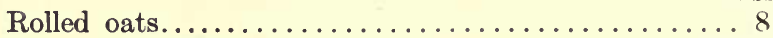

Bread crumbs or cracker waste............ 8

Sifted beef scrap (best grade)............... 2

Bone meal.......................... 1

Mixture No. 2*

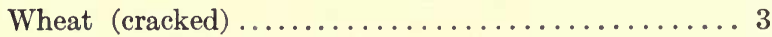

Cracked corn (fine) $\ldots \ldots \ldots \ldots \ldots \ldots \ldots \ldots \ldots \ldots$

Pinhead oatmeal...................... 1

Mixture No. $3^{*}$

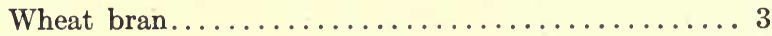

Corn meal............................ 3

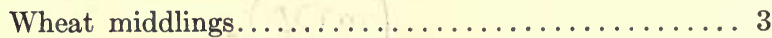

Beef scrap (best grade)...................... 3

Bone meal........................... 1

*Cornell University leaflet, "Cornell Ration for Chick Feeding." 
Mixture No. 1 should be moistened with sour skimmed milk and will prove a most satisfactory food for the first five or six days. Mixture No. 3 is best fed as a dry mash in a hopper and is a suitable food to keep constantly before the chicks until they are pretty well grown. No. 2 mixture is suitable for feeding in light litter after about the first week.

It is not best to give the little chick all it can possibly eat and then require it to become ravenously hungry before the next feeding. Under natural conditions the young chickens are seeking food during a large portion of the day and at no time are they completely gorged. A little food at frequent intervals undoubtedly is best. If they are given food in suitable quantities, feeding from five to seven times per day will be found to be none too often for the first five or six days. After this time it will not be necessary to feed more than three times a day if they have access to the dry mash in the hopper at all times. Finely shredded green food and charcoal are also necessary. Some authorities prefer to scatter the grit and charcoal over the food.

The following is quoted from an experiment station publication:* "If skim milk be added to the ration fed to young chickens it will increase the consumption of other foods given. The great increase

*Summary of Bulletin No. 71, Purdue University Agricultural Experiment Station. 
in average gain was coincident with the periods when the greatest amount of skim milk was consumed. Skim milk is especially valuable as a food for young chickens during the hot dry weather; and becomes of less importance as the chickens grow older and the weather becomes cooler."

Ground grain is preferred to whole or cracked grain, and should constitute the chief part of the daily ration. Practical poultrymen and experimenters are fairly well agreed on this point. The following illustrates:* "A ration consisting mostly of ordinary ground grain foods and containing no whole grain was more profitably fed to chicks than another ration consisting mostly of whole grain and containing no ground grain. . . In every trial more food was eaten when the ground grain was fed than when the whole grain was fed."

In addition to the grain given to the chickens, it will be necessary to provide some animal food. Various mixtures of grain foods have been compared to mixtures of grain and animal meal, but the latter have given the better results. The domesticated hen seems to thrive best, in all stages of existence, on a ration which consists in part of animal food. "A ration in which about two-fifths of the protein was supplied by animal food was much more profitably fed to chicks than another ration supplying an equal amount of protein, mostly from

*Bulletin No. 126, New York Agricultural Experiment Station. 
vegetable sources, but supplemented by skim milk curd." *

Experiments have demonstrated clearly that the ordinary grain foods, as usually fed, do not contain sufficient ash to permit the most rapid development of the young. The following briefly states the results of somewhat extended experiments at the New York Agricultural Experiment Station: $\dagger$ "Of two rations which contained practically the same proportions of the ordinarily considered groups of constituents, but different amounts of mineral matter, the one wholly of vegetable origin proved much inferior for growing chicks to the other ration, higher in ash content, containing animal food. When the deficiency of mineral matter was made good by the addition of bone ash, the vegetable food ration for chicks equaled or somewhat surpassed in. efficiency the corresponding ration in which three-eighths of the protein was derived from animal food."

Hard-boiled eggs mixed with ground grain, and perhaps a little milk, make a most excellent food. This is frequently fed with satisfactory results during the first few days of the chick's existence. Infertile eggs which are taken out of the incubator whenever the eggs are tested, if properly prepared, will furnish an excellent food for little chickens. These

*Bulletin No. 149, New York Agricultural Experiment Station.

†Summary of Bulletin No. 171. 
boiled eggs should be crumbled or chopped fine and may be fed alone or mixed with softened ground grain.

Corn may form a considerable portion of the ration for young fowls that are growing rapidly. Granulated oats make an excellent food for chickens after they are several days old. These oats may be placed in receptacles of such a character that the food may be readily accessible at all times and yet will not be soiled by tramping.

\section{EXERCISE}

It is of the utmost importance to provide a run or yard for young chickens. They require much exercise, and unless provision is made for this, it cannot be expected that the most satisfactory growth and development will be made.

The young of all animals are active and will take constant exercise if opportunity is given. Particularly is this true of the young of fowls. They are not only inclined to range freely on their own account, but under natural conditions the mother, wandering from place to place in search of food, compels the young to take a greater amount of daily exercise than they would if left wholly to themselves. Perhaps the reader, if he is a farmer, will be surprised to recall how far from home he has seen the old hen with her brood of little chicks. 
It is essential also that they be kept in a dry place, either on a floor or a dry soil. Young chickens should never be permitted to run on moist land, particularly if it is allowed to become filthy. Many chickens that are hardy when kept dry prove tender when compelled to occupy quarters that are more

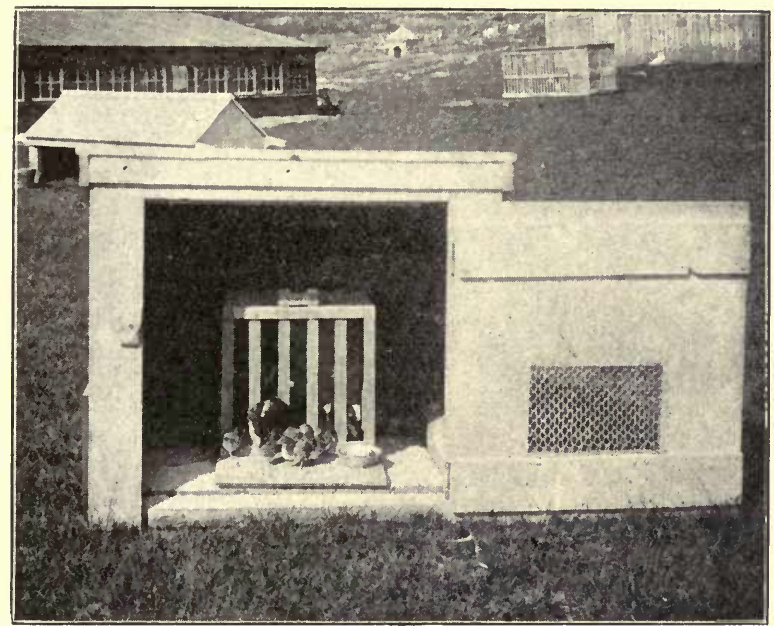

Fig. 77. Chicken coop-Rhode Island Agricultural Experiment Station.

or less damp. There are several breeds of poultry that cannot endure dampness, though hardy to a satisfactory degree when provided with warm and dry quarters.

It should be borne in mind that the attendant or feeder is responsible for the health and general condition of the chickens, quite as much as is the 
food which they consume. Skilful feeders, by noting carefully the wants and conditions of the chickens as regards thrift, are able to determine how best to feed and to accomplish satisfactory results with food that would prove entirely unsatisfactory with a little neglect or indifference on the part of the feeder.

\section{FEEDING-TROUGHS}

It is, necessary to provide feeding-troughs for little chickens in order to prevent them from tramping on the food; for if the food be placed on the floor of the brooder or poultry house, it soon becomes

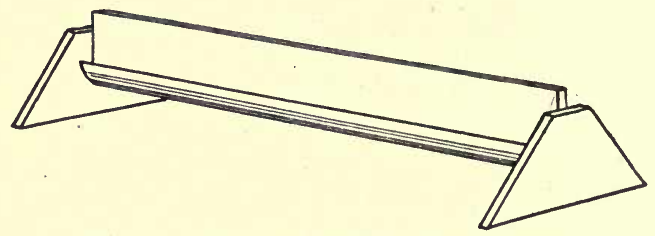

FIG. 78. A feeding-trough for little chickens.

soiled and unfit for consumption. A simple and efficient feeding-trough may be made by tacking a strip of tin about $3 \frac{1}{2}$ inches wide along the edge of a half-inch board so that the tin projects about an inch and a half on either side of the board. Bend the tin so as to form a shallow trough on each side of the board, then fasten the board to blocks which will hold it edgewise and raise it from one to two inches from the floor. (See Fig. 78.) The trough 
may be from one to three feet long. It is within easy reach of the chickens and so narrow that they cannot stand upon the edges. Food placed in such feeding troughs may be kept clean until wholly consumed. Small feeding troughs have been supplanted to a

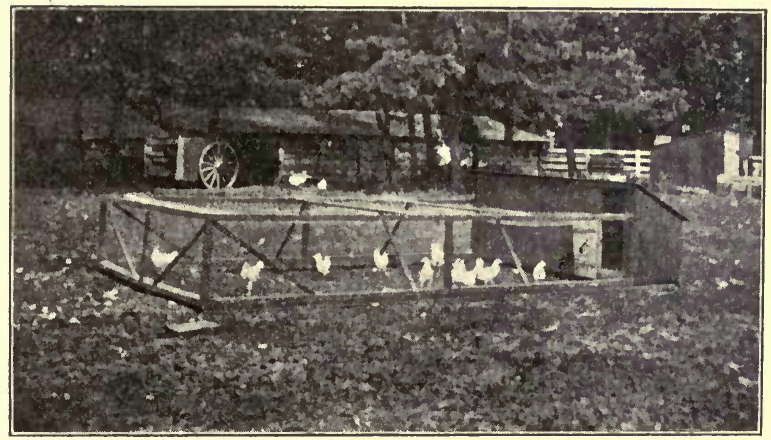

Fig. 79. A movable coop, showing a good device.

large extent by dry-feed hoppers for such food as will work well in hoppers. It is often desirable, however, to feed moistened food that can be best placed before the chickens in little troughs.

\section{GRIT}

Grit should be placed before chickens not later than the second day after they commence to eat. Coarse sand will answer the purpose very well for young chickens. Finely crushed stone or pulverized cinders will suffice if coarse sand or prepared 
grit is not at hand. As nature does not provide grit in the digestive organs of the newly hatched chicken, it is necessary to furnish this grit in order that the chick may grind its first hard food. As nature provides nourishment for a chicken for a day or two after it is hatched, grit is not absolutely needed until the third or fourth day, provided the first food is quite soft. As the chick becomes older, coarser grit is required and its supply should never be neglected.

\section{DRINKING-FOUNTAINS}

One of the difficult problems that the amateur poultryman has to solve is how best to keep pure drinking-water continually before the little chickens. Small chickens drink frequently, and as their little beaks are sometimes more or less loaded with soft food, which is deposited in the drinking-fountain whenever the beak becomes wet, the question of how to keep the water pure is not an easy one to solve. As it is necessary to keep the drinking-fountain at a warm temperature, it soon becomes tainted and, unless given frequent attention, will emit a disagreeable odor. This condition must not be allowed to exist, for all food and water consumed by the fowls, particularly the young, should be free from taint. There is no greater stumbling block to the novice than the lack of cleanliness.

Many automatic fountains will keep water before 
the chickens, but they are frequently difficult to cleanse if they once become tainted. Nothing less than frequent scalding with steam or boiling water will answer the purpose. Any drinking-fountain that is constructed of glass, that will not bear such temperatures, is objectionable. Tin or earthenware

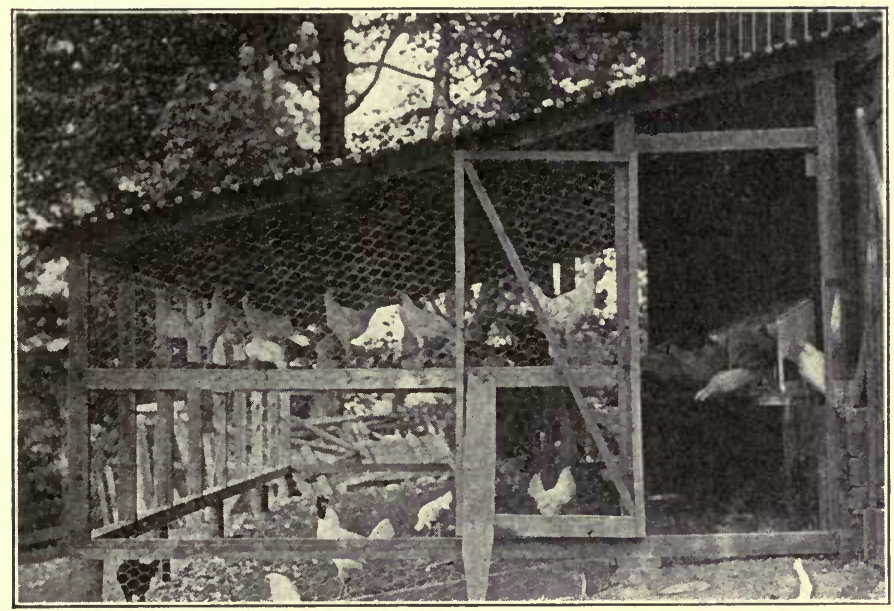

Frg. 80. Summer house for cockerels.

New York State College of Agriculture, Ithaca, N. I'.

is preferred on account of the ease of cleansing. A drinking-fountain made on the same principle as the one with a revolving reservoir, described in a previous chapter (see Fig. 47), will prove very satisfactory. An empty tomato can and a shallow saucer will answer every purpose. These may be readily cleansed and are convenient. 


\section{BROODERS}

Brooders require constant care to keep them clean and to see that no part becomes wet, which will frequently happen if water-dishes are placed within the machine. Cleanliness must be insisted on. The temperature at which the brooder should

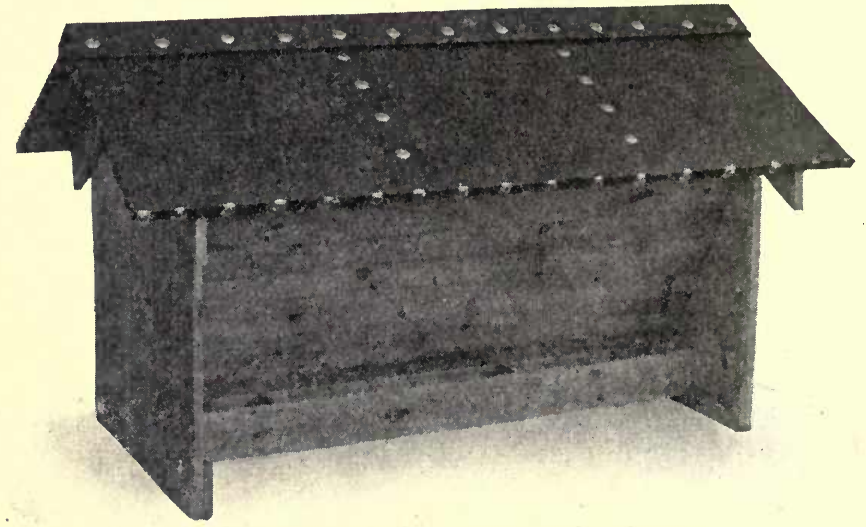

Frg. 81. A home-made outdoor dry-feed hopper.

be kept will depend largely upon the age of the chickens. It should be warm enough so that the chickens will not huddle together to keep warm, and, of course, should be cool enough for the greatest comfort. Bowel disorders are frequently caused by exposure and improper brooder temperatures. The person who makes his chickens the most comfortable will probably succeed best with the brooder. 
The following conclusions in regard to improper feeding and brooder conditions are given by the Rhode Island Agricultural Experiment Station:* "Post-mortem examination showed that the diseases may be classified under four heads. Disorders ascribable:

"A. To heredity or to environment during period of incubation. (Recent experiments have demonstrated that successive alternate periods of heat and cold during incubation are responsible for a very large proportion of abnormalities.) Thirty-three per cent of the chicks examined showed more or less trouble under this head.

"B. To mechanical causes, e. g., overcrowding in the brooders, resulting in death by suffocation, trampling, etc.

"C. To imperfect sanitation, lack of ventilation, sunlight, etc.; e. g., tuberculosis flourishes in dark, poorly ventilated brooders. Fifteen and one-tenth per cent of the postmortems showed more or less evidence of tuberculosis.

"D. To improperly balanced ration, i. e., improper feeding. For the continued maintenance of health there must be a definite proportion between the amount of carbohydrates (starch, sugar, etc.), fats, and the *Bulletin No. 61, p. 53. 
nitrogen-containing proteins. A ration wholly vegetable is almost certain to contain a too low percentage of nitrogen, while a ration exclusively animal is very sure to be deficient in carbohydrates. As a result of improper food, digestive disorders soon appear, either in the liver and gall-bladder, or in the intestines. Of the chicks examined, 75.7 per cent had abnormal livers; 38.6 per cent had various forms of intestinal disorders."

"In conclusion, special attention is called to the following facts, confirmed by experiments:*

"1. Careful external and internal examination (such as any one can readily make) of the dead chick will usually disclose the cause of death. The necessary remedies are usually not difficult to find.

"2. Death from overcrowding, suffocation and trampling can be readily corrected. It is more frequent than is generally suspected.

"3. For guarding against tuberculosis, give the interior of the brooders all the sun and air possible on pleasant days.

"4. Trouble of the liver and gall-bladder are usually easily recognizable from the green stains. For correcting this, feed more animal food. The use of the proper proportion of animal food will pay a handsome profit through decreased mortality *Bulletin No. 61, Rhode Island Agricultural Experiment Station, p. 59. 
and increased weight of the chicks. In feeding bear in mind that chicks in a state of nature spend practically all their waking hours in search of food, and that they do not fill their crops in ten minutes every two hours. Feeding should be, as far as the time of the attendant renders profitable, a continuous process, but by no means a continuous gorge.

"5. Diarrhœa, etc., frequently result from feeding a too large proportion of animal food, and are often brought on by cold, exposure, etc.

"6. If the yolk is present in considerable quantity in chicks a week old, or if more than 1 or 2 per cent of deformed chicks appears, look to the better regulation of the incubators or to the health of the breeding-pens." 


\section{CHAPTER XII}

\section{CAPONS AND BROILERS}

There is a question in the minds of many persons whether caponizing is really as profitable as it is often represented to be. The profits of capon rearing that are frequently given in captivating accounts are often very misleading. While it is true that these most favorable reports are well within the range of possibilities, yet many of them far exceed the probable returns of earnest and welldirected efforts of beginners. One of the first questions which should be decided as regards capon rearing is the profit which this enterprise will probably yield; -in other words, will caponizing pay? Without doubt this question should be answered both affirmatively and negatively. When capon rearing is compared with some of the most productive lines of poultry work conducted at this time by the most skilful operators, it probably will not make a very favorable showing. On the other hand, the profits from fine capons which have been prepared by the expert will undoubtedly compare favorably with results obtained in other directions. If the prices which capons bring are to be compared 
with those of the choicest broilers, one would be led to believe that broiler raising would be the more profitable.

It should be borne in mind, however, that it is quite possible to make good capons of fowls that at no time in their existence would have sold for the highest prices as broilers. Broiler raising, like the rearing of early or "hothouse" lambs, requires great skill. Those who do not understand how to secure these choice products, may make good capons from fowls that would not answer the requirements of the higher priced broilers.

In rearing broilers, it is impossible to bring all the birds to the desired condition - that is, all will not be so good as the best. The poorer birds may be retained on the farm and prepared for the capon market, provided the breed of fowls selected for broiler rearing will mature birds sufficiently large to make good capons. It will not pay to attempt to produce capons from small fowls. When the profits which choice capons bring are compared with the profits of rearing mature fowls that are sold for meat, a most excellent showing will be made. The question, then; whether capons will pay, depends largely on the point of view. Sometimes capons undoubtedly can be made to pay well, and the rearing of them should be encouraged under certain conditions.

To those who have had no experience in the rear- 
ing of capons, and to whom, perhaps, the word is almost a new one, it may be stated that they are castrated males. The capon bears the same relation to the cock as the steer does to the bull or the wether to the ram. The operation is performed in order that the fowls may grow larger, become more gentle, and fatten more readily than they would otherwise. The operation, if successfully performed, changes the nature of the indivividual to a marked degree. The change brought about by this operation on the fowls is quite as great as that caused by a similar operation upon other classes of farm stock, if not even greater than that. The birds lose their activity, which is a potent factor in easy fattening. They grow considerably larger than they otherwise would and appear much more gentle and consequently thrive well in close confinement.

As the bodies of capons are large, their heads appear somewhat out of proportion,-that is, the comb and wattles do not develop, which makes the head appear small. The capon never crows and loses the voice of the male and also most of the masculine characteristics except size. The flesh of capons is especially prized. The muscles are tender, the birds fatten readily, and their large size makes them especially desirable for certain methods of cooking. The largest capons sell for the highest price. In order to reach the highest 
profit, capons should be large and fat and not more than ten or eleven months of age. If they are kept until a later age, the meat becomes somewhat coarse and is not so desirable. While early chickens

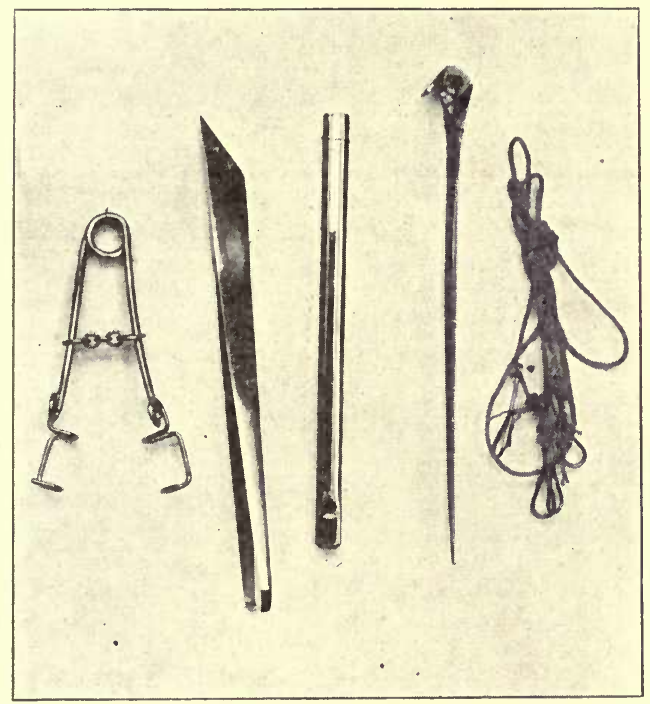

F1G. 82. A caponizing set.

are most highly prized for broilers, the later ones may be turned to a good account for the capon market. The question is sometimes asked, with all seriousness, whether the operation is not sufficiently painful to condemn the practice. Without doubt considerable pain is involved, but no more than in a similar operation which is performed so gener- 
ally on other classes of farm stock, and the pain is probably less than in those cases.

That capons are regularly quoted in markets of many cities shows that there is sufficient demand for them to warrant poultrymen in giving considerable attention to their production, particularly if they are so situated that fowls which would otherwise bring low prices can be turned to this use to a good advantage. The regular quotations also indicate that a considerable number of poultrymen find capon rearing a fairly profitable branch of the poultry business. Were this not true, poultrymen would cease to rear them and their presence in the markets of so fnany cities would be unknown.

It is not difficult to learn how to perform successfully the operation of caponizing fowls of the proper age, but some persons are naturally more deft in finger manipulation than others and are able to perform delicate operations neatly and rapidly. In districts in which large numbers of capons are reared, professionals are usually engaged by capon rearers to perform operations on large numbers of fowls at one time. They go about the country doing the work more satisfactorily and more rapidly than the owners could do it for themselves, and, as they have become so expert, they are enabled to perform the operation for a very small sum and still make good wages. From two to four cents per head usually pays for a skilful operator. Any one who is 
at all deft may perform the work by merely following the directions furnished by the manufacturers of caponizing instruments. Comparatively few farmers, however, will become expert if they operate only upon their own fowls. "While the novice might, and probably would, spend a half hour upon the first bird, and then possibly produce a slip, experts will do scores each hour during the whole day. One very sure and rapid worker caponized one bird per minute for three hours in succession, his day's work being 450 , of which not one per cent died."*

Not all breeds of fowls are equally well suited to the production of capons. The Black Langshans are generally especially recommended for this purpose. The birds of this breed are large and are easily operated upon. In a somewhat general way it may be said that the meat breeds and the general-purpose fowls are suitable for producing capons. It is held by some that the Brahmas though large are not easily operated upon. Crosses between the Light Brahma and the White Plymouth Rocks or the White Wyandottes are highly prized. The Cornish Indian Game is sometimes used to cross on other large fowls, as it improves the breast meat without decreasing the size. Commission men do not state that there is much, if any, difference in the value of capons from the different breeds of fowls; that is, it is not recognized that some breeds * “Pocket Money Poultry," Norys, page 171. 
produce capons decidedly superior to those of other breeds. Large-sized birds that are fat bring the highest prices.

It is recommended that the fowls should be operated upon when they have attained the weight of about two pounds. Some poultrymen recommend that the operation be performed a little earlier in life, while others are very successful in operating upon birds that are somewhat older. Without doubt the best time will depend somewhat upon the condition of the bird. If the fowls are growthy and thin, a somewhat lighter weight will suffice than if the fowls are very plump. In a general way, authorities on caponizing recommend that the operation be performed when the fowls are from $1 \frac{1}{2}$ to $2 \frac{1}{2}$ pounds in weight.

Sometimes birds of the larger breeds may be operated upon when 3 pounds in weight or even larger, but they should never be over six months old. It is more difficult to operate on young, small birds on account of lack of room to perform the operation. On the other hand, as the birds become older the testacles increase in size and the bloodvessels supplying these organs are more likely to be ruptured.

Chickens to be operated upon should be fasted from twelve to twenty-four hours, and in some cases even forty-eight hours is recommended. It is suggested not only to withhold food, but, during 
a considerable period of the fasting, to withhold water as well. Fowls are fasted in order to empty the digestive organs and to deplete somewhat the quantity of blood, and thereby reduce the danger of rupturing the blood-vessels while performing the operation. One great danger is in the liability of rupturing the arteries which are situated very near the organs that are to be removed. When it is borne in mind that the abdominal cavity is opened and that the intestines are pushed aside in order to perform the operation successfully, it will readily be seen how essential it is to have the bowels as nearly empty as possible, and, at the same time, to deplete

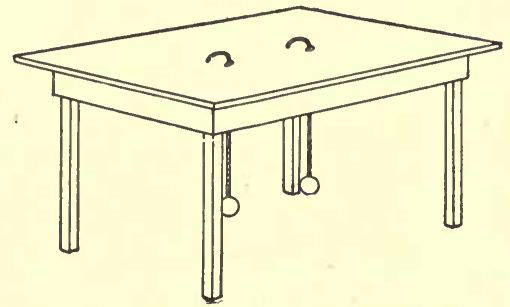

FIG. 83. Caponizing table, showing cords and weights used to hold the fowls. the quantity of blood in the blood-vessels so far as the good health of the fowl will permit. One objection that is frequently made to caponizing is, that good light is required, particularly if the operator is not the most skilled. Clear days when the sun shines brightly are preferred. It frequently happens that fowls may be fasted for the operation and cloudy weather prevail. This should be sufficient cause to prevent the novice from proceeding further until clear weather comes. In such an event, it will be necessary to keep the fowls on very light rations 
of soft food until the promise of clear weather is near at hand. Experienced operators are not hindered so much by improper light as are the inexperienced, yet all deem the brightest light desirable.

The head-reflector used by physicians in performing delicate operations upon the throat, is used by some operators, and is found to work successfully with artificial light. Expert operators are enabled to work with the reflector with almost as much ease and satisfaction as in bright sunlight. This reflector consists of a mirror fastened to the head by a band in such a manner that the mirror can be turned to any desired angle to throw the light into the cavity, and to show the location of the organs to be removed, as well as the place of the near-by veins and arteries.

When to make capons and the time to sell.The production of capons for market should be controlled largely by the market conditions. As capons sell best from soon after Christmas until the last of March or middle of April, they should be ready for market at this time. It takes about ten months to prepare properly a capon for market, and they should not be put on the market when over a year old. There is not much difference as to the seasons of the year so far as the effects of the operation are concerned. Cockerels hatched in May or June, especially of the early maturing varieties, like Plymouth Rocks or Wyandottes, or even 
thase crossed on Brahmas or Langshans, castrated in September or October, should find ready sale during the high market season.

Farmers who have cheap food, who are far from shipping points, and therefore kill and ship all at one time in cold weather, might profitably make capons of all young cocks. Those who keep birds until maturity for their own table should do the same.

The operation.--If one desires to attempt the operation without having received personal instruction, he will do well to commence on a fowl that has just been killed for this purpose. He may then take as much time as he desires to study the location, attachment, and removal of the organs without inflicting torture on the fowl. It will be best, however, to hold the fowl, and to perform the operation as though he were alive. The fowl should be held on its side on a table, box or end of barrel and secured by passing a strong cord around its shanks and another around both wings close to the shoulder joints. These cords may be held in place by weights as shown in the illustration. Remove a few feathers on the side over the last two ribs and moisten the others so they will not interfere with the operation. Make an incision well toward the back between the last two ribs, this may be about an inch and a half long and should be kept open by means of a spreader provided for this purpose. The lining membrane of the abdominal cavity should now be hooked and 
cut through or torn. The intestines may be pushed away from the back and the testacles readily seen. These may be removed by proper instruments. The manufacturers of caponizing instruments furnish instruments for the various parts of the operation and accompany them with explicit instructions for the beginner.

Preparing capons for market.--"Capons, like other fowls, should be fasted twenty-four hours before killing, that the crop may be empty and therefore need not be removed. The head, the distinguishing mark of a capon, has a particularly long and pointed appearance and should always be left on. They should be bled by cutting inside the mouth or throat. The neck and saddle feathers are unusually large and fine; these and the small size of the tail distinguish a capon from any other fowl; therefore they are left on, as well as the feathers on the leg from the hock joint half way up the thigh and those on the outer joints of the wings. The breast, back, the wings next to the body and the upper part of the thighs are picked clean. They should be dry-picked without tearing the skin, and the head, mouth, shanks and feet washed clean. Care should be taken to remove all clotted blood from the mouth. Capons for the New York markets should be sent undrawn. Some Boston dealers receive them undrawn. They should be packed in boxes or flour barrels washed clean and lined 
with white wrapping-paper. Neatness and attractive appearance are everything where quick sales and best prices are to be secured."*

\section{BROILERS}

Broilers are young, plump and fat chickens which have been forced to make the greatest possible weight during the few weeks of their existence. Broiler rearing may be regarded as one of the specialties of the poultry business, and one that does not appeal particularly to the farmer who keeps his fowls under what may be called good average conditions. If a farmer who keeps from fifty to one hundred and fifty hens should produce a few good broilers, the extra expense and trouble of preparing them for market and of marketing them would make serious inroads on the profits.

Great skill is required to bring this work to its highest perfection; consequently those who are prepared to raise a considerable number of fowls for this purpose are more likely to become expert than are those whose chief interests lie along other lines of work. On this account the production of broilers for the markets of the large cities is chiefly in the hands of comparatively few, who may be called specialists. These men make broiler rearing a considerable part of their business, and learn how

* Bulletin No. 20, Rhode Island Agricultural Experiment Station. 
to perform the various operations in the best manner and with the greatest exactness.

If one is contemplating the production of broilers on a somewhat extensive scale, he should not depend upon written directions for his guidance, but should make a thorough inspection of the markets, in order to learn what kind of product the market demands. He should also visit one or more broiler farms, where these birds are successfully reared in large numbers. The experience of practical men is the safest guide.

As broilers are often placed upon the market when they weigh less than two pounds per pair, the skill in feeding little chickens and the care of the brooder become of the utmost importance. Light-weight winter broilers may be regarded as strictly brooder chickens. The light-weight broilers, when in demand, sell for the highest prices. Skill is of more relative importance in the production of young high-priced meat than in the production of mature fowls or those which more nearly approach maturity.

While the cost of food is of less relative importance in the production of young fowls for the market than in the production of older ones, yet it should be remembered that the cost of food per pound of gain in live weight increases as the period from birth or hatching is increased. This cost continues to increase until a period is reached when the 
food consumed produces no gain, that is, until the fowls cease to increase in size and weight. If the production of flesh is considered from a standpoint of food alone, the young fowls are the most profitable. When the cost of hatching and the value of the eggs are taken into account, the youngest product may not be the most profitable to the producer. It is for each breeder to determine for himself at what age he can sell with the greatest profit. Young fowls will undoubtedly be selected, but, as a few weeks' growth often changes considerably the value per pound, fine discriminations must be made if one is to become expert.

The question is frequently asked, "Will it pay to raise broilers?" It will undoubtedly pay the right kind of people to enter into the business on a somewhat large scale; yet no one, no matter how enthusiastic he may be, should attempt broiler rearing on a large scale without experience and considerable capital. The chief essential to success is a good knowledge of the business. If this cannot be learned from the experience of others, it should be learned from personal experience, beginning in a small way at first and advancing as judgment seems to warrant.

Broilers are reared more for home consumption on the farms in some parts of the country than others. The South depends more on these young fowls than the North. 
Dry, sandy or gravelly soils are specially prized for broiler rearing. Cleanliness and freedom from moisture are requisites to success. These conditions are more easily maintained on light, porous soils than on heavy ones. Keep the chickens dry and clean and give them plenty of wholesome, easily digested food. Corn meal, wheat bran, ground oats with the hulls removed, and hardboiled eggs may make the bulk of the ration. These should be fed after thoroughly soaking or scalding. Some meat food and some green food should not be neglected. Baked foods are recommended and are undoubtedly safe. For further discussion of foods, see chapter on feeding little chickens (Chapter XI). Those who make a study of the foods used by successful poultry-raisers soon learn that there is no best food, but many foods are excellent if fed with judgment.

Various breeds of fowls are used for broilers, one of the favorites being the Wyandotte. Many prefer to use crosses, on account of the vigor and hardiness of the chicks. Heavy breeds are usually crossed on the smaller, quick-maturing ones. These crosses have suitable size and they mature early.

Broiler-rearing and egg production go well together. Experienced broiler raisers who have a good knowledge of the business are able to produce eggs that will give better and more uniform lots of chickens than those that are purchased from farmers 
who, perhaps, keep fowls of many different breeds. The ultimate success will depend largely on the fertility of the eggs and on the kind of fowls that produce them.

Many farmers who live near good markets are able to dispose of some of their best early chickens as broilers at remunerative prices. Sometimes the local demand is sufficiently great to cause rather indifferent birds to be marketed at good prices. 


\section{CHAPTER XIII \\ DUCKS AND GEESE}

The American farmer too often thinks of "poultry" as comprising only "hens and chickens." The term really covers all kinds of domesticated birds, including those grown for pets or for mere fancy. With the more diversified agriculture of the future, other species than hens must come into greater prominence.

\section{DUCKS-GENERAL DISCUSSION}

While ducks have been reared on farms for a great many years, yet a large proportion of the business of duck-rearing is now in the hands of specialists who conduct it on an extensive scale. A considerable proportion of the duck products of farms, where only small flocks are maintained, is consumed at home and does not affect the general market. The rearing of the so-called "green ducks" for market has provided a profitable occupation for many extensive duck-raisers. Comparatively few farmers enter into the business of duckraising extensively. Ducks are usually kept in 
moderate-sized flocks, that roam at will over a considerable portion of the premises. When reared under these conditions, the ducks frequently prove beneficial in the destruction of various insect pests. They will travel long distances, and in their rambles are continually on the lookout for food; both vegetable and animal life are greedily consumed. Ducks may become, under certain conditions, quite as destructive to farm crops as chickens, although if streams or wet fields are included within their range a considerable portion of their time is given to hunting food in these places.

Those who enter into duck-raising extensively rear the fowls almost exclusively for meat. The eggs produced by extensive duck-raisers are not put on the market as food to any great extent, in competition with eggs that are produced cheaper by the noted egg breeds of hens. Ducks can seldom successfully compete with hens for egg production.

Many farmers prefer, for various reasons, to keep ducks rather than hens. It is well known that ducks are comparatively free from disease and are not nearly so likely to be troubled with vermin as are hens. This is of considerable importance on many farms where the fowls are not given much care and attention.

Ducks are much more easily confined than hens. A fence two or three feet high should suffice for them under all ordinary conditions, particularly 
for those breeds which are the most profitable for farm use. It is true that some of the less profitable breeds, so far as meat production is concerned, are able to use their wings to good advantage and are quite as troublesome to keep within inclosures as Mediterranean fowls. Another reason why farmers frequently prefer ducks to hens, is that the young grow much more rapidly. Those who make a practice of fattening young ducks for the market, expect to secure birds that will weigh four and one-half or five pounds at nine or ten weeks of age, while good chickens would weigh only about half as much.

Ducks are adapted to the various parts of the country where chickens thrive well. They may be reared under a great variety of conditions as regards climate and exposure. Because ducks, in a state of nature, select shallow water or marshy land as their feeding-ground and largely prefer bodies of water to dry land, it is thought by many that streams or ponds are necessary for the successful rearing of domesticated birds. However, many of the most successful duck-raisers, who produce large numbers of young birds for the market, do not depend on streams or ponds of water for their fowls. It is true that the plumage of both young and old birds will be kept in a somewhat cleaner condition if the ducks have access to ponds or streams, but this is a matter 
of minor importance in the rearing of ducks for the market. Some hold that if the breeding ducks have access to water, a larger proportion of fertile eggs is secured. Other breeders, however, are able to conduct their business satisfactorily without such water, and consequently it may be said that the value of ponds or running water for breeding ducks may be somewhat questionable.

\section{DUCKS-BREEDS}

Ten breeds of ducks are described in the American Standard of Perfection; viz., the Pekin, Aylesbury, Rouen, Cayuga, Muscovy, East Indian, Call, Crested, Indian Runner and Swedish. Of these, the first four may be mentioned as the profitable breeds for farm use. While the Muscovy ducks are the largest, yet they are not the most profitable for farmers. The East Indian and Call ducks are too small to be most profitable. They have not been bred for eggs or meat and are considered as fancy fowls. They occupy a similar position among ducks to that which bantams occupy among chickens.

Pekin.-The white Pekins undoubtedly occupy a foremost position as to popularity. Without doubt, a larger number of White Pekins are reared for market than of any other breed. They are pure white, large, and are excellent layers. They 
are considered hardy and are easily reared. They mature early and are especially prized for the production of young birds for market. When walking they assume a more upright position than do the ducks of most other breeds. The Pekins

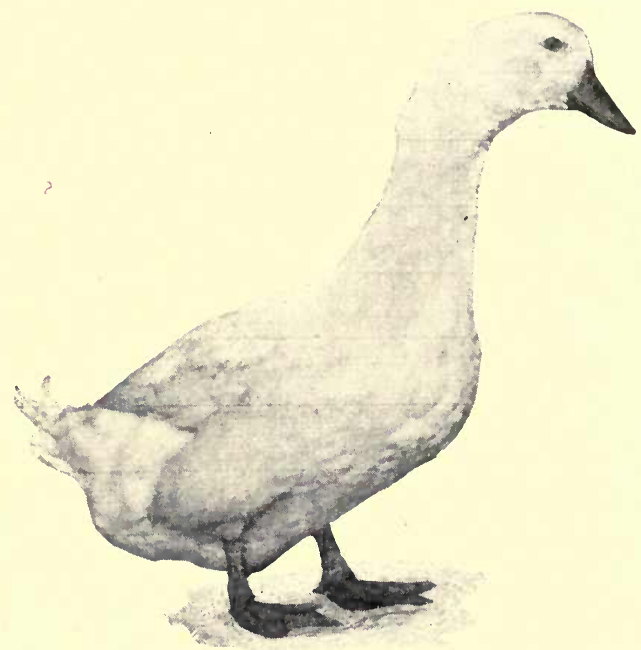

FIg. 84. White Pekin drake, young (one-eighth size).

are largely reared by extensive duck-raisers who make a specialty of the so-called "green ducks;" that is, young birds that will weigh about five pounds apiece when not more than ten weeks old. The standard weight for Pekins is 9 pounds for the drake and 8 for the duck.

Aylesbury.-The Aylesburys probably rank next 
to the Pekins in popularity. In general appearance they closely resemble the Pekins, but may be distinguished by their carriage. The Aylesburys have the same weight as the Pekins. They have the power of adapting themselves readily to the various conditions under which ducks are reared. They are considered even more hardy

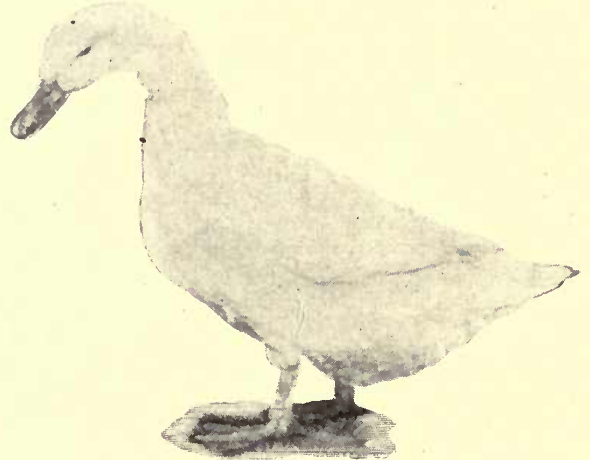

Fia. 85. White Pekin duck, yoụng (one-ninth size).

and prolific than the Pekins. Some practical duck raisers sometimes introduce an Aylesbury cross on their Pekin stock to increase vigor and prolificacy. For market purposes the white breeds (Pekin and Aylesbury) are preferred to the colored ones, because white young birds present a better appearance when dressed than do those of colored breeds.

Rouen.-The Rouens are especially prized as 
table fowls. As producers of fine-grained, delicate flesh, these fowls are not surpassed by any of the so-called useful farm breeds. The Rouens resemble the wild Mallards in color, the resemblance between the drakes being most marked. The Rouens are hardy, prolific, and of gentle disposition. Young birds may be kept in rather large

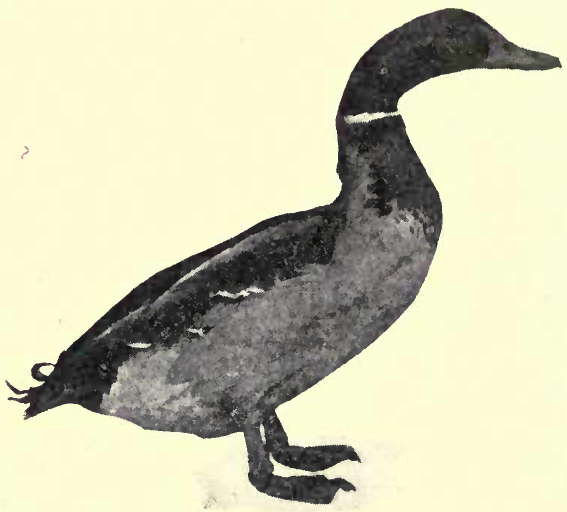

FIG. 86. Rouen drake (one-eighth size).

flocks without the danger of stampeding that is so troublesome with the Pekins. The standard weight for the Rouens is the same as that for Pekins, yet it is thought that they do not grow so rapidly as the latter. Extensive duck-raisers prefer the Pekins or Aylesburys on account of their quick growth. However, the Rouens are most excellent farm fowls and are highly prized on account of their hardiness, prolificacy, and gentle disposition. 
Black Cayuga.-The Black Cayugas are recognized as a distinctively American breed. It is asserted by some that the Cayugas grow as rapidly and mature as early as the Pekins, but those who are extensively engaged in rearing ducks invariably choose one of the white breeds. The Cayugas are profitable farm ducks. They thrive well in

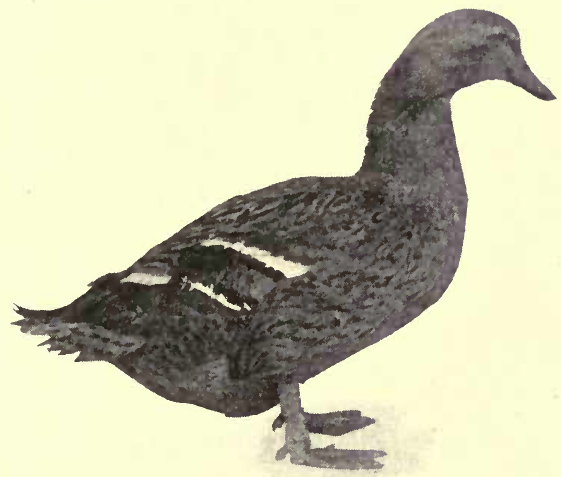

Fig. 87. Rouen duck (one-eighth size).

rather close confinement, are hardy, gentle, and do not care to wander so far from home as some other breeds. The standard weight for these is 8 pounds for the drake and 7 for the duck.

Muscovy ducks.-These are the largest of any of the breeds mentioned, but, for various reasons, are not such profitable farm fowls as others. When compared with the Pekins or Rouens, the Muscovies are not so good layers. They are not 
so easily confined. Muscovy ducks are often troublesome in the poultry yard on account of their disposition to attack other fowls, both young and old. On account of their disposition to fly they are not easily kept within inclosures.

Call ducks.-Call ducks are bred chiefly for exhibition purposes. The gray Call ducks are sometimes bred for decoys and are used by sportsmen to lure wild ducks within shooting distances. They are not recommended as profitable farm fowls.

\section{DUCKS-FOOD AND CARE}

The natural food of the duck differs in some respects from that of the hen. While ducks, like hens, eat a great variety of food, yet, because the duck is not possessed of a distinct crop, the food is passed more directly to the digestive organs and does not undergo so complete a softening process as that consumed by the hen. It is, therefore, of the utmost importance that the food be consumed in a soft condition. In nature the duck gathers a large proportion of its food from streams, ponds, or marshy places. This food consists of the young, growing shoots and roots of water plants, snails and the larvæ of various water insects, together with small fish and other aquatic life. Those who have made a success of rearing ducks on an extended scale have learned a valuable lesson from nature 
and give to their young, growing ducks very little or no hard food. While a considerable portion of the ration will consist of grain, it is ground and moistened with water or milk and fed in a soft condition.

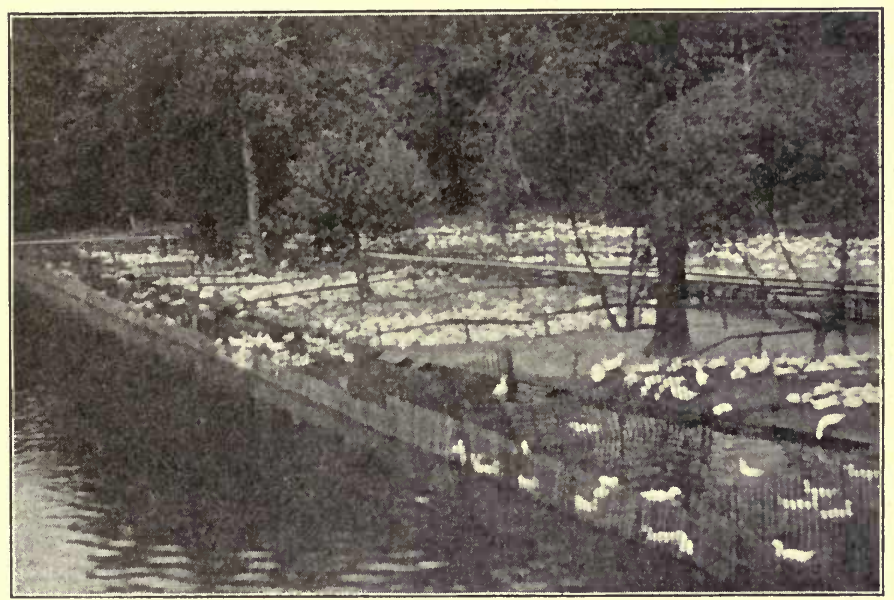

FIG. 88. View on Wm. H. Truslow's duck farm, East Stroudsburg, Pa., showing arrangement of yards and manner of supplying water.

It is important in duck-rearing to secure the greatest degree of cleanliness, although this is somewhat more difficult than with hens. Where ducks are kept in confinement in comparatively small pens or yards, it will sometimes be found impossible to prevent the runs from becoming foul, though occasional cultivation will aid materially in keeping the yards clean and in providing a sani- 
tary home for the occupants. Poultrymen use various disinfectants and absorbents in the yards in order to keep them as clean as possible. Yards that are not in use all the year should be planted to some crop if an opportunity is afforded. Those

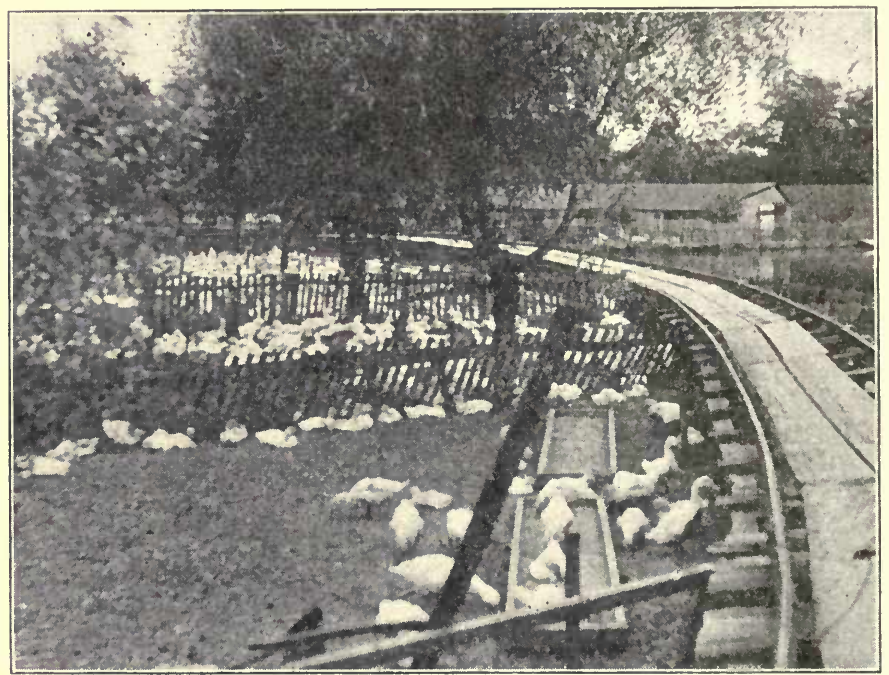

Fig. 89. Another view on Mr. Truslow's duck farm, showing the track on which a car of feed is pushed from pen to pen at feeding time.

poultrymen who make a specialty of producing young ducks for the market make a practice of sowing the yards and runs to some quick-growing crop as soon as the yards are vacant. Rye is often used for this purpose. During the rearing season, gypsum, sawdust, sifted coal ashes, and other absorbents are freely used in those parts 
of the yards that are most frequented by the ducks.

Young ducks should be fed from a shallow trough, which should be kept as clean as possible. (See Fig. 90.) Pure water and clean yards are prominent essentials in successful duck-rearing. It is true that ducks will make small ponds and streams muddy and

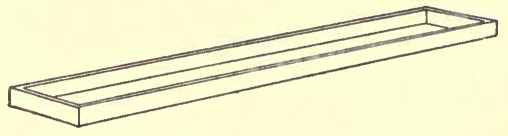

Fig. 90. A shallow feeding-trough. more or less filthy when they have access to them, yet those that are confined in yards without a running stream should be supplied with pure drinking-water.

If the young ducks do not have opportunity to obtain for themselves green and animal food, it should be supplied to them. Specialists frequently feed young, rapidly growing ducks a ration that consists of 10 or 20 per cent animal meal. Rations which contain considerable animal meal have proved superior to a purely vegetable diet. "Rations containing animal food proved very much superior for ducklings to rations of vegetable origin which had, according to the ordinary methods of estimation, practically the same nutritive value. A ration of vegetable food supplemented by bone ash proved much inferior to another ration of similar 'composition,' in which three-eighths of the protein came from animal food."*

* Summary of Bulletin No. 171, New York Experiment Station. 
If the ducklings are confined in comparatively small yards, it is best to provide some shade for them, particularly during the hottest months. Green food fed to ducks confined in yards should be cut fine in a feed cutter. Almost any green, succulent food will be readily eaten. Rye, clover, alfalfa, Canada field peas, and corn make

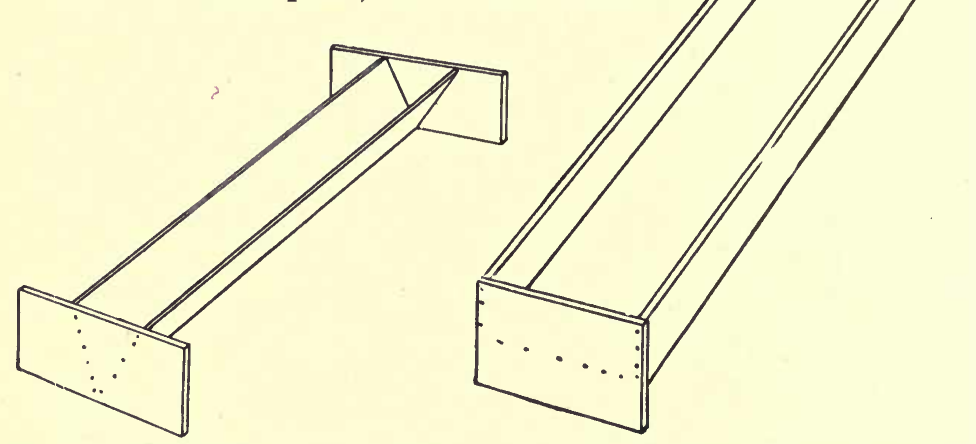

FIG. 91. A V-shaped water trough.

Fig. 92. A shallow water trough

excellent food if finely cut. Ducks will readily eat the plant, stalk and all, in this condition, while chickens will select the leaves and other tender parts and reject the more woody portions of the stalks. The green material may be fed alone or mixed with the moistened ground food. The latter may consist of wheat bran, corn meal and ground oats, the hulls of the oats having been removed. Various kinds of ground grains may be employed, although those mentioned are used most by experienced men. 
Ducklings of some breeds appear to be quite fearless in some respects, yet under other conditions they are easily frightened, and, if a considerable number are kept in one yard or pen, the injury done by "stampeding" is sometimes considerable. Pekin ducklings are particularly liable to injury from this cause. Some extensive duckraisers make a practice of lighting artificially that part of the yard occupied by the fowls during the night as a partial safeguard against this trouble.

\section{GEESE-GENERAL DISCUSSION}

The rearing of geese is not so extensive a business as that of raising ducks. The conditions requisite for the successful raising of geese are very different from those for ducks. The rearing of geese is not in the hands of a comparatively few extensive raisers. Geese are still raised on many farms in comparatively small flocks. The fact that geese require very much more room than ducks has probably been an important factor in keeping the business of rearing them in the hands of farmers who go into the enterprise in a moderate way. While ducks are frequently reared successfully without water, except as it may be necessary for drinking, yet geese thrive best where ponds or streams are provided. While ducks may thrive under practically the same condi- 
tions as geese, yet the conditions under which geese do best are not necessary for successful duckraising. Fields which are not suitable for cultivation on account of springs or streams make good pastures for geese. A comparatively low, springy or marshy land may be used to good advantage if some part of the run is comparatively high and dry. Geese do not thrive so well in large flocks as ducks do. There seems to be a somewhat general law which may be applied to all farm stock as regards the size of flocks or herds. The smaller animals, as a rule, thrive much better in large flocks than do the larger breeds or varieties. It is true that large herds of cattle are maintained on some of the great cattle ranches in the prairie countries, but an almost unlimited range is given them.

Geese do not require a great deal of attention. After the young are a week or so old, they are able to care for themselves largely, if a good range is given. The food of geese is largely grass, although insects and other low forms of animal life are eaten readily and are essential.

\section{GEESE-BREEDS}

The most common breeds of the pure-bred geese are the Toulouse, African, Embden, Chinese, Canada or Wild, and Egyptian. Many geese 
throughout the country are of no particular breed. It is probable that these geese have descended from those imported by settlers at an early date in the history of the country. In some instances improved breeds have been crossed on these common or mongrel geese, but many flocks are still maintained that are of no particular breed, neither color nor conformation indicating that they contain any considerable proportion of blood of improved kinds.

Toulouse.-The Toulouse geese are large, massive, and probably attain a greater weight than those of any other breed. I. K. Felch states* that geese of sixty pounds weight per pair have been exhibited in American exhibitions.

The American Poultry Association has adopted the following as standard weights: Adult gander 25 and adult goose 20 pounds.

"Toulouse geese usually lay more eggs in a season than Embden or African geese, but not so many as the best China geese. They are nearer non-sitting than any other variety, but some individuals make good mothers. The goslings are greenish yellow in color, generally hardy and vigorous. They are quiet and peaceable, and more easily confined by stone fences than other breeds, and would be more likely to be contented in close quarters. Toulouse geese are gray in color, with * "Poultry Culture," page 404. 
a square, massive body, carried fairly horizontal, the abdominal pouch, or loose folds of skin between and behind the legs, almost or quite touching the ground."*

It is often difficult to distinguish the sexes,

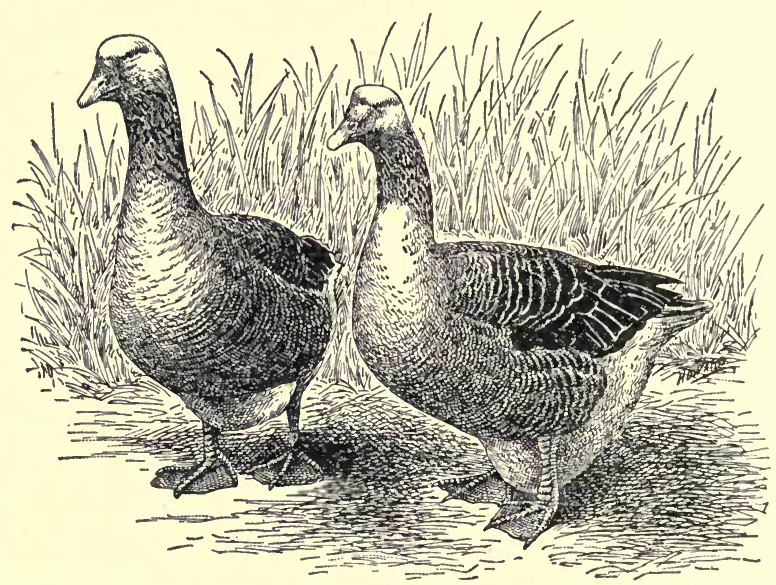

Fig. 93. A pair of gray Toulouse geese.-From United States Department of Agriculture, Farmers' Bulletin No. 64.-Howard.

as the gander and goose have exactly the same color and the same feathering.

Embden.-The Embdens very much resemble the Toulouse in general form; they are; however, pure white throughout, which enables one readily to distinguish one breed from the other. The Embdens do not have the great abdominal pouch of the Toulouse, although it is sometimes dis* Report, 1897, Rhode Island Agricultural Experiment Station. 
tinctly developed. "These geese are inclined to lay a little earlier than the Toulouse, and their eggs average a trifle heavier, but they do not lay quite so many eggs; and are much more persistent sitters. They make excellent mothers. The goslings when hatched are of a rich yellow color, which

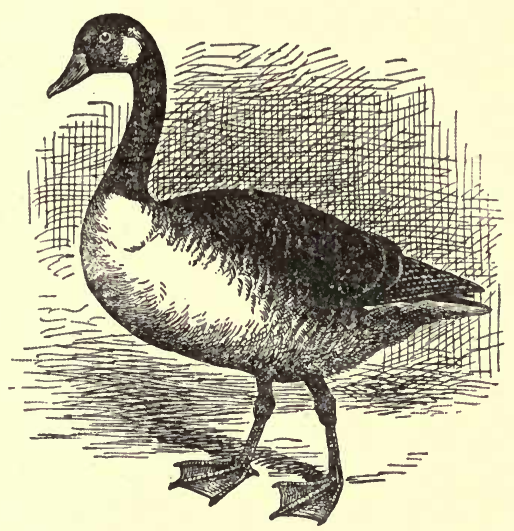

FIG. 94. Gray wild goose.-From United States Department of Agriculture, Farmers' Bulletin No. 64.--Howard.

changes to white as the quill feathers grow. They are generally hardy and grow rapidly." *

The standard weight for geese is 20 pounds for adult gander and 18 pounds for adult goose. African.- "Gray African geese are by many raisers considered the most profitable of all geese to keep. They grow the heaviest in the shortest space of time, and are ready for market in ten weeks,

*Report, 1897, Rhode Island Agricultural Experiment Station. 
weighing, at that age, between eight and ten pounds. They are very much like the Pekin duck in this respect, and, as compared with other geese, give the most satisfactory returns for the least labor and time spent in growing them."*

The African geese are called good layers, and are especially prized as table fowls. The flesh

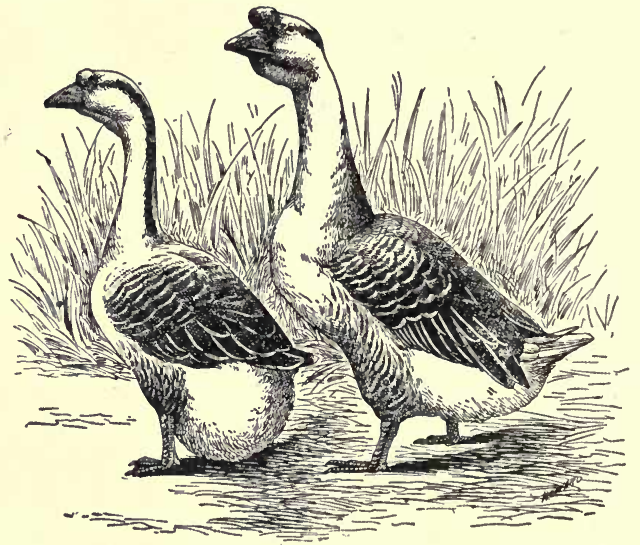

FIG. 95. A pair of gray African geese.-From United States Department of Agriculture, Farmers' Bulletin No. 64.--Howard.

is good flavored and not so coarse fibered as the Toulouse. The young are hardy and grow rapidly. The voice and notes of the African goose resemble those of the China goose quite as much as those of the Toulouse or Embden.

Chinese.-Individuals of this breed are several pounds smaller than those of the breeds pre*Farmers' Bulletin No. 64, U. S. Dept. of Agriculture. 
viously described. They are highly prized for the quality of their flesh and are recognized as excellent layers. Their lack of size, however, has made them unpopular except for exhibition purposes.

They are considered an ornamental variety and are small or medium in size. They have long, arched

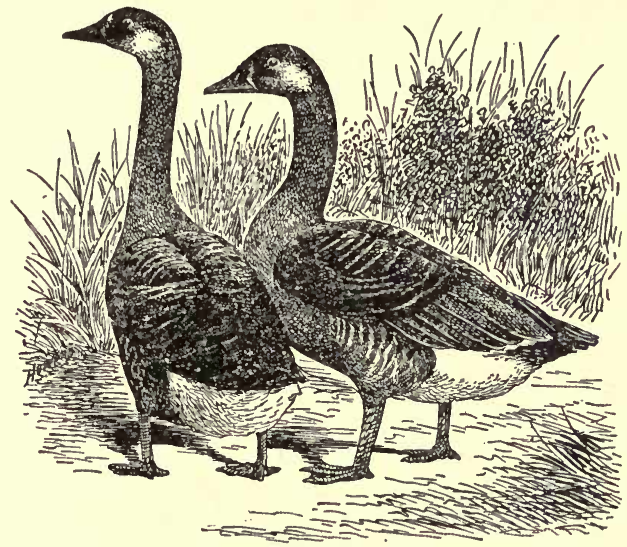

Fig. 96. Wild and African cross.-From United States Department of Agriculture, Farmers' Bulletin No. 64.-Howard.

necks and bear a knob at the base of the beak which gives them a peculiar appearance.

WILD, OR CANADIAN GOOSE

These geese are bred mostly for exhibition purposes and for parks. They are of medium size and are not bred for utility. They have long, slim necks 
and small heads. They, of course, retain the voice of the wild geese, which adds to their attractiveness.

\section{GEESE-FOOD AND CARE}

The first food for young goslings in nature is grass, and breeders prefer to provide this for the young of the domesticated geese. Grass at pasture is recommended. Moistened corn meal is also recommended. Grit in the form of sand or fine gràvel should be provided. Cooked vegetables make an excellent food and may be fed in the form of a mash. Bran, middlings, and corn meal, mixed with cooked vegetables, are highly recommended. As with ducks and chickens, it has been found best to give some animal food. Animal meal mixed with the moistened corn meal is recommended for young geese by many breeders. The food of breeding geese should consist chiefly of natural food gathered from the pasture. Insects, snails, and other animal life are then consumed. If animal food is not abundant, it may be supplied artificially to good advantage in the form of animal meal. It is essential to permit breeding geese to roam at will over areas of considerable size. For fattening geese, it is a general practice to confine them somewhat closely in order to prevent them from taking too much exercise. Europeans, who have become so noted for 
fattening geese, take great pains to keep them quiet. Every precaution should be taken to avoid any disturbance of the flock. Corn meal may form the larger portion of the daily ration for fattening geese. Meat scrap may enter into the ration up to one-fifth of the total amount, for immature fowls.

Pâté de foie gras.-In districts where the production of "pâté de foie gras" has developed into an industry, particularly about Strasburg, Germany, the geese are confined in individual stalls so closely that they are compelled to remain in a sitting or standing posture. The stalls are narrow, so that the birds are not even permitted to turn around. They are removed from this stall twice each day and fed, by the cramming process, whole Indian corn that has been thoroughly soaked. The corn is forced into the mouth by hand and pushed into the throat by the finger and is worked down the neck by rubbing externally. The geese are given plenty of pure water and grit in the form of fine gravel. The close confinement and abundance of corn cause the livers to grow abnormally large, sometimes weighing as much as three pounds each.

It is said that expert feeders will produce large livers in over 80 per cent of the geese fed. The livers when prepared are known commercially as "pâté de foie gras," and are esteemed a great 
delicacy. The feeders who sell livers to those who prepare them for the trade sometimes receive as much as $\$ 1.50$ per pound. In some districts, it is reported that great stress is laid on the grit which is furnished these fattening geese. Small pieces of antimony ore are said to be highly prized for this purpose. In some places the geese are suspended in nets, which prevent them from taking exercise.

Houses.-Geese require inexpensive and small houses. Comparatively rude and simple structures answer every purpose. Simple shelter from the storm is all that is necessary during the larger part of the year. While they require larger houses than ducks, and do not stand crowding to so great an extent, yet the buildings need not be expensive. Geese will require about the same space in the building per pound of live weight as ducks, but being much larger, require larger buildings for the same number of fowls.

Laying qualities.-Geese are long-lived. It is stated on good authority that they frequently live from thirty to fifty years, and individuals have lived to be more than a hundred years old. The females retain their breeding qualities through life, yet it is recommended to keep only young ganders. Those from three to five years of age are preferred. Geese are good sitters and make good mothers. In this respect they still retain well their natural instincts. Under ordinary conditions, 
a goose will lay from twelve to twenty eggs before incubation. If the eggs be removed from the nest, two or three sittings of eggs may be produced by one female before incubation will be persisted in. Usually it is recommended not to attempt to secure more than three sittings from one female before she is permitted to incubate. In practice, the first eggs are usually set under hens, the goose hatching the eggs that are laid last.

Geese frequently begin laying early in the spring, sometimes as early as February. Many instances have been noted where the laying commenced in in the late fall or early winter, but would not continue through the winter. In such instances the laying would begin again in the spring.

The period of incubation is stated by various authors to be from twenty-eight to thirty-one days, which without doubt will represent the limits under ordinary conditions. When eggs are placed under hens they are not covered quite so well as when placed under the mother goose, and incubation therefore may be delayed a little. 


\section{CHAPTER XIV}

TURKEYS, GUINEAS, PEAFOWLS, PIGEONS

OF the species of poultry aside from the hen, ducks and geese, none has risen to great popularity in North America except the turkey. The various kinds of pheasants and peafowls are grown more for fancy than for profit. At all events, they are not to be considered as important farm fowls.

\section{TURKEYS}

The wild turkey is a native of North America and still abounds in the natural forests of Pennsylvania, Virginia and other Atlantic states. It is also found in Tennessee and Kentucky, and is abundant in some of the western states, but its principal home in the eastern United States at the present time is in the mountainous regions of the Atlantic states. Like many other species of game it is rapidly disappearing, due to the great changes made by man in his onward march of civilization. Man is a great disturbing force of nature's equilibrium when he removes the forests in order to prepare the land for cultivation. He 
not only destroys the home of the game by removing the woods but causes frequent forest fires, which are destructive at the brooding season. Probably the number of wild turkeys is diminishing, yet, owing to their shy nature, they are not likely to become entirely extinct for many years.

The wild turkeys that are now found in the forests of North America are those which. have been strong enough to withstand the unfavorable conditions to which they have been subjected and which have escaped their natural enemies. In other words, they furnish a most excellent illustration of the "survival of the fittest." Persons who have had experience in breeding wild turkeys in confinement are convinced that they will do well and retain good breeding qualities on less food than will be required to keep domesticated turkeys in the same condition.

Wild turkeys appear to be somewhat taller in proportion to their weight than domesticated ones. "They thrive and keep in good condition on less food than the domestic turkey. Their slender, alert appearance is striking to the most careless observer. Their breadth of shoulder, deep chest and firm step are noticeable when they are compared with the domestic turkey. The head is small in proportion to the body, and has a clean, game-like appearance. The eyes are large, bright hazel, and full of intelligence and suspicion. . . Gobblers, 
when full grown, are about four feet high and weigh, according to the section of the country they are taken in, from 15 to 20 pounds each. They do not get their full growth until the end of the third year, and increase in weight and beauty for several years after that. Gobblers weighing 36 and 40 pounds have often been shot. . . Wild gobblers mate later and the hens lay later than domestic turkeys. The flesh of wild birds is of excellent flavor and is more delicate and juicy than that of domestic turkeys."*

The Rhode Island Experiment Station speaks as follows of wild turkey crosses: $\dagger$ "Where wild turkeys are plenty, crosses between wild and domestic birds frequently occur without design on the part of the owner of the latter. Scores of cases are recorded where a wild gobbler from the woods has taken possession of a flock of common turkeys, sometimes after first battling with and killing the domestic gobbler. The results of such a cross in almost every case have been so satisfactory that such matings are much desired by turkey-raisers in those sections, and young wild birds are caught for this purpose and brought up with common young turkeys. Very often nests of wild turkey eggs are found in the woods and hatched on the farm. These domesticated wild birds usually persist in roosting separate from the others, generally in

* Bulletin 25, Rhode Island Agricultural Experiment Station, p. 116. † Same, p. 119. 
the woods or on the top of a house or barn. When raised from the egg they become more gentle and fearless than the domestic turkey, but if chased or frightened they recover their wild habits very quickly. Wild turkey crosses are hardier and healthier than common turkeys and rarely have disease. Half-blood hens are generally too wild, but halfblood gobblers are not so wild and are suitable for crossing with domestic hens. A small proportion of wild blood improves the size, form, and general appearance, as well as the vigor, without being a disadvantage in any way. A quarter-wild cross is better for practical breeding than a pure wild or half-wild bird. Half-wild crosses do well if allowed a large range, but are not well suited to woody lands or as easily kept on small places as the domestic turkey.

"Wild turkey hens under domestication and wild first-cross hens often disappear in the spring and are not seen until fall, when they usually return to their own home with a brood of nearly full-grown turkeys. Half-blood mothers make their young too wild. Half-bloods reared by domestic turkey hens are not much inclined to stray. Quarter-bloods under certain conditions may be as wild as the wild bird of the woods.

"The flock of half-wild birds reared at the Station this season was very tame and unsuspicious until several were snared for exhibition at the Kings- 
ton Fair. Since then they have been so shy that we were unable to secure another lot. They take flight immediately if a suspicious movement is made. They will be more easily caught later in the season. The wild blood gives the cross an astonishing ability to care for themselves. It is apt to have the strongest influence in breeding. If first crosses are bred together the stock resembles the pure wild, and after several generations cannot be distinguished from the pure wild by good judges. The older the bird grows the more he shows the wild blood. Crosses have much of the superior game flavor of the wild and command a higher price for the table.

"Some wild bronze crosses that are half and threequarters wild blood are as large as the pure bronze turkeys. Several years' crossing, however, with the selection of the largest for breeding each season, gives the greatest size."*

Domesticated turkeys partake largely of the nature of the wild stock from which they have descended. Many of the domesticated flocks have been crossed with the wild fowl within recent years.

Turkeys that are commonly reared for profit on farms are of a roving disposition and do not thrive well when closely confined. On this account, they are not suited to rearing in large numbers on small areas. Owners of small farms or village lots, therefore, are practically debarred from rearing large

* Bulletin No. 25, Rhode Island Agricultural Experiment Station. 
numbers of turkeys, particularly if they are to be kept from trespassing on the holdings of their neighbors. While the mother turkey with her brooa may be confined in very limited areas for a time during the brooding season, yet as the young become older and are prepared to seek their own living, they thrive much better if close restrictions are not enforced. Whoever attempts to rear turkeys in considerable numbers should therefore plan to give them a wide range, particularly during the latter part of their growth. They are not able to adapt themselves to artificial conditions so well as chickens or ducks or even geese.

In North America there are two distinct species of native turkeys; one inhabits the United States and Mexico, the other is found in Honduras. The latter is sometimes spoken of as the ocellated turkey. The former has been separated into several varieties, the best known of which are the Mexican turkey, from which the common domesticated turkey is descended, and the wild turkey of the eastern United States. The Mexican form is somewhat smaller than the wild form of the eastern United States.

\section{TURKEYS-VARIETIES}

The recognized varieties of the domestic turkey are the Bronze, Narragansett, White Holland, Buff, Slate, Black, and Bourbon. 
The Bronze.-The Bronze is the largest variety. The weight adopted by the American Poultry Association is for this turkey, adult male 36 pounds, adult female 20 pounds. The origin of the variety is obscure. Some authorities maintain that it was formed by crossing the North American wild on

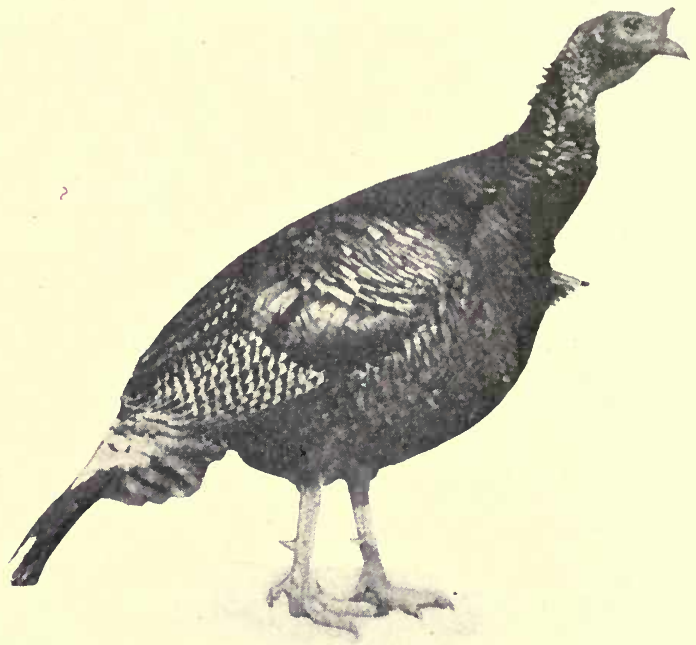

Fig. 97. Bronze turkey, male.

the domesticated Black. The wandering disposition of the Bronze is thought to be due to a comparatively recent infusion of wild blood. This is unquestionably the most popular variety, owing largely, no doubt, to its great size. Breeders and judges of turkeys lay great stress on the size of the Bronze. Correct plumage is not sufficient 
to redeem an exhibition bird if it lacks in size. (Fig. 97.)

Narragansett.-This variety takes its name from Narragansett Bay in Rhode Island. This state has long been noted for the large numbers and excellence of the turkeys which it has produced. The reputation ' of the Rhode Island turkeys was made largely when the Narragansetts were chiefly reared. In more recent years the Bronze has supplanted the Narragansetts to a considerable extent, which was due to the greater size of the former, although the latter are not small turkeys. The Standard gives the weight for Narragansetts as 30 pounds for the cock and 18 for the hen. They are of a gray color, although some bronze luster is seen on the wings. They have plump, thick-set bodies and grow rapidly. They mature early and do not roam so far as the Bronze.

The White Holland.-This variety is sometimes known as the White Turkey. It is not so popular as some other kinds, yet in a few localities it is a favorite. Many breeders who have had an opportunity to compare this turkey with others assert that it is one of the most profitable kinds. The White Hollands grow rapidly and attain a heavy weight at an early age.

"The White Hollands are perhaps the best layers among turkeys. It is sometimes reckoned as a fault that few hens want to hatch early in the 
season, and a large number of eggs and no broody hens is not an uncommon occurrence. . . . I believe them to be good turkeys and worthy of the best efforts of the breeders and farmers in general, and think no one need be seriously disappointed in them if he goes ahead properly and knows what he is doing."* The standard weight for White Hollands is given for cock 28 pounds and hen 18 pounds.

Buff turkey.-The Buff variety is thought by many to be the most beautiful of iurkeys. It is not known how the variety originated, although it was probably produced by crossing. The Buffs are about the same size as the White Hollands and are profitable fowls.

Slate turkey. - The Slate turkeys in many respects are very much like the Buffs. The color is thought by many to be the chief difference.

Neither of these varieties is largely bred, so their actual value as market turkeys has not been determined. Some breeders speak highly of them and, no doubt, they are valuable varieties, but there seems to be no indication that they are supplanting either the Bronze or the Narragansetts as profitable fowls for the farmer and poultryman.

Black turkey.-This is an old variety. It has been bred in England for a long time. "In certain parts of England it was, until quite recently, the *Geo. Enty, in "Turkeys and How to Grow Them."-Myrick, p. 28. 
favorite variety, and is known there as the Black Norfolk."**

Bourbon Red turkey.-These turkeys take their name from Bourbon County, Kentucky, where it is supposed they originated. In size they compare with the Narragansetts, cock 30 and hen 18 pounds. Breeders make rather strong claims for these fowls, yet it is very doubtful if they are superior to the three first-mentioned varieties. It is, however, an advantage oftentimes to have the different flocks of a neighborhood distinguished by variety characteristics so that they may be most readily separated should they become mixed.

\section{TURKEYS-GENERAL CARE}

At no time in the life of the turkey does its wild nature assert itself more than at the laying season. The domesticated turkey hen still loves secrecy as regards her nesting-place. Half-wild turkeys, when given their liberty, have frequently eluded all attempts on the part of watchers to follow them and to locate their nests. Many successful turkey-raisers who do not keep the breeding fowls confined within large inclosures provide nestingplaces for them in more or less secluded places. An empty barrel turned on its side or pieces of wide boards nailed together so that a low roof is formed *H.S. Babcock, in "Turkeys and How to Grow Them"-Myrick, p. 22. 
over a nest on the ground answer the purpose. As a good turkey hen will lay more eggs than she can cover well at one sitting, it is customary to remove the eggs from the nest daily and to place the first laid under broody hens. The last eggs should be given the turkey hen to hatch.

Some attempts have been made to rear turkeys by means of artificial incubators and brooders, but in many instances the results have been far from satisfactory. Most turkey-raisers depend upon natural methods of incubation and brooding. Turkey eggs hatch in twenty-eight days.

Selection of breeding stock.-Many farmers undoubtedly make mistakes in selecting young and immature birds for breeding stock. Experienced turkey-raisers insist on breeding from mature and well-tried birds. If a hen proves to be a good breeder and a careful mother, she should be kept as long as she proves profitable. The young of mature parents are thought to be considerably stronger than those of immature fowls. Two- or three-yearold toms are sometimes preferred to older ones on account of the great weight which older birds attain.

"A few plain rules which may be observed to advantage are as follows:

"First.-Always use as breeders turkey hens over one year old. Be sure they are strong, healthy, and vigorous, and of good medium size. In no instance 
select the smaller ones. Do not strive to have them unnaturally large.

"Second.- The male may be a yearling or older. Do not imagine that the large, overgrown males are the best. Strength, health, and vigor, with wellproportioned medium size are the main points of excellence.

"Third.-Avoid close breeding. New blood is of vital importance to turkeys. Better send a thousand miles for a new male than to risk the chances of inbreeding. Secure one in the fall so as to be assured of his health and vigor prior to the breeding season."*

"Mr. Grinnell, who lives on a farm near the Experiment Station, raises from 50 to 60 turkeys every season. Others in his neighborhood have poor success. He does not believe in changing gobblers when a good one has been secured. When he gets one that sires good stock he keeps him as long as he is good for anything. The one he now has is four years old. The hens also are kept as long as they live. . . . One hen that he has had for five years was said to have been eight years old when he bought her. She still lays from two to three litters of eggs each season, and her turkeys are larger than the others." $\dagger$

Number of females to one male.-The question is often asked as to how many females can be placed

*T. F. McGrew in Farmers' Bulletin No. 200.

† Bulletin No. 25, Rhode Island Agricultural Experiment Station. 
with one male for best results. It will be impossible to give any inflexible rule to govern this phase of the breeding operations, as freedom of exercise, strength, vigor, etc., are important factors bearing on this question. In extreme cases, the results have been all that could be desired, when twenty females were placed with one male; but under ordinary conditions it will be safest if no more than from four to eight females be placed with one male.

Care and food for the young.-Newly hatched poults are very delicate and require close attention on the part of the attendant. First of all, they must be kept dry. Wet or damp quarters should be avoided. A dry, porous soil is considered much more satisfactory than a heavy one, though the latter be underdrained. "Young turkeys should not be out in heavy showers until their backs are well covered with feathers. If they get wet, they may die from chill unless put in a warm room to dry. Black or red pepper and ginger in the food or drinkingwater aid them to overcome a chill, and are of great value on cold or damp days and are a preventive of bowel troubles in both old and young turkeys."*

For the first few weeks the young should be kept in dry places and not permitted to travel through tall grass when it is wet. During the warm and dry parts of the day they may be given a run on short grass or cultivated land. Many poultrymen prefer * Bulletin No. 25, Rhode Island Agricultural Experiment Station. 
placing the hen in a large, airy coop and giving the young a free run, rather than to confine the young and give the hen her freedom. In either case it is advisable to restrict the run of the young for a few days. It should not be omitted to move the coops frequently, that the young may be brooded on fresh ground.

The first food should be soft and easily digestible. Most turkey-raisers highly recommend hard-boiled

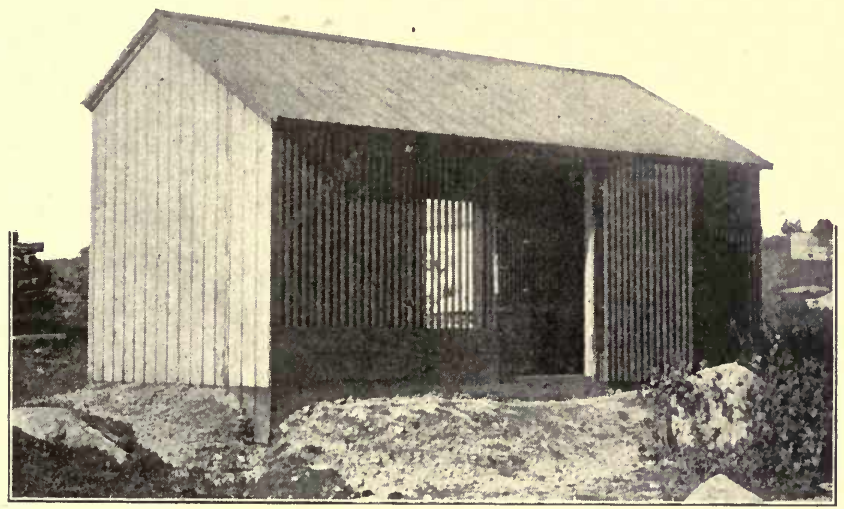

Frg. 98. Turkey house-Rhode Island Agricultural Experiment Station.

eggs chopped fine. This is a most excellent food, but should be fed in moderation and in connection with other soft foods. Stale bread dipped in milk and allowed to drain until it becomes dry enough to crumble is a most excellent first food. This may be fed until the young are several days old. It should be borne in mind that the bread, or any other food 
for that matter, should not be fed in a sloppy or very moist condition. Coarse bread baked for the purpose, if softened with milk, is highly prized.

It should be borne in mind that young turkeys are seed- and insect-eaters and not slop-eaters. While bread, milk, and eggs contain the elements most necessary for the growth of the young of nearly all fowls, yet it is important to have this food properly prepared as regards water content. Scalded bran and corn meal, to which some finely chopped hardboiled 'eggs have been added, is relished, and is a satisfactory food. As the poults become older, they may be fed bran, Indian meal and ground oats (the hulls removed) which have been thoroughly soaked. Freshly moistened meal foods are not equal to the same food that has become thoroughly softened by soaking or scalding. Thick sour milk or curd may be mixed with the soft foods to good advantage.

When the birds are beginning to "feather out," cracked corn may be added to the ration. Some successful poultry-raisers, however, recommend soaking the cracked corn at first. Later in the season whole corn may be fed. Old corn is preferred to new.

\section{GUINEA FOWLS}

These fowls are not reared in large numbers on farms devoted to that particular purpose, as are chickens and ducks, but comparatively small numbers 
are reared on many farms. The rearing of guineas in the southern part of the United States is of far greater importance than it is in the North. Where they are reared in the largest numbers the young fowls are highly esteemed for food.

Under ordinary farm conditions the domes-

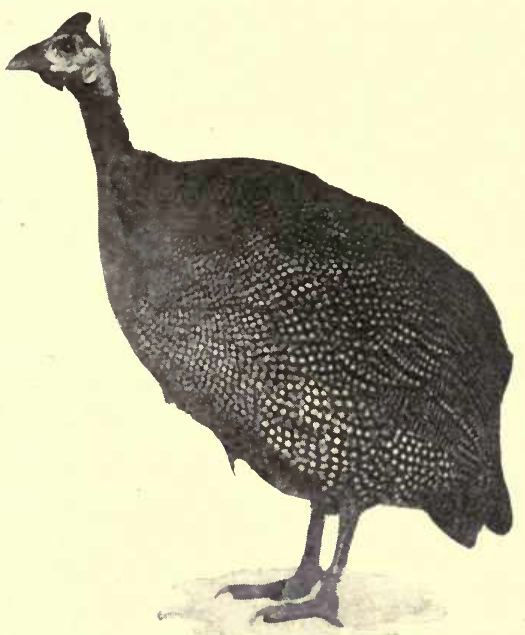

Fig. 99. A guinea hen (one-sixth size).

ticated guineas can hardly be called profitable farm fowls. They lay fairly well during the summer time if given a wide range, but, owing to the disposition of the hen to hide her nest, the eggs are often entirely lost. Many instances are known in which the hen has secreted her nest and continued to lay until it became well filled, when it would be 
abandoned for another. This, in turn, might be left to the same fate as the first. Instances are known of three nests being well filled with eggs before the hen showed any disposition to incubate.

Objections have been made to the fowl on account of its sharp, screeching voice. It is true that guineas make more noise than chickens and that their voices are somewhat piercing, yet they are not objectionable to most people unless the poultry yard and other places frequented by them are very near the dwelling-house. The writer has heard several farmers express a liking for these birds because they are "rather noisy." They are "company." Like geese, guineas are inclined to give an alarm if the poultry yard is molested. As a rule, these fowls mingle well in the poultry yard with chickens, both young and old.

Guineas like a wide range. They prefer to perch far from the ground-preferably in trees-although they will frequently perch with hens in poultry houses during severe weather, if given an opportunity to do so. Guineas are naturally shy and are easily frightened, although they may become tame with kind and careful treatment. While not strictly so, guineas are strongly inclined to be monogamous, and consequently it is necessary to keep almost as many males as females, if fertile eggs are desired. When several females are placed with one male, poor hatches are to be expected. 


\section{PEAFOWLS}

Peafowls are reared in small numbers by those who delight in seeing the most gorgeous plumage of domesticated fowls. They are not reared for their flesh nor for egg production. It is recorded,* however, that in the reign of Henry VI of England, peacocks were highly esteemed as a delicacy. In some respects peafowls are quite as near the wild forms from which they have descended as any species of domesticated fowls. They delight in perching at a great distance from the ground and frequently fly to the roofs of tall farm buildings. They fly easily and gracefully.

The male or cock bird is by far the most gorgeous of farm fowls. Peafowls are reared almost wholly on account of the proud and brilliant appearance of the male. The brilliant coloring of the head and neck feathers and his large and beautiful tail make him a source of delight to children and an interesting bird to adults. The hen is modest-appearing and unattractive in coloring. The cock is generally troublesome in the poultry yard on account of his disposition to kill other kinds of poultry, particularly young chickens and ducks. Cocks have been known to attack mature fowls and even children and adults. The male does not acquire his most brilliant and perfect plumage until he is more than * "Book of Poultry," Wright, p. 531. 
three years of age. The peacock is disliked by some on account of his loud, screeching voice, which he is inclined to use freely.

\section{PIGEONS}

While pigeons are not usually mentioned among the various kinds of profitable farm stock, yet the possibilities of profitable returns are so great that a somewhat full discussion of pigeon-rearing is warranted. However, only a short discussion will be devoted to the business as yielding money returns on the investment. To lovers of animal life, pigeon-rearing offers a most fascinating field, particularly to the boys and girls who delight in caring for stock that they may call their own. Many a farm boy has become interested in animal life and has learned many things which have been of great use to him in after years, that he acquired by caring for and studying the needs of pets which had been given wholly to his charge. Farm boys become dissatisfied with the farm and decide to leave it chiefly for two reasons-because they are not interested in farm life and work, and because they have not been taught how to make quick returns and good profits for the money invested. The rearing of pigeons will often afford satisfactory first lessons and may reveal possibilities that will be sufficiently enticing when considered from a standpoint of income alone. 
Interest in animal life, particularly those forms that are easily handled and controlled, serves a most useful purpose in leading the young mind along profitable channels of development. Interest in pigeon-rearing cannot fail to develop, to some extent, the powers of observation. Other things being equal, the boy who sees most will have the best understand-

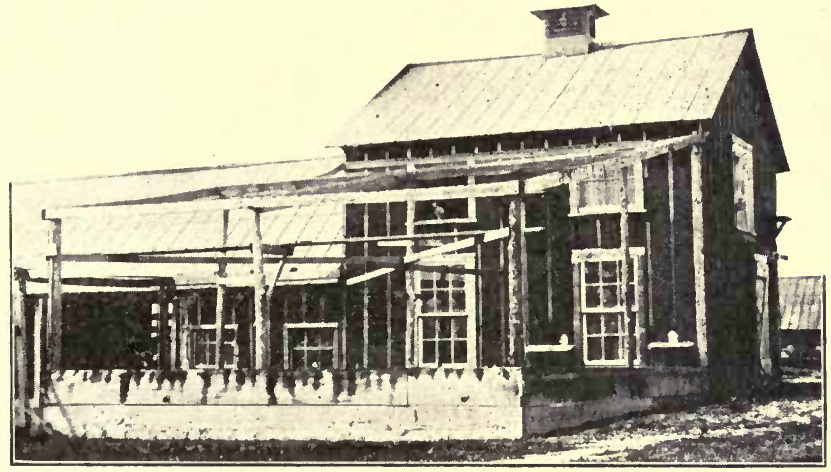

Fig. 100. Pigeon cote and aviary-Rhode Island Agricultural College.

ing of the subject in question. So long as knowledge is power, then those who are the closest observers will not only understand best the matter under consideration, but will be best prepared to meet the greater problems that each individual is required, sooner or later, to solve for himself.

The care of pigeons may be given almost wholly to quite young boys and girls, if a few simple directions for feeding and care be understood, and a suitable home be provided for the birds. On most 
farms only a small money outlay will be required, and very little trouble is necessary to prepare comfortable quarters for breeding pigeons, particularly if the young be sold as squabs.

"The shelters for squab-breeders should not be too cold, although the experienced can raise them in almost any old shell of a building, as far north as New York city. The fittings are only nests, perches and drinking- and bath-fountains, a space of two square feet of floor being counted to each bird, with never less than twice as much room in the flight yards, in the open air. The flight spaces are best enclosed by inch-mesh wire net, as this excludes sparrows, which are arrant thieves and fighters. The netting usually runs overhead, to the highest point of the roof."

A fine quality of squabs finds a ready market in the great cities. They are quoted from about 50 cents to $\$ 4$ per dozen, and frequently the expert producers obtain nearly twice this amount. For the money outlay, squab-raising offers a tempting field for those who are willing to give attention to the many little things. To those who are not willing to observe closely the needs of the birds and to use good judgment in meeting these demands, pigeonraising will probably prove unsatisfactory, affording neither pleasure nor profit. The negligent or careless person should not enter into the poultry busi* “Pocket Money Poultry," Norys, p. 140. 
ness, since success depends on the many minor things which cannot be neglected. Squab-rearing may be made very profitable if "eternal vigilance," the price of success, be given.

Most of the squabs that are now sold in the markets of the large cities average from one-half pound to three-quarters of a pound each, while the choicest birds may weigh nearly twice as much.* Many experienced squab-raisers prefer a cross of Runts and Homers for fine birds. The mother should be a Homer, as these birds are better breeders and better mothers than the Runts.

The health of pigeons should receive close attention. They should be given an opportunity to bathe, and such conditions should be provided as will produce the strongest and most vigorous squabs. Light-colored squabs sell best on the market.

A variety of grains is usually fed. Cracked corn, wheat, hulled oats, millet, hemp, and other small seeds are much used. Cracked corn is a favorite food. Pigeons are particularly fond of salt. Many pigeon raisers keep a supply of salt accessible to the birds at all times. As the old birds feed the squabs, it is essential that the parents be well fed. A clean sanded floor is an excellent place for feeding the old birds.

*"Pocket Money Poultry," Norys, p. 142. 


\section{CHAPTER XV}

PREPARING AND MARKETING POULTRY PRODUCTS

THE advance in price of poultry products, particularly the meat products, makes their condition when they reach the market of greater relative importance. With low prices the different grades do not vary greatly, but with comparatively high prices the variation in grades due to quality and appearance is very marked.

Those who are preparing poultry for market should constantly bear in mind that it is of the utmost importance to have the products reach the market in the most perfect condition. Flesh that is clean and bright always presents a more attractive appearance than that which is discolored. Fowls are sometimes discolored as the result of improper methods of packing and shipping. Careless packing and rough handling - the latter too often given by the employees of railroads and express companies - frequently cause a good article to reach the market in a poor condition, and it therefore brings a low price. It is the privilege of every shipper to prepare his fowls in such a manner that they may reach the market in as inviting con- 
dition as possible. The best-appearing fowls always sell at a higher price than equally as good stock that has been improperly prepared or is untidy. Commission men state that properly prepared meat will readily sell for twice as much as an equally good article that is poorly arranged and uninviting.

\section{DRESSING POULTRY}

Those who have taken the trouble to study the conditions of the markets in the great cities say, without hesitation, that the good stock is sold first and that the poor and indifferent often becomes a drug on the market. New York commission men are quite positive in the conviction that shippers who send considerable produce to market and who prepare their product in uniformly fine order readily acquire a reputation among buyers. This is always an advantage and is a material aid in securing better prices. Thorough and careful preparation enable shippers to secure a somewhat higher price than the same stock would bring if prepared in an indifferent manner.

In order to arrange products for market in the best possible manner, it is necessary to study the details of killing, dressing and packing, which will enable the producer to send not only those articles which the market demands, but to send them in the best possible condition. Fowls should 
not be fed for some time before killing. At least twelve hours, and in many cases twenty-four hours, should elapse after the last feeding before the killing takes place. At any rate, the crops of the chickens should become entirely empty. Some cities have passed ordinances prohibiting the selling of dressed fowls whose crops are not free from food. In such markets the law makes it imperative that solid food should be withheld long enough before killing to permit the crops to become entirely empty.

If for any reason a few fowls should gain access to food just before killing time, and it is not desirable to retain them longer on the farm, they may be killed and dressed with the rest, and after picking, a short, clean-cut incision may be made through the skin, which will permit the removal of the crop. An incision should be made in the crop, the crop turned inside out, thoroughly cleaned and returned. The practice of removing grain from the crop by forcing it out through the mouth by external pressure is not recommended; in fact, it is condemned in positive terms by dealers. While in some instances it may be possible to empty the crop without breaking the skin, yet it will be necessary to use sufficient force in many cases to cause discoloration.

There are two methods used in preparing dressed fowls for market. These are known as dry-picking and scalding. It may be stated in a general way 
that the finest quality of chickens and turkeys commands higher prices when dry-picked. On the other hand, lean or thin poultry does not present so good an appearance as when scalded and "plumped," as will be explained later, and therefore does not sell so well. Ducks and geese are usually scalded, with the exception of young, fat ducks, which are known on the market as "green ducks." These are usually dry-picked.

Killing.-Those who are required to perform the operation of killing fowls should bear in mind that it is desirable to remove all the blood from the body that can be withdrawn, and to cause the fowl to suffer as little pain as possible. In other words, the operator should be as humane as circumstances will allow. He may, at the same time, prepare his birds in the best possible manner.

All kinds of fowls are recommended to be killed by cutting through the roof of the mouth. This will cut through an artery, which will cause the blood to flow freely. A sharp-pointed knife should be used for this purpose, which should pierce the base of the brain; it will cause death at once. It is said by experts that a fowl may be killed so quickly that the blood will not flow as freely as desired and that the feathers will be removed with more difficulty, especially if dry-picking is practiced. The ideal condition is to have the knife enter the brain and paralyze the fowl, and while in this 
condition to have it bleed to death. If the fowl becomes paralyzed the muscles are relaxed and the feathers are easily removed. Too much stress cannot be laid on the importance of thorough bleeding. Americans prefer to have all flesh free from blood. The keeping quality is thought to be considerably enhanced by thorough bleeding. In all the operations of killing and picking, care should be taken to avoid bruising the flesh, tearing the skin or breaking the bones.

It is customary to suspend fowls by the feet before they are killed. In the case of heavy fowls they should be so suspended that they will not strike each other with their wings when flopping, or strike their wings against any hard object. Fowls bleed best when suspended head downward at the time of killing.

Dry-picking.-Immediately after killing, the feathers should be removed carefully and cleanly. Dressed fowls should be sent to market, if possible, without the skin being broken at any place. It is usually customary to commence picking immediately after sticking. "Green ducks" and broilers are usually picked while the bleeding is taking place. As soon as the incision is made with the knife, the birds are stunned by a blow on the head and then picking commences at once. It is essential in drypicking to remove the feathers as soon as possible after the birds are killed. 
When fowls are picked dry, to be shipped in cold weather, they should be hung in a cool place until thoroughly cold before they are packed. Poultry should not be packed until all of the animal heat has disappeared. A cool place is preferable to one so cold that the flesh will freeze quickly. If the skin is wet when the fowls are packed, they are likely to present a more or less discolored appearance when offered for sale. When dry-picked fowls are to be packed in ice for hot-weather shipment, they may be plunged into cold water for a short time immediately after picking and then placed in a tank of ice water and left for several hours. Some extensive duck-raisers make a practice of leaving the picked ducks in cold water over night. Either ice water or cold spring water may be used for this purpose.

Young fowls, especially ducks, that have many pin feathers are sometimes prepared by shaving with a sharp knife after the feathers are removed. This removes the projecting parts of the pin feathers and will help to place the fowl in the best possible condition for market. Of course white birds are much preferred on this account to colored ones. The English use a short, thin-bladed knife in removing the pin feathers. This operation is called "stubbing," and is generally performed by women and children.

Scalding.-When birds are scalded they should 
be immersed in hot water immediately after they are through bleeding. The water should be a little below the boiling-point. It is recommended to immerse the birds thoroughly in the water three or four times, lifting them out between each immersion in order to give them a little airing. Immediately after scalding, chickens and turkeys should be picked clean, and care be taken not to break the skin. The skin of young fat fowls is more likely to tear than that of older ones. As these birds are the most valuable, it is necessary to exercise the greatest care and skill in preparing them. After scalding ducks and geese, it is recommended to wrap them in a cloth for about two minutes, in order that the down may be more readily removed with the feathers.

Plumping.-Commission men recommend that scalded poultry be "plumped" after picking. That is, after the fowls are carefully picked, they should be dipped in hot water for a few seconds. This water should be about the same temperature as that used for scalding, perhaps not quite so warm. Then they are removed and placed at once in cold water, where they should remain from fifteen to twenty minutes. If fowls that are scalded and "plumped" in this manner are to be shipped dry, they should be hung up until the skin becomes thoroughly dry. If they are to be packed in ice for warm-weather shipment they may be placed in 
cold water for several hours, when they will be ready to pack. It is not necessary to dry the fowls when they are to be packed in ice.

In scalding fowls, care should be taken not to leave them in the water too long. Over-scalding will cause the outer surface of the skin to peel off, and consequently, they will not present a good appearance. If they are under-scalded, the feathers cannot be removed so readily, and salesmen find that they do not appear so well when exposed for sale.

\section{PACKING AND SHIPPING}

If the fowls are to be packed dry for cool-weather shipment, neat packages that are clean, and as light as will carry the contents safely, are to be preferred. Uniform packages are preferred to various kinds of rough boxes. Clean barrels or neatly prepared cases should be used. It is recommended to use cases or boxes for turkeys and geese, and barrels for chickens. In packing poultry, it is customary to use clean, dry wheat or rye straw. The straw should be free from chaff, and handthreshed is preferred to that which has been threshed by a machine. A layer of straw should be placed in the bottom of the package, and then alternate layers of poultry and straw until the package is full. Heavy paper is placed by some poultry shippers between the poultry and the sides of the package. 
All fowls should be perfectly clean and dry before packing. If there is any moisture or blood about the head it should be removed with a cloth. If a fowl is inclined to bleed a little at the mouth, the mouth should be thoroughly wiped out and a little cotton inserted to absorb any liquid that might otherwise cause discoloration.

Packing in ice.-Large barrels are usually employed for this purpose. If sugar barrels are used, they should be thoroughly washed, preferably with hot water, to remove all traces of sugar. Expert packers place a layer of cracked ice in the bottom of the barrel, then a layer of poultry, then another layer of ice, and so on until the barrel is full. After the top layer of poultry is in place, there should be a layer of cracked ice placed on top. On this layer spread a piece of burlap which is sufficiently large to cover well the top of the barrel. On this burlap some cracked ice may be placed and on top of all a large piece of ice. Over all place another piece of burlap. This may be held in place by driving the top hoop on over the burlap.

It is recommended to place the fowls heads outward, backs up and the feet toward the middle of the barrel. That is, the fowls as placed in the barrel should slope from the center toward the staves. This will cause the ice as it melts to work from the center toward the outside of the barrel. In transit the ice nearest to the outside of the barrel 
will melt first. It is, therefore, of considerable importance to have those parts of the fowls nearest to the outside of the barrel cooled by the ice which is in the center of the barrel. The water and ice from the center will continually work toward the outside.

Frozen poultry.-Poultry is frequently shipped during cold weather in a frozen condition. Commission men recommend that only the best quality of poultry should be shipped in this manner. Only dry-picked fowls should be selected for freezing. When poultry is frozen by natural out-of-door temperature, cases may be filled when the fowls are thoroughly frozen and the temperature is low. It is not necessary to use ice in packing when frozen fowls are shipped. Poultry that is frozen solid may be kept for a long time, even for months, provided it does not thaw out.

Marking packages.-If dressed poultry is sent to middlemen, each package should be marked with the name and address of the commission man and also with the name and address of the sender. It is also well to mark on each package its contents, whether chickens, fowls, turkeys, ducks or geese, and the number of birds or gross weight. It should not be neglected to forward advice by mail, giving a correct statement of all goods sent. If inferior or second-quality fowls are shipped, it is always best to state to the commission man the contents of 
the package and also the quality. If a poor quality of goods is sent, he is sure to find it out, and it may save him considerable annoyance if he knows what the package contains before it is opened.

There seems to be a disposition on the part of some shippers, who are not very familiar with the business, to refrain from marking packages as to quality. Nothing can be made by this practice as the quality will be known before a sale is made. A good rule is to help the dealer, then you may expect favors from him.

Time of shipment.-When poultry or eggs are sent to commission men, it should be borne in mind that these products, if for immediate sale, should reach them in the middle or early part of the week. Many commission men sell very little after Friday noon. In a general way, it may be stated that Saturday is retailers' day; that the retailers are supposed to have their stock on hand before Saturday, and that they do not go to the commission men for their supplies during that day. Shipments are often made so that they reach their destination late in the week and are, therefore, carried over until the beginning of the next week.

English and German methods.-The English method of preparing fowls for market is, in many respects, very different from that in vogue in the United States, and undoubtedly would not be acceptable to the most fastidious in this country, 
who have become accustomed to other methods of dressing and marketing fowls. The English method of preparing young fowls for market, which have been fattened by the cramming process and which affords a most delicate flesh, is to kill them without bleeding. While in the United States great stress is laid on removing as much blood as possible from the body, the English prefer not to have the fowl bled at all. The operator holds the fowl with his left hand and grasps the head with his right. He gives a forcible, forward pull with his right hand, holding the head at right angles to the neck. He uses enough force to dislocate the neck just below the head. This kills the fowl at once and frequently causes considerable blood to settle in the neck, although no blood leaves the body. When dry-picking is practiced the fowls are picked at once after the neck is dislocated. Pickers become very expert in dry-picking fowls. As the hand moves back and forth over the body the feathers gradually disappear, and in less time than it requires to describe the operation properly an expert picker will have the feathers removed from a good specimen. While the English do not meet our requirements as regards the drawing of blood, yet in some respects they take more pains in preparing the bids for market than Americans do. As soon as the birds are picked, they are frequently placed on what is known as a "forming machine," prepared for the purpose and weighted, 
in order to make the bodies appear plump. The legs are folded underneath the body, which gives a plumper appearance. Before the fowls are placed on the machine the breast bone is sometimes broken down, though not always. The stern of the fowl is pressed firmly against a smooth, hard object in order to give it a flattened appearance. This appearance is still further increased by the use of the machine on which the fowls are placed. They are left on the shelves until cool. Sometimes, however, they are sent to a near-by market before the animal heat has left the body. The English method of preparing fowls for market has some advantages over that in use in the United States. There is no doubt that fowls will appear plumper when cooled on a "forming machine," after the English fashion, than when hung up by the feet to cool according to the almost universal custom in America.

The "forming machine,"* see Fig. 101, is made by arranging conveniently a series of shelves so that each shelf has a backboard placed at nearly a right angle to it. The shelves slope backward somewhat, which keeps the fowls which are placed upon them snugly in the angle formed by the shelf and the backboard. The width of the shelf is determined somewhat by the size of the fowls to be placed upon it. Those who are extensively engaged in fattening fowls have different sizes of "forming machines." * "Fattening Fowls," E. Cobb. 
For medium-sized chickens, shelves about seven inches wide are used. The English become very skilful in using the machine to the best advantage.

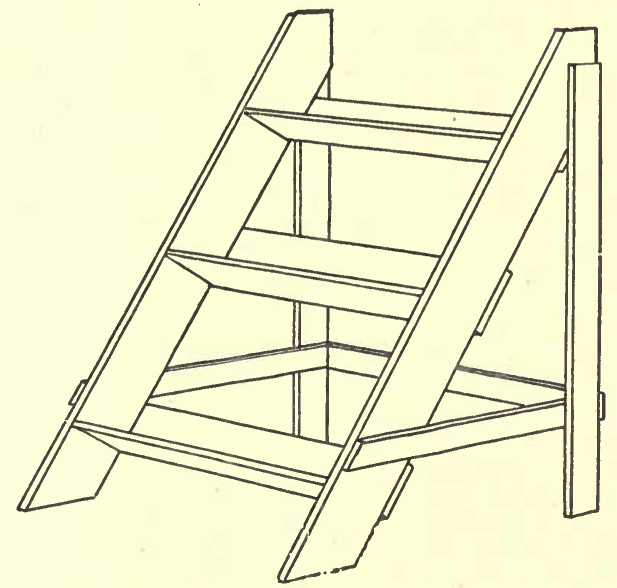

Frg. 101. An English “forming machine," which is used to give a plump appearance to dressed chickens.

The operation of preparing the fowls by the use of this machine may be briefly described as follows: They first squeeze out any matter from the vent, then grasp the bird, back uppermost, with both hands. The thumbs are placed on the back with the fingers clasping the legs, 'which are bent underneath the body. While held in this position the bird is pressed forcibly against a smooth wall or post, which forces the "parson's nose" upward so that its point is above the back. During this operation the body is held firmly, but care is taken not 
to mar the skin. The bird is placed carefully in the machine so that the "parson's nose" is held

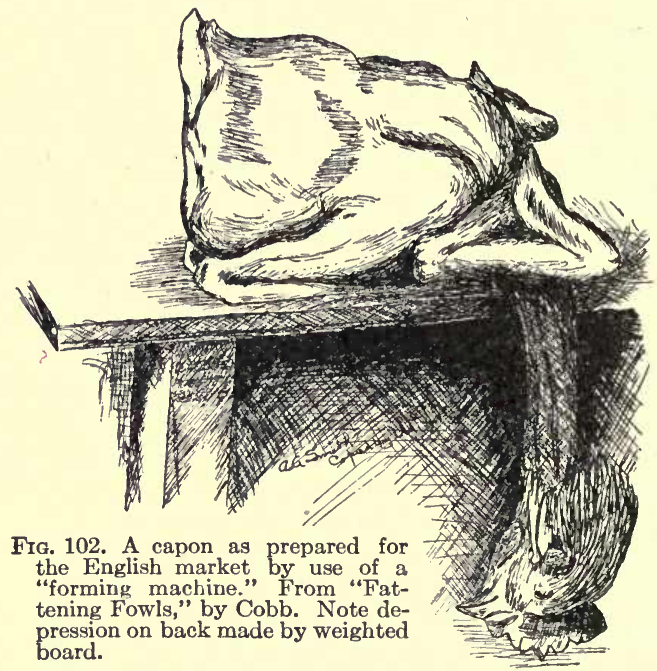

straight up against the backboard, the head and neck hanging over the front of the shelf. When the shelf is filled with birds that are tightly packed side by side, a board three or four inches wide is placed on the fowls and heavily weighted. They are left in this position until cold. (See Fig. 102.)

The English frequently break down the breast bone of young fowls that are not very fat, in order to give them a plumper appearance. This may be done by grasping the fowl with both hands and pressing with the thumbs on the breast until the 
bone, or the structure which supports it, breaks and leaves the fowl with a less prominent breast. The Germans frequently break down the breast bone of chickens and ducks by striking a smart blow on the most prominent part of the bone with a smooth, well-rounded paddle.

\section{SHIPPING LIVE POULTRY}

When live poultry is shipped long distances to market, it should be placed in coops which are high enough to permit the fowls to stand erect. It is also an advantage, and will give comfort to the occupants of the coop, if the top is made of slats which are far enough apart so that they may straighten up and pass their heads between the slats.

Shipping crates or coops should be as light as is consistent with the requisite strength. Large and heavy crates are awkward to handle and are expensive to transport. Large coops on many accounts are not so desirable as small ones, particularly if they are well filled with heavy fowls. It should be borne in mind that these shipping crates or coops are required to be handled quickly, and if they are heavy, rougher usage is given them than would be given to smaller ones. These coops are usually sent by express, and the employees of the express companies find it necessary to work rapidly and often are prevented from handling the coops carefully. 
If large coops are used, they should have one or more partitions across them so that the fowls will not all be thrown to one side, if for any reason the coop becomes tilted. When tilted, large coops without partitions cause great discomfort to the occupants on the lower side of the coop, and in many cases if the coop remains tipped for any considerable time, death may result from suffocation.

It is important that the fowls of a crate or coop should be uniform; that is, the sexes should not be shipped in the same division of a crate and young fowls should not be sent with old ones. It frequently happens that a commission man or dealer can find ready sale for a uniform lot of fowls but is unable to dispose of a mixed lot. It is often inconvenient, if not impossible, for him to sort and grade them, consequently the fowls are sold at a sacrifice. Middlemen and dealers of the great cities are busy and are accustomed to do a great deal of business in a short time. They do not have the time and conveniences for the grading that should be done before the fowls are placed in the shipping-crates. They want things ready.

\section{EGGS-CARE AND HANDLING}

It is important that eggs receive proper care immediately after they are laid if they are to be marketed in a strictly first-class condition. 
The loss to the country through the marketing of deteriorated eggs is great, and any movement that will tend to lessen the evil cannot help to be of value to the farmer and poultryman. *'It has been estimated that about five per cent of all the eggs marketed in this country are culled out as "dirties" causing a loss of about one per. cent on the total value of the egg crop of the country.

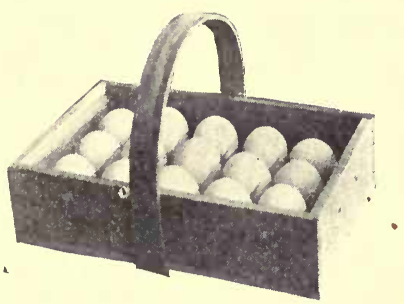

Frg. 103.

A convenient egg-carrier. For this the farmer and poultryman are alone to blame."

Eggs that are not perfectly clean should not be sent to market. Indifferent or careless poultrymen permit the nests to become fouled, and many eggs are not clean when gathered. Eggs may be stained from nest material, and they are sometimes colored with blood, particularly the first eggs of pullets. Stains of various kinds may be readily removed with a moistened cloth on which has been dusted a little cooking soda. Poultrymen who make a specialty of fancy eggs are particular to send clean eggs to market, and also take considerable pains to ship only those of uniform size and color. Uniformity is of great importance when the highest prices are to be secured. As a fruit-grower

* United States Department of Agriculture, Bureau of Animal Industry, Circular No. 140. 
recognizes that a few large apples when mixed with those of medium size do positive injury, so far as the market value is concerned, so expert egg producers recognize that a few large eggs mixed with those of average size detract from the appearance, and, consequently, from the market value. The purchaser is attracted by uniformity. If he sees that all the eggs on top of the crate are of uniform size, color, and shape, he naturally expects uniformity throughout. On the other hand, if he finds that they are of all sizes, he cannot expect uniformity in the lower layers. If one's flock consists of purebred stock, the eggs should be fairly uniform in shape and color, and also in size, although large eggs and abnormally small ones will occasionally appear; these may be kept for home consumption or for the local market.

Much has been said about marketing eggs in a strictly fresh condition. Those who have had years of experience, and have established a reputation that has become almost national, are convinced that the market will not distinguish between an egg one day old and one four days old. An egg four or five days old is in a perfectly fresh condition, if it has had good treatment. If it has been subjected to the heat of an incubator for that length of time, it would not be fresh. Eggs may be sent to market hundreds of miles by express and placed in the hands of the consumer when not more than 
a few days old. Whenever a poultryman who aims to produce the finest quality of eggs desires to establish a reputation for himself, it will probably be necessary for him, at first, to send his eggs under a guaranty that they were produced by his own flock, and that he knows them to be strictly firstclass in every respect.

Many deteriorated eggs are shipped to market and are there sorted out; some are known as "heated eggs." These are fertile eggs that have been subjected to a sufficiently high temperature to perceptibly start the development of the germ which if continued long enough would produce the fully developed chick. This may have been done in the nest, perhaps under a broody hen, or by keeping the eggs in too warm a place in the barn or house, or during the time occupied in traveling from the farm to the market where the poor eggs are culled out. The loss from this cause alone is thought to be several times that caused by eggs becoming spoiled.

\section{SPOILED EGGS}

Evaporated or "shrunken" eggs are those that have been allowed to dry out through the natural process of evaporation. They are readily detected by the increased size of the air-chamber which shows that the egg is not fresh. Eggs kept for some time in a dry, well-ventilated room lose so much 
moisture that they cannot be sold as fresh and are culled out as "shrunken."

There is another large class of deteriorated eggs known as "rots." These eggs have become totally unfit for food through bacterial contamination. The loss to dealers from this source is great, which eventually must be borne either directly or indirectly by the producer.

It is to be regretted that there has not been developed in this country a more rapid and satisfactory method of gathering eggs from the farm and transporting them to the consumer, in order that this great loss might be lessened as far as possible and the consumer be given a greater guarantee as to quality.

It has been suggested that in dairy districts where daily trips are made from the farm to the creamery or skimming station, that fresh eggs be delivered with the milk. This would enable the creamery to make frequent shipments and thus prove an efficient agency in the handling of this important food product.

Shipping-cases.-Eggs are usually sent to market in shipping-crates which are constructed specially for this purpose. The standard-size crate holds thirty dozens. (See Fig. 104.) These crates, or shipping-cases, contain trays which fit into the outer case, one above the other. The trays are divided by pasteboard partitions into many sepa- 
rate compartments, each compartment holding one egg. Some shipping-cases have wire springs instead of the pasteboard partitions to hold the eggs. The English prefer what is known as the Irish shipping-case. This consists of a case not unlike a small drygoods box. In this is placed a layer of sea grass similar to that used in packing

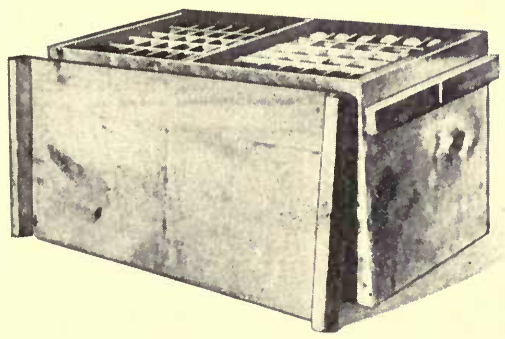

FrG. 104. A thirty-dozen-egg shipping case.

china and glassware. The grass is placed in the form of a shallow hen's nest. This is filled with eggs. On these is placed another layer of sea grass and another layer of eggs, the layers of eggs and sea grass alternating until the case is nearly full. More sea grass is then put on and the cover fastened by nails or screws. While this case is preferred by the English, it is doubtful whether it would be sufficient to withstand the rough usage given by the American express companies and freight lines.

Many commission men prefer to have eggs shipped to them in barrels, packed in dry, finecut, clean wheat or rye straw. Barrels are strong, rigid packages for their weight, and are well adapted for shipping. A barrel will hold about seventy dozen, if properly packed. 


\section{PRESERVING EGGS}

During the spring and early summer months, when a large proportion of the hens that are kept on farms are laying, the price of eggs is frequently very low, particularly in local markets where most of the farm eggs are sold. In such times many eggs are preserved until late fall, when the price is usually the highest. Many persons make a business of preserving eggs in order to reap the benefit of the advance in price; others preserve them in times of plenty for home consumption when the hens are not laying. Many others would attempt to keep them if they but knew of a simple and safe way of preserving them. To such persons it may be said that there is no well-known way of keeping eggs absolutely fresh for any considerable length of time. There are several methods, however, that are sufficiently satisfactory to warrant the preservation of eggs both for the market and for home use. Preserved eggs are thought to be injured by cold sooner than fresh ones. The following gives the results of experiments made in Germany with various preservatives:*

"The Berliner Markthallenzeitung reports about experiments made for the purpose of securing the most rational method of preserving eggs. Twenty methods were selected for these experi*United States Consular Reports, Dec., 1897, pp. 563, 564.-Thieriot. 
ments. In the first days of July, four hundred fresh eggs were prepared according to these methods (twenty eggs for each method), to be opened for use at the end of the month of February. . . . After eight months of preservation the eggs were opened for use, and the twenty different methods employed gave the most heterogeneous results

1. Eggs put for preservation in salt water were all bad.

2. Eggs wrapped in paper, 80 per cent bad.

3. Eggs preserved in a solution of salicylic acid and glycerin, 80 per cent bad.

4. Eggs rubbed with salt, 70 per cent bad.

5. Eggs preserved in bran, 70 per cent bad.

6. Eggs provided with a cover of paraffin, 70 per cent bad.

7. Eggs varnished with a solution of glycerin and salicylic acid, 70 per cent bad.

8. Eggs put in boiling water for twelve to fifteen seconds, 50 per cent bad.

9. Eggs treated with a solution of alum, 50 per cent bad. 10. Eggs put in a solution of salicylic acid, 50 per cent bad. 11. Eggs varnished with water-glass (wasserglas) 40 per cent bad.

12. Eggs varnished with collodion, 40 per cent bad.

13. Eggs covered with lac, 40 per cent bad.

14. Eggs varnished with sward, 20 per cent bad.

15. Eggs preserved in ashes of wood, 20 per cent bad.

16. Eggs treated with boric acid and water-glass, 20 per cent bad.

17. Eggs treated with manganate of potassa, 20 per cent bad.

18. Eggs varnished with vaseline, all good.

19. Eggs preserved in lime-water, all good.

20. Eggs preserved in a solution of water-glass, all good.

"The last three methods are consequently to be 
considered the best ones, especially the preservation in a solution of water-glass, as varnishing the eggs with vaseline takes too much time, and the treatment with lime-water sometimes communicates to the eggs a disagreeable odor and taste."

Water-glass.*_"We tried the keeping of eggs with sodium silicate (water-glass) with good results. Sodium silicate is a compound containing silicon, sodium and oxygen in the proportion of one, two and three respectively. It can be purchased from druggists in the form of a semi-fluid resembling thick sugar syrup, for which it might easily be mistaken. .

"An experiment was conducted in our department for the purpose of determining the most effective degree of concentration. The result of the experiment is of considerable importance, inasmuch as the cost of the mixture may be greatly reduced without destroying its value.

"On the 27th of May, we took twelve dozen eggs, all known to be perfectly fresh, and prepared the following solutions:

No. 1. One part of water-glass in the semi-fluid form to ten parts water.

No. 2. One part water-glass in the semi-liquid form to fifteen/ parts water.

No. 3. One part water-glass in the semi-liquid form to twenty parts water.

* 24th Annual Report Ontario Agricultural College, pp. 193, 194. 
"The first solution was found to be too strong, as it caused the eggs to float. The second was all right in this respect. The third, though much weaker, gave perfect satisfaction. We divided the eggs into three lots of four dozen each, and put one lot into each solution. We tested them from time to time, and in every case found them perfectly fresh; and, on breaking, we noticed that the yolk stood up exactly as in new-laid eggs, and did not show the slightest tendency towards decay. "We tested one-half dozen from each solution on the first of December, and could not detect any difference in the appearance or quality in the eggs out of the different solutions, all being perfectly fresh after being in the solution six months. . .

"In order to use water-glass successfully, the following plan should be adopted: Take one part by measure of water-glass, say one gallon, and twenty parts by measure of water that has been boiled (twenty gallons), and allow the water to cool; then place the water-glass and water in a vessel; stir the ingredients well together; put the eggs into the tub or vat in which they are to be kept, and pour the solution over them until the topmost layer is completely covered. The reason for boiling the water is to kill any putrefactive germs which may be in the water at the time. If water-glass is purchased by the cwt., it should be procured for $\$ 2.50$ to $\$ 3$ per cwt. (112 lbs.). 
"So far as we know this is the best solution yet tried for the preservation of eggs. When taken out of it the eggs have the appearance of freshlaid eggs, and when they are broken the yolk stands up exactly as in new-laid eggs, without showing the slighest tendency toward decay. It is first necessary, before boiling eggs that have been kept in this solution, as in lime pickle, to puncture the shell with a needle, otherwise the shell will crack as soon as placed in hot water, owing to the pores of the shell being closed."

The reports of tests, made with water-glass as an egg preservative, from different parts of the country would indicate considerable variation as to the strength or thickness of commercial water-glass. The Storrs (Conn.) Experiment Station recommends that the mixture be made in the proportion of nine quarts of boiled water to one quart of water-glass. At any rate the specific gravity of the preserving liquid must be low enough to allow the eggs to sink readily.

The following precautions should be quite strictly observed:

Use strictly fresh eggs

Keep the eggs, immersed in the preservative, in a dry, cool place where the variation in temperature is comparatively slight.

Do not attempt to preserve cracked eggs.

Keep all of the eggs submerged in the liquid at all times. 
The preservative should not be used for more than one year.

Lime-water.-A most satisfactory lime-water preservative may be made of the following ingredients:

$\frac{1}{2}$ bushel fresh quicklime.

15 pounds salt.

$\frac{1}{4}$ pound cream of tartar.

40 gallons of water.

Slake the lime thoroughly and add the water and salt. Stir it well. Dissolve the cream of tartar in a little water and add to the whole. Stir well. Let the solution stand until it is fully settled. Remove the clear liquid by dipping or by means of a siphon. Place the liquid in a cask or tank and put in the eggs. It is desirable to keep the eggs in a cool place that has an even temperature. Have at least one and one-half inches of the liquid above the eggs. New oak casks should not be used on account of the liability to color the eggs.

Cold storage.-Eggs that are kept in large quantities by dealers are placed chiefly in cold storage. A low, even temperature is maintained by the use of ice, or by means of ice machines: Ice machines have wholly superseded the use of natural ice in large establishments. 


\section{CHAPTER XVI \\ DISEASES AND ENEMIES}

IT would require an exhaustive treatise by one who had given years of study to the subject to present in a thorough manner a discussion of the various phases of the many diseases to which farm poultry are subject. Many of the troubles are insidious and are not yet well understood. However, a few general hints on the more common diseases, and a discussion of some of the parasites, may be valuable to those who have not the time or inclination to study the subject in detail. The one paramount safeguard against disease is thorough cleanliness; then avoid introducing infected fowls.

\section{LICE}

Various kinds of domesticated fowls and wild birds are infested with parasites that are known under the popular name of "lice." There are several species of lice which infest chickens. Some kinds are found only on a certain class of poultry, while others are sometimes found on more than one kind. There are at least four 
species which are very troublesome to chickenraisers, particularly to those who do not keep their poultry-yards and -houses in a cleanly condition. Filth and dampness seem to favor the propagation of these pests. Fowls are naturally cleanly, particularly those that have their liberty and, consequently, live under conditions nearest the natural ones. Weak fowls are always more likely to be troubled with lice than are strong, healthy, vigorous ones. Many years ago it was thought that filth and dampness produced lice. While these conditions undoubtedly favor the increase and development of these pests, yet they can only be produced in a flock by the introduction of an infected bird or by placing the fowls in infected quarters. The life-history of these parasites is so well known that it is not thought possible for them to be introduced in any other way. The species of lice which infest chickens vary considerably as to their shape and size, yet in their habits they closely resemble each other. They are very small insects, varying from one-fifth to less than one-fiftieth of an inch in length. These parasites rarely pierce the skin and suck the blood, as do mites and fleas. They cause much annoyance by crawling over the surface, and sometimes they bite the skin in a way that causes considerable irritation and perhaps some inflammation. When fowls are once infested they may become unthrifty 
and unprofitable if not given proper care. It has been estimated that a single pair of lice may produce, through the quickly successive generations which would be reared within three months, more than 100,000 individuals. As the weaker fowls of the flock are most likely to be infested, lice are often detected by the unthrifty condition of such birds. Upon examination, large numbers of these lice may be seen crawling over the skin underneath the feathers. They will likely be most prevalent on those parts which the fowl cannot reach with the beak.

Remedies.-Fowls may be effectually treated in several ways. Substances may be put upon the bird which will poison the lice, or the pests may be driven off by making the fowl an uncongenial home for them, or they may be killed by the application of substances, like oil, which stop the breathing pores and thus cause them to die of suffocation. The last plan is preferable in the case of the young chickens and weak fowls. Little chickens when but a few days old are frequently infested with lice from the mother or from the surroundings. As these little chickens are delicate, a few lice will cause serious trouble. In this case, it is usually advisable to place a few drops of oil on the head and perhaps on the wings and throat of each chicken Sweet oil or lard oil may be used. Other oils of about the same consistency may answer the pur- 
pose quite as well. Older fowls should be given an opportunity to take dust baths. This is nature's method and is effectual if the fowls will bathe thoroughly. Many of the heavier fowls, however, do not care to take dust baths frequently, nor to do the work thoroughly when they undertake it; consequently it is frequently necessary to use artificial methods to kill or drive away the lice, when they once become well established on adult fowls. Powdered sulphur or fresh insect powder dusted well among the feathers is found to be efficient. Fowls are sometimes placed in comparatively tight boxes with their heads protruding through close-fitting openings, the box then being filled with sulfur fumes for several minutes. This is said to completely destroy the pests and in no way to injure the fowls.

When poultry-houses become infested with lice a complete cleansing of the building is required. Movable fixtures should be taken out and the walls thoroughly washed and cleansed. The interior should be freshly whitewashed or sprayed with chlorides or other efficient insecticides. Kerosene emulsion is effective if the spraying is thoroughly done. Some modern spraying machines are so constructed that kerosene oil may be mixed with water in a fine spray to answer every purpose. This method is easier than to apply the kerosene in the form of a soap emulsion. 
MITES

These parasites are frequently called "lice," although they are entirely different from the animals described under that name. Mites are usually smaller than lice. The red poultry mite is one of the greatest pests. It is frequently called the "summer louse" and is found in great numbers in the poultry-house and other places frequented by fowls in the summer time. It is frequently seen about cracks and crevices, underneath and about the perches, and also in the nests, particularly those of sitting hens. It multiplies rapidly, so that if a few have been introduced into a poultry-house, the place may become overrun within a short time.

The habit of these pests is very different from that of lice. The mites breed in cracks and chinks about the perches and nests and go on the body of the fowls at night to feed. They pierce the skin and fill themselves with blood. Though they are small, each insect can remove an appreciable amount of blood. The fowl not only suffers from the loss of blood but is disturbed during the night when it should have perfect rest and be free from annoyance. Sitting hens are so much annoyed that they are compelled to leave the nests in order to relieve themselves of the parasites. If the nests and perches, and the cracks and crevices about them, are 
kept free from the pests, the fowls will not be disturbed. Free use of kerosene oil or kerosene emulsion about the nests and perches will usually suffice. Some manufacturers have taken advantage of the habit of these pests and construct perches which will not permit them to pass from the places of concealment about the poultry house to the body of the fowl, each perch being supported by means of slender iron supports, the bases of which are placed in small cups filled with oil.

A little care and watchfulness on the part of the poultry attendant to keep the poultry-house entirely free from mites will protect the fowls from these pests.

\section{GAPES}

Gapes sometimes destroy large numbers of small chickens; in fact, on some farms during certain seasons it seems almost impossible to rear broods of young chickens that are entirely free from it, particularly if the young chickens are kept under the ordinary conditions. It is well known. that gapes are caused by a small worm known as Syngamus trachealis. This worm is of a reddish color and varies in length from three-eighths to threefourths of an inch. The two sexes are united, which fact has given rise to the name of "branched worm." On account of its color it is also some- 
times known as the "red worm." It is stated that the male is always attached to the female, the former being the smaller of the two. These worms are found in the windpipe or trachea of the chickens, where they are attached to the membraneous lining of this air-passage. They are nourished by sucking the blood of the fowl and cause considerable irritation and inflammation, particularly if the chickens are weak. The stronger and more robust undoubtedly are considerably inconvenienced, but the attacks are not severe enough to prevent them from making a fairly good growth. It is stated, on good authority, that as many as thirty or forty of these worms have been found in a single chicken.

Dr. H. D. Walker, Newburgh, N. Y., states that the earthworm is the natural host of this pest. Chickens, robins and other birds have become infested with the gape worm by feeding them infested earthworms. Comparatively few gape worms are sufficient to destroy the life of weak young chickens. Many more, however, would not necessarily destroy a vigorous bird, either young or adult. These worms are frequently dislodged by coughing or sneezing. When they are thrown out in this manner other fowls may eat them and in turn become infected.

Remedies.-Keep little chickens in a dry place and away from infected ground. As the weak 
fowls are likely to succumb first, it is of the utmost importance that the brood be kept in as healthy and vigorous condition as possible.

It is recommended to dislodge the worms by introducing into the trachea a horsehair, doubled so as to form a loop, then give it several turns, and slowly withdraw it. As the loop is withdrawn the dislodged worms may be removed or coughed up by the fowl. This operation repeated several times will frequently give relief to aggravated cases. Other good authorities recommend the introduction of a feather which has been moistened with turpentine. The turpentine will cause the dislodgment of the worms and the chickens will sneeze or cough them up.

Some practical poultry-keepers recommend placing an infested brood in a barrel or comparatively tight box and dusting in the the compartment a considerable quantity of fine air-slaked lime. The infested chickens will be required to breathe the air heavily laden with this fine lime, which will cause the dislodgment of many of the worms. While this treatment is rather severe and may cause the death of some of the weakest of the birds, yet it will sometimes prove efficacious in saving the larger proportion of a brood which otherwise might succumb.

Preventive measures are more satisfactory than remedial ones. Keep the chickens in a dry place 
and in as healthy and vigorous a condition as possible, and away from sources of contamination.

\section{ROUP}

Roup is a common disease among farm poultry and one that often causes serious loss. When roup is permitted to remain in a flock unchecked, the loss from death alone may be considerable, and the loss occasioned by many sick birds which are for a long time thoroughly incapacitated for usefulness may be quite as great. Roup is considered contagious by the most eminent authorities. It passes from one fowl to another of the same flock, and may be carried from one flock to another by the introduction of infected birds. It has been considered by some as being produced by unfavorable conditions. This is not strictly true. Undoubtedly unsanitary conditions are potent factors in the development of the disease when the fowls are once exposed. Tender fowls, or those requiring particularly good care, are more susceptible to roup than are the more healthy, or robust. The introduction of the specific organism of the disease is necessary for its development; hence it is a communicable disease.

Symptoms.-Among the first symptoms that will be noticed is a thin, watery discharge from 
the nostrils, followed by obstructed breathing. A few cases of harsh breathing that had not previously been manifest should be looked upon with suspicion. These cases may be readily detected by passing through the poultry house in the evening when all is quiet. In the later stages of the disease the watery discharge at the nostrils becomes thicker and more sticky, which causes frequent sneezing in order to prevent the air-passages from becoming completely closed.

Dr. D. E. Salmon says* that the inflammation extends, as the disease advances, from the membrane of the nasal cavities to those of other connecting passages. As the orbital space which surrounds the eye connects with the nasal passage, this is frequently involved. The membrane of the orbital cavity becomes inflamed and swollen, and in severe cases apparently forces the eye from its socket. The sides of the head become unduly swollen and the fowl frequently becomes entirely blind, the birds presenting a most unsightly appearance. Breathing is performed with difficulty, and a thick discharge at this time, may escape from the nostrils. Death frequently follows after these serious symptoms.

Treatment.-Prevent healthy birds from becoming contaminated by removing them to clean quarters, or by the removal of the sick birds and * "The Diseases of Poultry," pp. 32-34. 
thoroughly cleaning and disinfecting the poultryhouse. Give wholesome and easily digested food and keep the fowls in as healthy and vigorous condition as possible. Antiseptic solutions are to be injected into the nostrils and on the roof of the mouth. If large swellings have appeared which are filled with cheesy pus, this should be removed and these cavities be injected with antiseptics. The following solutions are recommended:

1. Two per cent solution of creoline.

2. Two per cent solution of carbolic acid.

3. Peroxide of hydrogen and water, equal parts.

4. One grain of permanganate of potash to an ounce of water.

5. Kerosene oil mixed with equal parts of lard or olive oil. Some poultrymen recommend the use of pure kerosene oil, a drop in each nostril of the infected fowl.

When diphtheritic roup develops, white patches are frequently seen on the roof of the mouth and on the connecting air-passages. Later these patches become more or less yellow. Dr. Salmon also says* that the sick birds should be placed in clean, warm, well-ventilated quarters, where they can be readily examined and where they will not be exposed to drafts of air. In other words, these quarters should be most favorable for invalids. * "The Diseases of Poultry," pp. 224, 225. 
He recommends the application, to the diphtheritic spots in the mouth and eyes, of a 2 per cent solution of carbolic acid in water or a 2 per cent solution of creoline, and that some of the same should be injected in small quantities into the nostrils. The removal of this diphtheritic membrane is recommended if it can be accomplished without bleeding. Tincture of iodine has been applied to the diseased parts successfully. Boric acid, 15 grains to an ounce of water, may be applied to the roof of the mouth, nostrils and eyes. This application is often made with benefit, and is considered safe. Dr. Salmon further recommends the use of chlorate of potassium and salicylic acid in the following proportions: 2 grains of salicylic acid and 35 grains of chlorate in 1 ounce of water, to which may be added 1 ounce of glycerine. This should be applied two or three times a day on the diphtheritic spots and may be given internally in doses of about a teaspoonful to adult fowls.

"Disinfect thoroughly by sprinkling the walls of the building and the ground frequented by the diseased fowls with carbolic acid water $\left(1 \frac{2}{3}\right.$ ounces of carbolic acid to a quart of water). Wash feeding-troughs, water-dishes, etc., with the same solution. Cover the earth with straw or boards and keep the fowls perfectly dry.

"Mix with the soft food several hours before 
feeding, as a curative and a preventive, a pinch of the following mixture for each fowl:

Hyposulfite of soda..................50 grams

Salicylate of soda................. 50 "

Pulverized yellow gentian..............200 "

Pulverized ginger....................200 "

Pulverized sulfate of iron.................100 "

"Give sulfate of iron in the drinking-water, $11 / 2$ grams to a quart of water."*

\section{CHOLERA}

Dr. Salmon. states $\dagger$ that fowl cholera attacks chickens, geese, ducks, turkeys, pigeons, and in fact all varieties of domesticated fowls. The infection often takes place through drinking-water, or partaking of food that is contaminated by the excrement of sick birds. It is possible for fowls to be infected through wounds or by means of the germs which may be inhaled in the form of dust. He further states that the disease is generally brought in by the introduction of infected birds or with eggs that have been purchased for hatching. This disease may be communicated to mice and rabbits by inoculation.

Symptoms. - "The symptoms of American fowl cholera were first described by Dr. Salmon in * “Journal D'Agriculture Pratique," 1895, Tome 2, pp. 913, 914. $\dagger$ "The Diseases of Poultry," pp. 233, 234. 
1880. They include the voiding of feces, of which the part that is normally white is yellow. The white part of the feces is excreted by the kidneys, and the yellow discoloration of this excrement is usually the first indication of disease. Shortly thereafter the droppings become thin and fluid, and they are voided frequently and enveloped by a layer of thin mucus. The fowl becomes depressed; it stands still or assumes a sitting posture, goes into a sunny, warm place, if possible. The plumage becomes ruffled, the head is drawn down, the comb becomes pale and bloodless, and the appetite is depressed or lost. The depression and torpidity of the fowl increase until it seems to become unconscious. . . The bird then becomes thin and weak, and sometimes passes into a stupor and dies. In other cases, it may have convulsions prior to death."*

Treatment.- "The treatment of individual fowls afflicted with such a highly contagious disease as true fowl cholera is not to be recommended, because, in the first place, so long as the infected fowl remains around there is danger that its poisonous products may be carried to healthy birds; secondly, there is little chance of curing it and it is hardly worth while to try.

"The important point in this connection is the prevention of disease, and fowl cholera can usu* "Diseases and Enemies of Poultry," Pearson \& Warren, Bulletin No. 17, Pennsylvania State Department of Agriculture. 
ally be stopped by preventing the introduction of fowls suffering from it, or that come from infected localities. If the disease is once introduced the most stringent measures should be enforced as regards cleanliness, disinfection, and the total destruction of the carcasses of the dead birds. The birds that are still healthy should be removed from the flock and placed in a wholesome locality. The droppings from the diseased fowls should be burned or thoroughly disinfected by mixing with a 10 per cent solution of sulfuric acid or with a quantity of lime equal in amount to the manure. The building should be disinfected by cleaning it very thoroughly, flushing the floor with a saturated solution of copperas and spraying the interior with a 5 per cent solution of carbolic acid, followed by whitewashing. If the pens and runs can be abandoned for a year and grass or crops grown in them, this is the best plan, but if it is not possible to do this, they should be cleaned with as great thoroughness as possible and slaked lime scattered over the surface of the earth, which should be plowed.

"It should be remembered that the germs of fowl cholera may be carried in the feathers, so that a perfectly healthy fowl, coming from a diseased flock, may carry the disease to another flock a long distance away. These germs may also be carried on the shoes and clothing of persons; by vermin, as rats or mice, or they may become attached 
to light objects, such as leaves, and be carried long distances by the wind. If the disease exists among the fowls along the water-course, those lower down the stream may receive the germs with their water-supply. So, whenever this disease prevails in a locality, one cannot guard his fowls too carefully.",*

BACILLARY WHITE DIARRHEA OF YOUNG CHICKS

The term "white diarrhea" undoubtedly has, for many years, been used to designate a variety of bowel disorders in which the discharges of the digestive organs are more or less whitish in character and show to a greater or less extent symptoms of diarrhea. But not until recently has it been determined beyond question that the most serious of these disorders is due to a specific bacillus Bacterium pullorum. It has long been known that the so-called white diarrhea was sometimes one of the most serious and fatal disorders to which little chickens are subject, but knowledge as to the true nature of the disease has come through recent investigation and study.

†"Symptoms of bacillary white diarrhea.-As in many other diseases the symptoms may vary within certain limits in the individuals affected...

* "Diseases and Enemies of Poultry," Bulletin No. 17, Pennsylvania State Department of Agriculture.

† Storrs (Conn.) Agricultural Experiment Station Bulletin No.60. 
but most of the following will be apparent in epidemics of any considerable size. The earliest deaths may occur within a very short time after hatching without any prominent symptoms except perhaps weakness and lack of vitality. The characteristic whitish discharge from the vent soon makes its appearance in the flock . . . the discharge may be slight or profuse, in color white or creamy, sometimes mixed with brown. The voided matter has a more or less sticky or glairy character. It may streak down below the vent or may cling to the down sufficiently to seal up the vent. . . . Chicks soon become listless and sleepy . . . wings droop or project slightly beyond the body, with feathers ruffled. In acute cases the eyes are closed and chicks become indifferent to everything about them. Frequently when endeavoring to void excreta the chicks utter a shrill twitter apparently a cry of pain. The weakling is almost always big-bellied, the abdomen protruding to the rear so that it bunches out behind. . . With few exceptions deaths from typical bacillary white diarrhea occur while the chicks are under one month of age. Chicks which have had bacillary white diarrhea seem to be greatly weakened in constitution and fall an easy victim to disorders which would be easily resisted by normal chicks.

"The mother hen is the original source of infection of the chick . . although the disease may 
be transmitted through the food during the first three or four days of the chick's life.

"Prevention. - Since the disease cannot apparently be transmitted through the food supply after the chicks have reached the age of three or four days, every means should be pursued to prevent the spread of the infection during this critical period. We suggest the segregation of the chicks in small lots during this interval; perfect disinfection and cleanliness of brooders and brood coops; food and water supplied in such a manner as to prevent contamination by the droppings; the use in the brooder of a liberal amount of fine absorptive litter which will quickly cover and seal up the droppings. (For this purpose we have used alfalfa meal with much satisfaction.)

"Raise and maintain the vigor and vitality of the breeding stock and chicks by every reasonable means known to poultrymen. . . .

"If the breeding stock proves infected there are two courses of procedure open; (a) market the entire flock or refrain from using their eggs for hatching or (b) install trap nests in the breeding-pens . . and ascertain which individual hens are producing infected chicks, and remove them."

SCALY LEGS

This disease is caused by a parasite somewhat similar to that of the mange of the cat and dog. 
The disease is considered to be contagious, though it does not spread rapidly. It is most frequently noticed in old fowls of the heavy breeds, as of the Asiatic types. Ducks and geese are not affected with this trouble.

Treatment.-Soak with oil-sweet oil or lard oil mixed with kerosene is recommended. Kerosene alone is sometimes applied with most excellent results. However, it is a somewhat harsher treatment than is necessary. Those who keep on hand a stock solution of kerosene emulsion may find this a most excellent remedy for scaly legs. It should be applied thoroughly. A few applications are usually sufficient. If thorough work is to be accomplished the poultry-houses should be disinfected.

\section{FREEZING}

Valuable fowls sometimes die from frosted combs and wattles. Remedial measures are not so satisfactory as preventive ones. The most that can be done is to give good nursing. If the fowls are discovered to be frosted before the organs affected have thawed out, the frost should be removed by applications of cold water or snow. The gradual thawing of the frozen parts may sometimes save them. After thawing has taken place, the parts should be smeared with grease, vaseline or cosmoline. 
It is thought to be advantageous to keep the fowls in a fairly cool room.

\section{BUMBLE FOOT}

Bumble foot is caused by bruises on the bottom of the feet. These bruises are sometimes followed by swellings which suppurate and become greatly enlarged if they are not lanced and the pus permitted to escape. Causes which produce bruises should be removed. Heavy fowls that are required to fly from rather high perches and to alight on hard and uneven surfaces are liable to suffer from bumble foot. In serious cases it is advisable to inclose the feet in little bags filled with poultice in order to induce free suppuration. If the pus is not permitted to escape, it becomes cheesy and finally dries sufficiently to form a hard mass, which produces a permanent enlargement.

\section{EGG-EATING}

This habit sometimes becomes a most serious vice in the poultry-yard. It spreads from fowl to fowl. Fowls become very fond of eggs when they once learn to eat them. The habit usually starts through accident, either by eggs being broken or frozen. If eggs are not permitted to freeze in the poultry-house, and care is taken to prevent 
their being broken, the habit is not likely to be contracted. As soon as it is discovered that a fowl has the habit well formed this fowl should be removed from the others before the habit is spread. Unless the bird is a specially valuable one, it is often advisable to inflict the death penalty.

\section{FEATHER-EATING}

Feather-eating, like egg-eating, may become a most objectionable habit. Fowls of active breeds that are closely confined are more likely to learn feather-eating or feather-pulling than those that are given wide range and plenty of wholesome food. Close confinement with improper ration will often lead to this vice. When once the habit is well formed it may become most troublesome. Fowls pluck the feathers from each other. Those on the back at the root of the tail or high up on the breast are likely to be plucked first. If but few fowls have learned the habit, it is sometimes recommended to file the beak so that the front and sides will not close tightly. This will prevent the bird from pulling feathers but will permit it to eat ordinary food readily. When several fowls of a flock have but slightly contracted the habit, a wide range with change of diet, including plenty of animal food, will usually suffice to correct the evil. Above all, permit the fowls to take plenty of exercise. 


\section{DIARRHEA}

Diarrhea is caused by some irritation of the digestive system. Depression and loss of appetite frequently precede it. If the diarrhea is at all serious the excrement may be mixed with mucus or blood. Fowls suffering from this disease should be placed in comfortable quarters and given clean, wholesome food that is easily digested. Foods of gelatinous nature, like cooked linseed meal, are specially recommended. Some poultrymen place a high value on charcoal which has been broken into small pieces, about the size of a kernel of corn. This is placed before them and left to the judgment of the fowls to eat what is needed. A few drops of laudanum is recommended in severe cases.

\section{SALT POISONING}

Salt in small doses, as before stated, is very beneficial, but large quantities may produce death. It is stated on good authority that one-half an ounce to one ounce is fatal to a chicken. Salt fish and some salt meats, and the brine in which meats have been preserved, are specially dangerous.

Whites of eggs and the liquor of boiled flaxseed are recommended as remedies. Laudanum and finely powdered chalk in water, together or singly, may sometimes be given with good effect. 
Laudanum is especially valuable when considerable pain is manifest.

\section{RATS}

Rats sometimes become very troublesome in poultry-houses, and the question of their extermination is often a most perplexing one. Precautionary measures are usually the most satisfactory. If the buildings are so constructed that rats cannot burrow under them, the battle is largely won. If, however, the rats find suitable homes about poultry-houses, and cannot be driven out by ordinary methods, much annoyance and often severe loss may result. When traps and cats will not suffice, more extreme measures must be adopted. Sometimes it is advisable to remove the fowls temporarily and hunt the rats by means of ferrets. In some cases it may be necessary to resort to poisoning. In a general way it may be stated that animals should not be poisoned except in extreme cases. The author has on several occasions found it necessary to use poison to rid the premises of these pests. A little strychnine was placed in each of many small pieces of cheese. These little pieces were dropped into the rat holes and other places frequented by the vermin, care being taken in every case to cover the holes with boards so that the fowls would be prevented from gaining access to the poison. While 
the fowls were not killed or in any way.injured by this method of killing rats, the practice is always accompanied with more or less danger, particularly as it is necessary to place the poison near places frequented by the fowls.

\section{HAWKS, CROWS, ETC.}

It is sometimes necessary to protect the yards and runs from the depredations of these chicken thieves. Crows sometimes become so bold that they are serious pests in yards where little chickens are given their liberty. Covering the yard with wire netting is a perfect protection. If there are bushes in the yard, under which the fowls may hide, the depredations will be much lessened.

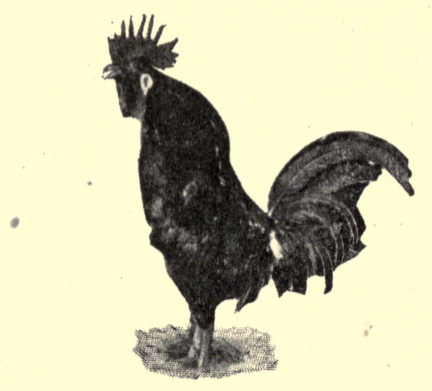





\section{APPENDIX}

SOME IMPORTANT POULTRY PUBLICATIONS

American Standard of Perfection.-American Poultry Association. Published by the Association.

American Standard Poultry Book.-John Taggart. Published by Wm. L. Allison, New York.

Animal Protein for Ducks.- - New York State Agricultural Experiment Station Bulletin No. 259.

Artificial Incubating and Brooding.-Reliable Poultry Journal, Quincy, Ill.

Appliances and Methods for Pedigree Poultry Breeding.Maine Agricultural Experiment Station Bulletin No. 159.

Asıatics.-Reliable Poultry Journal, Quincy, Ill.

Bantam Fowl.-Reliable Poultry Journal, Quincy, Ill.

Blackheads in Turkeys.-Rhode Island Agricultural Experiment Station Bulletin No. 124; Oregon Agricultural Experiment Station Bulletin No. 95.

Book of Poultry.-L. Wright. Published by Cassell \& Co., London.

Breeding for Egg Production.-Maine Agricultural Experiment Station Bulletin No. 192.

Breeds, Poultry Raising.-Colorado Agricultural Experiment Station Bulletin No. 164.

Breeds.-Kansas Agricultural Experiment Station Bulletin No. 150.

The Book of Hamburgs.-Theo. Hines. Published by Inland Poultry Journal Co., Indianapolis, Ind.

The Briggs System, Profits in Poultry Keeping Solved.Edgar Briggs, Springfield, Ohio. 
Brollers and Roasters.-Jno. H. Robinson. Farm Poultry Publishing Co., Boston.

Brooding.-West Virginia Agricultural Experiment Station Bulletin.

Brooder, Fresh-Air.-Maine Agricultural Experiment Station Bulletin No. 193.

Building Poultry-Houses.-Cornell Agricultural Experiment Station Bulletin No. 274.

Capons and Caponizing.-G. Q. Dow, New York.

Capons and Caponizing.-United States Department of Agriculture, Farmer's Bulletin No. 452.

Capons for Profit.-Cyphers.

Chicк Boок.-Reliable Poultry Journal, Quincy, Ill.

Chicken Hatching and Rearing.-H. A. House, St. Paul, Minn.

Common Sense Poultry Doctor.-John H. Robinson, Boston. Curtain-Front Poultry-House.-Theo. Whitman. American

Poultry Journal Publishing Co., Chicago, Ill.

Development of the Chick.-Frank R. Lillie. H. Holt \& Co., N.Y. Diseases of Poultry.-Dr. D. E. Salmon. Published by Geo. E.

Howard \& Co., Washington, D. C.

The Dollar Hen.-M. M. Hastings. Acadian Press.

Duck Culture.-James Rankin. Published by the Author, South

Easton, Mass.

Ducks and Geese.-Reliable Poultry Journal, Quincy, Ill.

Ducks AND Geese.-United States Department of Agriculture,

Farmers' Bulletin No. 164.

Drawn vs. Undrawn Poultry.-United States Department of Agriculture; Bureau of Chemistry, Circular No. 70.

Economy of Using Animal Food in Poultry Feeding.-Bulletin

No. 149. Published by New York Agricultural Experiment

Station, Geneva, N. Y.

Egg and Poultry Raising at Home.-M. M. Elkinton. Doubleday, Page \& Co., New York City.

Egg Production.-Maine Agricultural Experiment Station Bulletin No. 193.

Egg Trade of United States.-United States Department of Agriculture, Bureau Animal Industry, Circular No. 140. 
EGgs and Their Uses AS Food.-United States Department of Agriculture, Farmers' Bulletin No. 128.

Eggs-Classes of, for Market.-United States Department of Agriculture, Bureau of Animal Industry, Circular No. 140. EgGs AND EgG Farms.-Reliable Poultry Journal, Quincy, Ill. Experiments with Geese.-Eighth Annual Report. Published by Rhode Island Agricultural Experiment Station, Kingston, R. I.

Experiments with Turkeys.-Sixth Annual Report. Published by Rhode Island Agricultural Experiment Station, Kingston, R. I.

Facts about White Diarrhea.-Dr. P. T. Woods. Reliable Poultry Journal Publishing Co., Quincy, Ill.

Fattening Fowls.-Ernest Cobb. Published by The Feathered World, London.

The Feathers Practical Pigeon Book.-Josiah C. Long. G. E. Howard Publishing Co., Washington, D. C.

Feeding Experiments with Laying Hens.-Bulletin No. 90.

Published by New York Agricultural Experiment Station, Geneva, N. Y.

First Lessons in Podltry Keeping.-J. H. Robinson. Farm Poultry Publishing Association, Boston.

From the Shell to the Show Room.-R. E. Jones, and Theo. Hewes. Published by Inland Poultry Journal Co., Indianopolis, Ind.

Fowls: Care and Feeding.-G. C. Watson, Farmers' Bulletin No. 41. Published by the United States Department of Agriculture, Washington, D. C.

Gapeworms of Fowls.-H. D. Walker. Published by the Author, Newburg, N. Y.

GAPES.-Delaware Agricultural Experiment Station Bulletin No. 47. Geese, Standard Varieties and Management.-United States Department of Agriculture, Farmers' Bulletin No. 64.

Goose Breeding.-Tenth Annual Report. Published by Rhode Island Agricultural Experiment Station, Kingston, R. I.

Goose Septicemia.-Rhode Island Agricultural Experiment Station Bulletin No. 86. 
Guinea fowl and its Use as Food.-United States Department of Agriculture, Farmers' Bulletin No. 234.

House Construction.-Michigan Agricultural Experiment Station Bulletin No. 266.

How to Dress Poultry.-S. V. Thomas. Published by A. D. Hosterman Company, Binghamton, N. Y.

How to Keep Hens for Profit.-C. S. Valentine. Published by The Macmillan Company, N. Y.

How to Make Poultry Pay.-F. G. Paynter.

Hamburgs up to Date.-Charles Holt. Published by The Feathered World, London.

Illustrated Book of Domestic Poultry.-Martin Doyle. Published by Porter \& Coats, Philadelphia.

Improvement of the EgG FARM.-United States Department of Agriculture, Bureau of Animal Industry, Bulletin No. 141.

Incubation and Brooding.-E. B. Hawks, Clinton, Wis.

Incubation and Its Natural Laws.-C. A. Cyphers.

Incubators and Their Management.-J. H: Sutcliffe.'Doubleday,

Page \& Co., New York City.

Indian Game Fowl.-G. T. Whitefield. Published by The Fanciers' Gazette, London.

Indian Runner Duck Book.-C. S. Valentine, Ridgewood, N. J. Infectious Diseases of Turkeys.- Seventh Annual Report. Published by Rhode Island Agricultural Experiment Station, Kingston, R. I.

Inheritance of Fecundity.-Maine Argicultural Experiment Station Bulletin No. 166.

Inheritance in Poultry.-C. B. Davenport, Washington, D. C. Labor-Saving Poultry Appliances.-Cornell Experiment Station Bulletin No. 284.

Laying Hens, Selection of.-Kansas Agricultural Experiment Station Bulletin No. 164.

Lloyd's Modern Poultry Book.-W. B. Lloyd. Published by Howard \& Wilson Publishing Co., Chicago.

Management of Poultry.-United States Department of Agriculture, Farmers' Bulletin 287.

Marketing of Eggs.-Ohio State University Bulletin No. 8. 
Marketing of Eggs Throdgh the Creamery.-United States

Department of Agriculture, Farmers' Bulletin No. 445.

Making Poultry Pay.-Powell.

Marketing of Poultry Products.-Connecticut Agricultural Experiment Station Bulletin No. 38.

Miller System Book.-A. D. Hosterman Company, Binghamton, N. Y.

MinoRCAS.-Northrup.

Money in Broilers and Squabs.-M. K. Boyer, Hammonton, N. J. Moulting of Fowls.-Cornell University Agricultural Experiment Station Bulletin No. 258.

National Standard Squab Book.-C. E. Rice. American Poultry

Journal Publishing Co., Chicago, Ill.

New Book of Poultry.-Lewis Wright, London.

New EgG FArm.-H. H. Stoddard. Published by Orange Judd Company, New York.

The Orpingtons.-The Reliable Poultry Journal Publishing Co., Quincy, Ill.

One Hundred Formulas and Receipts for Podltrymen.Miller Purvis Poultry Herald Publishing Co. St. Paul, Minn. Parasites of Poultry.-Bulletin No. 131. Published by North Carolina Agricultural Experiment Station, West Raleigh, N. C. Perfected Poultry of America.-T. F. McGrew and G. E. Howard. Howard Publishing Co., Washington, D. C.

Plymouth Rocks.-Reliable Poultry Journal Publishing Co., Quincy, Ill.

Podltry Appliances and Handicraft.-Geo. B. Fiske. Orange Judd Company, New York.

Podltry AS Food.-United States Department of Agriculture, Farmers' Bulletin No. 182.

Poultry as Food.-Connecticut Agricultural Experiment Station Bulletin No. 27.

Poultry Architecture.-G. B. Fiske. Orange Judd Company, New York.

Poultry Book.-Wm. B. Tegetmeier. Published by Routledge \& Sons, London. 
The Poultry Book.-H. Weir. American Edition. Edited by W. G. Johnston, G. O. Brown and others, 3 vols.

Podltry Culture.-Connecticut Agricultural Experiment Station Bulletin No. 52 .

Poultry Culture.-I. K. Felch. Published by Donohue, Henneberry \& Co., Chicago.

Poultry Feeding and Fattening.-G. B. Fiske. Orange Judd Company, New York.

Poultry-House Construction.-Wisconsin Agricultural Experiment Station Bulletin No. 215.

Poultry-Houses AND Fixtures.-Reliable Poultry Journal, Quincy, Ill.

Poultry Keeping for Profit.-Bulletin No. 130. Published by North Carolina Agricultural Experiment Station, West Raleigh, N. C.

Practical Poultry Keeper.-L. Wright. Published by Orange Judd Company, New York.

Principles of Brooding.-Cornell University Agricultural Experiment Station Bulletin No. 277.

Principles and Practice of Poultry Culture.-J. H. Robinson. Profitable Poultry Keeping.-Stephen Beale. Published by Routledge \& Sons, London.

Profits in Poultry.-Orange Judd Company. Published by Orange Judd Company, New York.

Profitable Poultry Production.-M. G. Kains. Published by Orange Judd Company, New York.

Progressive Poultry Culture.-Brigham.

Races of Domestic Poultry.-Brown.

Science and Art of Poultry Culture.-E. A. Hawkes, Clinton, Wis.

Seven Methods of Feeding Young Chickens.-Cornell University Agricultural Experiment Station Bulletin No. 282.

Standard Varieties of Chickens.-United States Department of Agriculture, Farmers' Bulletin No. 64.

Studies of Poultry from Farm to Consumer.-United States Department of Agriculture, Bureau of Chemistry, Circular No. 64. 
Successfol Brooder House.-Connecticut Agricultural Experiment Station Bulletin No. 33.

Successful Poultry Farm.-United States Department of Agriculture, Farmers' Bulletin No. 355.

TAPEworms of Poultry.-United States Department of Agriculture, Bureau of Animal Industry, Bulletin No. 12.

Trap Nests.-Maine Agricultural Experiment Station Bulletin No. 193.

Turkeys and How to Grow Them.-Myrick. Published by Orange Judd Company, New York.

Turkeys, Standard Varieties and Management.-United States Depatment of Agriculture Farmers' Bulletin No. 200.

Twelve Months' Work in the Poultry-Yard.-Theo. Whitman. Tuberculosis.-California Agricultural Experiment Station Bulletin No. 161.

Water-Glass a Preservative for Eggs.-Connecticut Agricultural Experiment Station Bulletin No. 67.

White Diarrhea of Young Chicks.-Connecticut Agricultural Experiment Station Bulletin No. 68.

Wyandottes.-Reliable Poultry Journal Publishing Co., Quincy, Ill. 



\section{INDEX}

African geese, 273.

Air-space necessary, 102.

Amount of land necessary, 7.

Amount of salt necessary, 186.

Andalusians, 35 .

Animal and vegetable food for young chickens, 228.

Animal and vegetable food for young ducks, 267.

Animal meal, 183.

Arrangement of houses, 88.

Arrangement of nests, 127.

Artificial incubation, 204.

Ash, deficient in food for chicks, 229.

Asiatics, 46.

Automatic drinking-fountains, 131.

Aylesbury ducks, 260.

Bacillary white diarrhea of young chicks, 345; prevention of, 347; source of infection, 346 .

Bantams, 86.

Barred Plymouth Rocks, description of, 63 ; origin of, 63 .

Beets as food, 180; manner of feeding, 180.

Best products most remunerative, 12; sell quickest, 12.

Bone cutters, 183.

Bones as food, 182.

Bones, fresh cut, 182.

Bourbon turkeys, 289.

Bowel disorders of little chicks, 236.

Brahmas, characteristics of, 48; laying qualities of, 50 ; origin of, 47 ; varieties of, 47.

Breeding, 152.

Breed pure-bred stock, 163.
Breeds of ducks, 259.

Breeds of geese, 270.

Breeds suitable for broiler rearing, 254 .

Breeds suited to produce capons, 245.

Breed useful fowls, 168.

Broiler rearing, 253.

Broilers, description of, 251; food for, 254 ; size of, 252.

Brooders, 215; classes of, 215; homemade, 221 ; requisites of, 217.

Brown.Leghorns, 30.

Buckwheat as a food, 178.

Buff Cochins, 52 .

Buff Leghorns, 29.

Buff Orpingtons, 72.

Buff Plymouth Rocks, 66.

Buildings, foundation of, 102; roofs for, 109; side walls of, 105; size of, 100.

Bumble foot, 349 ; treatment for, 349 .

Business of rearing fowls, 1; suited to many persons, 9 .

Cabbage and rape, 181.

Canned meat foods, 183.

Capital required, 3.

Capon and broiler rearing, 241.

Caponizing, instruments for, 243; operation of, 249 ; results of, 242 ; when to operate, 248.

Care of incubators, 212.

Care of little chickens, 224, 231.

Care of pigeons, 299.

Characteristics of Bantams, 86; Brahmas, 48; Cochins, 52; Cornish Games, 77; Dominiques, 73; Dorkings, 75; Faverolles, 54; Frizzles, 85; Houdans, 76 ; Javas, 72 ; Langshans, 53; Orpingtons, 70; Plymouth Rocks, 63; 
Polish, 82; Red Caps, 40; Rhode Island Reds, 79; Silkies, 84; Sultans, 85; Wyandottes, 68.

Characteristics of egg breeds, 16.

Chickens, number of, in the United States, 2.

Chick rations, 226; manner of feeding, 227.

Cholera, 342; how communicated, 342; symptoms of, 342 ; treatment for, 343 .

Classes of chickens described, 14-16.

Classification of breeds, 13.

Close-feathered egg breeds, 23.

Clover as food, 179.

Clover hay, 181.

Cochins, characteristics of, 52 .

Cold storage for eggs, 329.

Combination form of roof, 112 .

Common fowls, improvement of, 165.

Community system of hatching, 213.

Construction of floors, 113; nests, 129; perches, 123; roofs, 110; side walls, 105; hollow, 107; straw ceilings, 121; ventilators, 118.

Construction of houses, 96 ; economy of, 87.

Convenience of buildings, 92 ; as regards labor, 93.

Corn as a food for laying hens, 175.

Cornish Games, 77.

Cramming, 198; machine for, 199; manner of feeding, 199.

Cross-breeding, 160.

Crows, dangers from, 353.

Dangers of in-and-in-breeding, 159; of cross breeding, 161.

Dark Brahmas, 49.

Description of egg breeds, 14 ; of fancy breeds, 16; of general purpose breeds, 15; of meat breeds, 15.

Description of gape worm, Syngamus trachealis, 335.

Description of lice, 331; of mites, 334.

Deteriorated eggs, 321.

Diarrhea, 351; symptoms of, 351; treatment for, 351 .
Diseases and enemies of poultry, 330 .

Diseases of brooder chicks, 237-239.

Disinfect fattening fowls, 200.

Disinfectants for roup, 340.

Disposition of egg breeds, 17 ; of generalpurpose breeds, 59 ; of meat breeds, 42.

Dominiques, 73.

Dorkings, 74; description of, 75 .

Drainage, 89.

Dressed fowls, how cooled, 307.

Dressed fowls, when to ship, 312.

Dressing poultry, 303.

Drinking-fountains, 130; essentials of, 133; for little chicks, 234; kinds of, 130-133.

Dry-feed hoppers, 233.

Dry-picking fowls, 306.

Duck rearing, animal food essential, 267; feeding troughs for, 267; green food for, 268; pure water essential, 267; stampeding, 269; water-troughs, 268.

Duck rearing, use of disinfectants, 266.

Ducks and chickens require little land, 7.

Ducks, breeds of, 259; Aylesbury, 260; Black Cayuga, 263; Call, 264; East Indian, 259; Muscovy, 263; Pekin, 259; Rouen, 261.

Ducks, cleanliness essential, 265.

Ducks, food and care, 264; natural food, 264.

Ducks, general discussion, 256; easily confined, 258; reared for meat, 256; streams or ponds not necessary, 258.

Ducks, number of, in the United States, 2.

Dust-boxes, 133; location of, 134.

Early maturity of egg breeds, 19.

Egg breeds, characteristics of, 16 disposition of, 17 .

Egg breeds classified, 13; are small or medium sized, 14.

Egg breeds, called "non-sitters," 22; close-feathered, 23 ; easily frightened, 
18; easily frozen, 23; fly readily, 18; generally hardy, 20; good foragers, 22 ; mature early, 19; nervous disposition, 19; poor sitters, 20; prolificacy of, 21.

Egg breeds described, 14.

Egg breeds, varieties of, 24.

Egg-eating, 128, 349.

Egg production and meat production, 45.

Eggs deteriorated, 321; shrunken, 321; spoiled, 321.

Eggs, feeding for, 171; selection for fertility, 150; selection of, 145 .

Eggs, forced feeding for, 174.

Eggs, how prepared for market, 319.

Eggs, preserving in cold storage, 329.

Eggs, preserving in lime water, 329; preserving in water-glass, 326.

Eggs, shipping cases for, 322 .

Embden geese, 272.

Enemies and diseases of poultry, 330.

English method of killing, 313.

English methods of dressing, 312 .

Essentials of a brooder, 217.

Evaporated milk by-products as food, 184.

Exercise and egg production, 172.

Exercise for little chicks, 230.

Exercise not necessary for fattening, 172.

Failures due to inexperience, 5 .

Fancy breeds, 81.

Fancy breeds described, 16.

Faverolles, 54; description of, 54 .

Feather-eating, 350.

Feeding and exercise, 191.

Feeding for eggs, 171.

Feeding for meat or fattening, 196; animal meal, 196; coops, 197; exercise, 197; grain food, 196.

Feeding in litter, 191.

Feeding little chickens, 224; food for, 225.
Feed-troughs, 191; for little chicks, 232.

Fencing yards, 138.

Fertility of eggs, 151.

Flavor of eggs affected by food, 173.

Floors, 113; kinds of, 113.

Floor space necessary, 100.

Flying-lofts for pigeons, 300 .

Food for broilers, 254.

Food for goslings, 276.

Food, ground, 189.

Food, manner of feeding, 187; for fattening fowls, 200.

Food, quality of, 172.

Foraging of egg breeds, 22.

Forced feeding for eggs, 174.

Formation of breeds through crossing, 162.

Forming machine, 314; how used, 315.

Form of house, 97.

Foundation of buildings, 102.

Fowls, Guinea, 294.

Freezing, 348; treatment for, 348.

Fresh bones, 182.

Fresh eggs, 320; how marketed, 320.

Frizzles, description of, 85 .

Frozen poultry, 311.

Fruit trees for yards and parks, 140.

Gable roof, 110.

Game fowls, 84 ; varieties of, 84 .

Games, Cornish, 77.

Gapes, 335; description of, 335; remedies for, 336.

Geese, general discussion, 269; African, 273; Canadian, or Wild, 275; Chinese, 274; Embden, 272; Toulouse, 271.

Geese, houses for, 278.

General-purpose breeds described, 15.

General-purpose fowls, 57; disposition of, 59; early maturing, 60; good foragers, 60; good sitters, 60; size of, 59 ; useful qualities of, 58 .

Good-sized eggs sell best, 30 .

Goslings, food for, 276; natural food of. 276.

Grading fowls for shipment, 318 .

"Grading up," 167. 
Grain foods, buckwheat, 178; corn, 175; linseed meal, 178; oats, 178; wheat, 177.

Grain rations for laying hens, 193; summer, 193; winter, 193.

Green foods, necessity of, 178; beets, 180; cabbage, 181 ; clover, 179 ; rape, 181.

Grit, necessary, 184.

Ground food, 189.

Guinea fowls, 294; esteemed for food, 295 ; great rovers, 296 ; number of females to one male, 296.

Hamburgs, 37; characteristics of, 38; unprofitable table fowls, 39 ; varieties of, 38. ?

Handling eggs through the creamery, 322.

Hawks, dangers from, 353.

Health of fowls, 89.

Heredity, 152.

History of Leghorns, 25; of Minorcas, 33; Andalusians, 33.

Hollow-side walls, 107.

Home-made brooders, 221.

Homers, 301.

Houdans, description of, 76.

Houses, construction of, 96 ; size of, 100 ; movable, 142.

Houses for geese, 278.

Houses for pigeons, 300 .

How to feed, 187; little chickens, 225.

Importance of exercise, 172.

Importance of the poultry industry, 1 .

Improper brooder conditions, 237.

Improvement of common fowls, 165.

Improvement of Leghorns, 26.

Improvement through variation, 155; through in-and-in-breeding, 158.

In-and-in-breeding, 157.

Incubating eggs, temperature of, 206.

Incubator buildings, 210, 211, 214.

Incubator rooms, 211.

Incubators, 203; care of, 212; operation of, 213.
Inexperience, cause of failures, 5 .

Influence of food on color of yolk, 176. Investments yield quick returns, 8 .

Irish shipping case, 323.

Javas, 72 .

Killing fowls for market, 305 .

Kinds of litter, 194.

Lamp brooders, objections to, 223.

Land, amount required, 7.

Langshans, characteristics of, 53.

Large combs and wattles sensitive to cold, 23.

Late-maturing qualities of meat breeds, 46.

Law of heredity, 152.

Law of variation, 154 .

Laying qualities of Brahmas, 50 .

Laying qualities of geese, 278.

Leghorns, history of, 25; improvement of, 26; hardy, 28; light eaters, 28; produce white eggs, 30 ; size of, 27 ; varieties of, 28 .

Lice, 330; description of, 331; manner of propagating, 331; remedies for, 332 .

Lime, necessary, 185.

Lime water as an egg preservative, 329.

Lime water, how made, 329.

Linseed meal, for molting hens, 178.

Litter, 194.

Live poultry, how shipped, 317.

Locating a poultry-farm, 88 .

Location of windows, 115 .

Machine, forming, 314.

Maels and egg production, 151.

Manner of beginning, 6 ,

Market price of squabs, 300 .

Marketing poultry products, 302 .

Marking packages, 311.

Material for nests, 130.

Maturing qualities of general purpose breeds, 60 .

Meat breeds described, 15 . 
Meat breeds, disposition of, 42; easily confined, 43; large fowls, 41; late maturing, 46; laying qualities of, 44; poor foragers, 43; quality of flesh, 41; varieties of, 46 .

Meat foods, 182; for little chicks, 228.

Meat production compared to egg production, 45.

Methods of cooking dressed fowls, 307.

Mexican turkey, 285.

Minorcas, description of, 34; history of, 33 ; varieties of, 33 .

Mites, 334; habits of, 334 ; remedies for, 334.

Money invested yields quick returns, 8.

Movable houses, 142.

Muscovy ducks, 263.

Muslin windows, 119.

Narragansett turkeys, 287.

Natural and artificial incubation compared, 203.

Natural food, of ducks, 264; of geese, 276.

Natural food of goslings, 276.

Necessary air-space per fowl, 102.

Nests, 126; arrangement of, 127; material for, 130; size of, 129.

Number of chickens in the United States, 2; ducks in the United States, 2; geese in the United States, 2; turkeys in the United States, 2.

Number of females to one male, turkeys, 291 ; guineas, 296.

Oats as a food, 178.

Open-front houses, 121.

Operating incubators, 213.

Operation for caponizing, 249.

Origin of Brahmas, 47; Cochins, 51; Faverolle, 54; Javas, 72; Leghorns, 25; Minorcas, 33; Orpingtons, 70; Plymouth Rocks, 63; White-faced Black Spanish, 36; Wyandottes, 68. Orpingtons, general description of, 71; origin of, 70; size of, 72; varieties of, 72 .

Outdoor brooders, 217.
Overfeeding, 188.

Oyster shells, 185.

Pâté de foie gras, 277.

Pea comb, 48.

Pea fowls, 297; habits of, 297; objections to, 297.

Packages, how marked, 311.

Packing dressed fowls for shipment, 309.

Packing fowls in ice, 310; detailed description of, 310 .

Parks and yards, 135.

Pekin ducks, 259.

Pepper, 187.

Perches, construction of, 123; location of, 124 .

Pigeons, general discussion, 298; houses for, 300 .

Placing an incubator, 209; even temperature desired, 209.

Plum trees for the poultry-yard, 140.

Plumping, 308.

Plymouth Rocks, 62; varieties of, 63; weight of, 63.

Poisoning from salt, 186; remedies for, 351.

Poisoning rats, 352.

Polish, 82; varieties of, 83.

Portable poultry-houses, 141.

Poultry, dressing for market, 302.

Poultry rearing compared, 4; a business of details, 5 .

Poultry, frozen, 311.

Poultry statistics unreliable, 2.

Precautions against vermin, 95.

Preparation for caponizing, 246.

Preparing capons for market, 250.

Preparing eggs for market, 319.

Preparing poultry for market, 302 .

Preserving eggs, 324; various methods, of, 325.

Preventive measures for gapes, 337 .

Produce good-sized eggs, 31.

Products easy to market, 11.

Profit from feeding, 188.

Profits of capon rearing, 240.

Pure-bred vs. common stock, 165 . 
Quality of flesh of meat breeds, 41 .

Quality of food, 172.

Quick returns from money invested, 8 .

Raising poultry as a business, 1 .

Rape as food, 181.

Rations for little chicks, 226; animal food, 228; hard-boiled eggs, 229; skim milk for, 228.

Rats, 352; extermination of, 352 .

Rearing capons, 240.

Rearing squabs, 300.

Red Caps, 40; characteristics of, 40.

Remedies for diarrhea, 347.

Remedies for gapes, 336 .

Remedies for lice, 332; for mites, 334.

Rhode Island Reds, 79.

Roofing materials, 113.

Roofs for poultry-houses, construction of, 110; essentials of, 113; form of, 109 ; materials for, 113.

Rooms for incubators, 211.

Root cutters, 180.

Rouen ducks, 261.

Roup, 338; general discussion of, 338; symptoms of, 338; treatment for, 339.

Rules for selecting eggs, 328.

Rules for selecting turkeys for breeding, 290.

Runs, suitable for geese, 270 .

Runts, 301.

Salt, beneficial, 186; poisonous in large quantities, 351.

Salt, necessary, 186; amount required, 186.

Scalding, 307; precautions of, 309.

Scaly legs, 347 ; treatment for, 348 .

Selecting eggs, 328.

Selecting eggs for hatching, 145.

Selection for vigor, 147; for egg production, 148; for utility, 170.

Selection of a breed, 143.

Selection of an incubator, 207.

Selection of breeding stock, turkeys, 290.

Shed-roof, 111.
Shipping-cases for eggs, 322 .

Shipping-crates, 317.

Shipping live poultry, 317.

Shrunken eggs, 321.

Shutters for windows, 115.

Side walls, construction of, 105 .

Silkies, description of, 84 .

Size of egg breeds, 14 ; fancy breeds, 59 ; general purpose, 59 ; meat breeds, 41 .

Size of fowls to caponize, 246.

Skim milk, 183; for little chicks, 228.

Slate turkeys, 288.

Slight elevation preferred, 90.

Soft foods most profitable, 189.

Solid colors preferred, 33.

Solid side walls, construction of, 105 .

South side of house desirable for yards, 92.

Spanish fowls, 36 .

Species of native turkeys, 285.

Spraying for lice, 333 .

Spoiled eggs, 321.

Squabs, 300; market prices of, 300 ; varieties of, 301.

Squabs, food for, 301.

Statistics, unreliable, 2.

Straw as litter, 194; buckwheat hulls, 194.

Sulphur, 187.

Sultans, description of, 85.

Sunshine desirable, 90.

Superior products create new demands, 12.

Symptoms of cholera, 342 ; of roup, 338.

Syngamus trachealis, 335 .

Temperature of incubating eggs, 206.

Theory of incubation, 205.

Time of feeding, 190.

Time of year to begin, 6 .

Time to caponize, 246, 248; to sell broilers, 252.

Toulouse geese, 271.

Transmission of characters, 153.

Treatment for bumble foot, 349 .

Treatment for cholera, 343. 
Treatment, for freezing, 348; for scaly legs, 348.

Treatment for roup, 339 .

Troughs, water, for ducks, 268.

Turkeys, care and food for the young, 292 ; first food for, 293; grain foods for, 294.

Turkeys, general discussion, 280 .

Turkeys, selection of breeding stock, 290.

Turkeys, varieties of, 285; Black, 288; Bourbon, 289; Bronze, 286; Buff, 288; Narragansett, 287; Slate, 288; White Holland, 287.

United States Census Report, 2.

Useful qualities of fowls, 44.

Variation, 154; law of, 154 ; male leads in, 156.

Varieties of Bantams, 86.

Varieties of egg breeds, 24.

Varieties of meat breeds, 46 .

Varieties of pigeons for squab rearing, 301.

Varieties of Polish, 83.

Vegetable and animal nitrogen compared, 182.

Ventilation, 117; by means of straw ceilings, 120; open-front houses, 121.
Ventilators, construction of, 118.

Vermin, precautions against, 95 .

Vigorous fowls most profitable, 188.

Water-glass as an egg preservative, 326 ; how made, 327.

Wheat as a food for laying hens, 177 .

When to ship poultry, 312 .

White diarrhea, 345 .

White-faced Black Spanish, 36.

White Leghorns, 30.

White or Brown Leghorns preferred, 32.

White Orpingtons, 72.

White Plymouth Rocks, 65.

Wild and domesticated turkeys compared, 281.

Wild turkey crosses, 282.

Wild turkeys, where found, 280 .

Windows, number and size of, 115; location of. 115; shutters for, 115.

Wyandottes, description of, 69 ; noted for utility, 70; origin of, 68; size of, 68 ; varieties of, 70 .

Yards and parks, 135; cultivation of, 138; fruit trees for, 140 .

Yolk, color of, affected by food, 176 .

Young ducks, food for, 267.

Young fowls require more exercise, 8: more land required, 11. 

The following pages contain advertisements of a few of the Macmillan books on kindred subjects 



\section{The Standard \\ Cyclopedia of Horticulture}

Edited by L. H. BAILEY

With the assistance of over 500 collaborators

New edition, entirely rewritten and enlarged with many features, with plates in color, 96 full-page half-tones and over 4,000 text illustrations.

Complete in six volumes.

Set: Cloth, $\$ 36.00$; Leather, $\$ 60.00$

Sold only in sets by subscription.

Two opinions of Volume I of the new Cyclopedia:

"No one who knows anything at all about the literature of gardening needs to be told that the Cyclopedia is unique. It is the Bible and Britannica of the garden-folk, amateur and professional alike. And the remarkable thing is that, while it is fundamentally a work of reference, it also contains limitless quantities of good reading of the sort dear to the heart of the garden enthusiast."-The Nation.

"It is no exaggeration to state that Bailey's new work is the best cyclopedia obtainable for all who are connected, either remotely or intimately, as amateurs or professionals, with horticultural pursuits. It is the best for the student of botany who is investigating the subject in a purely scientific way; best for the commercial grower who likes to be well informed on matters in general and his own trade in particular, and best for the other sort of commercial grower, who does not bother himself particularly about hunting for any information except such as will give him immediate help in producing a better crop."-The Florist's Review.

\section{THE MACMILLAN COMPANY}




\section{CYCLOPEDIA OF AMERICAN AGRICULTURE Edited by L. H. BAILEY}

With 100 full-page plates and more than 2,000 illustrations in the text; four volumes; the set, \$24.00; half morocco, $\$ 36.00$.

Vol. I-Farms Vol. III-Animals

Vol. II-Crops Vol. IV--The Farm and the Community

This is unquestionably the most important agricultural cyclopedic work published in this country. The leading experts in the United States and Canada, both investigators and practical farmers, contribute to its chapters, which are arranged not alphabetically, but topically, each subject being treated in its various aspects by men especially familiar with it. It contains advice for the city man who is seeking a home in the country, as well as for the professional farmer. The book is strictly new and up-to-date in its methods and advice, thoroughly readable, and a standard work of reference. It is profusely illustrated, about one-third of the total space being assigned to illustrations-all original.

"Indispensable to public and reference libraries . . readily comprehensible to any person of average education."-The Nation.

"The completest existing thesaurus of up-to-date facts and opinions on modern agricultural methods. It is safe to say that many years must pass before it can be surpassed in comprehensiveness, accuracy, practical value, and mechanical excellence. It ought to be in every library in the country."-Record-Herald, Chicago.

\section{THE MACMILLAN COMPANY}




\section{BOOKS ON AGRICULTURE}

ON SELECTION OF LAND, ETC.

E. W. Hilgard's Soils: Their Formation, and Relations to

Climate and Plant Growth . . . . . . . . . \$4 00

ON TILLAGE, ETC.

Elwood Mead's Irrigation Institutions . . . . . . . 125

William E. Smythe's The Conquest of Arid America . . . . 150

H. Snyder's Chemistry of Plant and Animal Life . . . . . 150

H. Snyder's Soil and Fertilizers. Third edition . . . . . 125

ON PLANT DISEASES, ETC.

A. S. Packard's A Text-book on Entomology . . . . . . 450

L. R. Hesler and H. H. Whetzel's Manual of Fruit Diseases . 200

ON PRODUCTION OF NEW PLANTS

L. H. Bailey's The Survival of the Unlike . . . . . . . 200

W. S. Harwood's New Creations in Plant Life . . . . . . 200

ON GARDEN-MAKING

Bailey and Hunn's Practical Garden Book . . . . . . . . 110

A. French's Book of Vegetables . . . . . . . . . . . . . 175

A. French's Beginner's Garden Book . . . . . . . . . 100

ON FRUIT-GROWING, ETC.

L. H. Bailey's The Pruning-Book . . . . . . . . . . 200

ON THE CARE OF LIFE-STOCK

W. H. Jordan's The Feeding of Animals . . . . . . . 175

ON DAIRY WORK, FARM CHEMISTRY, ETC.

Harry Snyder's Dairy Chemistry . . . . . . . . . 100

W. D. Frost's Laboratory Guide in Elementary Bacteriology . 160

Lincoln and Malton's Elementary Quantitative Chemical Analysis

\section{ON ECONOMICS AND ORGANIZATION}

Henry C. Taylor's Agricultural Economics . . . . . . . . 125

S. E. Sparling's Business Organization . . . . . . . . . 125

In the Citizen's Library. Includes a Chapter on Farming

L. H. Bailey's The State and the Farmer . . . . . . . . . 125

ON EVERYTHING AGRICULTURAL

L. H. Bailey's Cyclopedia of American Agriculture. Complete in four royal 8 vo volumes, with over 2,000 illustrations. Price of sets: Cloth, \$24; half morocco . . . 3600

For further information as to any of the above, address the publishers

\section{THE MACMILLAN COMPANY}

PUBLISHERS

64-66 Fifth Avenue

NEW YORK 


\section{RURAL SCIENCE SERIES Edited by L. H. BAILEY \\ Each volume illustrated \\ Cloth, $12 m o$}

A series of practical books for farmers and gardeners, sold as a set or separately. Each one is the work of a competent specialist, and is suitable for consultation alike by the amateur or professional tiller of the soil, the scientist or the student. Illustrations of marked beauty are freely used, and the books are clearly printed and well bound.

ON SELECTION OF LAND, ETC.

Isaac P. Roberts' The Farmstead . . . . . . . . . . . \$1 50

T. F. Hunt's How to Choose a Farm 175

E. G. Cheyney and J. P. Wentling's The Farm Woodlot . . . . 175

C. V. Piper and R. A. Oakley's Turf for Golf Courses . . . . . . . . 250

F. H. King's The Soil . . . . . . . . . . . . . 150

Isaac P. Roberts The Fertility of the Land..$\quad \therefore \quad 150$

F. H. King's Irrigation and Drainage

Edward B. Voorhees' Fertilizers. New Edition . . . . . . 150

Edward B. Voohees' Forage Crops . . . . . . . : : 150

J. A. Widtsoe's Dry Farming

L. H. Bailey's Principles of Agriculture . . . . . . 125

ON PLANT DISEASES, ETC.

E. G. Lodeman's The Spraying of Plants . . . . . . . . . . . . 150

ON GARDEN-MAKING

D. Lumsden's Greenhouse Construction and Heating . . . . . . Preparing

A. W. Gilbert's The Potato . . . . . . . 150

L. H. Bailey's Garden-Making $\ldots$

L. H. Bailey's Principles of Vegetable-Gardening . . . . 160

L. H. Bailey's Forcing-Book . . . 125

L. H. Bailey and A. W. Gilbert's Plant Breeding. New Edition . . 200

P. H. Rolf's Subtropical Vegetable-Gardening . . . . . . . 150

ON FRUIT-GROWING, ETC.

L. H. Bailey's Nursery-Book . . . . . . . . . 150

L. H. Bailey's Principles of Fruit-Growing. New Edition . . . . . . 175

F. W. Card's Bush-Fruits . . . . 150

W. Paddock \& O. B. Whipple's Fruit-Growing in Arid Regions . . . 150

J. E. Coit's Citrus Fruits . . . . 200

S. W. Fletcher's The Strawberry in North America . . . Preparing

S. W. Fletcher's Strawberry-Growing ........... 175

ON THE CARE OF LIVE-STOCK

Nelson S. Mayo's The Diseases of Animals . . . . . . . . . 175

I. P. Roberts' The Horse . . . . . . . 135

M. W. Harper's Breaking and Training of Horses : . . . 200

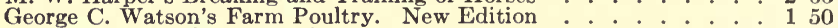

John A. Craig's Sheep Farming . . . . . . . . . . . . . . . 150

E. F. Phillips' Beekeeping … . . . . . . . . . 200

E. L. Potter, G. A. Samson, O. M. Nelson and C. N. Kennedy's

Western Livestock Management . . . . Preparing

ON DAIRY WORK, FARM CHEMISTRY, ETC.

Henry H. Wing's Milk and Its Products. New Edition . . . . . . . 150

J. G. Lipman's Bacteria in Relation to Country Life . . . . . . 150

ON ECONOMICS AND ORGANIZATION

William A. McKeever's Farm Boys and Girls . . . . . . . . . . . 175

I. P. Roberts' The Farmer's Business Handbook . . . . . . . . 125

George T. Fairchild's Rural Wealth and Welfare . . . . . . . . . 150

H. N. Ogden's Rural Hygiene . . . . . 150

J. Green's Law for the American Farmer : . . . . . . . 150

G. H. Powell's Coöperation in Agriculture : . . . . . . 150

J. B. Morman's Principles of Rural Credits

Glenn W. Herrick's Insects Injurious to the Household $::^{*}: 175$

\section{THE MACMILLAN COMPANY}


Edited by Professor L. H. BAILEY

Formerly Director of the New York State School of Agriculture at Cornell University

\section{The Potato}

By ARTHUR W. GILBERT, Ph.D.

Professor of Plant Breeding, Cornell University, assisted by

MORTIMER F. BARRUS, PH.D.

Professor of Plant Pathology, Cornell University, and

DANIEL DEAN

Formerly President of the New York State Potato Association

With illustrations, $\$$ I.50

The authors of this book are especially fitted to write upon the potato. Professor Gilbert, as professor of plant breeding at Cornell, has made a careful study of potato breeding and varieties for several years. Formerly teacher of farm crops and director of agricultural extension work at the University of Maine, he has become thoroughly familiar with potato growing in the East, particularly in the famous Aroostook County region. Dr. Barrus is considered one of the best authorities on potato diseases in the country. The chapters he has contributed to the work deal with disease and its control. Mr. Dean wrote the chapters on field practice. $\mathrm{He} \cdot$ is a successful commercial grower, and has given much attention to the different systems of potato growing throughout the United States.

\section{THE MACMILLAN COMPANY}




\section{RURAL SCIENCE SERIES - Continued}

\section{A Manual of Fruit Diseases}

BY LEX R. HESLER

Assistant Professor of Plant Pathology in the New York State College of Agriculture at Cornell University, and

\section{HERBERT H. WHETZEL}

Professor of Plant Pathology in the New York State College of Agriculture at Cornell University

With illustrations; cloth, I2mo, \$2.0o

This manual contains a presentation of the known facts and data with respect to the common diseases of fruits. It has been prepared primarily for the modern agriculturist, the farmer, the thinking fruit grower, but it should also be of service to anyone who has an interest in plant diseases. The fruits are taken up in alphabetical order. The discussion of the diseases proceeds in order of their importance and prominence in the United States. Particular attention is paid to the description and illustration of the symptoms, to the cause and to the generally accepted measures of control. Technical details are omitted as far as possible though the effort has been made to present the matter in as popular a fashion as possible.

\section{THE MACMILLAN COMPANY Publishers 64-66 Fifth Avenue New York}




\section{RURAL SCIENCE SERIES - Continued}

\section{Strawberry Growing}

By S. W. FLETCHER

Professor of Horticulture at the Pennsylvania State College

24 full-page plates and 22 figures in the text, $\$ I .75$

The strawberry occupies a position among North American fruits second only to the apple in commercial importance. Professor Fletcher here gives a clear outline of present commercial practice, taking up all the important points in considerable detail - location of beds, most desirable soils, planting, rotation of crops, treatment with fertilizers, tillage and irrigation, the training of the plant, mulching, pollination, picking, packing, marketing, varieties of berries, insects, diseases, and statistics on acreage, production, and value.

CHAPTER

\section{TABLE OF CONTENTS}

I. Locations, sites, and soils.

II. Planting.

III. Rotations, manuring, and fertilizing.

IV. Tillage and irrigation.

V. Training the plant.

VI. Mulching.

VII. Pollination.

VIII. Packages.

IX. Picking and packing.

X. Marketing.

XI. Cost of production, yields, profits.

XII. Propagation and renewal.

XIII. Everbearing varieties, forcing and other special methods of culture.

XIV. Insects, diseases, and frost.

$\mathrm{XV}$. Varieties.

ApPendix. Statistics on Acreage, Production, and Value.

\section{THE MACMILLAN COMPANY}

Publishers

64-66 Fifth Avenue
New York 






UNIVERSITY OF CALIFORNIA LIBRARY BERKELEY

THIS BOOK IS DUE ON THE LAST DATE

\section{STAMPED BELOW}

Bobs hot returned on time are subject to a fine of $50 \mathrm{c}$ per volume after the third day overdue, increasing to $\$ 1.00$ per volume after the sixth day. Books not in demand may be renewed if application is made before expiration of loan period.

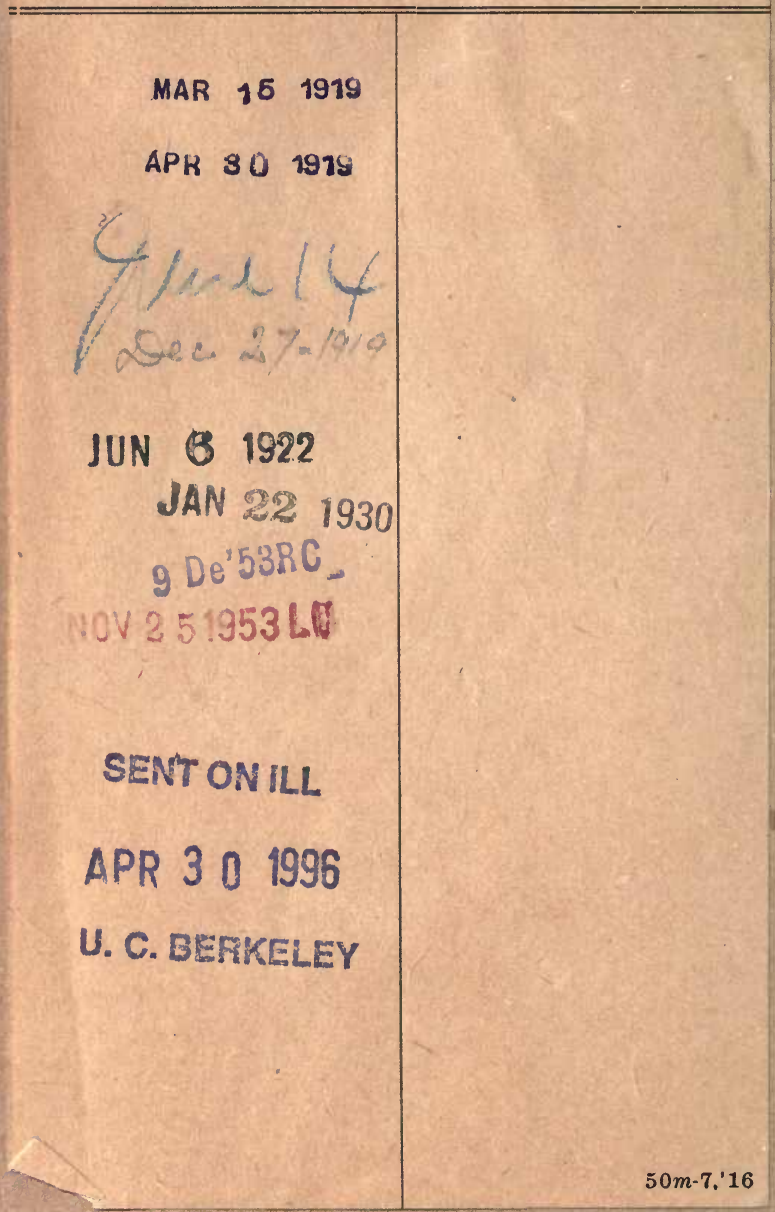




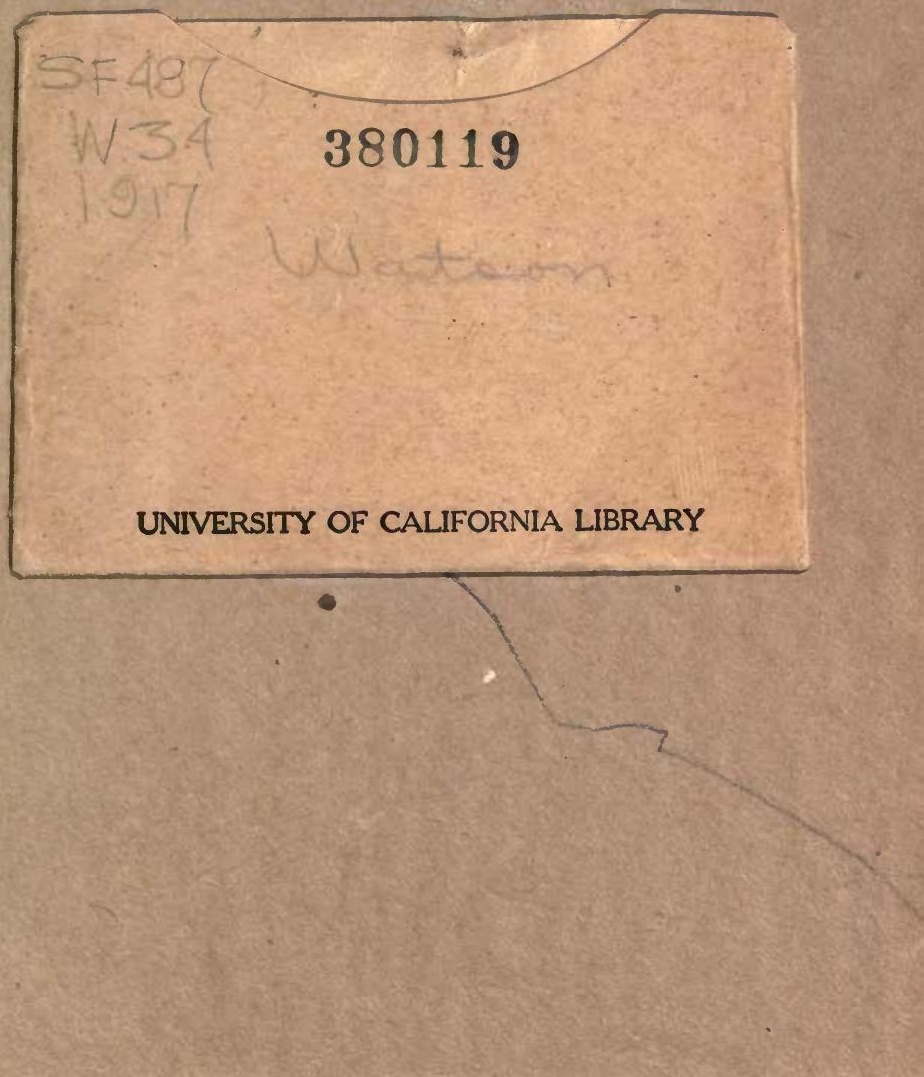


